\title{
On A Need to Know Basis: A Conceptual and Methodological Framework for Modelling and Analysis of Information Demand in an Enterprise Context
}

\author{
by \\ Magnus Jandinger \\ (formerly Lundqvist)
}

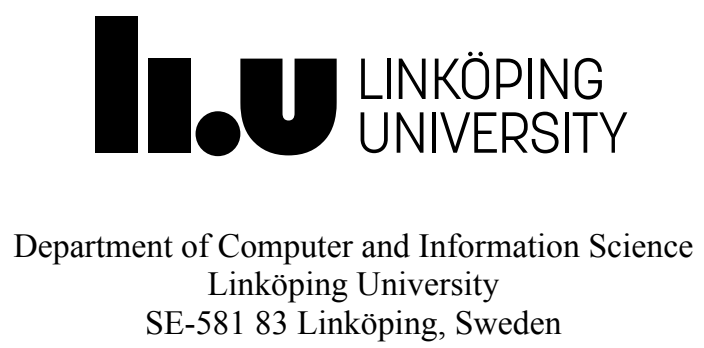

Linköping 2016 
Copyright (C) 2016 Magnus Jandinger

$$
\text { ISBN 978-91-7685-713-7 }
$$

ISSN 0345-7524

Printed by LiU-Tryck 2016

URL: http://urn.kb.se/resolve?urn=urn:nbn:se:liu:diva-130492 


To friends and family, without whose valuable assistance, the best parts of this thesis have been conceived. 



\section{ABSTRACT}

While the amount of information, readily available to workers in information- and knowledge intensive business- and industrial contexts, only seem to increase with every day, those workers continue to have difficulties in finding and managing relevant and needed information despite the numerous technical, organisational, and practical approaches promising a remedy to the situation. In this dissertation it is claimed that the main reason for the shortcomings of such approaches are a lack of understanding of the underlying information demand people and organisations have in relation to performing work tasks. Furthermore, it is also argued that while this issue, even with a better understanding of the underlying mechanisms, still would remain a complex problem, it would at least be manageable.

To facilitate the development of demand-driven information solutions and organisational change with respect to information demand the dissertation sets out to first provide the empirical and theoretical foundation for a method for modelling and analysing information demand in enterprise contexts and then presents an actual method. As a part of this effort, a conceptual framework for reasoning about information demand is presented together with experiences from a number of empirical cases focusing on both method generation and -validation. A methodological framework is then defined based on principles and ideas grounded in the empirical background and finally a number of method components are introduced in terms of notations, conceptual focus, and procedural approaches for capturing and representation of various aspects of information demand.

The dissertation ends with a discussion concerning the validity of the presented method and results in terms of utility, relevance, and applicability with respect to industrial context and needs, as well as possible and planned future improvements and developments of the method. 



\section{POPULÄRVETENSKAPLIG SAMMANFATTNING}

Det blir idag allt vanligare att medarbetare upplever att de har svårt att hitta sådan information de behöver för att lösa sina arbetsuppgifter, detta trots att de ofta har tillgång till en mängd olika stödsystem och informationskällor. Vad som en gång brukade vara ett problem förbehållet endast större organisationer, med allt för mycket intern information, har idag dessutom blivit allt vanligare även för mindre organisationer, mycket på grund av det informationsöverflöd Internet har medfört det senaste decenniet. Samtidigt har, de senaste åren, en mängd, allt mer avancerade, tekniska och procedurella approacher för att lösa denna typ av problem föreslagits utan att ha medfört en påtaglig upplevd förbättring.

En möjlig förklaring till ovanstående är att det finns en diskrepans mellan medarbetares upplevda behov och vad olika lösningar tillgodoser. En sådan diskrepans är högst troligen ett resultat av otillräcklig förståelse för medarbetarnas informationsbehov i relation till sina arbetsuppgifter. Vi har med andra ord blivit allt bättre på att bygga informationssystem som är kravställda ur ett funktionsperspektiv men har fortfarande inte kommit speciellt långt när det gället ett informationsflödesperspektiv. I denna avhandling diskuteras inte bara vad informationsbehov är i relation till en verksamhetskontext utan också hur sådana informationsbehov kan fångas, analyseras och beskrivas i syfte att utgöra ett underlag till bättre lösningar för informationshanteringen. Lösningar som faktiskt upplevs tillgodo se det behov av information verksamheters medarbetare har för att lösa sina olika uppgifter. Sättet på vilket detta görs i avhandlingen är genom att, baserat på teoretiska och empiriska studier, presentera ett begrepps- och metodramverk för informationsbehovsanalys som är empiriskt prövat $i$ verkliga organisationer. 



\section{ACKNOWLEDGEMENTS}

The research presented in this dissertation has only been possible due to a number of individuals and organisations, to which I would like to convey my deepest gratitude. Firstly, the bulk of the empirical knowledge is a result from the research project Information Logistics for SME: Improving information flow based on information demand patterns (InfoFlow), funded by The Swedish Knowledge Foundation (KK-stiftelsen). Without that funding and the cooperation of the partners in InfoFlow, this dissertation would simply not have been feasible. Special thanks go to Eva Holmquist and Arne Nilsson at SYSteam Management AB (today named Evry), Jan Strandesjö at Proton Engineering $A B$, Per Högberg initially at Kongsberg Automotive $A B$ but now at Skye Consulting $A B$, which all have contributed in one way or another to what is presented here. The same gratitude also extends to School of Engineering, Jönköping University and Linköping Institute of Technology for providing me with the opportunity and the facilities to perform and finish my long overdue Ph.D. studies. However, above all else I would like to thank three persons in particular, Prof. Kurt Sandkuhl, Assoc. Prof. Ulf Seigerroth, and Prof. Sture Hägglund, all acting as my supervisors and guides. Your help, and more importantly patience, have been crucial for the research leading up to the text you are about to read.

Thank you all! 



\section{TABLE OF CONTENTS}

Part 1 - Background, Prerequisites, and Approach ................................................... 1

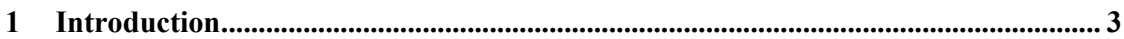

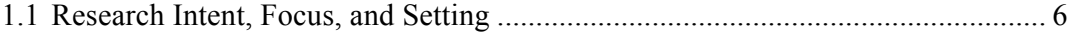

1.1.1 Research Context ...........................................................................................6

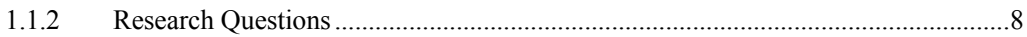

1.2 Practical \& Scientific Contributions............................................................ 10

1.2.1 An Information Demand Perspective on Enterprise Analysis ...............................11

1.3 Dissertation Structure ............................................................................... 12

1.4 Related Publications ................................................................................... 15

1.5 Intented Readers ........................................................................................ 19

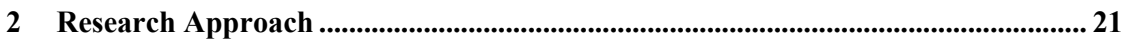

2.1 Theory Selection..................................................................................... 21

2.2 Defining Information Demand .................................................................. 22

2.2.1 Chosen Approach to the Initial Empirical Investigation .........................................23

2.3 Developing a Method in a Scientific Manner.................................................... 28

2.3.1 Ensuring Validity, Relevance, and Rigor of Methodological Efforts....................29

Part 2 - Information Demand from a Small-scale Business Context Perspective........ 35

3 Information Demand and Use: a Theoretical Perspective..................................... 37

3.1 Information as a Concept......................................................................... 37

3.1.1 Differences between Data, Information, and Knowledge ........................................37

3.1.2 Different Views on Information ............................................................................ 41

3.1.3 The Implications of Relevance and Context on Information ...................................41

3.2 Information Demand: Related Theoretical Work ............................................ 43

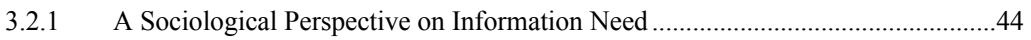

3.2.2 Information Need and Information Retrieval ........................................................45

3.3 Information Acquisition and Use from an Enterprise Perspective ..................... 47

3.3.1 Location as a Key Factor when Choosing Information Sources..............................48

3.3.2 Strategic and Managerial Aspects of Information Use within SMEs......................48

3.3.3 Perceived Source Credibility, Relevance, and Availability ..................................49

3.3.4 Utilisation of ICT-support for Information Use ...................................................50

3.4 Theoretical Implications for Conjectures …........................................... 51

4 Information Demand and Use: an Empirical Perspective......................................... 53

4.1 Relationship Between Role, Task, and Information Demand ........................... 53

4.2 Relation Between Role, Task, and Information Sources..................................... 58

4.2.1 Commonly Used Information Sources ……........................................................58

4.2.2 Information Management Related Issues and Problems..........................................65

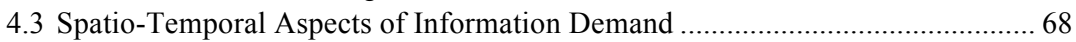

4.4 Information Use from an Organisational Perspective ........................................ 69

4.4.1 Visions and Wishes Concerning Information Management ....................................70

5 An Integrated View of Information Demand ..................................................... 71

5.1 Validity of the Initial Conjectures .................................................................. 71

5.1.1 Information Demand Dependency vis-à-vis Role and Task ...................................72

5.1.2 Spatio-Temporal Aspects of Information Demand ............................................ 72

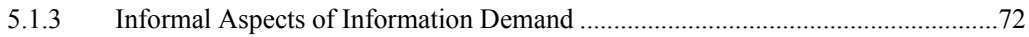

5.1.4 The Current and Future Situation of Information Management .............................73

5.2 Information Demand as a Concept .................................................................. 73

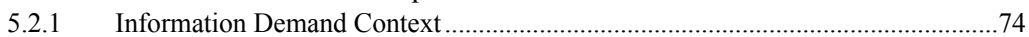

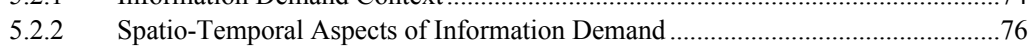

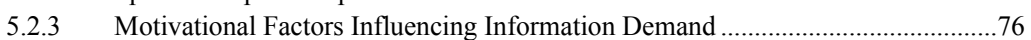




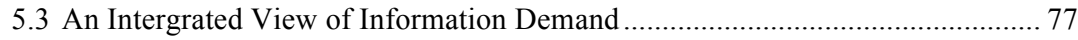

5.4 Information Use from a Business Perspective................................................... 78

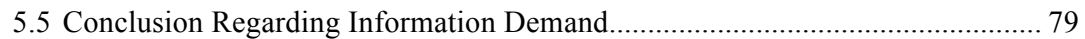

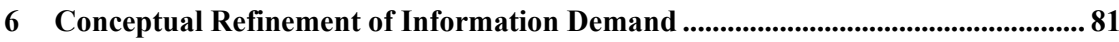

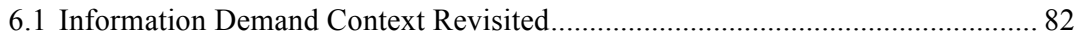

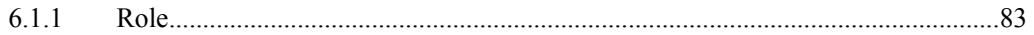

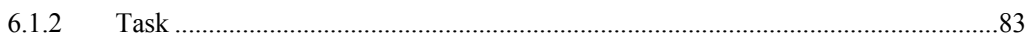

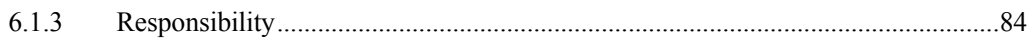

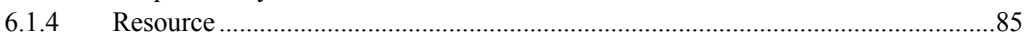

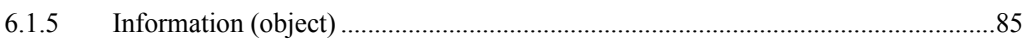

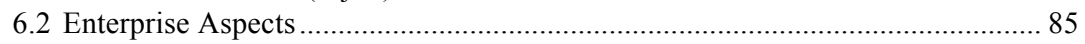

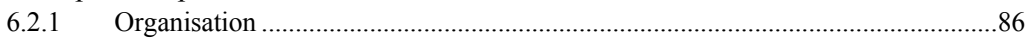

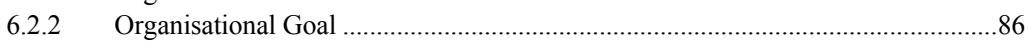

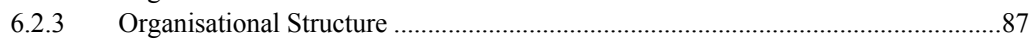

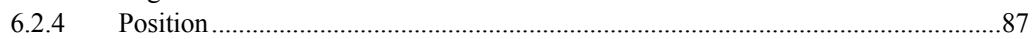

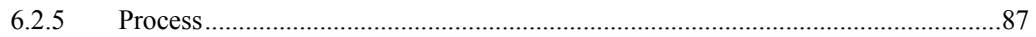

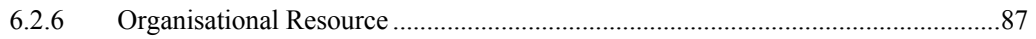

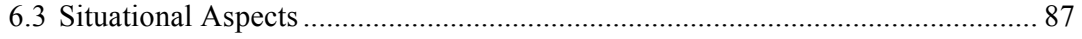

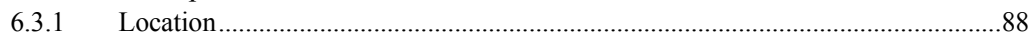

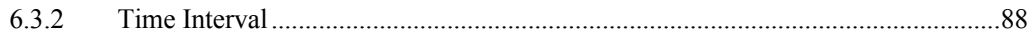

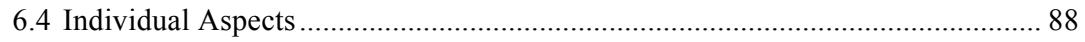

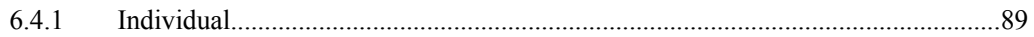

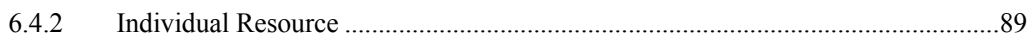

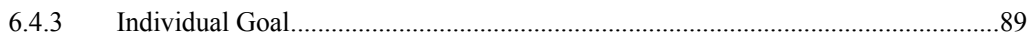

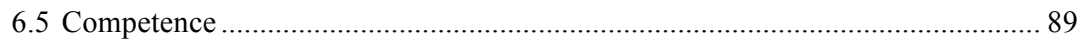

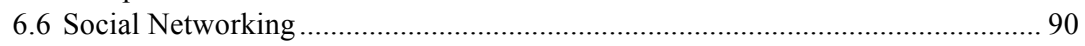

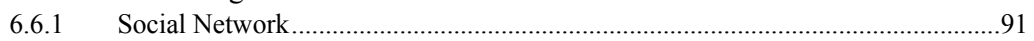

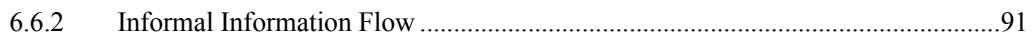

6.7 A Conceptual Framework for Information Demand .......................................... 91

Part 3 - A Methodological Framework for Analysing Information Demand................. 93

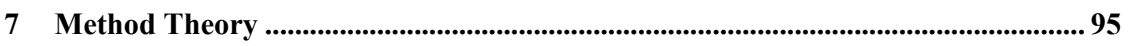

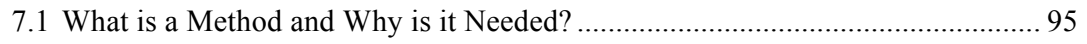

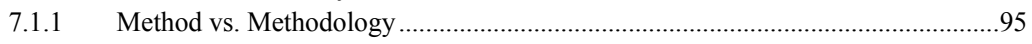

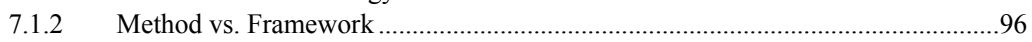

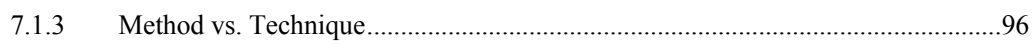

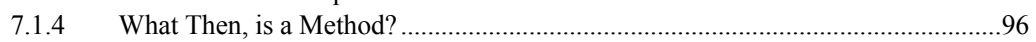

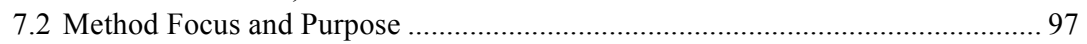

7.2.1 Enterprise Modelling...........................................................................................98

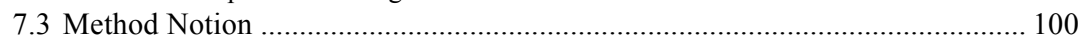

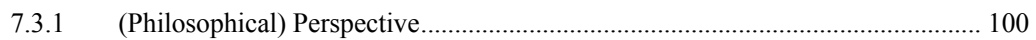

7.3.2 Cooperation and Collection Principles ............................................................... 100

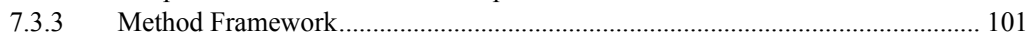

7.3.4 Method Components ......................................................................................... 101

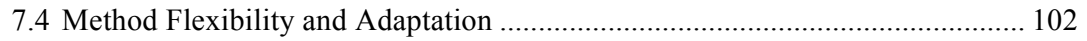

7.4.1 Situational Method Engineering ………………………………...................... 103

8 Method Development \& Initial Method Hypothesis ...................................................... 105

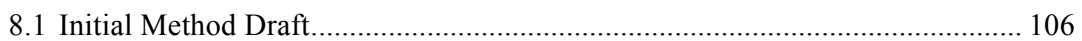

8.2 Empirical Evaluation of Approaches to Modelling of Organisational Aspects of

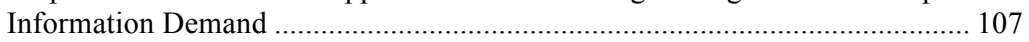

8.2.1 Case A: Knowledge Sharing through an Intranet Portal .................................... 107

8.2.2 Case B: Improving Engineering Change Management Processes....................... 112

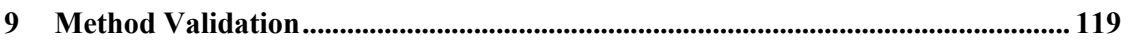


9.1 Case C: Evaluation of Draft of Method Component for ID-Context Modelling 119

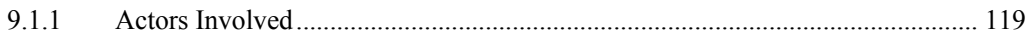

9.1.2 Work Approach................................................................................................ 121

9.1.3 Implications for Continued Method Refinement ................................................. 121

9.2 Case D: Defining Industrial Objectives and Requirements.............................. 121

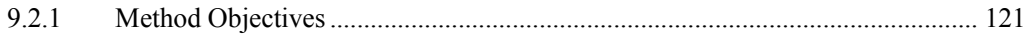

9.2.2 Method Requirements................................................................................. 123

9.2.3 Implications for Continued Method Refinement ................................................ 125

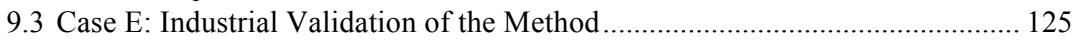

9.3.1 Method Component ……………………………............................................ 127

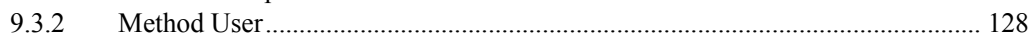

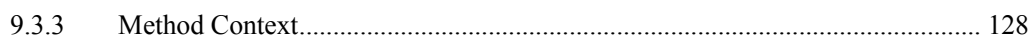

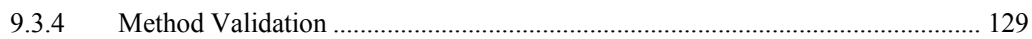

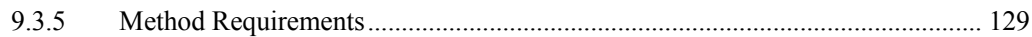

9.3.6 Wishes and Expectations of the Business Organisations..................................... 129

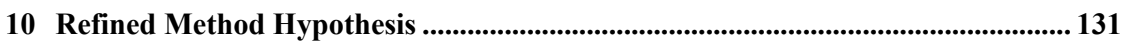

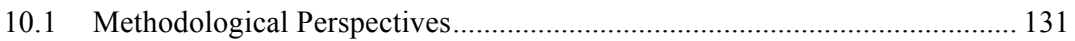

10.1.1 Method Focus and Purpose............................................................................ 132

10.1.2 Mode of Working (Cooperation and Collection Principles) ................................ 133

10.1.3 Method Applicability, Adaptability, Extendability, and Learnability ………….. 136

10.1.4 Documentation and Communicability of Method Results................................... 137

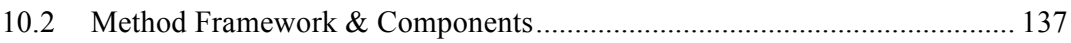

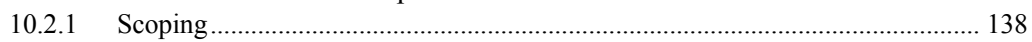

10.2.2 Information Demand Context Modelling ........................................................... 140

10.2.3 Information Demand Context Analysis and Evaluation ..................................... 145

10.2.4 Analysis of Additional and Optional Aspects of Information Demand .............. 146

10.2.5 Representation and Documentation of Information Demand ............................. 152

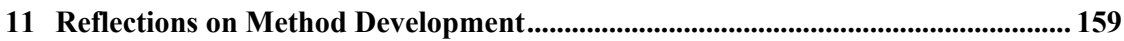

11.1 Relevance \& Utility for an Organisational Problem-domain ......................... 160

11.1.1 Information Demand Context Aspects ............................................................ 161

11.1.2 Individual Aspects of Information Demand ....................................................... 162

11.1.3 Method Modularity and Scalability ................................................................... 162

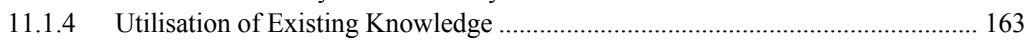

11.1.5 Machine Understandable Representation ............................................................. 163

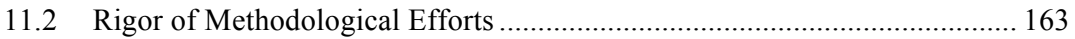

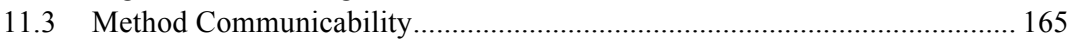

11.4 Summary of Methodological Efforts with Regards to Design Science.......... 166

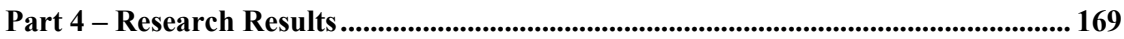

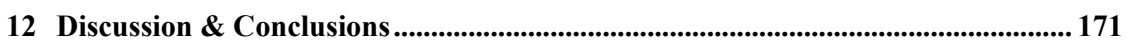

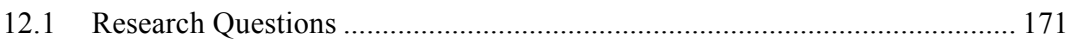

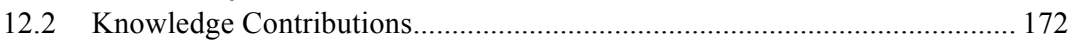

12.2.1 An Information Demand Perspective on Enterprise Analysis ............................ 172

12.2.2 Evaluation and Use of Existing Methods from a Demand Perspective................ 173

12.3 Methodological and Practical Reflections..................................................... 174

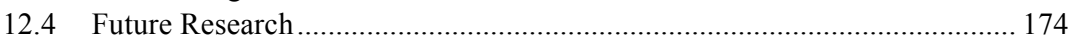

12.4.1 Notational Refinement ................................................................................ 175

12.4.2 Integration of Method Components................................................................. 175

12.4.3 Method Extensions............................................................................................. 176

12.4.4 Information Demand Analysis and the Field of Enterprise Modelling ............... 176

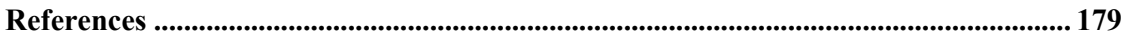

Appendix ............................................................................................................................. 189 



\section{FIGURES}

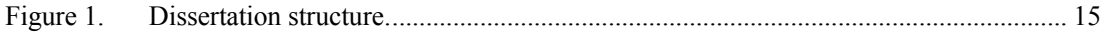

Figure 2. Purpose of, and interrelationships between, publications. ....................................... 18

Figure 3. A framework for IS research according to Design Science (Hevner et al. 2004)....... 33

Figure 4. Relationship between data, information, and knowledge (Clarke \& Rollo 2001)....... 39

Figure 5. Transformation of knowledge (Clarke \& Rollo 2001)............................................. 40

Figure 6. The question-asking, question-answering process (Saracevic 1975)........................ 42

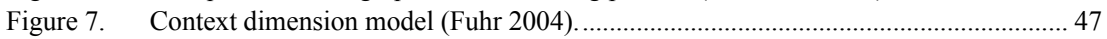

Figure 8. Distribution of informants that rely on colleagues for information. ........................... 63

Figure 9. An integrated view of information demand............................................................ 78

Figure 10. Symbol legend for concept models.......................................................................... 81

Figure 11. Conceptual refinement of information demand contexts. ........................................ 82

Figure 12. Enterprise concepts relevant to information demand............................................. 86

Figure 13. Spatio-temporal aspects of information demand as attributes to a context................. 88

Figure 14. Individual aspects and their relationship to information demand contexts................ 89

Figure 15. Conceptual relationship between competence and information demand contexts..... 90

Figure 16. Informal information sources in relation to information demand contexts. ............... 91

Figure 17. A complete conceptual framework for information demand. .................................... 92

Figure 18. Parts of a method and their interrelationships. (Goldkuhl et al. 1998). ................... 101

Figure 19. The initial version of the method framework..................................................... 106

Figure 20. The initial version of a notation for modelling information demand contexts. ......... 107

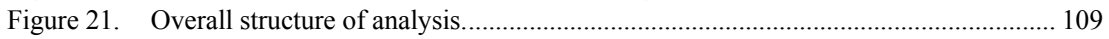

Figure 22. Excerpt from a larger process description. .......................................................... 112

Figure 23. Excerpt from the gaiter material change process model. .......................................... 115

Figure 24. Excerpt from the sensor arm change project model. .............................................. 116

Figure 25. A draft model of an information demand context. ................................................. 120

Figure 26. A complete conceptual framework for information demand. ................................... 133

Figure 27. Illustration of a typical participative modelling seminar....................................... 135

Figure 28. The process of information demand modelling, analysis, and representation........... 138

Figure 29. Information demand context entities. ............................................................... 143

Figure 30. Information demand context relationships. ............................................................. 143

Figure 31. Constructs for extending meaning of entities and relationships............................... 143

Figure 32. Example case illustration a notation for information demand context models......... 144

Figure 33. Enterprise Knowledge Development meta-model (Bubenko et al. 2001)............... 149

Figure 34. A meta-model for competence modelling in UECML ............................................ 151

Figure 35. The concept of task expressed in EEML-notation. ................................................ 153

Figure 36. The concept of role expressed in EEML-notation..................................................... 154

Figure 37. The concepts of tool and object expressed in EEML-notation. ................................ 155

Figure 38. An illustration of a compounded EEML-model........................................................ 155

Figure 39. An example information demand context represented in EEML. ............................. 157

Figure 40. Research process for grounded generation and validation........................................ 160

Figure 41. Extended process for information demand analysis............................................. 176 



\section{TABLES}

Table 1. Design Science Guidelines (Hevner 2004)................................................................. 29

Table 2. Well-grounded method generation and validation (Goldkuhl 1999)........................ 32

Table 3. Use and qualitative assessment of business information sources

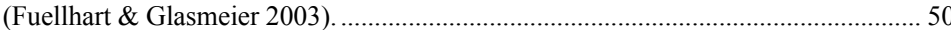

Table 4. The elements of the analysis and questions that it aims to answer (Nyberg \& Wass 2009). ........................................................................................ 127

Table 5. Development efforts from a generation and validation perspective. ........................ 164

Table 6. Development efforts in relation to Design Science guidelines. .................................. 166 

PART 1 - BACKGROUND, PREREQUISITES, AND APPROACH

This, the first part of the dissertation sets the stage for the coming chapters in terms of research focus, -motivation, and-structure. It does so by detailing the research questions that have guided the research presented in coming chapters, and the implications this has had on how the research has been executed. 
This page is intentionally left blank. 


\section{INTRODUCTION}

For many decades now, computer- and information science have concerned itself with the advancement of technology aimed at solving specific problems in various areas such as storage, retrieval, distribution etc. A booming IT-industry has produced ever faster and more powerful computers, new and more expressive programming languages, as well as advanced information storage and management solutions. Equal amount of effort has been put on defining methods and constructing tools for better determining how and to what end technology should be applied in order to improve real-life situations in all aspects of modern society. Furthermore, information is today abundantly available through the Internet, more or less independently of location or time, and regardless of traditional cultural and national borders. In fact, the technological developments of the last 50 years have made more information more available to more people than at any other time in human history (Feather 1998). From a business perspective, IT-systems are no longer used just as simple information repositories or computational tools, they are involved in almost every aspect of daily operation and are in many cases an absolute must for everything from distributing the workload, connecting employees with each other, managing taxes and salaries, to interacting with customers and suppliers, as well as authorities. Partly due to the possibilities brought on by more advanced IT-solution and the Internet, enterprises have gone through a technological and economical revolution in the last 15 years or so. The effects of which are self-evident not only by observing the new markets that have come into existence over these years (online auctioning and shopping, streaming services for music and video, software as a service, cloud computing etc.) but also by observing how existing traditional markets have been transformed through the use of new technology such as automation-, quality-, and production systems for the manufacturing industries, journaling systems for healthcare, customer relationship management systems for sales to mention just a few examples etc. In addition, approaches for understanding and improving enterprises such as Enterprise Modelling (Vernadat 1996), Business Process Reengineering and Improvement (Harmon 2010, Davenport 1993), and Organisational Renewal (Burke 1994) have in combination with technical approaches such as Information Retrieval (Baeza-Yates \& Ribeiro-Neto 1999), Data Warehouses, intranet portals, Enterprises Resource Planning (ERP) systems etc. given enterprises, from a historical perspective, unique opportunities and possibilities with regards to information management from a business perspective. 
Yet, despite all these advancements, information management is still perceived as highly problematic by many organisations. While we live in a society where professional survival depends on our ability to take on board vast amounts of new information, all from an exponentially growing source (Lewis 1996), the problem of analysing and filtering that information still remains, and it remains mainly a human problem (Delphi Group 2002, Lundqvist 2007, Öhgren 2009, Meyer 2011). After conducting a survey of more than 400 organisations, the Delphi Group concluded, already back in 2000 , that some 70 per cent of "business professionals" feel that they spend too much time, typically 25 per cent of their working day on finding and sorting through information they need to perform work related tasks. Time that unarguably could be better spent, fulfilling their responsibilities. On top of this, many of the informants perceive the available software support for retrieving information as insufficient (Delphi Group 2002). Usually this paradoxical situation, when there, despite being an abundance of information available, still is hard to obtain and identify relevant and useful information when needed, is referred to as information overload or sometimes also as information overflow or information fatigue. The concept of information overload is not a new one as it has been discussed continuously throughout the last five decades by sociologists such as Alvin Toffler who popularised the term (1965), cognitive scientists (Klintberg 2008), and researchers in the fields of organisational theory and economy (Edmunds \& Morris 2000, Eppler \& Mengis 2004). In the Edmunds \& Morris (2000) paper, the authors illustrate the adverse effects information overload has on business organisations based on an extensive literature review. Much the same patterns are shown in studies such as the one from the Delphi Group report (2002) and later also Öhgren (2009) and Meyer (2011), all pointing out that an increasingly large amount of time, money, and effort is spent on finding, managing, and interpreting information with respect to work tasks on both an organisational and individual level, in many cases without ever succeeding in doing so (Delphi Group 2002). Furthermore, what mainly used to be a concern mainly for larger organisations is now equally important and relevant for smaller organisations and individuals alike (Öhgren 2009, Meyer 2011), due to an ever-changing and dynamic business environment, requiring a higher degree of flexibility and adoptability. Nor is there any indication that the situation is improving with time. Looking at the last five to eight years, overflow-related problems rather seem to have compounded (Melinat et al. 2014), which partly can be explained by the rise of social networks and more advanced smartphones increasing connectivity and online presence.

As time passes it becomes more and more obvious that the answer to information overload lies, not in more information or ever-more advanced technical solutions to information storage and retrieval, but rather in getting the right information to the right individual given the contextual need, i.e. with respect to demand, time, and location. It is no longer enough with IT-solutions that simply support business activities, they also need to be an integrated part of the enterprise environment and in alignment with actual business needs. While there are modern approaches, such as Information Logistics (ILOG) (Deiters et al. 2003) and various other types of role-based approaches that aim at providing exactly this type of integration by means of demand-driven information supply, this by itself is, as will be shown in the coming chapters, not enough. No technical solution is better than the understanding of its application on which it is based. In other words, it is in most 
cases no longer technical limitations that define or delimit an organisation's possibility to provide its members with the proper support for information management, it is our understanding of such needs and our ability to translate them into technical and/or organisational solutions.

In 2007, as a result from several years of theoretical and empirical studies, the author published a licentiate dissertation detailing the concept of information demand (Lundqvist 2007) and how this relates to information use in work contexts with respect to the aforementioned aspects. The dissertation aimed at creating the theoretical and empirical foundation necessary for developing a methodological approach to analysing organisations with respect to how information could be managed, filtered, and distributed to best support an organisation's members in their various work endeavours. As is detailed in the licentiate dissertation, and partly also in Part 2. of this dissertation, a contextual perspective lies at the core of any wellintegrated business-oriented solution to information management. Supporting the end-users with the filtering, storing, retrieving, and distribution of task-related information according to contextual relevance, is key to such integration (Lundqvist 2005, Lundqvist 2007). It is in other words argued in this dissertation that to understand how to, from an information perspective, best support enterprises in their business endeavours is to understand the information demand its employees have in relation to their various work related tasks and responsibilities, and how such demands are best met. Only once this understanding is achieved is it possible to define suitable solutions, technical or organisational, which provide the necessary level of support and integration. Hence, it is here claimed that identifying, modelling, and analysing information demand is, and should be, a key activity in designing and implementing any type of solutions aiming at improving information management from a business perspective. As of yet however, no established and well-known methods for doing so exist, which brings us to the topic of the research presented in this dissertation.

The underlying assumption for the research presented here is that a well-structured approach to analysing and representing information demand would not only facilitate alignment between business needs and information management from an individual perspective. It is also considered a necessity for understanding the requirements on which various technical and/or organisational solutions should be based (Lundqvist 2005). Furthermore, and as will be shown throughout the dissertation, understanding the flow of information between an organisation's various roles can also contribute to a general increase in the understanding of organisational problems and structures. An approach to analysing and representing information demand therefore also has relevance in itself, much in the same manner as approaches to analysing and modelling such aspects as processes, goals, and requirements in relation to an organisation do. To further strengthen the relevance of the research presented here, the methodological framework on which this dissertation focuses has, as will be shown in Chapter 8. and 9., been developed in close cooperation with several industrial and academic partners. It is the author's belief that it is not only important but also crucial that any approach aiming at solving real-life business problems is developed in the context where such problems actually exist, rather than as a purely theoretical exercise. 


\title{
1.1 RESEARCH INTENT, FOCUS, AND SETTING
}

This dissertation is the combined result of several, more or less, separate and distinct research activities performed over the last ten years, all with one common intent; the understanding, definition, and development of the area of Information Demand Analysis (IDA). That is, how information demand can be identified, modelled, represented, and analysed in a systematic and structured manner with a specific focus on enterprise contexts. It should however be noted that the fact that the dissertation spans several distinct research activities and projects has some consequences. An example of this is that, while the research presented here is focused on enterprises in general, the term Small- and Medium-sized Enterprises (SMEs) is referred to quite a lot in Part 2. of the dissertation but hardly at all in the other parts. This is mainly due to the fact that some of the research activities performed had a specific focus on such SMEs as they were performed together with industrial partners with a particular interest in SMEs. It was therefore decided that any method developed had to be suitable and usable in what is referred to as a small-scale business context as well as in a more general enterprise setting. Once the conceptual foundation for information demand was defined and the emerging method considered the industrial requirements specific to a $S M E$-setting enough, there was however little need for a continued focus on such enterprises specifically and remaining method development efforts therefore had a more general enterprise focus. Consequently, not much is discussed about SMEs or small-scale business contexts in Part 3. and Part 4. of this dissertation.

\subsubsection{Research Context}

Partly for the purposes of providing the research presented here with the possibility of empirical grounding, a research project was defined and run over a four-year period. The project, Information Logistics for SME: Improving information flow based on information demand patterns (InfoFlow), was funded by the Swedish Knowledge Foundations (KK-stiftelsen) and run as a cooperation between a number of industrial and academic partners:

\author{
School of Engineering (JTH), Jönköping University (Sweden) \\ SYSteam Management AB (Today Evry) (Sweden) \\ Kongsberg Automotive AB (Sweden) \\ Proton Group AB (Sweden) \\ Centre for Information Logistics (Sweden) \\ Jönköping International Business School (JIBS) (Sweden) \\ Linköping Institute of Technology (LiTH) (Sweden) \\ Fraunhofer ISST (Germany)
}

As an integrated part of the InfoFlow-project, a number of joint activities as well as several empirical cases have been performed. The purpose behind doing so has been to further the development of the method presented here as well as to solve specific information flow-related problems within the various partners' organisations. The 
industrial aspects and consequences of these cases will not be covered here, as those are covered in the different project reports, listed in Section 1.4. below. Instead, focus will here be put solely on the methodological aspects of said cases and activities. From a purely scientific perspective, there have been several rationales behind performing the cases:

- Confirmation of the conceptual framework presented in Chapter 6.

Even though the bulk of the conceptual framework was defined before the cases, based mostly on the work presented in Part 1., additional evaluation and development was needed. The cases helped, not only in validating the conceptual framework, but also with completing it, as there has been an iterative process where the experiences from the cases have led to knowledge usable for continued development.

\section{- Evaluation of existing methods}

As will be shown in Chapter 8. and 9., the direction and purpose of the performed cases have been different. One reason for this was to get the opportunity to apply different existing methods for analysing enterprises and thereby determine their suitability for contributing to the method development. With respect to this part of the evaluation, focus has been but mainly on the more "traditional" enterprise aspects, such as process-, goal-, and problem modelling for which there is no reason to develop new approaches.

\section{- Evaluation of method draft and parts thereof}

After the first two cases both the theoretical and practical aspects of the research had reached the point at which a first draft of the core component of the method was finished. In order for the component to be refined, additional cases were performed to test the draft with respect to the results it would produce.

Even though the cases were designed to, either test specific aspects of the method or generate specific knowledge or insight, certain aspects of how this was done are shared by all cases. All cases have been performed together with industrial partners, focusing on actual organisational problems. The research environment of which the author is a part, adhere to what often is referred to as the participative approach to enterprise modelling, i.e. where knowledge about an organisation is extracted from the organisation itself by modelling (parts of) it in close cooperation with actors within the analysed area. As a consequence of this, all cases have also incorporated the extraction of knowledge from and together with representatives from each organisation.

To ensure that a number of different and separate research activities such as the ones presented in this dissertation, despite a somewhat changing focus and different prerequisites, still results in something that contributes to a general research intention, two research questions were defined as a way to guide and interrelate the various activities. 


\subsubsection{Research Questions}

The development of a method for Information Demand Analysis, which is the main goal of the research presented here (as further detailed in Section 1.2.), requires several other issues to be dealt with first, issues of a more general nature. To understand what information demand individuals and organisations have, and how such demands could be analysed, obviously means that information demand in itself, as well as how information is used when work-related tasks are being performed, must be understood. In order to achieve this understanding, the first part of the research has focused on the answering of one main question, this question has then been further broken down into a number of conjectures to further aid and support continued research activities. That question is:

RQ1. What is, and what defines information demand from an enterprise perspective?

To define the concept of information demand fully, and in all aspects is by no means a simple task and can of course be attempted in many different ways. Based on an initial literature review performed in the early stages of the research (see Chapter 3.) a number of conjectures were formulated and later empirically validated (Chapter 4). These conjectures represent the author's initial conceptual understanding of information demand and have as such partially guided the continued research relating to RQ1. in terms of methods and approaches. It would of course have been preferable to discuss the background to, and motivation for, these conjectures before presenting the actual conjectures themselves. However, while holding off with presenting the conjectures until after the relevant theory is discussed may have facilitated understanding it would unfortunately also have made the discussion about research focus, -structure, and -method much more difficult to follow. Hence, the conjectures are listed below but they will not be substantiated until the end of Part 2.

Firstly, it seems reasonable that information demand in a business- and work-related situation in some way would be related to aspects of that situation, that is to say:

C1. Information demand strongly depends on the role and tasks an entity has within a larger organisation, if that role and/or the tasks change, so too will the demand.

If this assumption holds true it is just as likely that such a demand also is dependent on the timing and duration of tasks that are to be performed within such a situation, as well as the location any entity might have while performing them. Therefore, it is assumed that:

C2. Information demand has a temporal aspect, i.e. a specific demand is only relevant at certain time intervals or points in time.

C3. Information demand has a spatial aspect. The demand changes based on the location as well as on any movements of the entity having it.

It was during the literature review presented in Chapter 3., realised that few, if any, of the existing views taken on information flow consider enough the social aspects of human interaction when it comes to information exchange and acquisition. 
It is the author's belief that any approach not acknowledging these aspects will fail its purpose. To test if this belief in fact holds true the following conjecture was formulated:

C4. Information demand is partly fulfilled through informal information exchange channels, i.e. such channels that are not represented in any formal description of organisational structures, processes or other enterprise models.

Finally, a conjecture relating the idea of information demand to the current state of information management in enterprises was defined in order to investigate whether the ideas regarding information demand have any actual industrial relevance:

C5. Existing approaches and systems do not consider the temporal, spatial, and informal aspects of information flow and -demand enough and thus, do not solve all information management related problems users have in connection with the execution of work-related tasks.

Since these conjectures also are quite complex and very well could constitute a research area, spanning many different research disciplines, in their own right, it would be presumptuous to believe that they ever could be researched fully within a single Ph.D. project. However, for the purposes of information demand analysis and an improvement of information flow-related problems in general, this is fortunately not completely necessary. As with so many other complex issues, information demand is, as will be shown throughout this dissertation, not really a question of true or false, right or wrong but rather one of understanding. The better the understanding, the better the possibilities to then answer the question on which Part 3. of this dissertation has focused; how information demand can be analysed and represented.

The view taken here is that analysing and representing information demand requires some sort of structured and well-defined approach, a method. A method is, somewhat simplified (and to be detailed in Chapter 7.), a collection of procedures, notations, and concepts tied together in a framework, guided by a set of governing principles with the purpose of achieving specific goals, or finding the solution to specific problems. Thus, the definition of a second research question:

RQ2. How is a structured and industrially relevant approach to analysing and representing information demand supported?

Following from this research question are some consequences that cannot be ignored. As the main research focus always has been to solve a specific set of reallife problems and the best way to do so, in the author's opinion, is by means of a well-defined method, the main result presented here is indeed such a method. However, in a pragmatic sense, the author has a rather relaxed view on methods. It is therefore not at all the author's intention to develop a method that strictly defines every step of the process of analysing information demand, as such rigidity rarely works in a generic industrial setting. Instead, focus has been more on providing a set of procedures and notations based on an underlying conceptual foundation, tied together by a methodological framework. It is believed, and will be argued for in later parts, that this approach helps the method user to achieve the intended goals 
while it at the same time allows for greater flexibility with respect to the situation in which the method is applied. Furthermore, while this, still rather general research question, of course also can be further broken down and detailed in terms of actual requirements, properties, and components on and of methods, doing so has no real relevance at this stage. Instead, this question will be used as a way to represent the overall purpose of the work presented in the rest of this dissertation.

\subsection{PRACTICAL \& SCIENTIFIC CONTRIBUTIONS}

The intended main results of the research presented here (1) a definition of the term information demand and (2) a method for information demand analysis, constructed in such a way that it is based on established theory as well as on an empirically grounded foundation. In order to ensure that the intended result is reached such a method is considered to be comprised of two different artefacts:

ART 1. A conceptual framework, covering the domain of information demand analysis in terms of definitions and interrelationships and constituting the foundation for ART 2.

ART 2. A methodological framework consisting of the following parts:

A. A set of general principles, guiding efforts to efficiently analyse information demand.

B. A method framework, detailing how to combine and sequence different method steps and -components to achieve specific results.

C. Descriptions of method components for analysing and documenting different aspects of information demand, such as information demand contexts, social networks, competence, and enterprise structure.

D. A notation for representing all analysed aspects of information demand.

In Chapter 5., where information demand is defined and in Chapter 6., where it is conceptualised and detailed, information demand context is stated to be the core of information demand analysis. It is the conceptual foundation on which all other parts of the method should rest. While, as will be shown in Part 3., all other aspects of information demand can and will be dealt with by using existing methods and notations, this core part cannot, as there simply are no methods available for doing so. A number of new constructs are therefore needed to support the method user in capturing and describing information demand contexts. In addition to this, a notation for representing and interrelating all analysed aspects of an organisation with respect to information demand is also needed.

It is here argued that answering the research questions, discussed in the previous section, by defining and producing definitions and artefacts as the ones described above, would improve the possibilities to understand the connection between individuals' work contexts and information demand, as well as how this relates to information flow within organisations. Doing so would also facilitate the development of any technical and/or organisational changes aiming at providing 
better approaches to providing workers with information that supports them in their various work tasks, and thereby contribute to reducing information overflow-related problems. In this dissertation, these two artefacts are together referred to as a method for Information Demand Analysis and to ensures that the method adheres to the overall research intent, it has to be developed in such a way that it:

- Has relevance for a specific set of problems regarding information flow within enterprise contexts (detailed in Part 2.).

- Is theoretically, empirically, and internally grounded in its development and validation.

- Contributes to the general body of scientific knowledge concerning information demand and -use in enterprise contexts.

- Is documented and represented in both a technical and a pragmatically manner, i.e. described in such a way that is perceived as suitable for both academic and industrial purposes.

While the artefacts detailed above together with the definition of information demand are the most prominent and obvious contribution of the presented research, they of course also have additional consequences from a knowledge perspective. It is therefore the author's intention that the dissertation should not only communicate the practical aspects of the method's conception and refinement, but also the possible benefits of using it in an industrial context as well as the consequences such application might have on the overall situation vis-à-vis information overload and other information management-related problems, detailed in the introduction of this dissertation. Furthermore, there are secondary benefits from developing a method in terms of conceptualisation of a problem domain hitherto relatively unresearched; increased enterprise understanding and experiences from a new perspective.

\subsubsection{An Information Demand Perspective on Enterprise Analysis}

Based on the background given in the introduction it can be argued that technical approaches such as ILOG, ERP-systems, role-base intranet portals etc. would benefit from a method for identification, modelling, and representation of the information demand on which such approaches shall focus. It is therefore the author's intention that the material presented here should constitute the foundation not only for such a method, but also for the shifting of focus from mere technical solutions and process-based views on organisations, to a more user- and demandoriented perspective on enterprise analysis, and in the long run thereby also a general improvement of information flow within enterprises.

Whether this will be an actual consequence of the research presented here is of course outside of the author's direct control as it is the industry that decides on the preferable perspective on common problems. However, the intended outcome can be facilitated by ensuring that the research is formulated, performed, and presented in such a way that it provides useful tools based on a solid and relevant conceptual underpinning. In that sense, this declaration of intention has therefore guided the research in terms of choices, methods, techniques, and formulation of results. Simply put, if the method and its possible usages and effects are correctly defined 
and described, it should help with the conceptual understanding of information flow and information demand within an enterprise, shared between its different parts and individuals, as well as support a better alignment between IT-solutions and business needs.

To provide a new perspective on something implies that one provides a new nomenclature for an existing domain. By defining the concepts and their interrelationships within the domain, one allows for focus being directed towards what is considered important and prioritised from said perspective. Any method aiming at solving problems within such a domain then of course has to be related to such a nomenclature. As a part of developing aforementioned method, in accordance with the argumentation above, a substantial amount of effort has been put on refining the concept of information demand from both a theoretical and empirical perspective. Such a refinement, and the increased understanding of enterprises and work contexts it signifies, has its own inherent value, independently from the method and its usages. This understanding is considered to be an important contribution to the general body of scientific knowledge as it facilitates the reasoning about work contexts from a demand perspective in general, and information flow perspective in particular. The focusing on conceptual refinement is in that sense not only highly relevant with respect to the research questions formulated but also an absolute requirement for the fulfilment of the other contributions. Consequently, a conceptual framework is presented in Chapter 6. together with definitions of each concept relating it to common usage within related organisational and technical theory.

\subsection{DISSERTATION STRUCTURE}

To better support the communication of the results from the research presented here as well as from the various research activities themselves, the structure of this dissertation reflects that of the actual research performed and is as follows:

\section{- Part 1 - Background, Prerequisites, and Approach}

This, the first part of the dissertation sets the stage for the coming chapters in terms of research focus, motivation, and structure. It does this by detailing the research questions that have guided the research presented in latter chapters, and the implications this have had on how the research has been executed.

○ Chapter 1 - Introduction

Motivates the research by pointing out a number of current, realworld problems. These problems are used to motivate research into two specific research questions. It also discusses intended results and contributions of such research.

○ Chapter 2 - Research Approach

This chapter details how the author has ensured that the answering of the research questions discussed in Chapter 1. is done in a scientifically sound manner. It discusses such aspects as:

- How and why theory have been selected and used 
- How the different empirical efforts have been design, performed, and analysed

- How and why the views taken on methods and method development have been selected.

- How the produced results have been validated with respect to the intended results, as well as the defined research questions.

- Part 2 - Information Demand and Use from a Small-scale Business Context Perspective

This part of the dissertation focuses on answering RQ1. by presenting related and relevant theory as well as an empirical foundation regarding information use in organisations with respect to roles, tasks, and resources. It should be noted that Chapter 3. and 4. that cover the theoretical and empirical knowledge on which much of this research rests, make no reference to the relevance of the material nor how it actually relates to the research questions and conjectures defined in Chapter 1. This information can instead be found in Chapter 5. where both theoretical and empirical results are discussed in relation to the conjectures presented in Chapter 1. The motivation behind this is to emphasise the relationship between specific parts of the theoretical and empirical knowledge and the conjectures to make it clear exactly how the answers to the first research question have been reached. It is then concluded the definition of information demand on which continued method development efforts are based.

- Chapter 3 - Information Demand: A Theoretical Perspective In this chapter, an overview of the theoretical foundation for information demand and related areas are presented. This is done with the purpose of giving the reader some background to the research described in this dissertation, as well as into the area as such. There are mainly three different theoretical perspectives covered here; information and knowledge classification, information demand as a concept present in several different research areas, and information use in an enterprise context

○ Chapter 4 - Information Demand and Use: An Empirical Perspective

This chapter details an empirical study, performed as one part of the effort to understand and define information demand as a concept. This chapter only covers the investigation in terms of results while such aspects as selection, data collection, and analysis are discussed in Chapter 2.

○ Chapter 5 - An Integrated View of Information Demand

This chapter discusses the validity of the conjectures regarding information demand listed in Chapter 1. with respect to the theoretical background and the results from the empirical investigation presented in Chapter 3 and 4 . The conclusions 
presented constitute the foundation on which the rest of the dissertation is based.

- Chapter 6 - Conceptual Refinement of Information Demand This chapter uses the background and conclusions presented in the previous chapters in order to elaborate and refine the concept of information demand to a level necessary for the development of a method for identifying, modelling, and representing such demands.

- Part 3 - A Methodological Framework for Analysing Information Demand

This part details the theoretical and empirical efforts spent on answering RQ2. by defining, developing, and validating a methodological framework for information demand analysis based on the conclusions regarding information demand drawn in Part 2. It also covers the notion of method used throughout the dissertation.

○ Chapter 7 - Method Theory

This chapter covers the theoretical background to, as well as the view on, method development and the notion of method used throughout the efforts of developing the method for IDA.

○ Chapter 8 - Method Development \& Initial Method Hypothesis This chapter describes the initial steps taken in the area of method development. It covers two cases that evaluated existing methods and were the basis for the initial versions of the method and its documentation.

○ Chapter 9 - Method Validation

This chapter details how the initial method hypothesis presented in Chapter 8. has been validated in additional empirical cases performed by the author as well as by external parties.

- Chapter 10 - Refined Method Hypothesis

Based on knowledge gained during the initial development efforts and the subsequent validation a refined version of the was developed and is presented in this chapter.

○ Chapter 11 - Reflections on Method Development

This chapter discusses aspects of the method and its development with respect to scientific validity as well as adherence to industrial requirements and demands.

- Part 4 - Research Results

This, the final part, concludes the research regarding information demand by discussing the results and consequences of what have been detailed in the previous parts of the dissertation.

○ Chapter 12 - Discussion \& Conclusions

This chapter discuss the research detailed throughout the dissertation with respect to the research questions and intended contributions. It also briefly touches on the subject of continued research. 
The structure and content of the dissertation's different chapters, as discussed above, is illustrated in Figure 1. to help the reader getting an overview of how they interrelate.

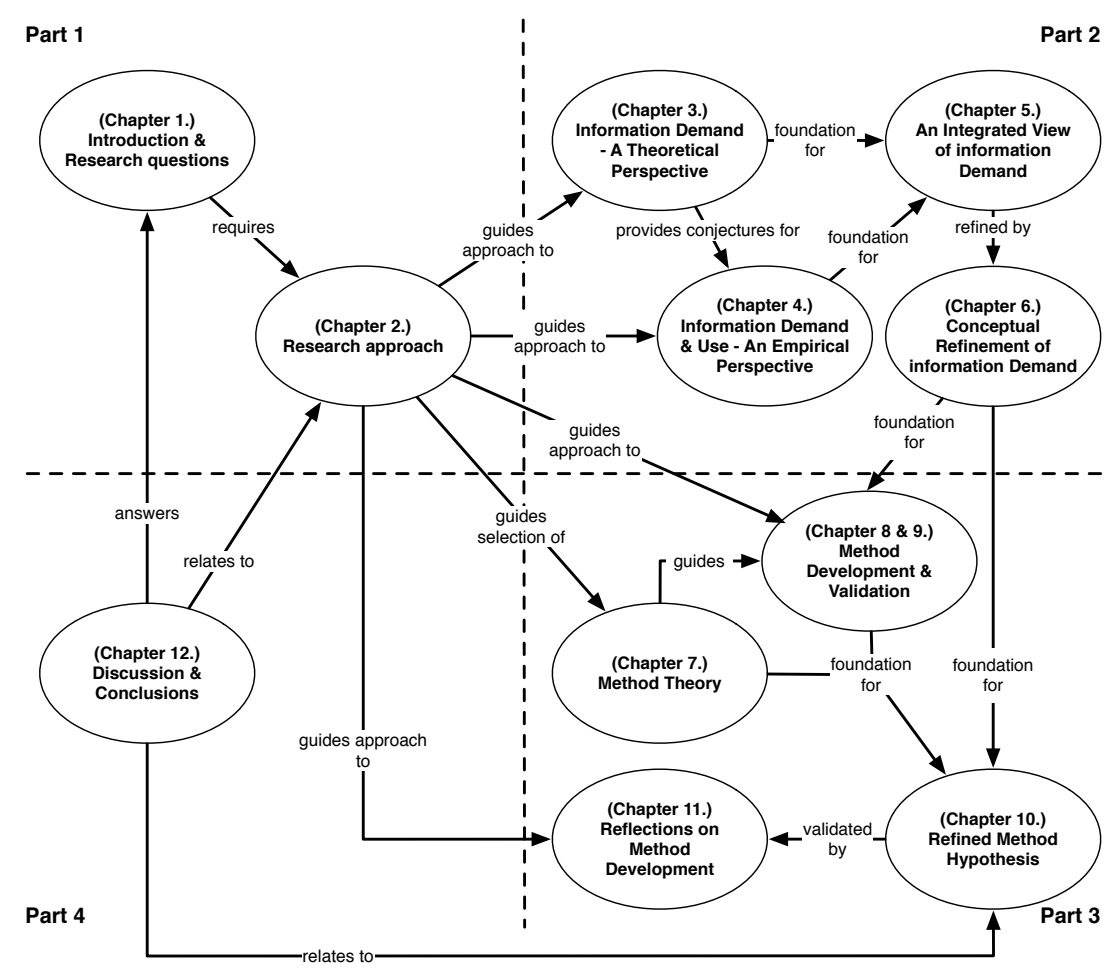

Figure 1. Dissertation structure.

\subsection{RELATED PUBLICATIONS}

This dissertation focuses more on communicating an overview of the research on which it has been based, rather than on detailing every activity that have been performed during the process. Much of the work leading up to what is presented here has however, in parts, already been subject to peer-review and published through various conferences and journals. The following is a list of such publications considered as an additional part of the scientific and practical knowledge contribution stemming from the research presented here:

1. Lundqvist, M. (2004) Improving Information Flow in Small-scale Applications: Selected Approaches and Concepts. Research Report, ISSN 1404-0018; 2004:9, Jönköping School of Engineering, Jönköping, Sweden.

2. Lundqvist, M., Sandkuhl, K. (2004) Modelling Information Demand for Collaborative Engineering, in Proceedings of $2^{\text {nd }}$ Intl. Workshop on Challenges in Collaborative Engineering (CCE'04), Stara Lesna, Slovakia. pp. 111-120. 
3. Lundqvist, M. (2005) Context as a Key Concept in Information Demand Analysis, in Proceedings of the Doctoral Consortium associated with the $5^{\text {th }}$ Intl. and Interdisciplinary Conference on Modelling and Using Context (Context-05), Paris, France. pp. 63-73.

4. Lundqvist, M., Sandkuhl, K., Levashova, T., Smirnov, A. (2005) Contextdriven Information Demand Analysis in Information Logistics, in Proceedings of the first International Workshop on Contexts and Ontologies: Theory, Practice and Applications (C\&O’05), Pittsburgh, Pennsylvania, USA.

5. Sandkuhl, K., Lundqvist, M., Tarasov, V. (2006) A Competence Model for Collaborative Design, in Proceedings of $4^{\text {th }}$ Intl. Workshop on Challenges in Collaborative Engineering (CCE'05).

6. Levashova, T., Lundqvist, M., Pashkin, M. (2006). Moving towards Automatic Generation of Information Demand Contexts: an Approach Based on Enterprise Models and Ontology Slicing, in On the Move to Meaningful Internet Systems 2006: CoopIS, DOA, GADA, and ODBASE. Lecture Notes in Computer Science Book Series, ISSN 0302-9743. pp. 1012-1019.

7. Levashova, T., Lundqvist, M., Sandkuhl, K., Smirnov, A. (2006). Contextbased Modelling of Information Demand: Approaches from Information Logistics and Decision Support, in Proceedings of the $14^{\text {th }}$ European Conference on Information Systems (ECIS) 2006, Gothenburg, Sweden.

8. Levashova, T., Lundqvist, M., Pashkin, M. (2007) Provision of Contextsensitive Enterprise Knowledge for Decision Support: an Approach Based on Enterprise Models and Information Demand Contexts, in Proceedings of the $9^{\text {th }}$ International Conference on Enterprise Information Systems: Artificial Intelligence and Decision Support (ICEIS) 2007, Maderia, Portugal. pp. 8893.

9. Lundqvist, M. (2007) Information Demand and Use: Improving Information Flow within Small-scale Business Contexts. Licentiate thesis, Linköping studies, in science and technology, ISSN 0280-7971; 1323, Department for Computer and Information Science, Linköping University.

10. Tarasov, V., Lundqvist, M. (2007) Modelling Collaborative Design Competence with Ontologies, in International Journal of e-collaboration, ISSN 1548-3673, vol. 3, issue 4. pp. 46-62.

11. Lundqvist, M., Sandkuhl, K., Seigerroth, U., Stirna, J. (2008) Requirements for Information Demand Analysis, in Proceedings of $2^{\text {nd }}$ International Conference on Adaptive Business Systems (ABS 2008), Glasgow, Scotland. 
12. Tarasov, V., Sandkuhl, K., Lundqvist, M. (2009) Ontology-based Competence Model for Collaborative Design, in Virtual Team Leadership and Collaborative Engineering Advancements: Contemporary Issues and Implications, Advances in E-Collaboration (AECOB) Book Series, ISSN 1935-2883.

13. Lundqvist, M., Mazalov, V., Sandkuhl, K., Vdovitsyn, V., Ivashko, E. (2009) Do Digital Libraries satisfy Users' Information Demand? Findings from an Empirical Study, in Proceedings of International Conference on Digital Libraries RCDL, September 16-18, 2009, Petrozavosk, Russia, ISBN 978-59274-0374-5.

14. Lundqvist, M., Holmquist, E., Sandkuhl, K., Seigerroth, U., Strandesjö, J. (2009) Information Demand Context Modelling for Improved Information Flow: Experiences and Practices, in The Practice of Enterprise Modeling, Lecture Notes in Business Information Processing Book Series, ISSN 1865-1348. pp. 8-22

15. Lundqvist, M., Sandkuhl, K., Seigerroth, U. (2011) Modelling Information Demand in an Enterprise Context: Method, Notation, and Lessons Learned, in Gustas, R. (Ed.) International Journal of Information System Modeling and Design, Vol. 2, Issue 3, July-September, 2011. ISSN 1947-8186.

16. Lundqvist, M., Sandkuhl, K., Seigerroth, U. (2012) Enterprise Modelling in Distributed Teams-Lessons Learned from Information Demand Modelling. In: M. Kirikova, J. Stirna (Eds.): Proceedings of the CAiSE'12 Forum, Gdansk, Poland, June 28, 2012. CEUR Workshop Proceedings 855, pp. 139-146.

17. Lundqvist, M., Sandkuhl, K., Seigerroth, U. (2012) Transfer of Method Knowledge and Modelling in Distributed Teams - Lessons Learned, in N. Asseva, E. Babkin, \& O. Kozyrev, eds. Perspectives in Business Informatics Research. $11^{\text {th }}$ International Conference, BIR2012, Nizhny Novgorod, Russia. Proceedings LNBIP 128, pp. 26-40. Springer 2012, ISBN 978-3-64233280-7.

In addition to the publications listed above, several technical reports detailing various parts of the method development process and results thereof have been published as a part of the research project InfoFlow in which most of the empirical work on method development has been performed:

1. Lundqvist, M., Seigerroth, U., Stirna, J., \& Sandkuhl, K. (2008) InfoFlow Deliverable D1. Information Demand Analysis Methodology - Initial objectives, requirements, and prerequisites.

2. Lundqvist, M. (2008) InfoFlow Deliverable D2.1. Application Case KAExperiences from Modelling Activities.

3. Lundqvist, M. \& Seigerroth, U. (2008) InfoFlow Deliverable D2.2 Application Case Proton Finishing - Experiences from Modelling Activities. 
4. Lundqvist, M., Seigerroth, U. \& Stirna, J. (2008) InfoFlow Deliverable D2.3 Application Case SYSteam Management - Experiences from Modelling Activities.

5. Lundqvist, M., Seigerroth, U. \& Sandkuhl, K. (2009) InfoFlow Deliverable D4.1. Handbook for Information Demand Analysis.

These project deliverables are not peer-reviewed, nor are they publically available (albeit available from the author on request) but have nevertheless in various ways contributed to the publications that are peer-reviewed, as well as to this dissertation.

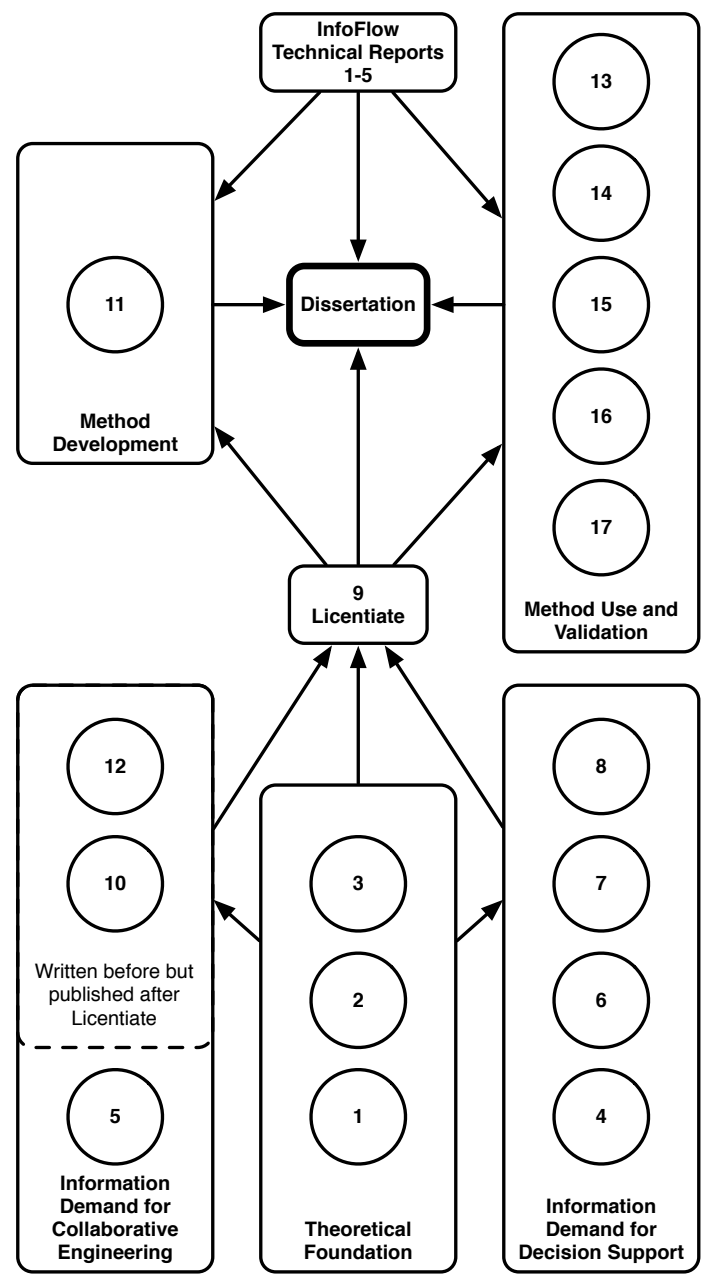

Figure 2. Purpose of, and interrelationships between, publications.

Figure 2. above details the purpose and interrelationships of the different publications in a larger context. Publication 1,2, and 3 constitute the initial foundation for the research presented in this dissertation and are mainly based on the theoretical studies detailed in Chapter 3. The ideas presented within those 
publications were then elaborated and evaluated in mainly two different application areas, collaborative engineering $(5,10$, and 12$)$ and decision support $(4,6,7$, and 8$)$. The knowledge gained from these exercises, together with the theoretical foundation and the empirical study detailed in Part 2. of this dissertation, led to the publication of the licentiate dissertation (9). It is on the findings detailed there, the remaining publications and the InfoFlow-reports as well as this dissertation rests. Just as the technical reports, publications 11, 13, 14, 15, 16 and 17 have focused more on detailing the emerging method, its conception, and its application in industrial cases. These six publications thereby support and substantiate the results presented in this dissertation.

\subsection{INTENTED READERS}

This dissertation is mainly oriented towards readers that have an interest in method development in general and the empirical and theoretical foundation of the method for information demand analysis presented here, in particular. While this dissertation covers all different parts of the method, it does not focus on the application of the method in real-life situations beyond evaluation and validation, nor does it provide any best practices for doing so. Information regarding such aspects can however be found in the various technical reports and papers 13-16 listed in the previous section, which have a more applicability-oriented focus. Because of this, it is also assumed that most readers of this dissertation have an interest in assessing the scientific merits of the method presented. Consequently, the dissertation has a structure and language assuming a reader with a scientific background in the areas of Enterprise Modelling, Method Development, and/or Organisational Renewal. 
This page is intentionally left blank. 


\section{RESEARCH APPROACH}

Just considering the focus and intent of researching a specific set of questions and problems is not enough in itself to ensure the quality of research results regarding such aspects as validity, relevance, rigor, and generalisation. The approach taken to produce the intended results also has to be considered in terms of structure, activities, and choices made. Usually this is dealt with by relying on a single, established and well-defined research method. In the case at hand this is however not really possible due to the fact that the intended results and contributions comprises both what could be considered design activities (answering RQ2.) as well as more explorative, knowledge generating activities (answering RQ1.). Performing research activities with two, such different goals also require different approaches to research in order to ensure the quality of the results. Consequently, rather than trying to find one single approach for solving all problems, it has, for the purposes of the research presented here, been considered more relevant to combine several different and specialised approaches. Doing so solves the problem of ensuring the quality of the results from the different types of activities throughout the research process. It does however also require the use of a general framework to ensure that results from different activities are combined together in a manner that makes the entirety of the results of equally high quality as that of its individual parts. This chapter details how the author has combined different research methods and perspectives in order to ensure the quality of the final results.

\subsection{THEORY SELECTION}

Unless one choses a strictly inductive approach to research, all research efforts need to relate to existing theory and results within the researched area. The research presented in this dissertation is no exception to this rule and as it is focused on what may be seen as an interdisciplinary subject, adjacent to many different theoretical subjects, the theoretical background to this work is quite extensive. It is consequently relevant to briefly discuss the underlying choices made by the author when selecting the theoretical foundation on which the research is based.

To ensure that the theoretical foundation for the research presented here was sufficiently complete and enough considered other sources and fields than those typically used in the author's research area, the approach to theory selection taken is based on the ideas presented in the structured literature review-approach (Webster \& Watson 2002). Theory reviews have been performed in three distinctly 
different manners. The initial theoretical studies made in the beginning of the process focused on getting an overview of the research area and any areas related to it. During this stage, there have been continuous iterations between studying theory and refining the emerging research questions and conjectures with a specific focus on concepts independently of domain, methodology, or publication fora. This is the main reason to why theory from such diverse research areas as sociology, economics, and computer science can be found in Chapter 3. As the research questions and -conjectures became increasingly defined, the theory selection was intentionally limited to, and focused on, specific subjects. Such delimitation was performed mainly by identifying relevant publications from the reference lists of already selected publications thus both deepening and broadening the understanding of the area. Once a clearer picture of the area as a whole was gained from both theoretical studies (see Chapter 3.) as well as an empirical investigation (Chapter 4.) the theory selection was geared more towards answering specific questions and solving problems as they arose. An example of this is the theoretical background for selecting a notion of method as discussed in Chapter 7.

The third manner in which theory has been selected is due to the nature and structure of the research process itself. A typical Ph. D. process in Sweden is five to six years long, which means that a lot will happen in a research field between start and finish of the process. In the case of the research presented here, studies concerning the theoretical foundation for information demand and -use were also performed quite early in the process. Consequently, there has been a need for continuously updating the theoretical parts of the dissertation every now and then in order to keep them à jour with new theories, knowledge, and ideas within the field.

\subsection{DEFINING INFORMATION DEMAND}

The first part of the research focused on answering RQ1., i.e. defining the concept of information demand. As it early on became clear that neither a lot of theory nor many studies about information demand in general, and from an enterprise perspective in particular, could be identified during the literature review. It was therefore concluded that the best approach to achieving a better understanding of the underlying aspects of information demand was to perform an empirical investigation looking deeper into the matter. Such an investigation was performed with the initial intention to investigate information use from a $S M E$-perspective in the south of Sweden. This focus was later changed, since the term SME can be somewhat difficult to define. What typically would be considered a SME in USA, an enterprise with less than 500 employees, would often be considered a rather large organisation in Europe where a $S M E$, according to some definitions is one with between 10 and 49 employees and with an annual turnover less than $€ 10 \mathrm{M}$ or no more than 249 employees and with an annual turnover less than $€ 50 \mathrm{M}$ respectively (EU-Commission 2003). Considering this in conjunction with the fact that many larger enterprises are made up by several subsidiaries, which in many aspects act on the market as independent smaller enterprises, it was considered more relevant to talk about small-scale business contexts. This shift in focus allowed for a broader choice of organisations to investigate while still keeping focus on the needs of smaller enterprises with limited resources. It should however be noted that the term

SME still is used throughout the dissertation in general, and Part 2. in particular, due to the fact that it is the term used in most of the studied theory. 


\subsubsection{Chosen Approach to the Initial Empirical Investigation}

Empirical investigations can be both conceived and performed in many different ways depending on intended purpose and goal. In the case at hand, it was considered important to get a relatively deep understanding of information demand from a role-perspective and any investigation therefore had to cover several different types of roles as well as roles acting within different types of organisation as further detailed below.

\subsubsection{Investigated Organisations}

In total 27 interviews with individuals from three different organisations have been performed. Out of the three investigated organisations, two, $P E$ and $K A$, are active within the automotive industry as sub-contractors to large international car manufactures and in some cases to each other. The reasoning behind incorporating the third organisation $S B A$, a public authority, which is a $S M E$ from neither a sizenor a business perspective, was twofold. Firstly, it was considered relevant to see if the use of information within non-profit organisations differs from that within business-oriented enterprises in order to generate results as generally applicable as possible. Secondly, while by Swedish standards, being a rather large organisation with its 1120 employees, the organisation is divided into nine departments and 43 divisions with their own fields of responsibility, thus making it possible to consider each department as being comparable with small-scale business units from an information demand and -use-perspective.

It should throughout this dissertation, be remembered that $S B A$ uses the terms department and division contrarily to common use in that the nine departments comprises the 43 divisions.

\subsubsection{Selection of Informants}

The informants, four from $P E$, fourteen from $K A$, and nine from $S B A$ were chosen in such a way that they as far as possible constitute a cross-section of the organisational structures with respect to both width and depth. The following is a complete list of the informants' roles within their respective organisations, with their Swedish titles in parenthesises:

- SBA

○ Deputy director-general (Överdirektör)

○ Head of Public Relations (Informationschef)

○ Head of Department (Avdelningschef)

○ Two different Head of Division (Enhetschef)

○ Two different Administrative Executives (Handläggare)

○ Administrator/Secretary (Avdelningssekreterare)

- Assistant (Assistent) 
- KA
- Chief Information Officer (IT-chef)
○ Quality Manager (Kvalitetsansvarig)
- Head of Product Development (Produktutvecklingschef)
○ Chief Economical Officer (Ekonomichef)
○ Economical Controller (Ekonomi-controller)
- Material Controller (Material-controller)
- Content Manager (Content Manager)
- Head of SAP training and Helpdesk (Utbildningsansvarig)
- Head of Production Technology (Produktteknisk chef)
- Head of Production (Produktionschef)
- Production Supervisor (Produktionsledare)
○ Production Technician (Produktionstekniker)
○ Group-leader, Production Technology (Gruppledare)
- Supervisor, Service and Maintenance (Arbetsledare)

- PE
- Head of Logistics and IT (Logistikchef/IT-chef)
○ Head of Sales (Försäljningschef)
- Production Supervisor (Produktionsledare)
- Operation Supervisor (Driftsledare)

The idea behind this sample is that, by investigating all levels of the organisations, from top-level management via middle management down to production- and administrative personnel, conclusions can be drawn about the differences in demand for, and use of, information depending on the type of work activities performed by, and responsibilities related to, roles.

\subsubsection{Data Collection}

The collection of empirical data, while certainly possible to do in many different ways, has in this case been done by means of semi-structured interviews. While such interviews tend to result in quite extensive amounts of data in comparison to using questionnaires or other highly structured approaches to data collection, and thus make the analysis of data more difficult, they, in this particular case, have their benefits. Even though the aim of the investigation performed is to answer a specific, well-defined research question (RQ1.), it is also considered relevant to try to 
discover other unknown aspects of information demand and -use. To add the possibility for this explorative aspect of the investigation means that new knowledge can be generated as a positive side effect. For this purpose, semi-structured interviews, as opposed to questionnaires, is well-suited since it allows the researcher to control the overall direction of the investigation while at the same time giving the informants the freedom to expand on the subject from their own perspective and thus introduce topics and ideas previously unknown to the researcher.

During the early stages of the research the idea of viewing organisations and individuals as both being subject to the same type of information demand arose. It was assumed that the differences between individuals and organisations when it comes to information demand, can be seen as a mere question of abstraction or granularity, in that both need information for the same reasons and collects it much in the same manner. In order to see if this line of reasoning indeed was reasonable, the questions asked during the interviews were divided into two different sets as described below. One set of questions focusing on the roles and one focusing more on the organisation in general.

\section{Role-focused Questions}

In order to determine the different aspects of information demand and use as well as how this relates to the conjectures formulated in Chapter 1. the following questions were asked all of the informants, independent of their role within their respective organisation:

1. Who are you and what is your role within the organisation?

2. Which are the tasks related to that role?

a. Would you describe your role as consultative or producing?

3. What information do you need to perform your work tasks?

a. How would you categorise that information? As knowledge, data, instructions etc.?

i. What form does it have (Tacit/Structured)?

b. From where do you get that information

c. Do you consider that information to be:

i. Reliable

ii. Relevant

iii. Available

4. From where are you supposed to get your information, if different from $3 b$ ?

5. To what extent do you rely on your colleagues for getting information?

a. When you do, on what do you base your choice of colleagues? 
6. How do you deal with the information you collect/receive with respect to:
a. Storing
b. Forwarding
c. Retrieving

7. Have you identified any problems with the information handling from a personal viewpoint?

8. Do you have access to some form of support for information handling and if so, what kind of support? (Information systems/instructions/guidelines)

9. Do you experience any problems with receiving or having access to more information than you need and if so, what consequences, does this have?

a. Does it make it harder to find "your" information?

b. Does it make you avoid any particular information sources?

10. Do you see any connections between any specific locations or points in time and what information you want/need and how it should be formatted?

11. If you are allowed to decide, without any limitations, how the information handling should work from your personal perspective; what are your preferences, visions, and/or ideas?

\section{Organisational-focused Questions}

In the cases when the interviewed informants were believed to have insight into the organisations overall information related issues, questions were also asked with respect to the information situation for the organisation as a whole:

1. What information would you describe as the most important for the operation of the organisation?

a. What are the main sources for that information, internally and externally?

2. How is that information managed with respect to:

a. Storing

b. Distribution within the organisation

3. What, if any, are the problems connected to such management?

4. What information systems are used within the organisation to handle information? 
5. Are there, to your knowledge, any connections between information management and:
a. The organisational structure
b. Work- and business processes
c. If so:

i. How does the management change when the organisation or the processes change?

ii. Is any such connection used in the daily work or do the employees choose their own ways to manage the information flow?

Each of the one to two hours long interviews were documented by means of both audio recordings and note taking, which at a later stage were transcribed and categorised as described in the section Data Integration and Analysis. While the interviews themselves as well as the actual questions were performed and formulated in Swedish and thus also resulting in Swedish answers and transcriptions, they have been translated into English for the purpose of understanding and scientific transparency of this publication.

\subsubsection{Data Integration and Analysis}

27 interviews, which is the total number of interviews performed during the empirical investigation, might seem to be a somewhat odd number from both a qualitative and quantitative perspective. Bordering too many to be analysed fully in a truly qualitative way and yet too few to be enough for statistical purposes, it nevertheless has its points in this particular case. Before explaining why, something must be said about the intended use of the material collected. Verifying or negating the conjectures presented in Chapter 1. is indeed one purpose with the investigation but not enough in itself. While this of course in some respect would be considered relevant it would be nothing else than a reflection of the authors initial views on information demand and thus would not really provide any deeper understanding nor knowledge not already acquired. It is therefore just as important to get a clear view of what was not known from the start, i.e. to identify important aspects of information demand that are not expressed in, or captured by, the conjectures and interview questions. This duality in purpose also affects the choice of methodological approach when it comes to analysing the resulting material. While it may be that verifying or negating a number of conjectures does not require a very sophisticated methodology since it really only is a question of comparing statements to conjectures, it is harder to generate new knowledge. At the same time, it would due to the sheer data volume, be too time consuming to analyse all of the material at the depth necessary for generating new knowledge and/or theories in a truly inductive manner. Nevertheless, since understanding to some extent is the issue at hand, focus is put more on the qualitative aspects than quantitative ones even though there to some extent also are quantitative statements being made.

To solve the complexity of the analysis the author has relied on the idea of coding (open, axial, selective) presented in Grounded Theory (Strauss \& Corbin 1990) However, for readers with a background in the ideographical sciences it should be clear that a somewhat relaxed view has been taken on the rest of GT due to the 
nature of the mainly nomothetic research area in which the author acts. As to the reason behind the relatively, at least from a qualitative perspective, large number of interviews this is simply a result based on the fact that the conjectures concerning context and spatio-temporal aspects of information demand, only can be validated by investigating all organisational levels in several different organisations.

\section{Validation of Conjectures}

Validating the conjectures are in many respects rather easy once statements significant for a specific conjecture are identified in the material, but identifying such statements in the recordings of 27 interviews of 45 to 120 minutes length is not. In order to facilitate the identification, the recordings were not transcribed in their entirety. Instead, and as a sort of ad hoc open coding approach, only the parts considered relevant to any of the question were noted down and thus resulting in one to two pages of statements per interview. To ensure that the author's initial assumption concerning relevance did not leave out important aspects, the transcription was later repeatedly compared to the recordings made during the interviews.

Since, as an effect of the nature of the questions, a certain amount of overlap exists between statements and questions, every statement was categorised and related to a question thus generating a number of documents containing information from all of the informants relevant to a specific question (axial coding). By doing so, the complexity of the material was reduced. Having the material reduced, categorised, and clustered in this manner allowed for matching categories against the conjectures and thereby also making it possible to relate them to statements from the informants. The consequences of this approach will be apparent in Chapter 4. where each conjecture is discussed based on a number of statements from the empirical investigation into information demand and -use.

\subsection{DEVELOPING A METHOD IN A SCIENTIFIC MANNER}

Once a theoretically and empirical foundation for the intended method was defined, focus was shifted towards the answering of the remaining research question (RQ2.). Doing so required a different approach than previously used, one that, even though more focused on design activities, ensured the validity, relevance, and rigor of the intended results. Generating scientifically valid and sound research results from an industrial, empirical context is by no means a unique or novel problem from a scientific point-of-view but nor is it easily done. As the author has his background in a research environment, performing most of its research in industrial contexts, where methods tend to be viewed as tools chosen and evaluated based on their applicability on, and suitability for, a given problem or situation, it was a natural choice to approach this problem in much the same manner. Consequently, exactly such a pragmatic view has been taken for the research presented here by relying on the ideas expressed in Design Science research methodology (DS) (Hevner et al. 2004). $D S$ views research as an iterative problem-solving process where knowledge and understanding concerning a given problem is acquired through the building and use of an artefact with a specific purpose, in a specific context. In other words; designing a method for analysing information demand in an industrial context is according to $D S$ best approached by developing the method in exactly the same context it is intended for. In doing so knowledge that is relevant and usable for the 
development process itself will also be generated. However, it is when doing so also important to realise that there is a difference between developing a method as a part of a research-effort and regular, industrial method-design. In the case of the latter, the end-result might be justification enough but when it comes to research, other aspects also have to be considered. That is of course not the same as saying there is no intrinsic value in the developed method by itself but rather that when it comes to $D S$-research, one also has to consider such things as constructs, knowledge, metrics, and methods that transcends the developed artefact. Put differently, for a development-process to be considered research rather than product development, it should generate meta-knowledge that furthers the research area as a whole (Hevner et al. 2004).

\subsubsection{Ensuring Validity, Relevance, and Rigor of Methodological Efforts}

To ensure that artefacts that are produced in accordance with the ideas behind $D S$ indeed have the intended effects and consequences, the $D S$-method defines a number of guidelines or principles to be considered.

Table 1. Design Science Guidelines (Hevner 2004).

\begin{tabular}{|l|l|}
\hline \multicolumn{1}{|c|}{ Guideline } & \multicolumn{1}{c|}{ Description } \\
\hline 1: Design as an Artefact & $\begin{array}{l}\text { Design-science research must produce a viable artifact in the } \\
\text { form of a construct, a model, a method, or an instantiation. }\end{array}$ \\
\hline 2: Problem Relevance & $\begin{array}{l}\text { The objective of design-science research is to develop } \\
\text { technology-based solutions to important and relevant business } \\
\text { problems. }\end{array}$ \\
\hline 3: Design Evaluation & $\begin{array}{l}\text { The utility, quality, and efficacy of a design artifact must be } \\
\text { rigorously demonstrated via well-executed evaluation } \\
\text { methods. }\end{array}$ \\
\hline 4: Research Contribution & $\begin{array}{l}\text { Effective design-science research must provide clear and } \\
\text { verifiable contributions in the areas of the design artifact, } \\
\text { design foundations, and/or design methodologies. }\end{array}$ \\
\hline 5: Research Rigor & $\begin{array}{l}\text { Design-science research relies upon the application of rigorous } \\
\text { methods in both the construction and evaluation of the design } \\
\text { artifact. }\end{array}$ \\
\hline 6: Design as a Search Process & $\begin{array}{l}\text { The search for an effective artifact requires utilizing available } \\
\text { means to reach desired ends while satisfying laws in the } \\
\text { problem environment. }\end{array}$ \\
\hline 7: Communication of Research & $\begin{array}{l}\text { Design-science research must be presented effectively both to } \\
\text { technology-oriented as well as management-oriented } \\
\text { audiences. }\end{array}$ \\
\hline
\end{tabular}

When comparing these guidelines to the discussion on results and contributions presented in Chapter 1., stating that a method for information demand should be developed in such a way that it:

- Has relevance for a specific set of problems regarding information flow within enterprise contexts.

- Is theoretically, empirically, and internally grounded in its development and validation. 
- Contributes to the general body of scientific knowledge concerning information demand and -use in enterprise contexts.

- Is documented and represented in both a technical and a pragmatically manner, i.e. described in such a way that is perceived as suitable for both academic and industrial purposes.

It becomes clear that not only does the research presented here aim higher than "just" on the development of a method but also that the guidelines of $D S$ are well aligned with the author's intention. The guidelines above have therefore been used as a way to guide the research in its planning, execution, and documentation of results.

$D S$-research should, by definition, produce results in terms of viable artefacts. Such artefacts might be in the form of constructs, models, or methods. However, the artefacts in themselves are not enough for it to be considered DS. Such artefacts must also purposely address important organisational problems in an effective and efficient manner, i.e. being for a specified domain and having utility within that domain. It should be made clear that, from a $D S$-perspective, artefacts rarely are viewed as full-grown methods, ready to be used in real-life situations, as that would be more a question of design rather than research. Artefacts are usually innovations that define the basic ideas, capabilities, and practices on which such methods or systems can be based. This idea, of research producing "demos" rather than finished methods or systems is also present in the area of IS-design as presented by both Wallis et al. (1992) and Markus et al. (2002). From and scientific point-of-view there are several benefits stemming from viewing artefacts in this manner. Constructs can be considered the theoretical and conceptual foundation as they provide the necessary vocabulary and symbols on which future work such as models, methods, and representations can be based. Similarly, representations are a necessity for expressing problems and domains in a consistent and communicable manner. Instantiations on the other hand is used to demonstrate not only a designed product, but also the process leading up to it, in terms of feasibility.

This view on design as something that produces artefacts is also well aligned with the ideas behind the research presented in this dissertation. Chapter 1. states that the author's intention is to produce a method for information demand analysis, which according to the view taken in $D S$, by definition, is an artefact. When reading this, one could get the impression that function is the main value focused upon. This is of course not true, in fact quite the opposite. $D S$ clearly states that both artefacts and the processes resulting in them have to be relevant and purposeful with respect to a specific domain and the problems within it. That is to say, the purpose with any artefact should be to over-bridge the differences between a goal state and the current state of a domain.

However, the author's intention goes beyond only creating a method, there is also the intention of developing the area of information demand in itself. Consequently, the research presented here is not just about artefacts, it is also about a specified domain and the role the artefacts have within it. A lot of focus has, throughout the research process, therefore been focused on establishing a solid theoretical and conceptual foundation (as detailed in Part 2.) as well as on defining notations and representations for communication of method results (Part 3.). 
The third $D S$-guideline, tying into the idea of innovative, purposeful artefacts with problem relevance requires that the utility, quality, and efficacy of the artefacts should be demonstrated through well-executed evaluation methods. Such evaluation has to be done based on the requirements defined by the organisational context in which the artefact was developed, i.e. not only should the internal cohesion and consistency of the artefact be evaluated but also its integration with existing artefacts in the domain. The evaluation itself might be focusing on such varying aspects as functionality, completeness, consistency, accuracy, performance, reliability, usability etc. It should also be noted that not only is such evaluation essential from a research perspective, it is also a support for the continuous improvement of artefacts during the highly iterative process of design. In the case of the research covered here, and as detailed in Part 3., such evaluation has continuously been performed in terms of empirical cases performed together with industrial partners in which the emerging method has been applied. The concluding result from each case has then been used as a foundation for both methodological and theoretical improvements of the artefacts being designed. Taking this approach has not only had consequences for the utility of the method but also for yet another important aspect of $D S$; rigor. One of the main differences between design-oriented research and regular design is the importance of meta-aspects regarding the artefacts as well as their conception. Rigor addresses the way or manner in which research is conducted in terms of the use of rigorous methods for both construction and evaluation of artefacts, typically referring to the use of well-established and proven methods or formalisms i.e. building upon an existing body of well-proven knowledge and to utilise existing theory and methods. This aspect of research has, from the perspective of the results presented in this dissertation, been considered of utmost importance due to the fact that the presented artefacts and their associated meta-knowledge are the result from so many distinctly different and separate research activities.

Consequently, much effort has been spent on ensuring that the emerging method for information demand analysis has a foundation in both theoretical and empirical knowledge as well as being internally coherent and consistent. The main manner in which the author has tried to ensure that the developed method is scientifically sound is by means of continuous evaluation of results from empirical application of the emerging method against existing theory as well as against the design and intention of the method itself. The view on methods taken during the method development phase is, as further discussed in Chapter 7., a prescriptive one, i.e. viewing a method as consisting of statements about how to achieve goals, by performing actions on a conceptual subset of a domain in a prescribed manner. Both the generation and the validation of a method is therefore viewed as a question of defining such actions and ensuring that those actions achieve the defined goals in the best possible way. When combining this view on methods and the $D S$-principles presented in the beginning of this section, three apparent aspects of method development emerge; theoretical, empirical, and internal. Table 2. below, covers grounding of these three aspects from both a generation and validation point-ofview (Goldkuhl, 1999). It should however be noted that while the table uses the term method rather than artefact, the terms are, with respect to this discussion, considered interchangeable by the author. The reasoning behind this is that just as a method can be generated and validated in well-grounded way, so can a conceptual 
framework. Hence, both artefacts (ART 1. and ART 2.) detailed in Chapter 1. have been developed accordingly.

Table 2. Well-grounded method generation and validation (Goldkuhl 1999).

\begin{tabular}{|c|c|c|}
\hline & Generation & Validation \\
\hline Internally & $\begin{array}{l}\text { A method is continuously refined by } \\
\text { the understanding and knowledge } \\
\text { generated by the act of development } \\
\text { itself. In that sense, a method to some } \\
\text { extent inductively generates parts of } \\
\text { itself. }\end{array}$ & $\begin{array}{l}\text { A method should be cohesive in the } \\
\text { sense that its different parts should be } \\
\text { consistent. The framework should } \\
\text { support and reflect the method's } \\
\text { perspective, the components should } \\
\text { contribute to the sequence and } \\
\text { outcome expressed by the framework. }\end{array}$ \\
\hline Theoretically & $\begin{array}{l}\text { A method has to be positioned in and } \\
\text { related to existing methods. If, as is } \\
\text { the case here, it uses (parts of) other } \\
\text { methods one has to consider to what } \\
\text { extent definitions, views, values, and } \\
\text { contexts may differ between the } \\
\text { methods used and the method } \\
\text { developed. }\end{array}$ & $\begin{array}{l}\text { The developed method has to be } \\
\text { validated with respect to existing } \\
\text { methods and method theories to } \\
\text { ensure that that it does not contradict } \\
\text { commonly agreed upon conventions, } \\
\text { definitions, and approaches without a } \\
\text { well-motivated reason for doing so. }\end{array}$ \\
\hline Empirically & $\begin{array}{l}\text { By applying the method on, and using } \\
\text { it in, its intended context, the method } \\
\text { can be refined with respect to such } \\
\text { aspects that is not apparent from a } \\
\text { theoretical point-of-view. }\end{array}$ & $\begin{array}{l}\text { Observing and evaluation the use of } \\
\text { the method as well as the effects it has } \\
\text { in its context ensures that the } \\
\text { prescribed actions achieve the } \\
\text { intended goals in the best possible } \\
\text { manner. }\end{array}$ \\
\hline
\end{tabular}

Taking this multi-grounded view on development of artefacts has not only contributed to a continuous cross-pollination between the various activities involved in developing and validating. It has also, throughout the research process, guided and supported the author in combining distinctly different research activities and results into a sound, coherent end-result. Generating an artefact raises not only certain questions about existing knowledge within the field but also creates new knowledge and understanding on which further development can be based. Much in the same way as empirically validating an artefact by applying it in an industrial context might point out problems between the artefacts internal parts as well as in its relation to existing theories. Looking at the framework for IS-research according to Design Science, illustrated in Figure 3. below, one can see that the multigrounded approach to artefact development used fits well into the framework and its rigor- and relevance cycles. Internal and theoretical grounding facilitate rigor while empirical grounding on the other hand facilitates relevance. This type of continuous evaluation also generates knowledge that can be used both as a way to iteratively refine the artefact during the development process and to feed newly generated knowledge back to the existing body of knowledge. 


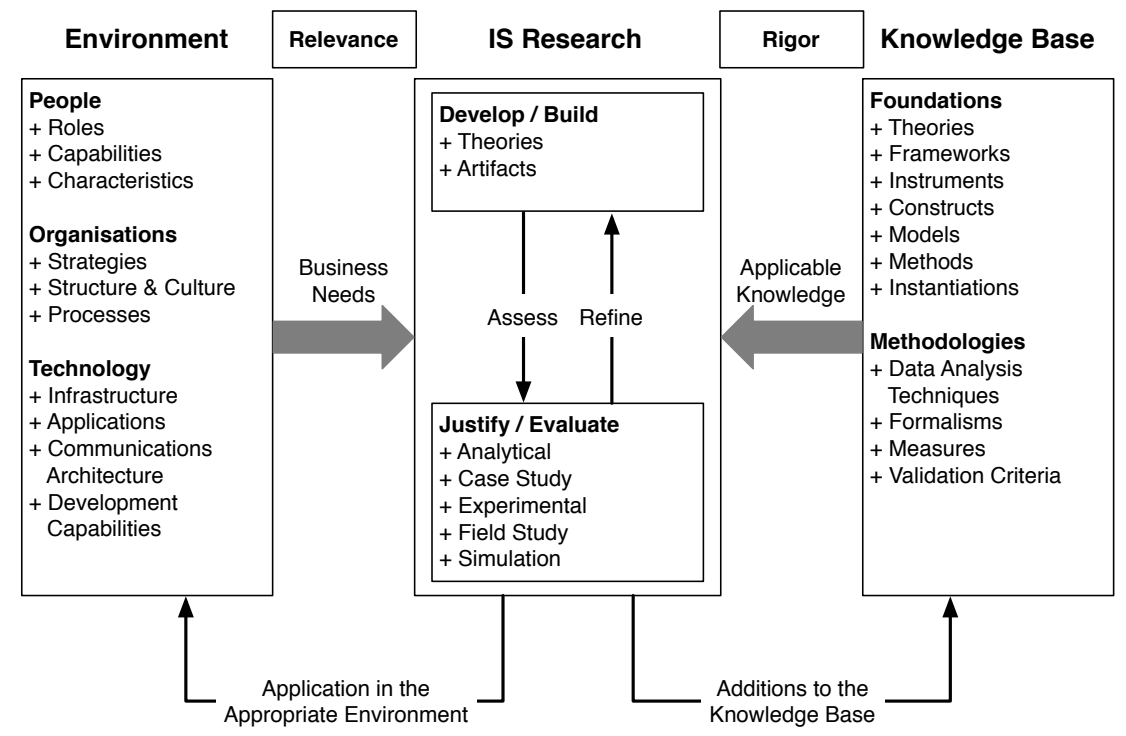

Figure 3. A framework for IS research according to Design Science (Hevner et al. 2004).

Further describing the approach, and activities performed, to ensure validity, relevance, and rigor of the resulting artefacts is difficult to do without first having presented the different artefacts and the various development efforts leading up to them. To facilitate the communicability of what have been done in terms of ensuring the scientific validity of claims made in this dissertation, further details regarding the matter will be held off until Chapter 11. and 12. respectively, once the proposed artefacts and their theoretical and empirical foundation have been presented. 
This page is intentionally left blank. 


\section{PART 2 - INFORMATION DEMAND FROM A SMALL-SCALE BUSINESS CONTEXT PERSPECTIVE}

This part of the dissertation focuses on answering RQ1. by presenting related and relevant theory as well as an empirical foundation regarding information use in organisations with respect to roles, tasks, and resources. It should be noted that Chapter 3. and 4. that cover the theoretical and empirical knowledge on which much of this research rests, make no reference to the relevance of the material nor how it actually relates to the research questions and conjectures defined in Chapter 1. This information can instead be found in Chapter 5. where both theoretical and empirical results are discussed in relation to the conjectures presented in Chapter 1. The motivation behind this is to emphasise the relationship between specific parts of the theoretical and empirical knowledge and the conjectures to make it clear exactly how the answers to the first research question have been reached. It is then concluded the definition of information demand on which continued method development efforts are based. 
This page is intentionally left blank. 


\section{INFORMATION DEMAND AND USE: A THEORETICAL PERSPECTIVE}

Before it is possible to evaluate or construct a method for analysing information demand, a clear definition of what information demand actually is, is needed. Though it might seem obvious at first, it turns out that it is not, as a wide range of different definitions and uses of that, or similar, terms exist within different research areas. This chapter gives an overview of a number of perspectives on information demand from different research areas as well as a theoretical background to concepts central to the research presented here.

\subsection{INFORMATION AS A CONCEPT}

So far, when the term information has been used in this dissertation it has been done without any further consideration given to the meaning of the term. While information as a term seems intuitive to most people, it nevertheless has its relevance to briefly discuss different views on information. Furthermore, besides information, the terms data and knowledge are also often mentioned here and even though all three terms can be, and often are, used without distinction, relevant differences do in fact exist.

\subsubsection{Differences between Data, Information, and Knowledge}

The distinction between data, information, and knowledge is an elusive subject and especially so the concept of knowledge, which has been an object for countless of publications and much debate throughout the years by philosophers and researchers alike. Any deeper coverage of epistemology would have to be based on such classical accounts as Plato's "Theaetetus" and "Phaedo", Descartes' "Discours de la Methode”, Locke's "An Essay Concerning Human Understanding”, Hume's "An Enquiry concerning Human Understanding", as well as Kant's "Kritik der reinen Vernunft" and is as such well beyond the scope of this dissertation. However, epistemology aside, one quite common and straightforward distinction between the three terms is as follows (Clarke \& Rollo 2001): 
- Data

Data is a set of discrete, objective facts, presented out of context and without judgement or external interpretation. Data becomes information only when it is analysed, categorised, summarised, and put in a context, thereby becoming intelligible to the recipient. Data relates to the actual bits and characters (as in an information systems) or some other physical manifestation of communication.

\section{- Information}

Data are usually arranged to provide some meaning to the observer, typically as text, images, etc. whereby the patterns and relationships in data is pointed out. Thus, information is created when data are endowed with relevance and purpose or in other words, when it is put in a context.

\section{- Knowledge}

Knowledge can be seen as information that comes with insight, framed experience, intuition, judgements, or value. In some sense, knowledge represents (individual) truth and does as such offer a reliable basis for action. Knowledge is the body of understanding and skills, and is increased through interaction with information.

\subsubsection{Tacit versus Explicit Knowledge}

Data and information is relatively easy to aggregate, manage, and communicate by means of technology due to its tendency of being codified in some structured manner. Knowledge as it is defined above is however not as easy to deal with from an information system perspective due to the individual framing in which the knowledge exists. Michael Polanyi, a Hungarian-British scientist famous for his critique of the positivistic view on knowledge, argued, "We can know more than we can tell" (Polanyi 1967) meaning that knowledge that is expressible in words and numbers only represents a fraction of the entire body of possible knowledge. He furthermore argued that knowledge for this reason has to be divided into tacit and explicit knowledge.

\subsection{Tacit Knowledge}

Such (subjective) knowledge is highly personal in that it is deeply rooted in an individual's actions and experiences as well as the ideals and values he or she embraces and is therefore hard to formalise, making it difficult to communicate or share. Typical examples of things that fall into this category of knowledge are subjective insights, intuition, and hunches. Tacit knowledge is also further broken down into two different dimensions (Polanyi 1967):

- The technical dimension - comprising the informal personal skills of craft often referred to as "know-how"

- The cognitive dimension - comprising the beliefs, ideals, values, schemata, and mental models that constitute a large part of who we are and therefore shapes our perception of the world. 


\subsection{Explicit Knowledge}

Polanyi categorised explicit knowledge as knowledge that has been objectified and codified in a way that allows it to be transferred between individuals in some formal, systematic way. Such knowledge is captured in records of the past such as libraries, archives, and databases and is assessed on a sequential basis. It can be expressed in words and numbers and shared in the form of data, scientific formulate, specifications, manuals and the like.

When combining the differentiation between data, information, and knowledge with that between tacit and implicit knowledge the relationship between the terms can be illustrated as in Figure 4. (Clarke \& Rollo 2001). Tacit knowledge is to some extent internal in the sense that it, as a concept only can exist within the realm of the human intellect and is as such by definition out-of-bounds for any type of information systems.

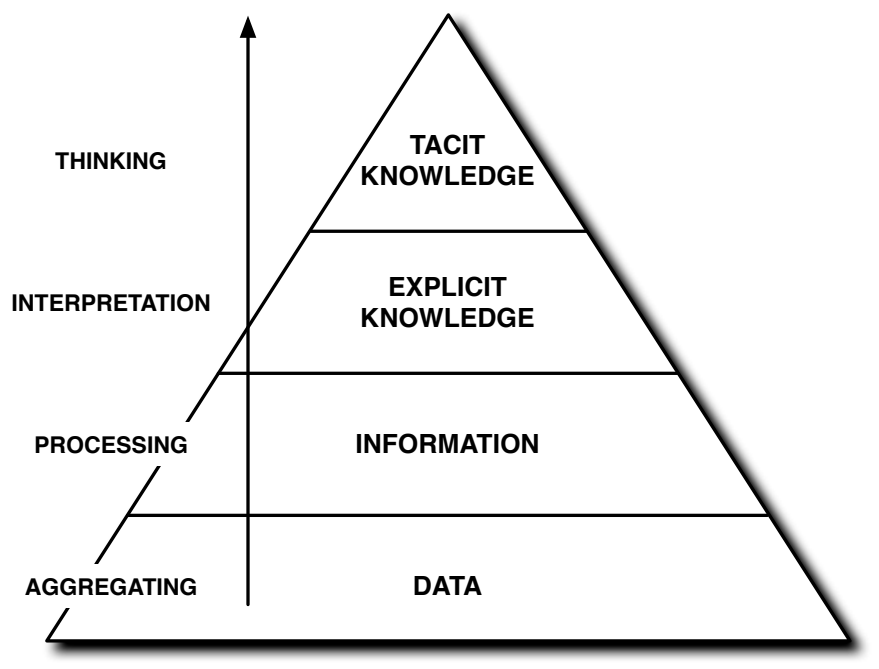

Figure 4. Relationship between data, information, and knowledge (Clarke \& Rollo 2001).

\subsubsection{Transformation of knowledge}

Polanyi's ideas have been further developed by Ikujiro Nonaka, alone in his "The Knowledge-Creating Company" (1991) and together with Hirotaka Takeuchi in the book "The Knowledge-Creating Company: How Japanese Companies Create the Dynamics of Innovation" (1995). In these publications, the author(s) examines the transformation of tacit knowledge into explicit ditto for organisational purposes. Four different interrelated processes by which knowledge flows and transforms are identified to explain how knowledge transmutes into different forms when communicated and received by individuals and organisations; Socialisation, Externalisation, Combination, and Internalisation:

- Socialisation is the process of sharing experiences and creating tacit knowledge such as shared mental models and technical skills.

- Externalisation is the process of articulating tacit knowledge into explicit knowledge. 
- Combination is the process of categorising and integrating explicit knowledge from different sources and of different types.

- Internalisation is the process of transforming explicit knowledge to tacit knowledge by relating it to personal experiences, values, and ideals.

When transferring knowledge, that knowledge has to be objectified in some way in order to make it communicable, something that often means transforming it into information or data. It is then up to the receiver to, through combination of such information or data, internalise it into knowledge again. This flow of knowledge, as illustrated in Figure 5. (Clarke \& Rollo 2001) means that an individual's knowledge never can be transferred or communicate in its entirety, it furthermore means that any knowledge communicated always will be subject to the receiver's interpretations during the internalisation process.

\section{Knowledge Flow}
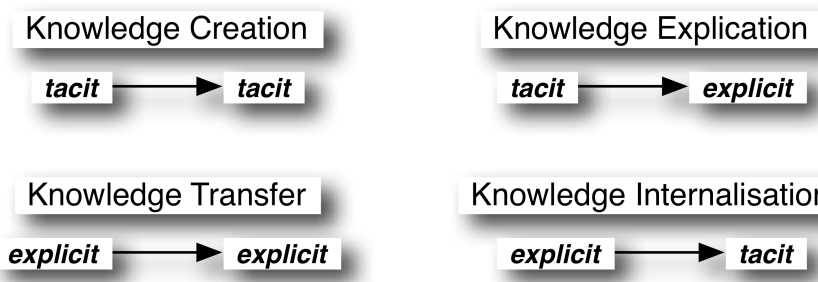

Knowledge Internalisation

Figure 5. Transformation of knowledge (Clarke \& Rollo 2001).

In light of the implied transformation of knowledge into information or data necessary when transferring or communicating it, it is relevant to consider the importance of the distinction between data, information, and different types of knowledge. Anthony G. Oettinger (1999), founder of Harvard University's Program on Information Resource Policy comments the attempts to distinguish between the terms with:

"The term 'information' appears to cover too much that seems distinctive: knowledge, data, information in a narrow sense that some treat as synonymous with data, news, intelligence, and numerous other colloquial and specialized denotations and connotations. However, the distinctions implied by oppositions such as observations/theories, data/knowledge, raw intelligence/finished intelligence, accounting details/management are secondary, not fundamental, in characterizing information resources. They reflect only relative judgments."

This constitutes a very valid point, especially so with respect to information demand. One could always argue that one individual's knowledge can be seen as another's raw data, which quite often is the case when moving over boundaries in an organisation's managerial hierarchy. For example, the tacit knowledge utilised by individuals working on an assembly line results in statistics and key performance indicators for a controller. The opposite is equally true in that a controller's intricate knowledge about the current state of suppliers and stock levels transmutes into data about how many units to produce, for people on the assembly line. 


\subsubsection{Different Views on Information}

Depending on the purpose or intended use of information, users might, when performing tasks as part of the roles they act in, require different types of information. One possible way to categorise such information is (Sundgren 2005):

- Operative data (facts) is information that is necessary for the completion of a particular task or process. For example, in an e-commerce application the buyer must provide name, address, product(s) ordered etc., while the seller must provide availability and price information.

- Analytical data is, in contrast to operative information, not necessary for the proper functioning of the process but analytical, or directive information as it is also called, is supposedly of some added value to the efficiency of the process and for the quality of the results. Examples are statistics, performance indicators etc.

- Procedural data (rules) is descriptions and other representations of rules. Such rules might emanate from legislative or administrative processes or be a consequence of design.

- Metadata usually defined as "data about data", describes the content and meaning of data as well as its relevance, accuracy, and comparability with other data.

- Paradata is data that is fed back from the process to which it pertains. Examples of such process data are verification of transaction results, error reports etc.

While the distinction between data, information, and different types of knowledge certainly might be considered relevant from a general perspective, it is from an information demand point-of-view, not as important in itself as it is due to the implications regarding structure and communicability that follows from it. Hence, the term information will be used in its most general sense here, denoting data, information, and (explicit) knowledge alike. When a distinction between different types of information is needed, it is more so with respect to format, structure, and intended use and will therefore be based on the five different types above. With that said it should be noted that the concept of knowledge flow has some relevance when categorising information according to the aforementioned types. The procedural type differentiates itself from the others in that it is tacit in its nature. Procedural data is really transferred and externalised knowledge that needs to be internalised by the individual acting on it in some setting.

\subsubsection{The Implications of Relevance and Context on Information}

The previous sections cover different views on information as a concept, but if information is to be used with a specific purpose it also has to relate to specific issues, problems, needs or demands. It is therefore also important to realise that there are two additional core concepts involved, concepts without which it becomes impossible to fulfil any need or demand; Relevance and Context. Relevance, at least within the information sciences, is about the effectiveness of communication of information, that is, any discussion about demand or need implies a demand or need for something specific, for a specific purpose (Saracevic 1975), something that is 
pertaining to the matter at hand (Saracevic 1996). The concept of relevance has a very long history in areas such as logics and philosophy but was first introduced to information and computer science in the 1930's and 40's by S.C. Bradford in conjunction with the development of Information Retrieval systems (Saracevic 1975). Such systems made it relevant to start distinguishing between information and relevant information. From a historical point of view, there has been much controversy about the meaning of the term relevance but it is nevertheless, relatively intuitively used in every day conversations where relevance has little or no importance. However, when aspects like productiveness and effectiveness become an important part of our communication the concept of relevance also becomes more complex and dependent on a number of different factors, involving equally different criteria. While the finer distinction between these criteria might not be relevant for the work presented here, there still is some relevance in discussing the role of relevance in connection with information need. In information sciences, information need is a psychological state associated with uncertainty and with a desire to know an unknown (Saracevic 1975). This concept is considered important because it allows for the distinction between a state of the mind and the subsequent representation of that state into a question. In Figure 6. (Saracevic 1975), the process of transforming such an internal state of the mind via a question into an answer to that question is illustrated from an Information Retrieval system perspective (see Section 3.2.2).

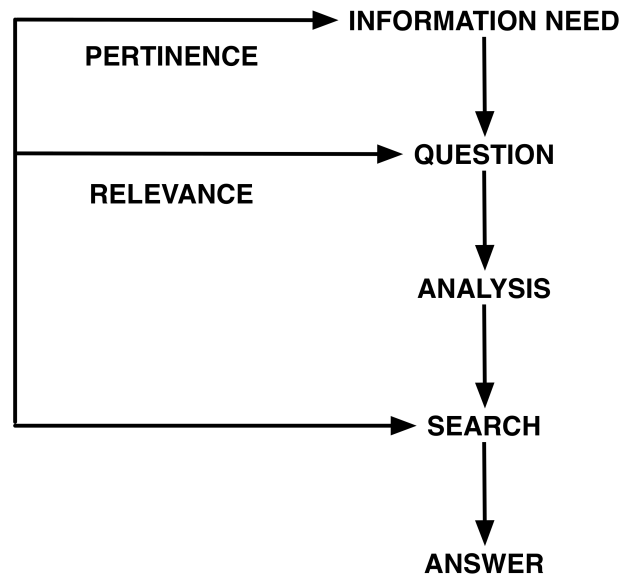

Figure 6. The question-asking, question-answering process (Saracevic 1975).

According to this process, relevance is the property that assigns certain parts of a file, document, or other piece of information, to a question as it is defined by the party having an information need. Pertinence on the other hand, is the property that assigns such parts to the information need.

While a formal definition of information demand is yet to be given within technical areas focusing on solutions for demand-driven information supply, this does not mean that the importance of the users' need is not recognised at all. The general idea behind concepts such as Context and Situation introduced into the informatics and computer science areas, is that, by knowing something about the setting an 
information need exists within, something is also known about the need itself. In fact, there exist empirical results (on how people make their choice of media for information provision) that show that the context of a user explains more about the choice than the characteristics of the actual user itself (Bouwan \& van de Wijngaert 2002). In these results context is simply defined as the settings that define availability to different types of media but the definition of context might just as well be broadened to comprise all aspects of a user's surroundings and thus enable the possibilities for information demand fulfilment approaches to adapt accordingly.

The terms context, contextual and context-sensitive are widely used within computer science describing everything from help systems providing help depending on what a user does in a program to the profiling of users' buying habits in web shops in order to provide hints on other objects of possible interest to the user and so on. In areas like Ubiquitous Computing, Information Logistics, Artificial Intelligence, and other disciplines that concern themselves with contextual aspects from a technical perspective, context is often defined as (Dey \& Abowd 1999):

Any information that can be used to characterize the situation of an entity. An entity is a person, place, or object that is considered relevant to the interaction between a user and an application, including the user and application themselves.

While a system is considered context-aware if it uses context to provide relevant information and/or services to the user, where relevancy depends on the user's task (Dey \& Abowd 1999). Another view on context is that it is everything but the explicit input and output to and from an application (Bouwan \& van de Wijngaert 2002). This includes anything from the state of the user and its physical environment to the history of user-computer-environment interaction.

This view on context is more that of a technical one. Context is said to be something that can be decided by different types of sensors. Even "softer" aspects of users such as emotions are considered measurable by biometrical sensors, measuring pulse, blood pressure, retina response etc. The view taken on context in the research presented here is somewhat different but the background to, and the purpose of, the technical variant is still in large parts considered useful. The same is true for the concept of Situation, which is defined as a subset of variables in a context at one particular instance of time (Meissen et al. 2004). That is, by identifying a user's location, movement, availability etc. at a given moment in time, we say that we know the situation the user is in and that this situation is a part of the user's context.

Relevance and context are obviously two tightly coupled concepts since relevance as such is pertaining to the matter at hand (context) while only certain elements of a specific context are pertinent with respect to some information need.

\subsection{INFORMATION DEMAND: RELATED THEORETICAL WORK}

In Chapter 1. it was stated that not much research regarding information demand as a concept and methodological approaches to analysing information demand have been performed from the perspective taken in this dissertation. This statement is actually only partially true. The fact is that quite a lot of research into the subject seems to have been performed in Germany throughout the years, most of it in the recent decade but some efforts dating as far back as 1976. Examples of such research that refers to the term Informationsbedarfsanalyse, which translates to information demand analysis, are: 
- Stroh, F. (2010) Methodische Unterstützung von Informationsbedarfsanalyse für die Gestaltung und den Betrieb analytischer Informationssysteme.

- Strauch, B. (2002) Entwicklung einer Methode für die Informationsbedarfsanalyse im Data Warehousing.

- Koreimann, D. S. (1976). Methoden der Informationsbedarfsanalyse.

- Becker, J., Brelage, C., Crisandt, J., Dreiling, A., Holten, R., Ribbert, M., et al. (2003). Methodische und technische Integration von Daten- und Prozessmodellierungstechniken für Zwecke der Informationsbedarfsanalyse.

There are also a number of German researchers that consider information demand analysis as an integrated part of their various methods and approaches:

- The H2 method: http://www.prof-becker.de/de/kategorie/kompetenzen/ business-intelligence/phase-5-kontinuierliches-berichtswesenmanagement/

- Schelp. (2000) Modellierung mehrdimensionaler Datenstrukturen analyseorientierter Informationssysteme.

- Dinter, B., \& Winter, R. (2008) Intergrierte Informationslogistik.

- Heinrich, L., J., \& Stelzer, D. (2009) Informationsmanagement-9 Auflage.

The problem with such research is that it only is documented in German, consequently making it much less accessible to the research community and the author.

Considering only such research documented in English, the initial statement does hold true, especially so regarding the topic of methods for information demand analysis. However, if one takes a somewhat more general perspective on information demand then what is focused on here, there has been some research performed. The following sections cover a selection of such research in order to provide an overview of the status of theory regarding information demand.

\subsubsection{A Sociological Perspective on Information Need}

One subject of research within sociology concerning information need is how such a demand can be modelled and met. Even though the interest in information need is focused more on how information, and the demand or need for it, is the basis for people's possibilities to make informed, democratic choices in their role as citizens, or as part of a community, rather than on an enterprise perspective specifically, the definitions and models used are relevant also in a more general setting. In one of the many different approaches, social information need is considered to have six different dimensions (Moore 2002):

- Function - why do people need information?

People need information to support them in the two roles the play as members of society - as citizens and as consumers.

- Form - what kind of information do people need?

People seek, process, and absorb many different kinds of information, either 
by scanning the social environment in fairly random and unconscious ways or by actively searching for information that they need.

- Clusters - about what do people need information?

People's need for information can either be viewed as what is needed to fulfil the basic human needs defined by Abraham Maslow (1943) in his five level hierarchy (physiological, safety, belonging, esteem, and selfactualization) or as the need for information associated with a series of major life events like beginning school, having children, retirement etc.

- Agents - who initiates the information activity?

- The user itself when actively searching for information.

○ Information providers who provide the users with information.

○ Intermediaries who process information on behalf of users.

- Users - how do needs differ between different groups of people?

Even though users as individuals are inherently different, they belong to many different social groups and even though not many individuals belong to the same patterns of social groupings, it is still possible to define groups of users who share common needs for information.

- Mechanisms - which mechanisms can be used to meet information needs?

- Recording and storage by which information can be fixed and used later.

- Copying and reproduction by which information can be distributed to several users without making cost an issue.

- Transmission and communication by which the means for physical distribution are provided.

- Tailoring and customisation by which information can be changed to fit users' particular prerequisites.

By defining the model with these six different dimensions, Moore (2000) claims that it can be used to identify and analyse social information needs as well as for analysing information provision.

\subsubsection{Information Need and Information Retrieval}

Information Retrieval (IR) is also an area in which the users need or demand for information is central but from a technical viewpoint, IR-systems are designed based on the assumption that the user's information need already has been identified and encoded by the user itself in the form of a query before any actual retrieval takes place (see Figure 6. ). As may be exemplified by any Internet search engine, the perspective taken on the users' need for information is a pragmatic one. The user knows what kind of information he or she needs and the need is stable over time, i.e. the system does not need to know anything about how the user's need changes over time (not even during the time of the interaction with the system) since this, from the systems point-of-view, then simply becomes another need (Cole 1998). The rest is a question of matching query to information by means of mathematics, statistics, or similar methods, and finally presenting the result. This is of course a very crude view on information need fulfilment since it does not support the users 
much in their need and results in an retrieval process that is very ad-hoc oriented in its nature (Stojanovic 2005). The biggest problem with this approach is that the users more often than not do not know for what they are searching. R. S. Taylor concluded as early as 1968 in his work on information seeking behaviour in libraries that, when users asks a reference question to a librarian they do not ask for what they actually "need" because (1) they do not consciously know what it is they need and thus cannot ask for it and (2) they believe that information systems require them to "encode" their need "up" into an appropriate level of language and topic conceptualisation (Cole et al. 1996). Similar findings (see Section 3.3.) were also made when information use in Small- and Medium-sized Enterprises (SMEs) was investigated in USA: they (SMES) do not know what they do not know and they cannot realise that they do not know it since they are not aware of their ignorance (Fuellhart \& Glasmeier 2003).

There is however some effort being put on helping the user understanding the need in itself as well as making systems adapting to changes of the need during the search and thus making retrieval systems, to some extent, intelligent. One such effort is called differential diagnosis of information need and makes use of the conceptual similarities that exist between the doctor's task of diagnosing patients and the search intermediary's task of retrieving information (Cole 1998). The general idea is that just as the patient visiting the doctor only knows about the symptoms of the disease, the information searcher only knows about the reasons behind the information need's existence. It is therefore up to the search system to, much like a doctor asking questions and doing tests in order to diagnose a condition, define the users search question and provide the relevant information. The main argument of this approach is that the underlying cause of a user's perceived information need can be used to "diagnose" the actual need for information.

Similar ideas are expressed when suggesting interactive mining as a way to identify information need based on the mapping between such need and the categorisation of information (Lin \& Lin 2003). By keeping record of the type of information, a user search for, a profile can be built up incrementally. This profile can then be used to specify within which categories of information the users are likely to find the wanted information and thus minimising the search space. 


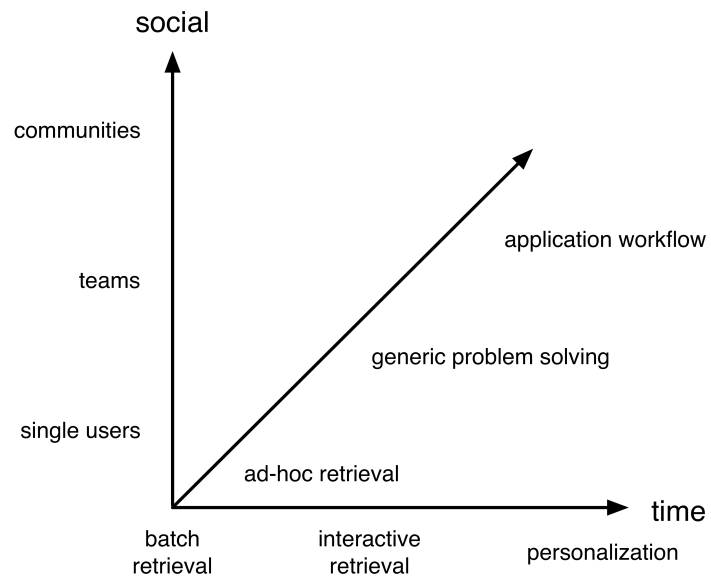

Figure 7. Context dimension model (Fuhr 2004).

To take this even further the user's surroundings could be utilised to derive even more such delimitations of the search space. To do exactly this, is the purpose behind introducing the concept of context-sensitivity into the IR-community. Contextual IR is the combination of search technologies and knowledge about the users' context into a single framework. The motivation behind this is to provide the best possible answers with regard to users' information need. One of the ideas behind Contextual $I R$ is that the retrieval of information can be based on three different context dimensions, the social-, work-, and time dimensions as shown in Figure 7. (Fuhr 2004). Based on this model IR-systems can be classified from a context-sensitivity perspective. A traditional system like an Internet search engine would typically be found at the $\mathrm{y}-$ and $\mathrm{z}$ axes origin and in the middle of the $\mathrm{x}$ axis in this model since the functionality is focused on performing interactive ad-hoc retrievals for many different individual users. While systems adapted to provide information, based on applications workflows, for communities of people, or in a personalised manner would be considered highly context-sensitive.

\subsection{INFORMATION ACQUISITION AND USE FROM AN ENTERPRISE PERSPECTIVE}

In order to define a method for information demand analysis within an enterprise contexts it appears quite natural to start with looking at how, why, and when enterprises actually use information and what, if any, kind of software or organisational support they have readily available for doing so. Information use, which in a business and marketing context often is defined as "the extent to which research influence users' decision making" (Moorman et al. 1992), is unfortunately a subject with little available literature. There are some reports on how many companies that have computers and Internet-access, and in the other end of the range, what kind of organisational structure companies have to preserve knowledge within the organisation. This, however, is not that relevant from the perspective of information demand analysis since it is more about technology and infrastructure than actual organisational need. There are however, some interesting work done, mainly in the areas of knowledge management and business management that will be presented below. 


\subsubsection{Location as a Key Factor when Choosing Information Sources}

One can choose to have one of two different perspectives on organisational use of information, that of the organisation as an entity in itself, or that of the organisation as a number of individuals. Here focus is put more on the former since individuals' use of information tend to be related to specific tasks, something that will be discussed in length and depth in Chapter 4., 5., and 6. In an empirical investigation performed in USA, with focus on how manufacturing Small- and Medium-sized Enterprises (SMEs) acquire, assess, and use business information, some important factors concerning this subject were identified. It was found that, despite all kinds of advanced computer systems and communication devices, location still matters when it comes to acquiring information, mostly due to two reasons (Fuellhart \& Glasmeier 2003). The first reason has to do with the format or type of information and to what extent it can be codified (see Section 3.1.). Quite a lot of information can be considered tacit in nature and is as such hard to capture in documents, databases etc. (Maier 2002). Such information tends to be centred around and exchanged between humans directly, something that is made substantially easier by cognitive proximity, thus making location in relation to possible information sources important. Even information often considered easily codified is to some extent always related to tacit information, which also makes location important when it comes to the possibilities an enterprise has to collect information. The second reason is networks, i.e. the connection between businesses' information-seeking behaviour and clustering of businesses. Yet another study done in the US shows that most of the SMEs business information comes from sources within a $10 \mathrm{~km}$ radius of the company's location (Bennett et al. 2000). Agglomerations of $S M E S$ can therefore increase the access to information and such agglomerations are in turn facilitated by spatial proximity.

\subsubsection{Strategic and Managerial Aspects of Information Use within SMEs}

Location, however, is not the only important factor when it comes to business information gathering and use. Organisational and managerial aspects are just as important. Assessing and interpreting information from different sources takes resources, something sparsely available to SMEs. It is therefore not surprising to find that $S M E s$ also typically use external information sources less than larger companies (Fuellhart \& Glasmeier 2003). It has also been shown that smaller firms neither have the same strategic view on information that larger ones have nor the same interest in finding it, with an event driven, contingency approach as a result. Due to organisational reasons, decision-making, and therefore also information demand, tends to be tied to individuals within the firm's management rather than the firm as a whole. SMEs largely, compared to bigger firms, also lack awareness of information need and the importance of getting such need fulfilled (Williams 2003). The main reasons for this are (Mackenzie \& Wiercx 1995):

- A low general level of knowledge and understanding when it comes to the value of information.

- A limited subject interest when it comes to strategic information.

- Focus is put on familiar and perceivably reliable information sources.

- SMEs mostly need highly condensed, easy to grasp, practical information, something not easily obtained or available from most information services. 
These reasons are in turn due to the fact that it is entrepreneurs with knowledge, skills, and interest in their specific areas, rather than business management in general, that start most SMEs. This situation, with the lacking awareness of the importance of information use, is unfortunate because as it has been shown, businesses fails because managers fail (Braverman 1984) and in SMEs in particular the owner/manager has an essential role as the searcher and assimilator of information. It has also been shown that when the manager of a $S M E$ values internal and external tasks the rest of the organisation tends to follow and thus, the manager's, and thereby the organisation's, sensitiveness to information is a personspecific characteristic of the manager (Gibb et al. 1984). These ideas were also confirmed in a Belgian investigation involving the owners/managers of 208 Belgian $S M E s$ where it was concluded that not only did SMEs that use more information also achieve better results but they in general also were more optimistic about the future (Lybaert 1998). This insight is important since it further supports the idea that managers of SMEs have to deal with the same problems and decisions as bigger firms but without the benefits of experts and with fewer resources. Statistics also confirms that the smaller the firm, the fewer the information sources used are (Voerman et al. 1998). However, it is important to realise that the relationship between the acquisition and management of information, and its use not necessarily is clear-cut. The collection of information per se is no guarantee that it will be used effectively or even used at all (O'Reilly 1980). All this resulting in a tendency for smaller firms to focus more on ad hoc, informal, often hasty information gathering and a more "intuitive" use of information (Calof 1994). There is in other words no real doubt about the fact that SMEs and the IT-solutions focused on them, constitute a unique challenge, a challenge that, as has been the case hitherto, cannot be dealt with by viewing $S M E s$ as smaller versions of larger enterprises.

\subsubsection{Perceived Source Credibility, Relevance, and Availability}

When 173 SMEs were asked to list the sources of information they receive/retrieve their information from and what their perception of the credibility, relevance, and availability of those sources is, some surprising facts were discovered. It might be expected that firms rely heavily on internal experience but the fact that they rather use competitors as a source for information than the Internet, universities, or the government, as listed in the seven grade Likert-scale shown in Table 3. (Fuellhart \& Glasmeier 2003) is not only surprising, it also proves the importance of social networks and channels for exchange of tacit information. It also seems to confirm the theories about SMEs lacking the view on information as something important for strategic purposes. 
Table 3. Use and qualitative assessment of business information sources

(Fuellhart \& Glasmeier 2003).

\begin{tabular}{|c|c|c|c|c|}
\hline Information source & $\begin{array}{l}\text { Frequency } \\
\text { of use }\end{array}$ & $\begin{array}{l}\text { Credibility } \\
\text { of source }\end{array}$ & $\begin{array}{l}\text { Relevance } \\
\text { of source }\end{array}$ & $\begin{array}{l}\text { Availability } \\
\text { of source }\end{array}$ \\
\hline Own practice \& experience & 5.96 & N/A & $\mathrm{N} / \mathrm{A}$ & N/A \\
\hline Vendors/factory reps. & 4.98 & 5.11 & 5.18 & 5.50 \\
\hline Customers & 4.94 & 5.46 & 5.53 & 5.45 \\
\hline Magazines, books, periodicals & 4.59 & 4.82 & 4.58 & 5.33 \\
\hline Trade shows & 4.28 & 4.84 & 4.59 & 4.87 \\
\hline Other firms in same industry & 3.39 & 4.63 & 4.64 & 4.13 \\
\hline $\begin{array}{l}\text { Companies' } \\
\text { catalogues/Promotional literature }\end{array}$ & 3.81 & 4.03 & 4.11 & 4.89 \\
\hline Trade associations & 3.74 & 4.59 & 4.39 & 4.61 \\
\hline Seminars/technical sources & 3.71 & 4.41 & 4.25 & 4.40 \\
\hline Competitors & 3.16 & 3.87 & 4.46 & 3.29 \\
\hline Firms in other industries & 3.00 & N/A & N/A & N/A \\
\hline Recently hired employees & 2.92 & 3.60 & 3.43 & 3.90 \\
\hline Consultants & 2.67 & 3.75 & 3.66 & 4.03 \\
\hline Database/on-line searches & 2.44 & 3.58 & 3.31 & 3.63 \\
\hline Universities/community colleges & 2.39 & 3.94 & 3.46 & 3.80 \\
\hline $\begin{array}{l}\text { State/federal technical } \\
\text { assistance/transfer programmes }\end{array}$ & 2.12 & 3.25 & 3.00 & 3.22 \\
\hline Overall & 3.66 & 4.28 & 4.19 & 4.36 \\
\hline
\end{tabular}

\subsubsection{Utilisation of ICT-support for Information Use}

When focusing on use of information, and software systems to support such use, the problem of form is once again encountered. Most of the times when individuals within an organisation search for information, something that is readily and abundantly available today, in order to solve some task, it is not really information they want but rather solutions to problems. Knowledge however, is tacit in its nature and requires codification in order to be transferred from a human to computer, and back, since the level of aggregation that humans' use is different from what is useful to computers (Rodgers et al. 1998). Nevertheless, quite some effort has been put down on producing a variety of IT-systems for supporting work and knowledge management:

- Intranets - provide information, applications, and functionality in one single place as well as storing, exchanging, search and retrieval of data and documents.

- Document and content management systems - handle different types of documents and versions thereof throughout their lifecycle.

- Workflow management systems - support work processes and the execution thereof. 
- AI technologies - contribute with profiling, matching, and mining of data.

- Business intelligence tools - support the analysis of fragmented data for strategic purposes.

- Visualization tools - facilitate the organisation of knowledge, people, resources, and processes.

- Groupware - helps collaboration in teams and projects.

- E-learning systems - provide interactive learning.

The use of such systems within enterprises is common, mostly so Intranets in different shapes and forms. However, these, at least in the case of larger enterprises, usually in-house developed systems tend to lack integration with other types of systems and/or functionality. Furthermore, such systems often provide a lot of functionality not intensively used due to both technical and organisational reasons such as limited bandwidth or insufficient strategies for integration between IT-systems and work processes (Rodgers et al. 1998). Such lack of integration means that the systems often are of very little real use to the users, which is true for all applications or systems not integrated with overall organisational objectives or with other, already, existing systems (Sommerville 2001).

Information and knowledge management systems are perceived as, and to some extent also are, a very complex area, not only because of the technical complexity of the systems due to the "intelligence" distinguishing them from ordinary systems but also due to the link to organisational and human factors resulting from the integration of business processes and knowledge. Yet another complexity factor is the impact such systems have on the way work is done. This added complexity that follows from advanced technical solutions put additional strains on SMEs that already have problems in the area of strategic use of IT-systems compared to bigger firms. As a result $S M E s$ tend to focus on such advanced systems only when it has a direct implication for cost-reduction while bigger firms also focus on other factors like customer service, improvement of internal and external collaboration and communication etc. (Deschoolmeester et al. 2002).

\subsection{THEORETICAL IMPLICATIONS FOR CONJECTURES}

While a lot of the theory covered in this chapter in a general sense have relevance for the research presented here, it mainly constitutes a selection of the initial knowledge acquisition that was necessary in order for the author to get an understanding of the area as such and to formulate research questions. However, as less theory regarding the topic of information demand than expected was found during the review, it was concluded that additional knowledge acquisition was necessary in order to define information demand to a degree that would be useful for further research efforts. It was also concluded that such additional knowledge acquisition needed to be focused on specific areas to facilitate and support the definition of the term information demand. The way this focus was achieved was by defining the conjectures presented in Chapter 1.1.2., the reasoning being that validating them would result in acquiring the knowledge necessary for continued work. 
As the theory reviewed, showed that information as a concept, as opposed to data, is contextualised, i.e. being pertinent to a specific setting or purpose, and the author was interested in how the demand for information relates to work tasks, the conjecture C1. was formulated. Building on that conjecture and theory regarding context, situation, and information use and -acquisition from an enterprise perspective presented in Chapters 3.1, 3.2., and 3.3. above, conjectures C2. and C3. were formulated. The complexity of knowledge and knowledge transfer presented in Section 3.1. together with the insights regarding how information is used in an enterprise setting made the author assume that social factors may be of greater importance with regard to information demand than first realised, hence conjecture C4. The final conjecture C5. was not derived from, or based on, the theory review per se but rather from the current state of the field, as discussed in the introduction of the dissertation, and the fact that no apparent solution was found during the review. As the theory review by itself was not considered enough to ensure the validity of the conjectures the author designed an investigation with the purpose of evaluating the conjectures from an empirical perspective and hence, the following chapter will present such an empirical perspective.

Further discussing the conjectures and the implications they may have on the definition of information demand, have no real relevance before the investigation, and the results following from it, have been presented. It can however, from what has been covered in this chapter, already now be concluded that the distinction between data, information, and knowledge in itself, has no real importance for how the topic of information demand is approached. As will be discussed in Chapter 5., it does however have some implications for how information demand can be fulfilled. There are also, as has been illustrated in this chapter, a number of existing ideas about what information and information demand is, what importance it has to various aspects of people's and organisations' everyday situations, as well as how and why it should and could be dealt with. 


\section{INFORMATION DEMAND AND USE: AN EMPIRICAL PERSPECTIVE}

As described in the section Data Integration and Analysis in Chapter 2. the interviews performed during the investigation have been categorised according to subject. In this chapter, the results from the interviews are summarised and generalised with respect to each such subject category, in order to present the reader with a structured and comprehensible selection of the data. It is important to notice that the empirical data presented here is tightly coupled to the five conjectures presented in Chapter 1. as those have guided all aspects of the empirical investigation in terms of questions, coding-categories etc.

\subsection{RELATIONSHIP BETWEEN ROLE, TASK, AND INFORMATION DEMAND}

Though it at a first glance might be considered fairly obvious that information demand, at least in a work setting, is dependent on whom one is and what one does, that conjecture (C1.) still needed to be investigated and empirically confirmed in order to better understand how information demand can be identified and analysed.

During the interviews, all of the informants were asked what role they have within their respective organisation and to list the typical work tasks connected to that role. They also gave their own view on the information needed to perform such tasks. Since the informants not only had different roles on different organisational levels but also work for completely different organisations, it is only natural that there is a wide range of different examples of information demand identified and expressed by the informants. To provide the reader with an idea of the work tasks and information demand identified by the informants, a sample of roles has been selected as examples:

\section{- Head of Department, SBA}

Considers herself to have a consultative role that mainly focuses on overall strategies for and management of the department in accordance to the guidelines given by the Swedish Government, as well as providing support to the division managers. In order to do this, she needs information about the current situation in, and status of, the department and its position with regard to certain issues, and information from other Swedish public authorities. This information is gathered mainly by means of documents and oral communication and is therefore mainly tacit and unstructured in nature. 
- Head of Division (one of the two interviewed), SBA

Is responsible for the general management of his division through project planning and management as well as to act as a support for the staff. He also has the budgetary responsibility for the division. In order to perform tasks related to these responsibilities he uses information about the daily operation that is gathered through communication and meetings with the head of the department and the staff. Information regarding what to do and how to do it comes from the Swedish parliament as specifications and as guidelines that can be downloaded from the intranet. While most of the information is tacit, parts of it has some structure.

\section{- Administrator/Secretary, SBA}

Acts as a link between the head of department and the different division managers. Besides traditional secretary tasks she also has some responsibilities for case handling and budget follow-up. She considers this role to be a combination of producing and consultative and states that she mostly needs regulations for and instructions on, case handling. She also states that such information mainly is tacit and unstructured in nature.

\section{- Material Controller, KA}

Has as her main responsibility to tie together the raw material aspects of production with respect to customers and suppliers. Based on customer orders she produces production plans that then are distributed to both the production and to suppliers. She also needs data necessary for billing and ordering (stock levels, production data etc.) as well as general information about suppliers and the products or materials they provide. For the most parts, she deals with highly structured data.

\section{- Quality Manager, KA}

Mainly produces internal regulations and policies concerning environmental and quality aspects of, as well as methods and instructions for, the production. He also publishes and structures information on the intranet for the employees of the enterprise. In doing so, he requires information about the current state of affairs in the enterprise and knowledge about his role and responsibilities. The former is collected from internal revisions and the Enterprise Resource Planning application keeping track of production statistics and customers while the latter is acquired through courses, literature, and guidelines. Even though he considers his role mainly consultative he mostly utilises structured information.

\section{- Administrative Executive (one of the two interviewed), SBA}

Her main tasks are to manage subsidy applications concerning some aspect of farming and growing as well as keeping herself up-to-date on the regulation and rules in the area. She also produces documents that represent Sweden's opinions and attitudes regarding these matters in the European Community. These tasks are based on both work instructions as well as information about the nation's strategy, objectives, and agricultural production. 


\section{- Chief Information Officer, KA}

Responsible for the administration, development, and refinement of all internal processes, except production related ones and has therefore mainly a consultative role in the organisation. Because of this, he performs such tasks as development and improvement of the business applications used, definition of the IT-related strategies with respect to current and future requirements, analysis of the status and situation of the enterprise, and helpdesk related issues. The information necessary for this is tacit and undefined with respect to sources but in general, information about trends within the IT-area, current internal status, as well as the status of competitors is needed.

\section{- Production Technician, KA}

Produces maintenance instructions, follows up on any bottlenecks or standstills in the production, and occasionally also performs some maintenance work. In addition to this, he prepares equipment for test and development projects. In order to perform these tasks information about current problems and equipment usage is needed. For the project preparations, he needs manufacturing estimates and calculations as well as information regarding any necessary changes on existing equipment and production lines. In large parts, this information is structured and collected from different IT-systems but information acquired through oral communication is obviously tacit.

- Production Supervisor, KA

Supervises projects for product prototyping as well as maintenance on machinery, equipment, and tools. He also has the responsibility for the ordering of external services with respect to maintenance. For this he needs information about the overall maintenance planning, maintenance specifications from the production technicians, error reports from the production, and work instructions from the intranet.

\section{- Chief Economical Officer, KA}

Responsible for accountancy towards authorities and the corporate group for which general knowledge about accounting, any internal changes in regulations, and major events and developments within the organisation is needed. This information exempt the pure financial data is tacit.

While both the roles and actual demand may vary a lot in the excerpts above, there seem to be several general aspects with respect to the properties of the demand that are independent of both organisation and role. It is certainly possible to talk about an individual having an information demand but it is important to realise that such a demand is not uniform but rather of different types, depending on for what the information is needed. Almost all of the informants, when talking about their personal need for information in connection with work tasks, unknowingly identify two different main types of information, as illustrated by the following statement: 


\section{Statement 1.}

"I manage cases regarding fruit and vegetables...prepare and watch the regulations concerning the area...preparing documents for the Ministry of Agricultural expressing Sweden's stance on related issues in the European Community... requires knowledge about how to prepare reports... knowledge about SBA and Sweden's opinions and views from a political and legal perspective as well as production statistics etc....

\section{Administrative Executive, SBA}

The first type identified is not as one may think operative information, i.e. basic information intended as input to work tasks exemplified by the production statistics in the excerpt above but rather instructions on and knowledge about how to perform such work tasks, i.e. procedural information. This distinction between operative and procedural information (see Section 3.1.) is important since while the operative information at least for a rather big part of the roles interviewed, is highly structured and explicit, the procedural information is almost never due to its tacit nature. Furthermore, there is also a difference in how well defined the demand for these different types of information is. Most informants have a clear idea of what information they need and where to get it, when it comes to the operative information. Concerning the procedural information, the case is however not always as clear-cut and often requires much more effort in form of acquisition, aggregation, and evaluation due to the fact that such information often requires some form of internalisation as defined in Section 3.1.1.2.

\section{Statement 2.}

"Information needed for performing this comes from subordinates [supervisors] and through E-mails...knowledge about the role and its tasks comes from courses, manufactures, trade fairs, academy and enterprise agglomerations [competitors]...information has to be aggregated from several different sources..."

Head of Production Technology, KA

\section{Statement 3.}

"...need to keep track of trends to be able to create [customer] demands [with respect to new functionality], we try to get such information from the marketing department. Sometimes I also meet the customers directly... a broader network is also used for the sake of information... universities, trade associations, trade fairs. Information from the sales department is mostly in form of e-mail, the rest comes orally, as brochures...customer contact"

\section{Head of Product Development, KA}

The procedural type can, as illustrated in Statement 2. and 3. above, further be broken down into two different types or perhaps rather two different abstraction levels, (1) general knowledge about the responsibilities of a role, i.e. such knowledge more related to general competence (know-how), and (2) instructions for specific tasks. Even though most informants of course know about what, they need procedural information and to some extent where to get it in form of instructions, guidelines etc. they have a harder time identifying what general knowledge they need and how and where to obtain it. In addition to this it is also relevant to discuss yet another type of information demand, that for directive or analytical information (see Section 3.1.), i.e. information about the current status of 
the organisation like, statistics, performance indicators and other information of importance for the quality of the processes within the organisation. It is however not really relevant to consider this as an independent type of information demand but rather more so as a subset of the operative type since this kind of information mostly is used as input to work tasks for top- and middle-management roles like, material controllers, sales representatives, quality managers etc. which is illustrated in Statement 1.

Another difference that seems to have, at least in part, to do with what organisational level a role belongs to, is how extensive and evident the information demand is. For lower-level roles work task are self-evident in the sense that it is obvious what needs to be done in terms of producing parts, publishing material etc. For higher-level roles, the situation is quite different. Many tasks and projects have no clearly defined scope in the sense that defining the task or project often is a required part included in the task or projects itself. This situation obviously influences the nature of, and awareness for, information demand. The higher up in the organisational structure, the more general, wide, and unspecified does the information demand seem to get, as exemplified in Statement 3. The degree of structure in the information needed as well as the relation between procedural and operative information changes much in the same manner. This relationship is however not as strong as that between demand and role since exceptions to this do exist, most commonly so for people working with economics or quality management were much of the operative information seemingly tend to remain highly explicit and structured. Interesting in this context is that while the need for procedural information increases with responsibilities and complexity of work tasks, provision of the more general aspects of it decreases. Instructions and guidelines might very well be available also for higher-level roles within an organisation but when it comes to general information necessary for such tasks as development of strategies, new product introduction etc. it is left much up to the individual to find, aggregate, and evaluate that information (Statement 2. and 3.). This is equally true for knowledge and competence with respect to responsibilities. In lower levels of an organisation courses, training and detailed instructions is provided to the different roles but on the higher levels individuals are implicitly expected to be able to obtain any necessary knowledge and competence themselves. This can be exemplified by comparing the following two statements:

\section{Statement 4.}

“...extremely tacit and unstructured information... have the responsibility for acquiring it myself...”

Head of Product Development, KA

\section{Statement 5.}

“...need maintenance plans, maintenance specifications...download instructions from the intranet and get error reports from the supervisors or the production..."

$$
\text { Supervisor, Maintenance and Service, KA }
$$

There does however not seem to be a connection between the classification of roles into producing or consultative ones and the various dimensions of information demand. During the investigation, informants belonging to both groups stated that 
they need and use explicit, tacit, operative, and procedural information independent of to what organisational levels they belong.

\title{
4.2 RELATION BETWEEN ROLE, TASK, AND INFORMATION SOURCES
}

As mentioned in the previous section, most informants tend to have a rather good idea of what information they need but how about, from where to obtain it. Answering that question is somewhat problematic because it is highly dependent on the type of information needed. When it comes to highly structured, operative information the question of where to get it is not really an issue for most roles since very little choice is given to the individuals in terms of sources. More often than not this is something decided by the organisations through the choice of systems used.

\section{Statement 6.}

"Sysprod [The ERP-system] reports manufacturing capacity and production data for the coming two weeks"

Operations Supervisor, PE

\section{Statement 7.}

“...order information used as basis for production plans is handled by SAP"

\author{
Material Controller, KA
}

While this makes a lot of sense from an administrative and organisational perspective and in many aspects work well, it does introduce quite a few problems that will be discusses further in Section 4.3. For procedural information and such operative information not typically distributed through information systems the situation is somewhat different though, especially so with regard to sources and reliability. While not all commonly used sources of information discussed in this section are of an informal nature, quite a lot of them nevertheless seem to at least provide access to information exchange channels not controlled by the investigated organisations. Hence, some of the data relates directly to the conjecture $\mathbf{C 4}$.

\subsubsection{Commonly Used Information Sources}

The informants identified a number of different information sources as both useful and important for their daily work. Furthermore, most of them also initially stated that they get the information they need from the sources intended to be used (Statement 8.) but when asking them additional questions this turned out to not be completely true. In many cases, several different sources can be and are being used to obtain the same information, even more so when considering procedural information in particular.

Operative information, and especially so, structured information intended for lower-level roles is mostly distributed throughout the organisations by means of business applications and solutions, documents, and oral communication. To some extent, these channels are used for procedural information too (Statement 8.) but for that type of information, external sources like trade fairs, standards, customers, and suppliers etc. play a bigger role as well as intranets and other "paperless" document collections. 


\subsubsection{Business Applications and Solutions}

All three of the investigated organisations have rather advanced solutions for controlling and keeping track of many aspects of an organisation from a statistical and operative perspective. Due to the differences in orientation between the two organisations belonging to the automotive industry and the public authority it is only to be expected that there are corresponding differences in the type of information those solutions focus on, however, despite the differences in content such information is utilised much in the same manner with respect to work tasks. Systems used for quantitative aspects of enterprises are business applications and Enterprise Resource Planning systems like SAP, Sysprod, and data warehouses (Statement 6., 7., 8.). It is from an information demand perspective, interesting to observe how these solutions are used within the different organisations. In many cases, such systems contain information relevant to almost all organisational levels and roles but despite this, the lower levels rarely use them, which seems to confirm the findings that information use within SMEs usually is tied to the management (see 3.2.2). Instead, information is extracted from the systems by middle management and then distributed either as documents or orally (Statement 9.). The same is in many respects true for the inverse, it is middle management that gathers information from the lower levels of the organisation and then input it into the business applications rather than the lower-level roles doing so themselves.

\section{Statement 8.}

"Production indicators [production statistics] and standard procedures are distributed through SAP while information about [production] problems is communicated in forms of minutes from the daily meetings with the production... get information from the intended sources"

Group-leader, Production Technology, KA

\section{Statement 9.}

"For the daily activities information about any existing problems and status of equipment is needed... for the projects production calculations and action lists is needed...the information is distributed through personal communication with internal sources as well as equipment and machine manufacturers... in the projects information comes mostly from project managers... mainly paper based...action lists are downloaded from project network shares.

Production Technician, KA

\subsubsection{Electronic/Paper Documents}

When studying the replies given by informants representing lower-level roles, regarding information sources it becomes clear that in most cases those roles almost never utilise the more advanced IT-solutions. Information needed by them is instead often distributed orally or in form of electronic or paper-based documents. In fact, the bulletin board still lives on as an important information distribution channel and only in few cases and for few lower-level roles have these been completely replaced by their digital equivalence. However, with respect to this it should be pointed out that there are obvious differences between the representatives of the automotive industry and the public authority. $K A$ and $P A$ are manufacturing industries and lower-level roles therefore have somewhat different working conditions compared to their counterparts at $S B A$. While all of the individuals, even on lower levels, 
working within the $S B A$ have offices and do the bulk of their work on computers, producing or processing information the equivalent roles working in the automotive industry are to be found on the factory floor operating machinery. This obviously also influence both the amount of information needed and the means by which it is and can be distributed.

The use of documents as a distribution form is of course not limited to only one organisational level. Even if higher levels utilise business applications and solutions to a higher degree than the lower ones these systems are typically only used for explicit information. With regard to more tacit information different documents like minutes from meetings, status reports etc. are still the most common and important form of distribution.

\section{Statement 10.}

“...subsidy request directly from the source, regulations from EU and protocols from the case managers' meetings in Brussels...Information to be published on the Net is received from the co-workers..."

\section{Assistant/Secretary, SBA}

While it still, at least according to the informants, seems to be the case that documents in many cases are distributed and stored in paper form, a number of different solutions are used for dealing with electronic versions. All three of the organisations use both intranets and shared network drives for storing documents but all of them also have structural problems with respect to these solutions. In addition to this, steps have been taken towards more structured document management solutions but this has so far, not been done completely without problems.

\subsubsection{Oral Communication}

Despite the number of advanced IT-solutions found in all three of these organisations, oral communication still remains a highly important information channel, especially so with regard to information distribution between organisational levels and occupational groups. Meetings are by many of the informants considered one of the most important means by which to get information. However, it is also pointed out by several of the informants that information communicated orally can be problematic from a reliability and relevance perspective.

\section{Statement 11.}

"... information from case managers [oral and as statistics]...the reliability of information from the case managers can be so and so, you often have to double check it with several different managers..."

\section{Administrative Executive, SBA}

\section{Statement 12.}

"The availability is dependent on your knowledge of whom to talk to...much of the information coming from suppliers is irrelevant" 


\section{Statement 13.}

"...the information from the suppliers is often 'adjusted' to appear better..."

Head of Production Technology, KA

\subsubsection{External Sources}

While there are some problems related to internal information of both the operative and procedural types at least a certain amount of control is possible for those sources with respect to reliability, correctness, accuracy, structure and so on, this is not the case for external sources. Nevertheless, external sources are not only useful but for many of the interviewed roles also crucial. As already stated many, typically higher-level, roles are left much without technical and/or organisational support when it comes to gathering information of a more general nature (as opposed to operative ditto) used in order to perform work activities. No matter if, this is for the purpose of knowledge acquisition or just keeping up with trends and currents. Regarding external sources there are obviously too many different sources to cover them all but some of the, from the informants' perspectives, more important ones will briefly be mentioned here together with a description of the informants' purpose behind using them.

\subsection{Internet}

As in so many cases, Internet is an abundant source of information on most subjects and it is therefore often used for a variety of work related tasks. However, some of the informants claiming that they use Internet as an information source also state that it is important to use official sources to ensure reliability of the obtained information as far as possible.

\section{Statement 14.}

“...EU legislation and regulations is published on the Internet and minutes from EU meetings is also distributed from electronic sources...try to use official sources as far as possible..."

\section{Head of Division, SBA}

This is also how the Internet differs from the rest of the sources mentioned here, it can be viewed as a general source of information but also as a distribution channel used for official information, especially so for the $S B A$, which in many cases gets information from official sources like the European Community and the Swedish Government distributed over Internet.

\subsection{Customers and Suppliers}

When it comes to mandates, overall direction of, and requirements for, daily activities there are obviously some differences between the investigated organisations. For the two enterprises active within the automotive industry, much of the information necessary for such general aspects as planning, running, and developing an enterprise, comes from customers in the form of demands and requirements on products, price, logistics etc. Suppliers on the other hand, to some extent constrain what can be done through the properties of the material, equipment, and services they supply. It is therefore not particularly surprising that several of the top-level roles within those two organisations identify both customers and suppliers 
as important sources of information. This is completely in line with what was found during the empirical investigation performed in USA (Fuellhart \& Glasmeier 2003).

\section{Government and Authorities}

Much as customers and suppliers dictate the demand on the automotive industries different authorities and branches of government, both Swedish and European, do so for work activities performed within the $S B A$ and are therefore a vital source of information to them. For the automotive industry, such official institutions are important sources for information related to laws and regulations concerning everything from environmental, safety and fire factors as well as financial aspects of production and business administration.

\subsection{Competitors and Enterprise Networks}

At least some of the informants points out competitors as another important source of procedural information. While this might be expected in terms of keeping track of what competitors are doing in terms of products and solutions it is surprisingly not mainly this aspect, the informants refer to.

\section{Statement 15.}

"...it has become clear to us that we all stand to win more from sharing both information and technology than we do from keeping it to ourselves."

$$
\mathrm{CIO}, \mathrm{KA}
$$

As a consequence of this, different types of networks, interest- and user groups are formed in which representatives from what traditionally would be perceived as competing businesses are exchanging experiences and knowledge. While this, at least as far as this investigation goes, does not seem to have any equivalence within the $S B A$, much due the fact that they have no competitors in the real sense of the word, there is nevertheless some cooperation between different public authorities in terms of information exchange.

\subsection{Trade Fairs and Press}

Other means to collect information from potential customers and suppliers as well as competitors are trade fairs and press. However, due to the nature of such information sources they are used more for obtaining an overview of current trends within the trade rather than as for specific purposes.

\section{Statement 16.}

"...flow of information [from the Ministry and the parliament] through the director-general...other sources [of information] is the director-general's operation meetings, Anna Olsson [CIO], the CFOs... general information from agricultural press..."

\section{Deputy director-general, SBA}

\subsection{Universities and Research Institutes}

Even though, as a researcher, one would hope that the academic world is considered a both relevant and important source of knowledge and information, this unfortunately does not seem to be the case since only two of the informants claimed to utilise such institutions in work related activities. One possible explanation for this lack of interest in academia can be that smaller enterprises do not have the time 
and resources needed in order to try and experiment with unproven technologies and solutions, and therefore prefer to stay with what is proven and known to work.

\subsubsection{Informal Sources of Information}

Conjecture C4. assumes that information demand partly is fulfilled through informal channels. When interviewing the different roles participating in this investigation the importance of oral communication for the performance of every day work activities became quite clear. However, while such communication most certainly is how information in large parts is exchanged within organisations, as illustrated by the previous section, this should not be confused with the concept of informal information exchange channels. First of all, the main difference is that information exchanged by means of meetings or telephone not is informal but on the contrary often a highly planned or intended way of exchanging information in most organisations, while informal information channels are such information exchange that takes place in an organisation despite not being planned or described in any formal description or model of the organisation. Secondly, informal networks as discussed in this dissertation are, as it has become clear, more about exchanging procedural information than operative ditto. It turns out that when colleagues turn to each other, or external parties, for information and help on some specific task it more often than not a question of needing information about how to do something rather than needing information to use as input to specific tasks. Another interesting result from the investigation is that this is done even if the information needed can be found in guidelines or instructions already available on intranets and in document repositories (Statement 17.).

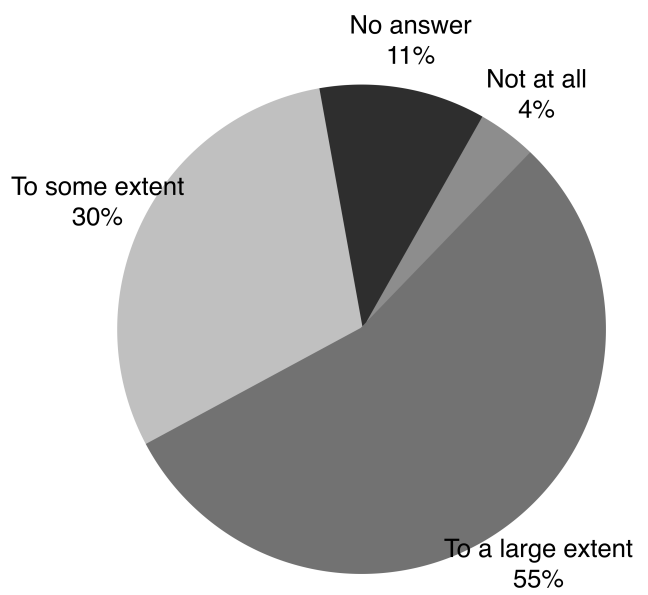

Figure 8. Distribution of informants that rely on colleagues for information.

When formulating the conjecture regarding informal information exchange channels it was expected that it would be confirmed during the investigation but not to the extent it actually was. When asking the informants to what extent they rely on colleagues for information 23 out of 27 answered that they do so. In fact, as can be seen in Figure 8., fifteen of them state that they do so to a large extent (meaning daily or several times every day) and eight said that they do so to some extent (meaning from time to time). Only one claims to never do so at all. 
Of course, when answering questions regarding this subject, many of the informants refer to such things as meetings and telephone calls, which according to the view taken here are not really to be considered informal. Nevertheless, many of the informants claim that they also use their co-workers as a source of information in a more informal manner. The reasons for doing so may vary as well as on what the choice of colleagues to turn to is based but the informants enumerate a number of different reasons to and situations in which such informal information exchange channels form:

- Reuse of knowledge or information

- Problems with finding the right information

- Lack of structure and processes

- No information available through established channels

- Information reliability (see Statement 11.)

- Social/strategic reasons

These six situations or reasons are not necessarily independent of each other. On the contrary, they are according to the statements made by the informants often related to each other in different ways. An example of this is reuse of knowledge or information related to projects or tasks. Even though information pertaining to results from specific projects or on how to perform a particular task often can be found in the information systems used within the organisations, it seems to be easier or more convenient to simply ask a colleague when such information is needed:

\section{Statement 17.}

"A certain amount of direct communication with other roles is a natural part of the work, informally, help is wanted from colleagues for experiences from what has been done in terms of enterprise development [the main work task in the informant's department] rather than utilising the original source. The same goes for searches in the data warehouse...there are also examples on case managers that prefer to talk to each other rather than using existing support systems because they are unsatisfied with them..."

\section{Administrative Executive, SBA}

According to the results from the empirical investigation, this can be due to several reasons. It can be hard to find information on network shares or intranets, people do not know that the information is available, or in some cases, the information simply is not available in any system at all. Furthermore, some informants state, that they do not always trust that the information they can find in the systems is correct or upto-date and therefore prefer to ask someone to be sure. However, statements of that nature are somewhat ambiguous because there are also statements made that say that most of the internal information sources are perceived as very reliable. Yet another aspect of informal networks like these is social reasons, as several of the interviewed individuals state that they prefer to ask their colleagues rather than use information systems simply because it is nice to talk to other individuals (Statement 19.). In some cases, this is not only considered nice but also necessary due to the fact that work processes and workflows are not structured enough (Statement 17.) or do not cover all aspects of certain tasks (Statement 18.). 


\title{
Statement 18.
}

"...not all documents are available in the systems, some do not even exist electronically so you have to talk to others..."

\author{
Head of Division, SBA
}

\section{Statement 19.}

"...because it is important to see the humans behind the computer..."

\section{Head of Production, KA}

A typical example of this is creative processes connected to the development of new products within one of the investigated organisations where spontaneous brainstorming meetings are used as a way to work.

It is also, based on the investigation, motivated to reflect over what choices individuals make concerning whom to talk to or form informal networks with concerning exchanging information in the aforementioned manner. Two main factors seem to influence this choice, competence or knowledge and personality or personal preferences. That is, one tends to turn to individuals that one likes and knows have the competence or knowledge needed. In some cases, the choice is also made on a strategic basis.

\section{Statement 20.}

"I definitely do that [talk to colleagues] because it is hopeless to find anything on the Intranet or the network drives...it is based on knowledge and personal contacts"

\section{Material Controller, KA}

\section{Statement 21.}

"[talk to colleagues] often because the systems are so complex and contain so much information ... you "know" whom to talk to..."

\section{Head of Production Technology, KA}

It was expected that location and proximity also would be an issue but according to the informants, this does not seem to be of any greater importance. One can of course always speculate on why this is but considering the possibilities for communication IT-solutions provide, perhaps location simply is not a big problem anymore. Another perspective on the lack of argumentation for location as an important factor might of course also be that roles with similar job descriptions tend to be grouped together with each other anyway and therefore simply do not consider location as an important factor.

\section{Statement 22.}

"...areas of expertise coincide with the office arrangement which leads to the office neighbours being used often"

Administrative Executive, SBA

\subsubsection{Information Management Related Issues and Problems}

Concerning how the information the informants use is stored, handled, and distributed in every day work, there are many interesting aspects to study. However, during this investigation, focus was placed more on how such solutions relates to 
informal, temporal, and spatial aspects of information demand, i.e. the validation of conjecture C5. While there are as many different approaches to information management as there are informants in the investigation, there are some general observations to be made. Most importantly, as the requirements for retrieving, aggregating, and processing information increases, at the same time as the support for doing so is not, many of the informants feel that the situation is problematic at best.

\section{Statement 23.}

"...experience difficulties with the management because it is too much information...the official information from EU is not a problem because it is so regulated but the self-acquired information is harder to deal with...the organisation relies too much on chronological ordering, something that causes problems when searching for things like product name... Retrieval is performed through the predefined structures [standard file system searches or browsing]. Reuse of information or material is not common since there is no real insight into what other departments or individuals do or have done...Information overflow is a general problem and so is E-mail...some E-mails are thrown away without being read"

\section{Administrative Executive, SBA}

The main internal sources used in the investigated organisations have been developed to facilitate the access to, and use of, information necessary for performing work related tasks but in many case those very sources instead aggravate the perceived problems. In this section some observations on how the individuals deal with their own personal information management will be covered together with problems they have identified in relation to this. For most of the informants, daily information management is about identifying what information they need for specific tasks, finding the right source for that information and then find the actual information within that source. In some cases, this, as already discussed, also requires aggregating information from several different sources. Once the right information is acquired, it also has to be processed or utilised with respect to the task at hand and finally it should be stored and/or distributed. On top of this, there is also a constant stream of pushed information, mostly through E-mail and phone calls, that most of the informants have no control of in terms of amount, sources, timing, availability, etc.

While all three of the investigated organisations according to the informants have solutions that work well for operative information like cases, orders, production quotas etc. the situation for procedural information seem to be more problematic. Because of this, the informants having more unstructured, less defined work tasks, to a higher degree state that they have information management related problems. All of the informants working in what should be considered a middle- or top-level role state, without exceptions, that they have information overflow related problems. Most of those problems seem to be related to finding the right information and organisational memory, i.e. such information and knowledge that is useful for and needed by an organisation but only is available in form of its employees' competence and knowledge: 


\section{Statement 24.}

"Retrieval of experience from previous projects does not work since there is no feedback between projects, one has to ask others that were part of the project. Some retrieval [of project experiences] is made based on one's memory but there is no system support for this...Version management is based solely on file structures."

\section{Administrative Executive, SBA}

The two main approaches to storing tacit information in all three organisations is the use of intranets and network shares, both suffering from problems with structure and scale. While most informants that utilise those approaches seem to know that the information they want and need, can be found there they also state that they often cannot find it. This is due to several reasons but mainly the fact that the sources simply contain too much information and that they are not structured in an understandable and sufficient way. To some extent, this has also resulted in some of the informants' preference for finding the relevant information from alternative sources or asking someone rather than trying to locate it on intranets and network shares (Statement 20. and 21.). It is also stated several times that, despite frequent attempts to clean up and structure sources, the problem is really more a question of a lack of process and role support. There is no connection between who one is, what one does, and the structure of the information. Furthermore, in some cases there is also a lack of actual work processes, resulting in individuals and projects solving information management related issues in many different ways. Because of this there are also, within the investigated organisations, several different structures, solutions, and procedures that to some extent counteract and overlap each other. Other problems identified related to internal information storage approaches mentioned by the interviewed individuals are shortcomings in version management, routines for deciding what to save, and prioritising of information according to importance. There also seem to be far more serious problems than individuals, having a hard time finding information, related to information management issues. Some of the informants in a position to see the effect these problems have on the organisation as a whole, single out the lack of organisational memory as very serious issue that must be dealt with in some way.

\section{Statement 25.}

“...the lack of file structures shared between projects leads to difficulties with retrieval...In order to utilise experiences from earlier projects you have to now that a project that can be useful to you exists and you also have to know who was responsible for it..."

\section{Head of Product Development, KA}

All of the investigated organisations store much of the information they process or produce. Document repositories, business applications, etc. are getting larger and larger. Consequently, individuals do not longer have the possibility to take stock of what the organisation already knows and what it does not know. It has in this dissertation been said several times that organisations and individuals do not know what it is they do not know (Fuellhart \& Glasmeier 2003) when it in fact also seems to be the case that they do not know what it is they do know either. This is exemplified by a number of the informants when they say that they only reuse information in projects if they, or someone working in that project, happen to know that it exists. That is, despite all collected knowledge and information, there is today 
no way to identify which knowledge or experience the organisation has, except through the memory of the individuals working within it. This is problematic for several reasons, firstly because this makes the organisation dependent on individuals that sometimes get sick, change roles, or leave the organisation entirely, secondly because individuals from time to time forget.

Finally, what almost all of the informants identify as the single most problematic aspect of personal information management is E-mail. According to the informants, there is too much E-mail, irrelevant E-mails and spam, E-mails with information that contain information already in some information system etc. Because of this, many of them also state that they from time to time miss important information. E-mail is also often problematic because it is completely up to the individuals themselves to handle it. While there with more common information systems, at least are attempts to structure and improve different aspects of the information, nothing is done when it comes to E-mail.

\section{Statement 26.}

"...definitely have problems with information overflow...problem finding the relevant information, "my" information...mostly so with E-mails ...It is very stressful with information coming from so many different sources...sometimes I avoid some sources"

$$
\text { Material Controller, KA }
$$

\section{Statement 27.}

"Yes, the lack of common project file structures causes a lot of unnecessary E-mail traffic with redundant information... you get more than needed"

Head of Product Development, KA

However, it should be pointed out that not everything is considered bad when it comes to information management. Many of the informants, mention systems and solutions that work well as well as a number of plans on how some of the issues will be remedied in the future.

\subsection{SPATIO-TEMPORAL ASPECTS OF INFORMATION DEMAND}

The author's initial view on information demand placed the idea of right time and place at the core of the concept and consequently it was relevant to try to identify any temporal and spatial aspects of information demand the informants might see in their work contexts, i.e. validating C2. and C3. Based on the replies on the questions relating to these aspects it however became clear that most informants had not really reflected over this before. Most of them actually had quite a hard time identifying any situations for when it would be relevant to filter or direct information with respect to time and location, especially so for spatial aspects. However, when given some examples of what the result of introducing temporaland spatial-sensitive information supply could be, several individuals started to realise that there actually are some situations where this could be useful to them.

Several of the interviewed persons have tasks that are related to both absolute and relative points in time as well as durations of time. While some have to generate reports on a weekly or monthly basis, others always have to perform the same task every morning etc. There are also roles that cannot single out such specific points in 
time but instead can see information demand that exists in relation to specific events or tasks. An example of this, given by one of the informants, is that she has meetings for which she needs to collect and aggregate information and even though she does not know exactly when these meetings will take place she always receives an E-mail some time before them, something that could be used as a trigger for providing her with the necessary information. The same seem to be true for those individuals who strictly follow processes in their daily work, like assemblers, but they on the other hand do not have to deal with that much information and therefore do not really have the need for solutions of this kind.

For spatial aspects of information demand, the situation is quite different. While some informants identified obvious locations that would influence their information demand this is more a question of either wanting to have all the information or none at all. The only exception to this was roles that work with time and mission critical issues like maintenance of machines etc. who always want information about any standstills or bottlenecks independent of time and location even though they are not interested in any other information at that time or place. Consequently, the approach taken today in all of the investigated organisations is simply; everything is available to everyone, always.

\subsection{INFORMATION USE FROM AN ORGANISATIONAL PERSPECTIVE}

Some of the informants interviewed during the investigation are in positions that allow them to make statements concerning the organisation as a whole. As mentioned in Section 2.3.3., these individuals have been asked a number of questions regarding the information situation from an organisational perspective. This has been done in order to learn something about the differences in information use and demand between individuals and organisations. By relating the answers on these more general questions to those on the individual ones, some interesting observation have been made.

It turns out that when it comes to important information and the sources it comes from, much of what is true on an individual level also holds true on an organisational ditto. Most of the information considered important, like orders, reports, payments, customer and supplier information etc. is distributed through and stored in much the same way as for individual roles. This is of course only logical since organisational and individual information is not two distinct sets of information but rather the same information viewed from two different perspectives. It can be argued that the organisational information use and demand simply is the sum of the individual counterparts and thus the sources for that information are also the same as the ones used by individual roles. There are however, when taking an organisational view on information management some differences when it comes to problems or perhaps rather some additional problems. What is identified as a serious issue, from an organisational perspective is that not all of the information is available to everyone in the organisations. The solutions used for storing and distributing information are more often than not dependent on departments, divisions, groups etc. all with their own structures and approaches (Statement 24.). However, while stating this some of the informants at the same time also state that one of the problems today is that employees of their organisation in order to find the right information have to deal with information that from their perspective has no relevance at all. 


\title{
Statement 28.
}

"The connection between processes and technical support systems is too weak"

\author{
Chief Information Officer, KA
}

\section{Statement 29.}

"...that you can control which information you want and not want"

Production Supervisor, Proton Engineering

\section{Statement 30.}

"...more structure and better flow is sooner or later necessary both for economic reasons and the health of the staff members..."

\section{Head of Public Relations, SBA}

On the other hand, there seems to be an awareness of the impact information overflow has on the organisations because according to the statements made by the informants there are attempts and to some extent also existing approaches to filter information based on such aspects as organisational belonging, processes, and tasks. Such approaches are however considered a balancing act between forcing structure on individuals and allowing them the freedom to work, as they want to.

\section{Statement 31.}

"...the flow in the main process is connected to guides and documents divided after areas of responsibility but this is only for procedural documents..."

\section{Quality Manager, KA}

\subsubsection{Visions and Wishes Concerning Information Management}

While there obviously are some problems related to information management in all of the investigated organisations there also are many ideas, visions, and possible solutions identified by the informants. What most informants identify as aspects they would like to see improvements on are:

- Structure of information and improved information flow

- Better information retrieval solutions

- Relevance filtering according to role or task

- Categorisation according to importance and relevance

- Version and workflow management

- Automatic summarisation and condensation of information

- Susceptibility to changes (both organisational and technical)

There seems to be a firm belief that if these seven aspects of information management could be improved the informants' situation with respect to such things as information overflow, task prioritising, and stress would be made a lot easier. 


\section{AN INTEGRATED VIEW OF INFORMATION DEMAND}

There exist, as shown in Chapter 3., concepts within different research areas, such as Information Retrieval, sociology, and business and marketing that are similar to the concept of information demand and the definition thereof, presented later in this chapter. Unfortunately, none of these concepts is suitable as-is for the purposes intended here since they only partly consider what is believed to be essential aspects of information demand, such as location and time as well as the informal aspects of information exchange. Common information retrieval tools, such as Internet search engines, can be taken as an example to illustrate this. In those, the time perspective usually is the time it takes to answer a request for information and then such a demand can be forgotten until the next time a user has it again. Exceptions do exist as for example search engines based on contextual information retrieval as described in Section 3.2.2., but even in those, the time perspective does not exceed the user's current task (though such tasks might be stored in profiles for later use). Furthermore, since the user actively visits and uses the search engine rather than the search engine pushing information to the user, no more attention to the location aspect than the development of interfaces for different platforms is needed. When considering information demand from an enterprise perspective however, the information need for a complete work context has to be known as well as all possible locations a user can be at, at any given time. To this the complexity of demand for different types of information is added. Yet another comparison between an enterprise perspective on information demand and the exemplified search engine can be used to illustrate the differences. While a search engine usually only needs to provide information that according to some method is deemed relevant based on a user's information request that always is possible to formalise in some query language, information demand in general has to be considered for a wide range of situations rather than just one type or form of queries.

\subsection{VALIDITY OF THE INITIAL CONJECTURES}

Based on the findings made during the investigation enough empirical grounding has been obtained in order to evaluate the validity of the initial conjectures (see Section 1.1.2.) and they are therefore shortly discussed here in relation to the results from the investigation. 


\subsubsection{Information Demand Dependency vis-à-vis Role and Task}

C1.

Information demand depends on the role and tasks an entity has within a larger organisation, if that role and/or the tasks change, so too will the demand.

In the light of the investigation in general, and of what is presented in Chapter 4.1. and 4.2. in particular, it can be stated that this holds true. Information demand in a work setting, is dependent on such aspects as roles and tasks. Attention to such settings is therefore essential when discussing information demand. Consequently, this is done in Section 5.2.1.

\subsubsection{Spatio-Temporal Aspects of Information Demand}

C2.

Information demand has a temporal aspect, i.e. a specific demand is only relevant at a certain point in time or time interval.

C3.

Information demand has a spatial aspect. The demand changes based on the location as well as on any movement of the entity having it.

While, as covered in Chapter 4.3., both temporal and spatial aspects of information demand in a general sense seem to exist, they are not obvious or even always useful for everyone. Furthermore, temporal aspects seem to be of somewhat greater importance than spatial dittos. Based on this it can be argued that even though the second and third conjecture might be considered confirmed, their importance when it comes to information demand analysis might be questioned. Further investigation might produce results that are more conclusive from an empirical perspective. From a practical perspective the situation is however somewhat different. There are a number of situations where spatio-temporal perspectives might be considered relevant even though end-users might not realise it until presented with the idea. Examples on when such aspects could be beneficial are when work tasks either, are highly structured in terms of sequential order or absolute points in time, or in situations when information cannot be of any use to the end-users, i.e. when they are in meetings etc. Adding such aspects to information filtering does however add some new conditions to the concept of relevance as situational aspects like this might change what is considered relevant from one moment to another.

\subsubsection{Informal Aspects of Information Demand}

C4.

Information demand is partly fulfilled through informal information exchange channels, i.e. such channels that are not represented in any formal description of organisational structures, processes, or other (enterprise) models.

The fourth conjecture, stating that there are some informal aspects of information demand, can and, in the light of the empirical results, must be considered confirmed. In fact, the results obtained (presented in Chapter 4.2.) indicate that these aspects are of much greater importance than what was originally assumed by the author when the conjectures were formulated and the investigation were initiated. It is now clear that failing to consider informal patterns and behaviours 
when developing methods for analysing information flow and exchange would constitute a serious mistake.

\subsubsection{The Current and Future Situation of Information Management}

C5.

Existing information systems do not consider the temporal, spatial, and informal aspects of information flow and demand and thus, do not solve all information management related problems users have in connection with the execution of workrelated tasks.

It is undoubtedly so that the informants perceive the current information related situation as problematic (as presented in Section 4.2.2.). Not all of these problems are due to issues with currently used systems and technical solutions, some are more related to organisational, social, and cultural aspects. Even though technical approaches to demand-driven information supply very well could improve some aspects of the current situation one should be careful with attributing any such solution too much value. After all, no technical solution works better than the organisation within which it is used. However, based on the empirical findings, the area of information demand analysis is considered relevant and useful enough for continued work to be highly motivated.

\subsection{INFORMATION DEMAND AS A CONCEPT}

Based on the results from the investigation as well as the theoretical background it is now possible to discuss what information demand is. As already concluded, information demand needs to have a connection to the situation in which such a demand exists, that is, something need to be known about the role having the demand and for what task the information is needed. The information also has to be up-to-date, correct, and reliable as well as available when and where it is needed. These aspects of information demand can be summarised into the following definition:

Information Demand is the constantly changing need for relevant, current, accurate, reliable, and integrated information to support (business) tasks, whenever and where ever it is needed.

This definition implies a number of aspects that must be considered when analysing information demand:

- Changing - as tasks, roles, and responsibilities changes so does the information demand connected to them. This means that any models of such a demand need to be able to capture the dynamics of information demand in order to reflect changes over time.

- Information not considered relevant, current, accurate, and reliable by the party having the information demand cannot be considered useful and will therefore only contribute to information overflow. Some form of quality and relevance measurement is therefore necessary when fulfilling information demand. 
- Integrated as well as (business) tasks imply a need for awareness of the situation in which the demand exists as well as some mechanism for understanding when a change of situation takes place.

- Whenever and where ever states that the timing and location aspects of the information demand are important to analyse. Although not obvious, it also states that the demand as well as the possibilities to fulfil it may vary depending on time and location.

In the light of these implications, it is assumed that to capture and model information demand it is needed to develop a number of different dimensions of information demand and the reality in which it exists further.

\subsubsection{Information Demand Context}

The aforementioned definition of information demand identifies the inherent complexity of the concept, a complexity that has to be dealt with in a suitable manner when analysing information demand. Based on the results from the empirical investigation presented in Chapter 4. and the theory review presented in Chapter 3. it is therefore here proposed that the most important aspect of information demand is the Context of the entity having the demand.

To be able to support (business) activities and provide integrated information, which according to the definition of information demand is the main purpose, something obviously has to be known about the activities in question. This is equally true for providing integrated information, it has to be integrated with respect to something and that something is the context. That is to say, providing the "right information at the right time and place" entails that it should be right given the demanding party's context. It is also important to notice the use of the term (business) tasks because, even though it certainly might be relevant to speak about information demand from the perspective of individuals in such contexts as family life, spare time activities etc., it is reasonable to assume that such contexts mostly are too informal and random in nature for any information demand analysis based on the ideas presented in this dissertation to be meaningful or useful. Because of this, the focus in this dissertation is on information demand contexts within a business application context in.

There exist, as covered in Section 3.1.3., many different views of context in areas such as ubiquitous computing, contextual information retrieval etc. but for the purpose of information demand analysis, information demand context is here defined as:

An Information Demand Context is the formalised representation of information about the setting in which information demand exists and comprises the organisational role of the party having the demand, work tasks related, and any resources and individual assets available, to that role.

From this definition, several important concepts can be identified and the most central of them all from an information demand perspective is that of role, thus when context is mentioned here it is considered the context of a particular role. It could be argued that it is equally relevant to speak of an information demand as related to a specific task and that some resources are necessary for performing some activities no matter who performs them but role is nevertheless the one concept that, 
as it will be shown here, in a natural way interconnects the others. One can of course imagine situations where there exists overlap between roles, when one individual has several different roles, or even when several different individuals share one role. However, in its simplest form role can be described as a part of a larger organisational structure clearly defined by the responsibility it has within that structure. Associated with such a role are a number of tasks that fall within, as well as define, the responsibility of that role, i.e. a role is also defined by the tasks it performs within an organisation. Furthermore, there are a number of different resources available to a specific role, which can be utilised to perform tasks. Such resources might be anything from supporting information systems to a particular device used for some reason during task execution and are dependent of both the role as well as the task to be performed, i.e. not all resources are available to all roles within an organisation and not all resources are suitable to use for all tasks.

Finally, it is also proposed that an information demand context incorporates yet another important concept, not acknowledged enough in existing enterprise analysis methodologies, individual assets. This concept captures the informal aspects of work that individuals bring into a role in their capacity as individuals, despite them not officially being a part of their work context. This might include personal resources, networks, and relationships with other human beings (both personal and work related). Such individual assets are important not only because they may affect how work is performed on a personal level, e.g. with privately own smartphones or laptops, at home on the personal computer etc. They also have a crucial role in the information flow within an organisation with respect to the informal information exchange that seems to always exist. Such informal structures might, as the empirical findings have shown, be based on anything from competence, personal preferences, or the comfort of turning to other individuals with whom a common interests or the same educational or demographical background is shared. Even seemingly futile things as the layout of an office landscape might be a reason to the existence of such structures. Since such individual assets are associated with individuals rather than roles, they are considered independent of any one particular context. They, or some subset of them, may however be both relevant for, and utilised, when activities are performed and are therefore introduced into the context as relevant assets. It is also reasonable to assume that contexts create new additional networks, relationships etc. that the individual having the role might consider so useful that they are utilised even outside the specific context.

It is also important to emphasise that there is not always exactly one and only one context for every user. In fact, every user may have a number of different contexts, to some degree unique to that user, between which he or she constantly is switching. Contexts may at times even overlap each other. Examples of such contexts are different roles within an enterprise, associations, or even family, all with their different and unique demand for information. Moreover, within a context there may be sub-contexts that change everything from the role of a user to the activities to be performed. Also worth noticing is the granularity of information demand. So far in this dissertation the perspective of demand has mainly been that of individual roles but it might just as well be an organisational unit, a division or an enterprise since they too have information demand related to some role within a larger organisational structure, perform tasks, and have a variety of resources to their disposal. Even though the nature of the information demand of an organisation 
might be inherently different than that of a single individual due to the differences in role and its responsibilities within a larger organisational structure the context definition is still assumed to be valid. As a consequence of this it can be stated that an individual role's context is just a sub-context to the context of the organisation that role belongs to.

\subsubsection{Where to get Information Demand Contexts}

If context is to be considered as the most important aspect of information demand, as stated above, it also makes sense to think about how such contexts can be identified. This can of course be done in a number of different ways; one can imagine such sources as quality documentation, task guidelines and checklists, role descriptions etc. However, as such things as roles, tasks, and resources, all very central parts of an enterprise, make up a large part of information demand contexts, it is here suggested that one possible and particularly suitable source for contextrelated knowledge is various types of descriptions and models. Such models are usually referred to as Enterprise Models and is a quite common approach to describe things like organisational structures, processes, and the interrelationship between tasks, information, and resources. Enterprise models and -modelling will be discussed further in Chapter 7.2.

\subsubsection{Spatio-Temporal Aspects of Information Demand}

Once the context has been used to determine the actual subject or type of information needed two other dimensions remain to be consider, time and location, i.e. to what place and/or platform, and at which point in time, the information is needed. Since the empirical results did not clearly identify these aspects as crucial (see Chapter 4.3.), at least not from the end-users' perspective there is, at this stage, no real reason for spending a lot of effort on defining a theoretical framework for dealing with such matters. Instead, the concept of Situation introduced to the area of Information Logistics by Meissen et al. (2004) is utilised. For the purposes presented in this dissertation a situation is simply put just a way to describe or represent what the users are, or should be doing, when they are doing it, and where they are doing it. Situations are derived from and belong to a specific context in the sense that they relate to the role and tasks of an individual, but there might exist predefined situations so general and common that they are considered relevant to speak of in many different contexts. One specific context may on the other hand, dictate new situations not previously defined in any other context. For that reason, situation is considered more to be an attribute of information demand that restrict the user's context rather than being an integrated part of it.

\subsubsection{Motivational Factors Influencing Information Demand}

So far, it has been argued that the single most important aspect of information demand is the context in which such demands exist. It has also been argued that aspects like individual assets, social networks, and spatio-temporal restrictions affect such contexts. There is however, a final aspect to take into account when analysing information demand, an aspect not considered by the author before the empirical investigation; Motivational Factors influencing the users individual view on information demand. 


\section{Statement 32.}

“...regarding analytical tasks it happens that I study the case material [not part of her responsibilities]...mostly has to do with me being new in the area and therefore wanting to have a better understanding for it.

\section{Head of Department, SBA}

In Section 3.2.1., it is stated that information demand from a sociological perspective has to do with citizens being able to make informed choices. Statement 32. above can be seen as an example of exactly this. Factors like career strategies and ambitions can influence the demand of information beyond what is dictated by information demand contexts alone. The same is true also for external expectations and requirements. It is therefore important to realise that even though the concept of demand-driven information supply based on ideas presented in this dissertation might be helpful or of use to individuals, such solutions should never be forced on them. Even though the might need technical support for filtering information and remedy problems related to information overflow, they may still, from time to time, want or need additional information. Refusing them that information can only result in unsatisfied users feeling deprived of control over their own working situation.

\subsection{AN INTERGRATED VIEW OF INFORMATION DEMAND}

To provide a clear and complete picture of information demand as a concept, describing the different dimensions of information demand is in itself not enough, they also have to be interrelated. In the light of the definitions and descriptions given of the aforementioned dimensions of information demand, the following is together with Figure 9. presented as the author's concluding view on the concept of information demand and the relationship between its components:

The information demand of an entity, be it an individual or (part of) an organisation, is defined by that entity's context. The context comprises the role the entity has within a larger organisational structure, the tasks performed by the role and any resources available to and/or required by it for doing so. While parts of a context can be derived from enterprise models or other types of formalised descriptions of organisations additional aspects affecting the context such as individual assets and situations contributes to and restricts the context in terms of susceptibility and availability to formal or informal information. Different motivational factors adding to the demand dictated by the context can further influence the information demand of the user. 


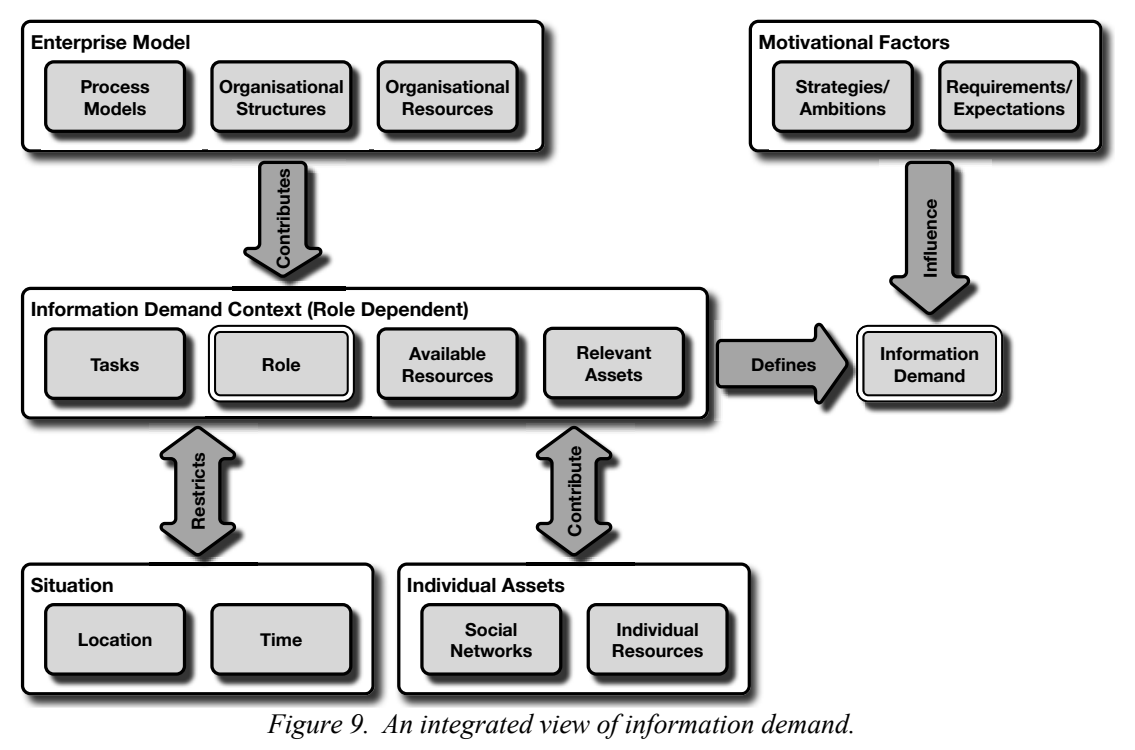

\subsection{INFORMATION USE FROM A BUSINESS PERSPECTIVE}

While the purpose of the study on information use primarily was to validate the conjectures in order to define the concept of information demand with respect to the actual reality within organisations, some additional findings concerning the current information management situation were made. Most of these findings have been presented in Chapter 4. and do therefore not have to be covered once more here. However, some additional aspects of information use and its relationship to information demand have not yet been mentioned.

Studying the results from the empirical investigation there is no doubt that many of the informants perceive the current situation as problematic in many ways. Informants do indeed experience information overflow-related problems, difficulties finding the right information and prioritising information according to importance and reliability related issues. Moreover, with E-mail as one of the main communication methods and information distribution channels the situation is getting even worse, something that is further corroborated by a Gartner Group study concluding that the average office employee spends 49 minutes every day only on managing e-mail (Delphi Group 2002).

Furthermore, when comparing the results from the investigation with the theoretical background concerning information use from a business perspective presented in Section 3.3. a large number of correspondences exist. Even though no real insight into the organisations more strategic aspects of information use has been achieved during the investigation and nothing therefore can be concluded concerning that subject, a number of other aspects do in fact correspond very well to one of the investigations aforementioned. Just as was concluded when investigating SMEs in the US (Fuellhart \& Glasmeier 2003), the investigated individuals and organisations also seem to put focus on familiar sources perceived as reliable. The same is true when it comes to classification of information sources according to frequency of 
use, credibility, and relevance as well as the solutions and applications organisations relied on with respect to information management (Fuellhart \& Glasmeier 2003).

It is also quite clear that current technical solutions have shortcomings that have to be remedied in order improve the situation. Based on the results from the investigation, various types of demand-driven information supply certainly seem to be a useful and suitable approach to solve some of the problems identified. However, no matter what approach chosen to solve these problems it is important to do so with care. There are several issues concerning information filtering and distribution in relation to individuals' attitudes that need to be considered. Implied by the concept of demand-driven information supply are also the concepts of channel and source integration as well as information segmentation. That is, from a user-perspective, specific information channels and sources becomes irrelevant when information automatically is aggregated and presented, however when also considering the reliability aspects of different sources this might be somewhat of a problem since users then lose control over the underlying sources used. Furthermore, while most of the informants in the investigation indeed would benefit from solutions that filter or structure information according to their needs many of them would also feel uncomfortable having neither control over the filtering, nor access to unfiltered information when they so wish. In fact, from an individual perspective information demand with respect to work tasks does, as shown in Section 5.2.3. not necessarily have anything to do with what information that is actually wanted. Several of the informants identify other reasons for wanting information besides actual work tasks connected to their roles within an organisation. These reasons can be related to such things as career opportunities, strategic issues, or just plain curiosity as illustrated by Statement 32 .

\subsection{CONCLUSION REGARDING INFORMATION DEMAND}

The conclusion based on the theoretical and empirical findings must be that information demand is a central concept for improving information flow and management within organisations whether it is by means of technical solutions to demand-driven information supply or organisational approaches. The author's initial view, as expressed by the conjectures C1.-C5., on information demand has proven to be well-supported by the empirical findings, especially with respect to the importance of context and informal information exchange channels, while on the other hand, support for the ideas behind spatio-temporal perspectives on information demand is somewhat less convincing. Nevertheless, the possible benefits of an shorten and simplified analysis process as a consequence of contextdriven methods could prove to be an important contribution. However, for the view on information demand presented in Figure 9. above to be useful as a foundation for method development it needs to be elaborated and clarified in terms of conceptual definitions and interrelationships, which will be done in the next chapter. 
This page is intentionally left blank. 


\section{CONCEPTUAL REFINEMENT OF INFORMATION DEMAND}

While the concept of information demand covered thus far, is detailed enough for presenting the schematic overview of the area of information demand necessary to discuss it in a general sense, is by no means elaborated enough for being a foundation for the development of a method. Consequently, the concept, its inherent parts and their interrelationships need to be refined and elaborated upon. Such an elaboration is by its very nature conceptual and thusly includes many of the author's personal views and experiences regarding the subject. To ensure that the conceptual framework remains scientifically grounded, it has iteratively been refined by constantly relating it to relevant theory and emerging empirical results gained during the cases covered in Chapter 8. and 9. Each concept relevant for the analysis of information demand will therefore be presented and discussed in terms of its definition in various theoretical fields, its relationship to other concepts, as well as its grouping in accordance to the schematic view on information demand presented in Chapter 5. Once each such conceptual cluster is sufficiently defined and refined, a complete conceptual model will be presented. Figure 10. below details the different elements that will be used to illustrate concepts relating to information demand throughout this chapter.

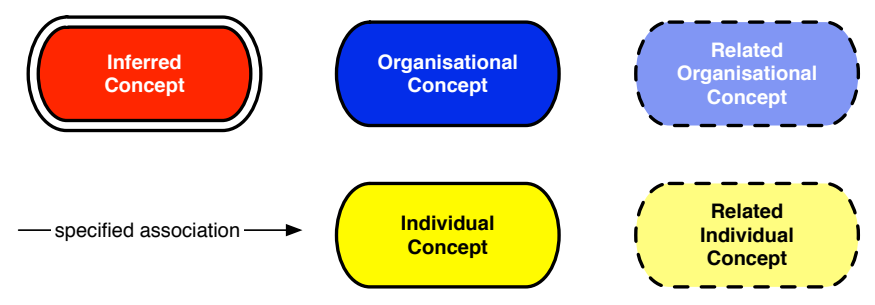

Figure 10. Symbol legend for concept models.

In addition to the elements themselves each concept is also numbered in order to facilitate the traceability between each concept in the various concept models and their respective cluster and definition. The first number indicates which cluster a concept belongs to, i.e. all concepts relating to information demand context has a number on the form 1.n while all organisational concepts have numbers on the form 
2.n. Furthermore, each definition's section heading ends with the same digit and term as in the figures (as an example see Figure 11. where the concept role has the number 1.1 and the definition for that concept consequently has the heading 6.1.1 role).

\subsection{INFORMATION DEMAND CONTEXT REVISITED}

As shown in previous chapters in this part, information demand is highly subjective, depending on prerequisites and requirement unique to each individual even within the same context. It is therefore clear that an individual centred perspective on information demand is necessary. However, from an organisational point-of-view it makes no sense in analysing information demand for actual individuals, as such individuals tend to change over time. Furthermore, an organisation usually has little or no interest in spending effort and/or money on analysing information demand contexts not relevant to its various goals, i.e. purely individual and personal contexts. Consequently, focus is initially put on the representation of individuals in an organisation in terms of actions and behaviour within that organisation, i.e. roles and the tasks performed by such roles. To understand what tasks a role performs and why, it is important to understand the responsibilities a role has within a specific context, thus defining the role as well as the actual tasks. As task is considered the main unit of analysis with respect to information demand, it is only after those are identified, information demand for a specific role performing a specific task can be considered. Figure 11. details this relationship while the rest of the section further definer the various context-related concepts.

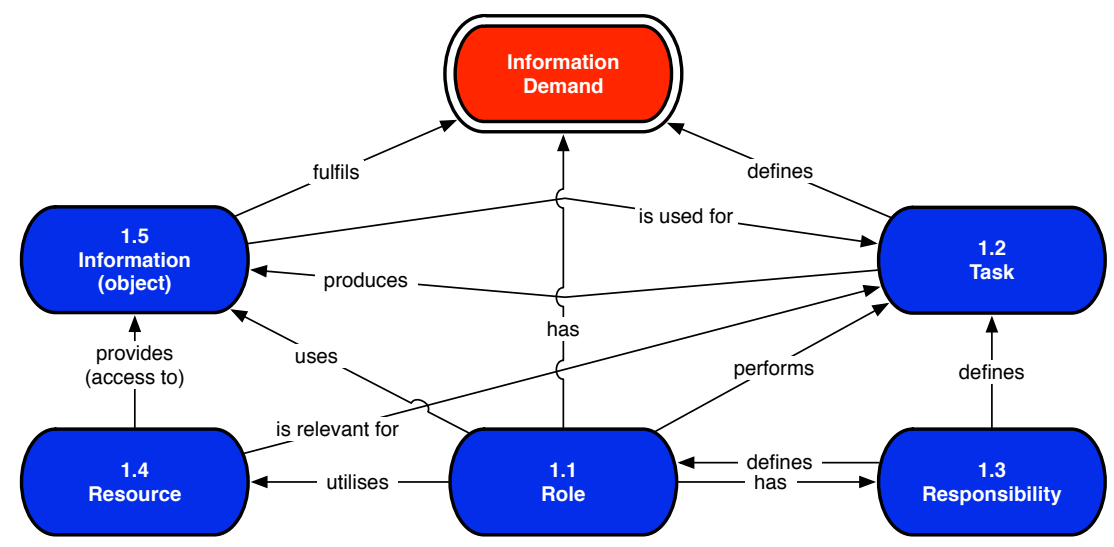

Figure 11. Conceptual refinement of information demand contexts.

It is expected, and verified by the cases presented in Chapter 8. and 9., that a clearcut distinction between concepts such as Role, Position, and Responsibility is not always possible to identify in all organisations. However, the flexibility needed to deal with such situations does not have to exist on a conceptual level but rather in the application of the method itself. Having a clear conceptual view supports the method user in identifying synonymous real-life entities and expressing them in terms of the conceptual underpinning. 
Figure 11. also includes a graphical element named "Information Demand", this is not an actual concept in the model but rather inferred from of other concepts. That is to say, an information demand in relation to a specific task is in reality an identified need for a specific piece of information a role has when performing a task.

\subsubsection{Role}

The concept of role is widely used in various fields from both a pragmatically and theoretical perspective. Intuitive definitions, in accordance with everyday usage of the concept, are exemplified by the New Oxford American Dictionary (NOAD) as; the function assumed or part played by a person or thing in a particular situation, and WordNet (Princeton's English lexical database) as; the actions and activities assigned to, or required or expected of a person or group. From an enterprise, and thereby also from an information demand, perspective these definitions are a bit too vague and simple. In such a setting, role is the function through which organisations distributes accountabilities for fulfilment of its goals while at the same time separating the job from the individuals (Cushway \& Lodge 1999). From an enterprise perspective, roles therefore only exist as a function of its goal-setting (Gartner \& Bellamy 2008). From a more general sociological perspective, a somewhat less functional view on role is taken in the area of organisational theory; a central unit of analysis referring to the duties, obligations, and expectations which accompany a particular (work) position (Gabriel et al. 2000) thus elaborates as well as supports the definitions listed by NOAD and WordNet.

For the purpose of information demand, this rather straightforward view on role as an entity performing tasks as defined by the responsibilities of individuals having that role, utilising information and resources in accordance to its information demand in doing so, is suitable. It can therefore be said that a role also indirectly is defined by the tasks it performs within an organisation. The notion of role as something different from an employment position is important in information demand analysis for several reasons. Firstly, a role in more complex organisations divides the responsibilities and thereby defined tasks of a position, into smaller subsets for which the information demand easier can be analysed than would be the case if focus where put mainly on individuals. Secondly, from an organisational point-of-view it makes sense to, at least to some degree, separate the information demand of roles from that of individuals as this allows for defining a role-based information demand while at the same time allowing for individual variations depending on differences in competence, goals etc. There are however cases where analysis of less complex organisations might result in positions and roles as concepts being interchangeable. As will be shown in Chapter 10. this does not pose a problem from a methodological point-of-view.

Conceptual definition of role with respect to IDA: Role is a function of the assignment of tasks within an area of responsibility to an individual or group of individuals.

\subsubsection{Task}

Task is another term that also has as an intuitive meaning for most people, commonly something in line with; a piece of work to be done or undertaken (NOAD) or any piece of work that is undertaken or attempted or a specific piece of 
work required to be done as a duty or for a specific fee (WordNet). Task is often viewed as a subset of a larger process or project (Gartner \& Bellamy 2008). In organisations with a task-oriented culture, tasks are often specified in terms of sequence, goals, and requirements as processes, dividing responsibility for specific tasks or processes over a set of roles (Cushway \& Lodge 1999). Since information demand is considered role-dependent, this view on work activities makes most sense. Because whereas processes from an organisational point-of-view might be better defined in terms of resources, requirements, goals etc., tasks are easily connected to specific roles. Process analysis also has its role within information demand analysis as discussed in Section 6.2.5. but from a contextual perspective, tasks are considered the smallest and most relevant unit of analysis when modelling work activities in relation to roles. For that purpose, task is viewed as a series of interdependent activities performed by one role in order to fulfil a desired outcome in accordance to the responsibilities, and different goals thereof, as defined by the organisation to which the role belongs, i.e. from an information demand perspective a task is the smallest unit of work that completely fulfil a responsibility.

A task might require a role to utilise a specific resource that is relevant for that task. Furthermore, the task is always performed during a time interval and at one or more specific locations. Tasks therefore define the information demand of the role performing them, i.e. a role needs information in order to perform tasks. As a consequence of performing such tasks, a role might also generate new information relevant for the performance of other tasks by the role itself or other roles within the organisation.

Conceptual definition of task with respect to IDA: Task is the smallest possible set of activities performed by a single role, fulfilling a specific goal, requirement, or purpose, defined by a responsibility.

\subsubsection{Responsibility}

Responsibility is yet another concept central to information demand as it not only defines the tasks to be performed within an organisation but also the different roles individuals have to take on in order to do so in accordance to the goals defined by the organisation. However, responsibilities are by themselves only relevant as a mean to identify the relationship between roles and tasks. As responsibility often is defined as (1) the state or fact of having a duty to deal with something or having control over someone. (2) the state or fact of being accountable or to blame for something. (3) the opportunity or ability to act independently and make decisions without authorization. (4) a thing that one is required to do as part of a job, role, or legal obligation. (NOAD) or as the actions and activities assigned to or required or expected of a person or group. (WordNet), taking this view on responsibility is well supported and in accordance to the intuitive understanding of the concept. In fact, in organisational theory responsibility is generally considered in precisely this manner, as a central unit of analysis referring to duties, obligations, and expectations accompanying a specific organisational position or role (Gabriel et al. 2000).

Conceptual definition of responsibility with respect to IDA: Responsibility is the set of all tasks to be performed by a role in accordance to organisational requirements and goals. 


\subsubsection{Resource}

In process-oriented theory, resources are traditionally viewed as any physical or virtual entity of limited availability required to perform a task of any of the following types; people, equipment, facilities, funding or material (NOAD, Gabriel et al. 2000). However, from an information demand perspective this view is not entirely relevant. While it indeed is recognised that resources can be of many different types, information demand only focuses on such resources that provide or facilitate access to information.

Resources can furthermore be divided into two classes, organisational and individual as defined in 6.2.6 and 6.4.2 respectively. In the area of information demand, as opposed to some process modelling approaches. information is however not viewed as a resource in itself but a resource can provide access to information. It should also be noted that the availability or state of a resources might constitute relevant information in itself.

Conceptual definition of resource with respect to IDA: $A$ resource is an artefact that contains or provides access to information relevant when performing a specific task and therefore utilised by specific roles when doing so.

\subsubsection{Information (object)}

Defining information as a concept is not easily done as it can mean many different things. A longer discussion regarding various types of information as well as the differences between data, information, and knowledge was presented in Section 3.1. Here information is instead simply defined as any kind of representation of externalised knowledge, stored and provided by a resource of some kind (technical or human), which might be used by a role when performing a task or be produced as a consequence of a task being performed. Information, if existing, can fulfil the demand of a role as defined by the task that role performs.

While this definition of course is very simplified, this view on information is suitable from an information demand-perspective because the information itself is not in focus but rather the demand for it. That is to say, when identifying the information demand, one also indirectly identifies the type of information that fulfils it.

Conceptual definition of information with respect to IDA: Information is the externalised representation of knowledge needed by a role when performing tasks. Such information can be of a procedural type, i.e. descriptive in nature or of an operational type, i.e. declarative in nature.

\subsection{ENTERPRISE ASPECTS}

As stated above the information demand context defines the setting in which information demand exists. However, information demand contexts are not something pre-defined and readily available in organisations. They are rather a synthesis, a logical representation, of parts of more general enterprise aspects. Defining contexts has to be done by understanding and representing these general aspects. There are several such enterprise concepts considered relevant when modelling information demand, as illustrated by Figure 12. below and they all relate to contextual concepts in one way or another. 


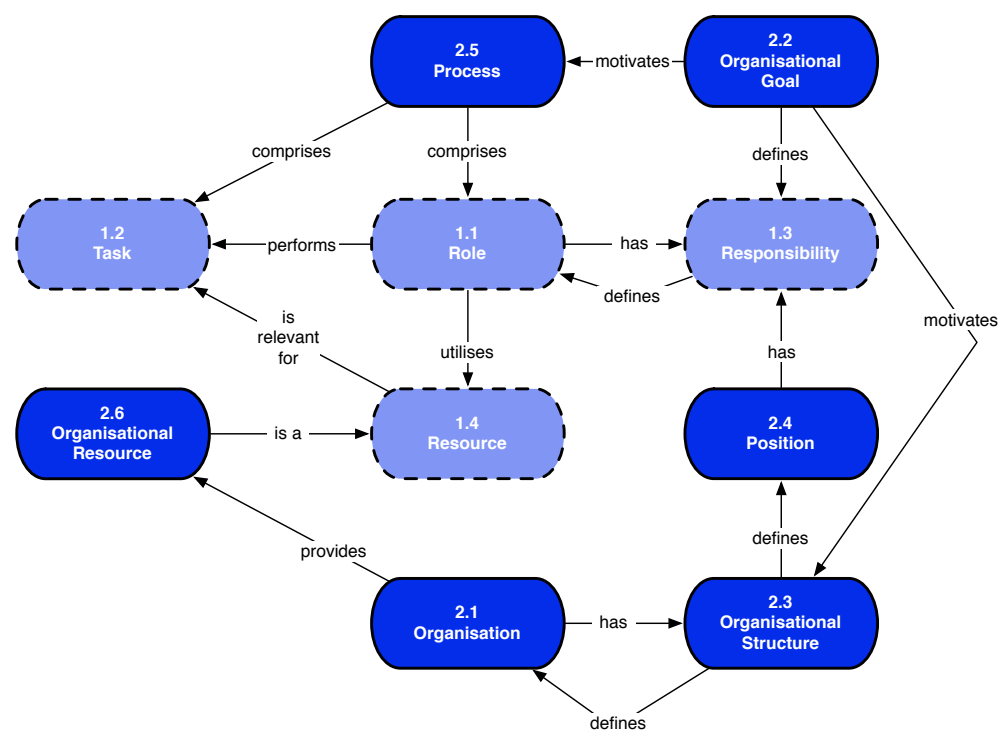

Figure 12. Enterprise concepts relevant to information demand.

However, as these aspects of enterprises have no direct relevance for information demand except as the basis for information demand contexts and they furthermore, as will be shown in Chapter 8., are derived by the use of established enterprise modelling methods, there is no point in redefining them. Instead existing and widely used definitions are used whenever possible.

\subsubsection{Organisation}

There are many different definitions of organisation as a concept. Furthermore, it is not always clear what constitutes an organisation and thereby differentiating it from a collection of individuals. However, generally speaking an organisation is often considered a social arrangement, which pursues collective long-term goals, controls both its own performance and the resources for doing so, and which has a boundary separating it from its environment (Gartner \& Bellamy 2008) or as an entity involving division of labour with different people assigned to different tasks (Gabriel et al. 2000).

From an information demand perspective, an organisation is the highest abstraction level of analysis. It is organisations that contain all the concepts, relationships, behaviours etc. upon which information demand analysis is applied. The concept of organisation is therefore more seen as a placeholder or a container for other concepts, rather than as an important concept in itself. It is the implications of organisation in terms of goals, structure, and resources that focus should be put on.

\subsubsection{Organisational Goal}

A goal is the driving force behind any action of an organisation and thus controls both its definition of positions and responsibility as well as motivates it choice of processes, resources, and organisational structure (Cushway \& Lodge 1999). When, in an information demand setting, organisational goal is referred to, this 
relates to such goals that exist on an organisational level as opposed to the personal goals, individuals within the organisation might have.

\subsubsection{Organisational Structure}

An organisational structure allows for the expressed allocation of responsibilities for different functions and processes to different entities within the organisation (Cushway \& Lodge 1999). Such structures might be of various different types (prebureaucratic, bureaucratic, post-bureaucratic, functional, matrix etc.) (Gabriel et al. 2000).

\subsubsection{Position}

A position is an individual's formal employment or assignment within an organisation and does as such constitute the relationship between an individual and its responsibilities within the organisation and thereby its role(s) within that organisation. In less formalised organisations a position and a role can be the same thing.

\subsubsection{Process}

Process is generally defined as a series of actions or steps to be taken in order to achieve a particular end (NOAD) or as all the systems of an organisation, which ensure that its activities are successfully undertaken (Cushway \& Lodge 1999). In terms of information demand analysis, a process is just a way to group a number of sequenced tasks performed by one or more roles in order to achieve a specific goal, together.

\subsubsection{Organisational Resource}

The concept organisational resource as it is used in this dissertation is viewed as a specialisation of the more general concept resource (6.1.4). Organisational resources are such resources that the organisation provides to its roles in order to facilitate the performance of tasks. Only a subset of the collective amount of organisational resources are available to a specific role based on their relevance for the responsibilities of that role, and as aforementioned, information demand only considers itself with such resources that might be used to access information.

\subsection{SITUATIONAL ASPECTS}

While time- and location-aspects of information demand initially was considered core concepts, not much support for these aspects being needed or wanted as information filtering mechanisms, was identified during the empirical investigation detailed in Chapter 4. It was therefore decided that such aspects simply should be viewed as attributes of an information demand context when wanted or necessary, i.e. time and location can be used to specify when and where a context, and the information demands it defines, is valid. Figure 13. below illustrates this. 


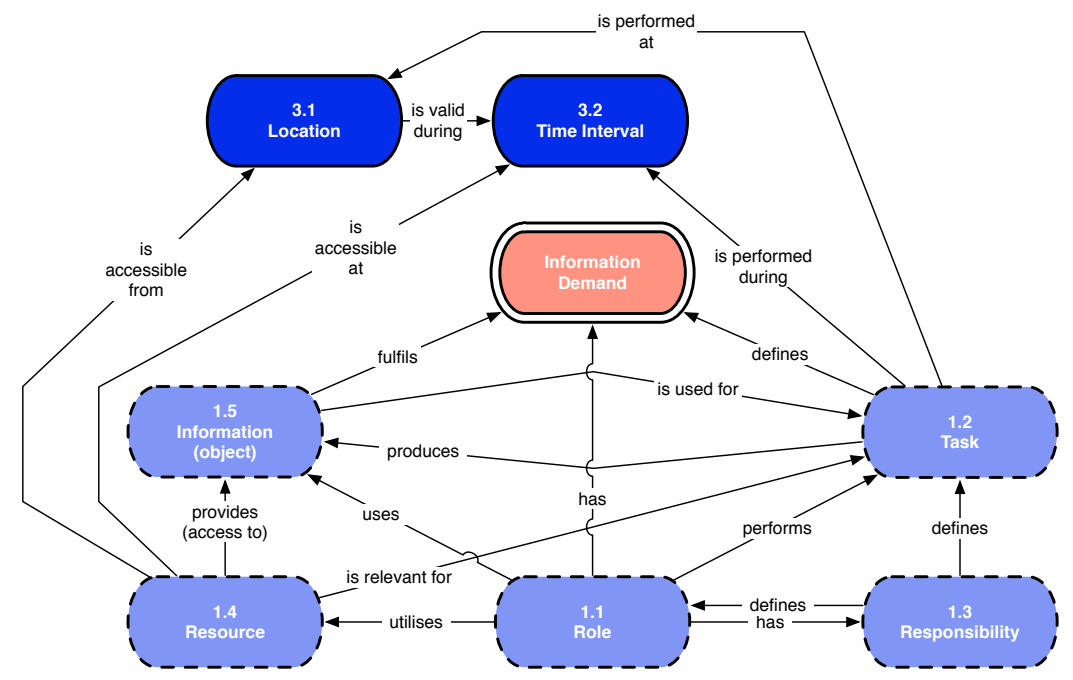

Figure 13. Spatio-temporal aspects of information demand as attributes to a context.

\subsubsection{Location}

A location is a physical, geographical point in space expressed in a coordinate system, in which a role is performing a task and is valid during a specific time interval, even though the same location can be valid during many such time intervals. A location might restrict a role's accessibility to a resource and thereby also to information.

\subsubsection{Time Interval}

A time interval is a duration of linear time expressed in a time system, during which a task is performed and/or a location is valid. A time interval might restrict a role's accessibility to a resource and thereby also to information.

\subsection{INDIVIDUAL ASPECTS}

Every concept discussed so far has its foundation in an organisational setting but as discussed in Part 2. a large part of an individual's information demand is dictated by aspects unique to each specific individual. While such organisational aspects as roles, responsibilities, and tasks may be defined by the organisational context, this only defines a baseline for the information demand of that role. Depending on the individual actually filling the role, there might also be additional constraints put on top of the initially identified demand. This of course relates to the fact that individuals differ in background, competences, experiences etc. It is therefore considered relevant, although not necessary, to analyse such aspects to further refine the understanding of information demand from an individual perspective. Figure 14. below illustrates how such individual aspects relate to selected contextual and organisational concepts. 


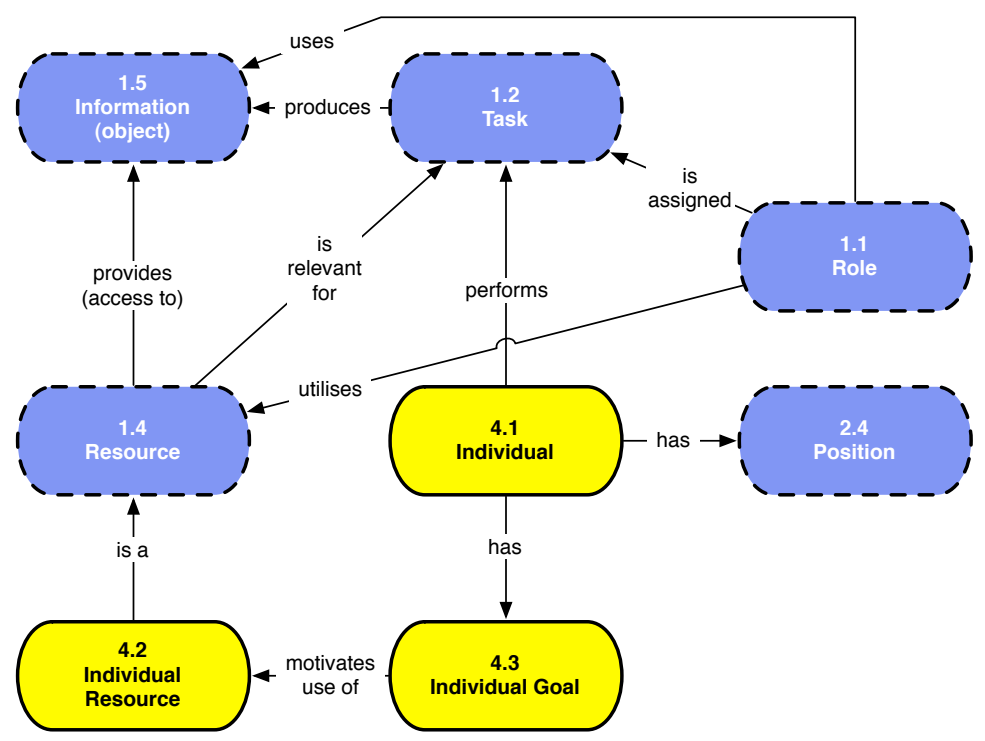

Figure 14. Individual aspects and their relationship to information demand contexts.

\subsubsection{Individual}

An individual is the actual human being having a position and thereby responsibilities, as well as performing tasks as part of the role(s) it has, within the organisation. An individual has some competence considered relevant for the position it has within an organisation. An individual might furthermore have both individual resources and-goals that it takes with it into the organisation.

\subsubsection{Individual Resource}

An individual resource is such resources an individual own and control, and for some reason might chose to utilise when performing tasks that is part of the responsibility connected to the position that individual has within the organisation. From an information demand perspective such individual resources are viewed as no different from resources provided by an organisation and is therefore considered as a subset of resources as defined in 6.1.4.

\subsubsection{Individual Goal}

While responsibilities and thereby also tasks mainly are governed by goals defined by the organisation to which an individual is connected, that individual might, as discussed in Chapter 5., also have its own personal goals for its position within the organisation, that affects the information demand connected to the tasks performed by the individual. Such individual goals might furthermore influence the choice of social networks the individual takes part in, as well as the individual resources brought into the organisation and utilised when performing tasks.

\subsection{COMPETENCE}

Competence is the quality of being physically or intellectually adequately or well qualified for a position within an organisation and the tasks connected to it, i.e. 
having the ability to do something successfully or efficiently (NOAD). The competence of an individual can therefore affect the information demand as defined by the task that individual has to perform within an organisation in terms of amount, detail, format, and presentation. That is to say, while it might be convenient to view all individuals having a role in the organisation as equal in their capabilities to perform tasks, this is not necessarily always the case. Information that might be necessary for one individual in order to perform a task might not be needed at all by another. While it might be reasonable to assume that these finer differences in information demand may not always need to be considered or analysed, it is nevertheless important to ensure that the lowest common denominator is used when deciding on demands for roles without individual consideration. Figure 15. illustrates how competence as a concept relates to select contextual, individual, and organisational aspects of information demand.

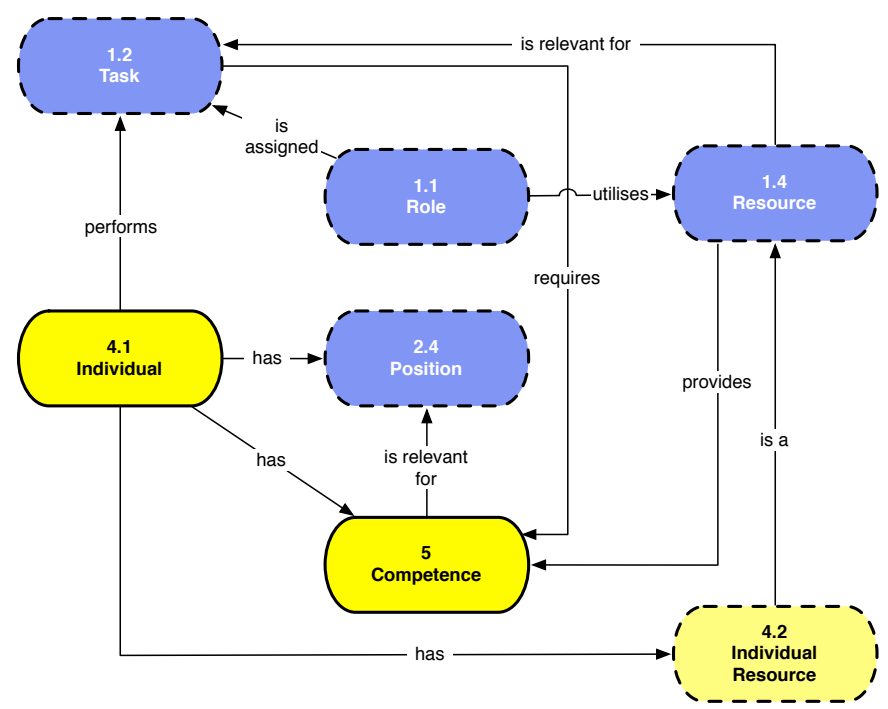

Figure 15. Conceptual relationship between competence and information demand contexts.

\subsection{SOCIAL NETWORKING}

As an extension of the idea that it is individuals that acts within organisations in terms of roles, positions, and responsibilities it is easily realised that such individuals also interact with both each other, as well as external individuals in a manner that is outside the control of the organisation. This construct is often referred to as social or informal networks (Gabriel et al. 2000) and tends to be driven by individual goals, interests, and ambitions (Gartner \& Bellamy 2008). While the organisation might not be directly responsible for such networks it may both facilitate and benefit from them, as they can be an additional channel through which individuals can retrieve information needed to perform tasks. Figure 16. illustrates the relationship between such social networks and individuals. It should however be noted that while such social networks might be present in an 
organisation they may not necessarily be possible to easily analyse. Chapter 10 . elaborates on methodological support for doing so to some extent.

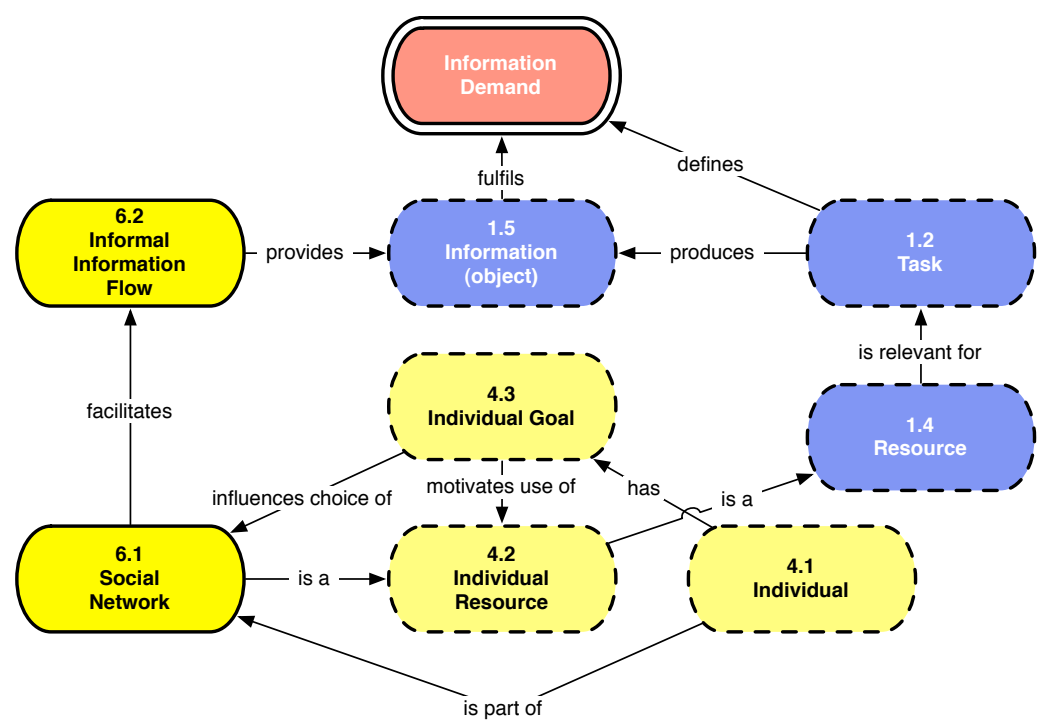

Figure 16. Informal information sources in relation to information demand contexts.

\subsubsection{Social Network}

A social network is defined as the personal or professional set of relationships between individuals, both internal and external to an organisation within which an individual has a position, who directly or indirectly interact with or influence each other. While the purpose of such a social network might not directly be purposed towards supporting the tasks performed by an individual in a specific context it might in some way contribute to doing so and may therefore be considered as an individual resource. Furthermore, such social networks might facilitate the provision of information relevant to a specific task through an informal information flow and thereby indirectly fulfil an individual's information demand.

\subsubsection{Informal Information Flow}

Informal information flow is the flow of information from, to, and between members of an organisation by means of other methods, channels, or resources than the organisation have planned, provided, or taken into consideration. Such informal information flow is mainly exchanged within different types of social networks and provides its participants with information as defined in 6.6.1.

\subsection{A CONCEPTUAL FRAMEWORK FOR INFORMATION DEMAND}

Tying these six different dimensions of information demand together reveals a rather complex topic as illustrated in Figure 17. It stands to reason that developing a method capable of analysing all these aspects of information demand would be a very difficult undertaking. As will be shown throughout Part 3. of the dissertation, this complexity is partly dealt with by relying on existing knowledge and partly on 
taking a component-based approach to method development. However, the most important reduction of the inherent complexity lies not in the way the method is contrived, but rather in the compartmentalisation of the conceptual underpinning just presented.

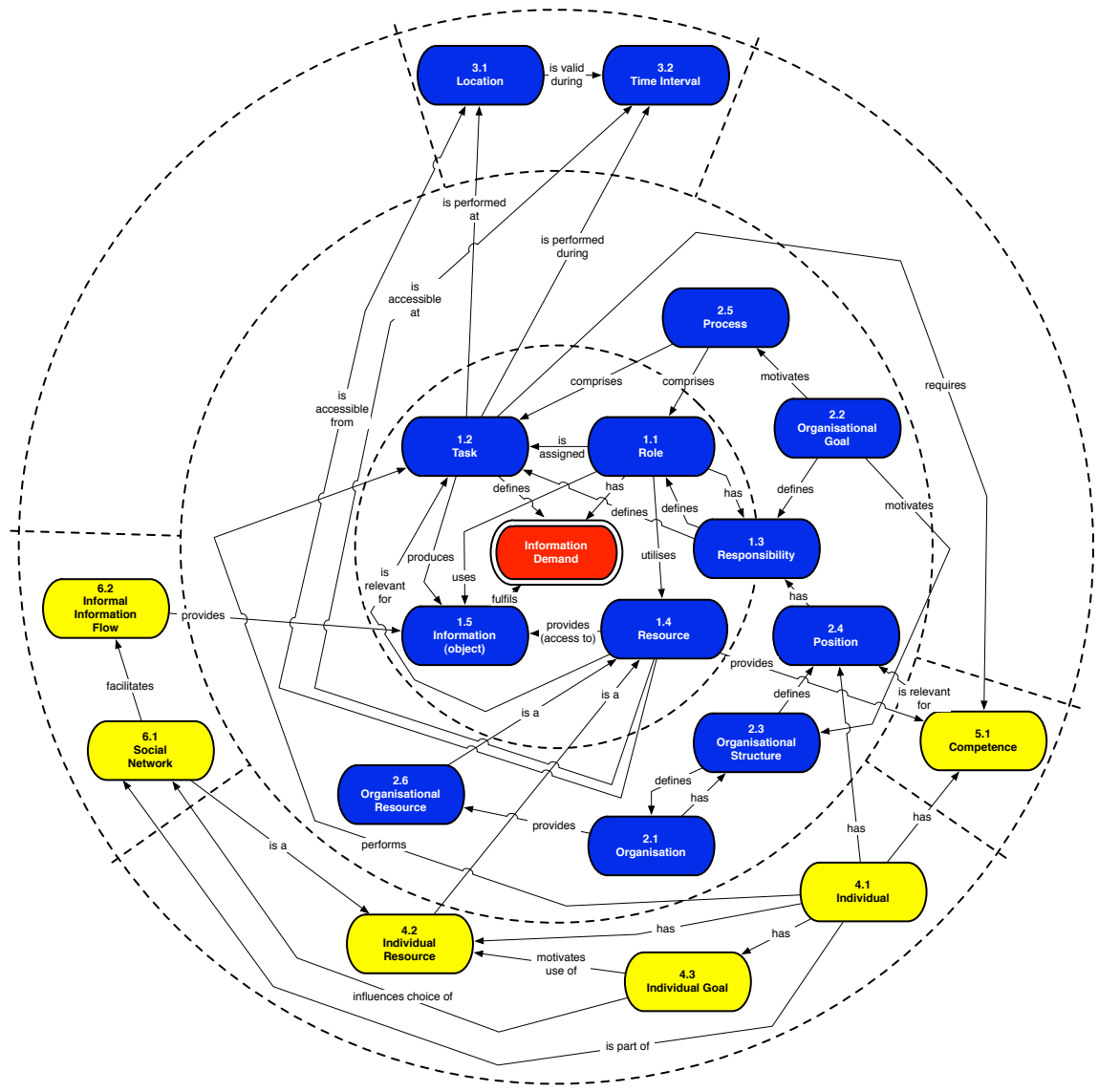

Figure 17. A complete conceptual framework for information demand.

By starting with information demand contexts that then, depending on the requirements of the given problem-situation, can be refined based on the situational needs, this conceptual framework allows for the development of highly flexible and extensible methods. The various layers and partitions of the graph presented in Figure 17. merits additional explanation with respect to the implications they have on the method as well as its design and use. Such an explanation will be given in Chapter 10. once a methodological background and -framework for information demand have been given. 
PART 3 - A METHODOLOGICAL FRAMEWORK FOR ANALYSING INFORMATION DEMAND

This part details the theoretical and empirical efforts spent on answering RQ2. by defining, developing, and validating a methodological framework for information demand analysis based on the conclusions regarding information demand drawn in Part 2. It also covers the notion of method used throughout the dissertation. 
This page is intentionally left blank. 


\section{METHOD THEORY}

The previous chapter covered the conceptual foundation on which the development of a method for information demand modelling and -analysis, as detailed throughout this dissertation, rests. This conceptual foundation makes a number of claims regarding the nature of information demand that allows one to think and reason about information demand, as well as how such demands relate to various individual and organisational aspects of enterprises. However, a conceptual framework such as this has no immediate practical applicability in terms of how to actually identify and capture information demand. It merely is the foundation on which various procedures and notation have to rest. That is to say, the conceptualisation previously presented, only focuses on what information demand is about and says nothing about how one should go about to actually analyse it. To support such efforts a more comprehensive set of procedural guidelines, notations, and principles is needed. This chapter is about such underlying methodological aspects, necessary for the development of an information demand analysis method that will be presented in Chapter 10. However, a number of assumptions and clarifications regarding methods and methodologies in general must first be clarified.

\subsection{WHAT IS A METHOD AND WHY IS IT NEEDED?}

Terms like technique, approach, procedure, framework, method/methodology, and paradigm are used in many different aspects of daily life and in literature but unfortunately rarely so in a consistent manner. In fact, quite the opposite is true with numerous different meanings and definitions as a result. Questions such as "what is a method?" and "what is a method made up by?" can therefore be answered in many different ways. While this chapter intends to cover some of those answers by giving an overview of methods in general it should here be noted that as both the author as well as the area of information demand has its background in IS-research, it is only natural that the view taken on methods here is heavily inspired by the traditions in that field. Furthermore, as the terminology within the field suffers from inconsistency and ambiguity some conceptual clarification of how the author views the area is needed before continuing on defining methods

\subsubsection{Method vs. Methodology}

The confusion, or perhaps rather the interchangeability, between the two terms is today increasingly common. While the word - methodology - in its original Greek meaning means - the study of systematic methods of scientific research - it has 
unfortunately become more or less synonymous with method during the last 25 years. In fact, it has recently also been used as a fancier replacement for such diverse terms as techniques, procedures, and models. Even though this pragmatic use is well established in the computer science area in general and in information system development in particular, it nevertheless introduces some difficulties with respect to the research presented here and thus warrants further discussion.

As this dissertation focuses on the development of a method and therefore by definition is about methodology in the term's original meaning, the author has decided to distinguish between methodology and method. Consequently, when the term methodology is used in this dissertation, it is to denote the meta-aspects of methods, i.e. the study, comparison, development, and refinement of new or existing methods. On the other hand, when the term method is used it is to refer to the results of such methodological efforts.

\subsubsection{Method vs. Framework}

To make matters worse both method and methodology as terms are often used instead of the term framework. While framework does have its place in the nomenclature of methodology and indeed is about structuring thoughts (Jayaratna 1994), it is more a static model describing the interrelationships between various parts of a method. As it will be shown later in this chapter, framework is what interconnects the various notations, concepts, and procedures thus making it a meta-structure for the method to which it belongs. A framework in the sense as discussed here shall however not be confused with a conceptual framework like the one covered in Chapter 6. A conceptual framework is more about on what methodological focus is put while a methodological framework focuses more on sequence of thoughts and action (Jayaratna 1994).

\subsubsection{Method vs. Technique}

Just as with framework above, method as a term is sometimes used to describe what really should be considered a technique. This term does relate to methods in the sense that it tends to be a crucial part of methods but it does not constitute a method by itself. A technique is a well-defined sequence of elementary operations with the clearly stated purpose of achieving a specific result when executed fully and correctly (Iivari et al. 2001). While this at a first glance might sound confusingly similar to a method, the difference lies mainly in, as will be shown in the next section, the focus on how and in what order to perform actions, and not why.

\subsubsection{What Then, is a Method?}

It is both a simple and highly relevant question but also one that is not easily answered due to the previously mentioned ambiguous uses of the term. In this section a number of different views on method as a concept are presented and discussed as an background to the notion of method, presented in the end of this chapter, and on which the method for information demand analysis, presented in Chapter 10. rests.

First, let us start of by putting method on the conceptual map. Checkland (1981) describes method (actually methodology as a synonym for method) as the concep- 
tual interrelationship between a philosophy or school of thought and technique in the following way:

A method will lack the precision of a technique but will be a firmer guide to action than a philosophy. Where a technique tells you 'how' and a philosophy tells you 'what' a method will contain elements of both 'what' and 'how'

(Checkland 1981)

The view on philosophy taken by Checkland is by no means unproblematic as it is meant more in the general sense rather than the professional or academic meaning of the word. However, if Checkland's definition of philosophy is viewed as something providing us with a consistent set of beliefs for understanding and actions, it basically translates into the term paradigm in the sense of 'school of thought'. That is to say, a methodology, and from it resulting methods, are based on a consistent value system that guides not only the intentions behind method development but also the various subparts of the method (Iivari et al. 2001). Thus, a method differs from regular human behaviour in the sense that it has a purpose and a specific nature. This view on methods is further supported (once again, from a computer science perspective) by Avison and Wood-Harper (1990) that, building on Checkland, concluded that a method is:

a coherent collection of concepts, beliefs, values, and principles supported by resources to help problem-solving groups to perceive, generate, asses and carry out, in a non-random way, changes to an information situation.

(Avison \& Wood-Harper 1990)

Of particular interest here, is the use of the word coherent because without coherence there is no reason for the particular concepts, beliefs, values, and principles to be grouped together. Thus, it is implied that the method has to be coherent with respect to something, this something is the problem solving also covered in the definition. Implied are also the practical aspects of problem solving. In order for a method to actually help in the solving of problems, it has to provide support for or instructions on how to do so. Consequently, it would be reasonable to argue that a method can be viewed as a goal-directed way of solving problems by the use of various techniques and procedures in a specified problem-domain guided by a set of beliefs, values, and principles or to put it differently:

an explicit way of structuring one's thinking and actions. Methodologies(!) contain model(s) and reflect particular perspectives of 'reality' based on a set of philosophical paradigms. A methodology should tell you 'what' steps to take and 'how' to perform those steps but most importantly the reasons 'why' those steps should be taken, in that particular order.

(Jayaratna, 1994)

\subsection{METHOD FOCUS AND PURPOSE}

Expressed by the text above is that a method has a specific focus and purpose. A method is for solving a specific set of problems, or as it is put above, it exists in $a$ specified problem-domain. In the case of the method discussed in this dissertation, that problem-domain is, as should be clear by now, information demand modelling and -analysis. This however, does not really say anything about what type of problems, found in the problem-domain, the method needs to be able to solve. 
Based on the content of Chapter 4., 5, and 6. it can be concluded that much of the challenges with identifying and representing information demand really are about finding a way to capture knowledge in a way that communicates the structure, behaviour, and organisation of an enterprise and its individual parts. Luckily, there just so happens to be a whole area that deals with this subject, Enterprise Modelling $(E M)$, a term that thus far has been used repeatedly throughout the dissertation without much of an explanation.

While most readers of this text is assumed to be, at least somewhat, familiar with the role modelling plays in areas such as information systems or business improvement and-reengineering, it is nevertheless important to clearly define how the term enterprise modelling is used here. Not only because an understanding of the term itself is needed, but also because the method for information demand analysis, that will be developed in accordance to the ideas expressed in the rest of this chapter, for all intents and purposes will be a method for performing EM.

\subsubsection{Enterprise Modelling}

As with so much else covered in this thesis, enterprise modelling as a concept can refer to a number of things but in a general sense it means producing descriptions, of various aspects of an enterprise, i.e. organisational structures, processes, business rules, goals, concepts and information etc., expressed in some type of modelling notation (Persson \& Stirna 2002). More formally, this is viewed as EM being the externalisation of such knowledge about an enterprise that brings value to said enterprise (Vernadat 2002). Having such knowledge in an externalised form is considered a prerequisite for all forms of Enterprise Integration (Vernadat 2002) and re-engineering or improvement of an enterprise (Whitman \& Huff 1997), i.e. enterprise models is a help for managers to further develop the organisation and/or solve organisational problems (Sandkuhl 2014)

The last 25 years or so have seen the birth of a large amount of different methods, frameworks, notations, and techniques for $E M$ being developed, all with their own claims on being the answer to (parts of) common business- and organisational issues. If one studies some of these existing approaches one will quickly realise that the term enterprise modelling often has to be used in a very general sense as there is a wide variety in focus and scope between different approaches. Some tend to be very specialised and oriented towards specific aspects of organisations, such as process flows or business rules. Others have a much broader focus, also including organisational aspects such as goals, concepts, organisational structure etc. and yet others try to be a general framework for capturing all aspects of an enterprise, both organisational and technical. A common distinction between these different levels of enterprise models are (Schuster 2005):

- Enterprise Modelling Languages - such as Business Process Management Notation (BPMN), Property Specification Language (PSL), Unified Enterprise Modelling Language (UEML) to mention just a few. These languages are often also referred to as modelling notations.

- Enterprise Frameworks and Architectures - such as The Zachman Framework for Enterprise Architecture, GERAM, Architecture of Integrated Information Systems (ARIS), TOGAF etc. 
- Enterprise Modelling Methods and Procedures - such as ARIS, Enterprise Knowledge Development (EKD), Extended Enterprise Development and Operations (EEDO), For Enterprise Modelling (4EM) etc.

The list could be made much longer and more detailed than what would be practically feasible for the purposes of this dissertation but from a pragmatic perspective, enterprise modelling is a highly useful tool for supporting an organisation with the analysis and design of its functions, as a foundation for discussion and communication, and as a facilitator of control and governance (Whitman \& Huff 1997).

Relating the concept of $E M$ to the topic of this dissertation, it is quite apparent that the methodological support needed is wider in scope than what can be solved by a mere notation, although one most certainly will be needed as well. It is also apparent that there is no real need for trying to describe and relate every aspect of an enterprise as Chapter 6. already defined the concepts a method for information demand analysis need to handle. Thusly, what really is needed is one or more method construct for capturing and representing the different aspects of information demand detailed in Figure 17. which can be utilised when performing information demand analysis. Furthermore, as many approaches to $E M$ have a background as a tool to support enterprise integration and re-engineering many of them also focus specifically on processes- and value-flows as well as the information and resources needed for supporting such flows. Having such a clear focus on processes and information is indeed both useful and relevant when working with business development and improvement, but it is however not the best view from an information demand perspective. In a process-oriented approach everything in an enterprise is related to the value-creating sequences of activities, i.e. business rules are said to implement business goals by steering activities, information is used to support performance of activities, and activities are performed by roles and so on. As detailed in previous chapters the focus, when it comes to information demand analysis, has to be on the individual or role as this is the entity having an information demand. Consequently, a process-oriented approach would not be sufficient, as this would not allow for the relevant grouping of concepts. The same is true for information modelling-approaches as most of them focus solely on the information objects, their attributes, and transformations but express nothing about their relationships to roles and activities. That is not to say that process- or information modelling have no purpose for information demand analysis, it most certainly does, just not for the core concepts needed to be represented during the identification of information demand contexts.

Given the background above, the method for information demand analysis presented here really is an enterprise modelling approach that include a new perspective on enterprises but that still need to be able to express the more traditional aspects of enterprises as well. That is to say, the method will have to support a number or different perspectives on an enterprise and therefore have to include constructs for describing such perspectives. Consequently, the method needs to be designed in a way that allows for the combination of newly developed constructs as well as utilising constructs from existing methods, i.e., it needs a method notion that support such a combination of parts from different methods. 


\subsection{METHOD NOTION}

Considering the conceptual background and the general view on method presented so far, it is finally relevant to start talking about how a method for information demand modelling should be constructed in terms of its structure and inherent parts. However, in order to actually develop a method some additional theoretical support is needed with respect to these aspects. A clear and unambiguous notion of method must be chosen, or if one prefers, a meta-model describing the method's various parts and their interrelationships has to be defined. Such a meta-model is not only a prerequisite for method development but also, as will be shown in Section 7.3.3. facilitates and improves the developed method in terms of flexibility and adaptation.

\subsection{1 (Philosophical) Perspective}

As pointed out by Checkland (1981), Avison \& Wood-Harper (1990) as well as Jayaratna (1994) a method is defined based on some philosophical paradigm or value-base, and therefore constitute a certain perspective or view, taken on the world. The consequence of taking such a view on the reality in which the method will act is quite naturally that the resulting method will make certain assumptions regarding goals, results, and outcomes, as well as a preferred approach to reach them. The perspective taken in a method is not just a theoretical construct guiding the methodological work, it is also reflected in the various parts of the method itself. That is to say, techniques, conceptual focus, procedures etc. are all heavily influenced by the implications following from the philosophical perspective taken. This is however not to say that a method has to include explicitly expressed perspectives but rather that such perspectives are seamlessly incorporated into the method in the form of choices made based on underlying values (Goldkuhl et al. 1998). Furthermore, the perspective is also made apparent in form of the conceptual underpinning of the method, i.e. the concepts on which the method focusses and acts upon is partly a result of what is considered important in the method from a philosophical point-of-view. In the case of the method presented in this dissertation its perspective is the focus on the identification, representation, and analysis of information demand in a way that incorporates the knowledge and experience of individuals acting within the investigated organisation.

\subsubsection{Cooperation and Collection Principles}

As illustrated in Figure 18. below (Goldkuhl et al. 1998) a set of principles describes the form in which knowledge is acquired during the use of the method. While, as will be shown later in this chapter, knowledge is gained as a result of performing various procedures as part of method components, those procedures focus on how to perform certain tasks or what questions to ask. Cooperation and collection principles focus more on how and by whom the questions are asked as well as by whom they are answered. Such choices are quite obviously made based on the overall perspective of the method. This does however not necessarily mean that such principles have to be completely separated from the various procedures. In fact, for the method presented in this dissertation, which will be shown in Chapter 10., these principles are but in a few general cases incorporated into the defined procedures. Because of this choice, not much focus will be put on cooperation and collection principles as a separate area of the method. Instead such aspects will as far as possible be incorporated into the method's principles and the various method components. An example of such a principle that is incorporated 
into the method's various components is the participative property of how the modelling sessions are performed. That is, the fact that the method has a perspective declaring the importance of knowledge about information demand in an organisation being gained by asking the individuals within that organisation, is reflected by the principle of participative modelling.

\subsubsection{Method Framework}

If the methodological perspective is about what is considered important in the method, then the framework is more about how the various method components interrelate in order to best achieve the intended goals expressed implicitly or explicitly in the method. A framework can therefore be seen as a pattern for when to apply method components and how method components are interrelated with a specific purpose in mind (Lind \& Seigerroth 1997). Thus, the framework realises the perspective by defining a sequence of activities with expected results fulfilling goals, generated by one or more method component.

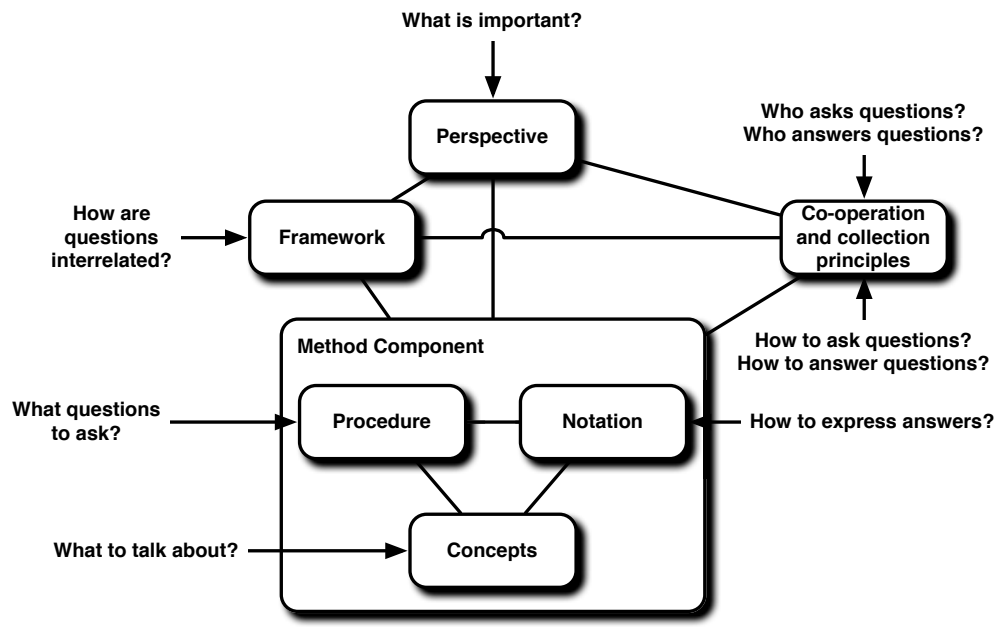

Figure 18. Parts of a method and their interrelationships. (Goldkuhl et al. 1998).

What a framework is and how it can be structured, is best exemplified by the framework defined in the method for $I D A$. It defines a process for $I D A$, it defines the various activities in that process in terms of prerequisites and expected results as well as which method component to use. Chapter 10.2. details the method's framework

\subsubsection{Method Components}

Having a goal with performing a certain sequence of task does not constitute a method in itself. In order for the method to actually support the undertaking of problem-solving in a certain domain, there is also a need for instructions on how to perform the necessary activities, on what these activities shall focus, as well as how the results from these activities should be documented in order to contribute to the expectations defined by the method's framework. Depending on the preferred methodological view on methods, this can be solved in a number of different ways. 
In the method notion chosen for this research, a component-based view has been considered beneficial for reasons that will be clarified throughout the rest of this chapter as well as in Chapter 11. While a method might include an arbitrary number of components, they all share the same internal structure, all with the purpose of contributing to the integrated results expected by the method's framework. Three interrelated parts; procedures, notations, and a conceptual focus therefore make up each method component (Goldkuhl et al. 1998).

An example of such a component is the one for information demand context modelling (presented in Chapter 10.) that defines how such contexts should be modelled, what focus should be on during modelling as well as a notation for documenting models of information demand contexts.

\subsubsection{Procedures}

A procedure is the set of sequenced work steps to be performed in order to achieve a specific effect or result. The degree to which this sequence is specified and why, is defined by the framework in terms of expected results expressed either explicitly or implicitly. If a knowledge generating view is taken on methods, procedures can be viewed as the set of questions to ask in order to gained the wanted or needed knowledge about the world.

\subsubsection{Notations}

The results from this question-asking process that constitutes the procedural part of a method component obviously have to be documented and/or represented in some way in order for the component to have any purpose from a framework-perspective. The notation part of a component details how this shall be done by setting rules for how answers should be documented. An example of a notation can be found in Figure 32.

\subsubsection{Concepts}

The concepts are both the focal area for the procedures, i.e. the part of the problemdomain the procedure concentrate on and the terminology in which the results will be expressed, and thusly interconnects the procedures and the notations within each method component. Practically, this means that there has to be a connection between the conceptual focus of a methods various components and the conceptual framework presented in Chapter 6. Chapter 11. discusses the intended method with respect to this relationship in detail.

\subsection{METHOD FLEXIBILITY AND ADAPTATION}

While formalised methods and rigid frameworks have an important place within many different research and application areas, it has become increasingly clear during recent years that such methods might not always be suitable in their entirety in a given context. Criticism to blind faith in methods and method-ism has been voiced from several directions on several different levels (Introna \& Whitley 1997, Russo \& Stolterman 2000). As illustrated in the area of software and system development where there is a variety of different methods available, it still has proven hard to get universal acceptance for one or a couple of methods. Despite the efforts of both industrial and governmental standards and certification bodies (Fitzgerald 1994), there is a low general acceptance for formalised methods in the 
industry (Russo \& Stolterman 2000). While the exact nature of this low acceptance is not completely elucidated, it is believed that formalised methods in general, are considered improperly matched against the actual industrial needs in terms of flexibility and adaptability (Stolterman \& Russo 1997). Furthermore, it is a historical fact that many methods in the computer science area have focused more on technical aspects than on organisational needs, thus ended up restricting rather than supporting creativity, context, and intuition (Fitzgerald 1994, Introna \& Whitley 1997). Consequently, it comes as no surprise when many software designers report some level of adaptation of existing methods to better fit the current situation (Stolterman 1992, Hardy et al. 1995), if they chose to use methods at all, that is (Hidding 1996). Without penetrating deeper into the underlying faulty assumptions of methods causing this apparent mismatch, it can be concluded that when developing methods, it makes sense to add a certain degree of flexibility and adaptation by design rather than trying to construct monolithic, all-comprising methods.

Many different approaches have been suggested to make methods situational sensitive, adaptable, and even extendible. Having a well-defined meta-model as described above is obviously a first step towards this goal because without it, it is hard to reason about the method at all, but it is by no means enough. Method engineering has been suggested as an approach to build better, more flexible methods (Brinkkemper 1995). It was suggested as an engineering discipline to design, construct, and adapt methods, techniques, and tools for the development of information systems. The idea behind the field was to introduce situational methods based on method components or -fragments that can be combined into a method suitable for a specific problem or project. It was believed that a standardised view on methods would lead to a harmonisation and reduction of what was referred to as the methodology jungle (Harmsen \& Brinkkemper 1994) but also improve the flexibility of existing methods. Time has unfortunately proven that this line of research has not had the wanted effects. However, the idea of situational methods and component-based view on methods based on meta-models has lived on and has relevance for the research discussed here. This shows mainly in how the method have been developed in relation to existing methods as well as industrial needs and requirements (see Chapter 8. and 9.).

\subsubsection{Situational Method Engineering}

There are generally speaking, three different approaches to construct situational adapted methods, a component-based approach, a repository approach combining method chunks or -fragments depending on the current needs, and integration of existing methods in to new methods (Harmsen \& Brinkkemper 1994, Brinkkemper 1995, Ralyté \& Rolland 2001, Henderson-Sellers et al. 2014). The common foundation they all need in order to work is as already mentioned, a well-defined meta-model describing the various parts of the method. The view taken on methods in this dissertation actually relies on all three approaches to some extent. By now, it should be obvious that the notion of methods presented in this chapter is a component-based one. The reason behind this methodological choice is due to the compartmentalised nature of information demand and the context in which such demands are found, as was detailed in Chapter 6. Method components with its combination of procedures, notations, and concepts are by the author considered to be more effective in focusing on a complex problem-area than the alternatives. 
Method fragments or -chunks have proven to have a tendency to lack in coverage and holistic view as well as being hard to integrate with each other, as they require a quite extensive framework for being assembled and combined into actual methods (Mirabel \& Ralyté 2006). The idea of method fragments is however appealing to the author as it does allow for parts of existing methods to be broken out and integrated into the method being developed here. The difference between this approach and a truly situational-driven repository approach is that it is done at the method design stage rather than during actually use of the method. Thusly, when a need arises, parts of existing methods can be used in the method for IDA by being made into method components. As the notion of method used here has a framework that guides the integration and use of components to ensure the realisation of the underlying principles, such new components can easily be integrated into the method. In addition, the framework, if correctly defined, helps in evaluating existing methods with respect to parts that could be considered relevant for the method covered here. An example of this will be shown in Section 8.3. where the enterprise modelling method $E K D$ was used in an evaluation case in order to deduce its suitability for deriving the organisational parts of information demand. 


\section{METHOD DEVELOPMENT \& INITIAL METHOD HYPOTHESIS}

Considering how the research presented in this dissertation has been conducted, as a sequence of separate and distinctly different research activities guided by an overall goal, the method development has been highly incremental in nature. Furthermore, while the various research activities may be presented here in a strict sequential and structured order, this does not necessarily reflect the order in which they actually were performed. As discussed in Chapter 2., this incremental aspect of the method development also requires that the emerging method's various parts are continuously evaluated in a real-life setting to ensure the method's scientific and industrial soundness and applicability. The constant switching between generatingand validating activities that has been done during the development process also means that the method development has been highly iterative in nature. To communicate and reflect this in the best possible way, this chapter focus on how the method initially was constructed and how its core constructs were empirically grounded. Chapter 9. then builds on this by focusing on how the method was refined with respect to the conclusions gained from the empirical grounding, as well as on how the refined method was additionally validated. Finally, Chapter 10. presents a revised and more extensive version of the method hypothesis.

Based on the theoretical and empirical foundation of information demand, presented in Part 2., it was clear to the author that information demand contexts are a crucial aspect of information demand analysis. Furthermore, as there are many different methods for analysing most aspects of information demand but no such method exists for analysing said context aspects, it made sense to focus the initial method development efforts on this area. Consequently, the method development was initiated by means of two main activities in order to create a starting point for continued development efforts:

1. a method framework and a method component for modelling information demand contexts were defined as a purely theoretical exercise. This was done mainly in order to generate the methodological understanding necessary for evaluating existing method for analysing and enterprise aspects of information demand. 
2. two different types of methods for analysing organisational aspects of information demand were evaluated with respect to their suitability for providing the modelling of information demand context with relevant understanding of the analysed organisations.

In addition to these two main activities work was also initiated on a method handbook. The purpose of the handbook was to document and communicate usageoriented aspects of the method being developed rather than focusing on the scientific dittos that are covered in this dissertation. As the handbook is intended mainly for individuals wanting to use the method in an industrial setting without having to read a dissertation in order to understand how to, it will however not be discussed further here.

\subsection{INITIAL METHOD DRAFT}

As previously detailed, analysing $I D$-contexts is really a question of understanding which role needs what information to perform what task. Such understanding can either be gained by analysing and modelling an organisation or by utilising existing models. Considering this in conjunction with the selected notion of method presented in Chapter 7., the author concluded that development of the initial version of the method meant focusing on the order of analysis-related activities and the prerequisites and results from such activities (the method's framework) as well as notations and procedures used for analysing context-aspects of information demand (the method component).

The framework had to reflect how one would go about to create the necessary organisational understanding by combining a series of activities in order to generate a predefined result. The initial framework created, as illustrated in Figure 19. below, was quite simplistic but did specify the main activity ID-context modelling together with the prerequisite of having a defined Scope \& Schedule as well as the defined end-result of information demand context models. To help creating such models a single method component for information demand context modelling was defined.

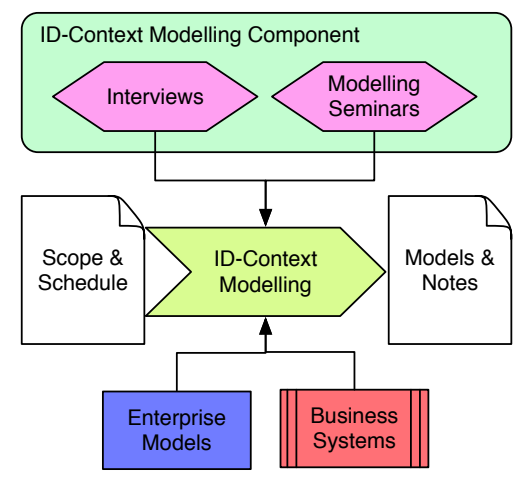

Figure 19. The initial version of the method framework.

The method component defined two different procedures, interviews and modelling seminars without further detailing how these procedures would best be performed as this was not considered necessary at this stage of the method development. While 
the conceptual focus (see Figure 11. for the method component was given by the results presented in Part 2., the notation necessary for modelling information demand contexts was not. Consequently, a first version of a modelling notation was created as illustrated in Figure 20. below.
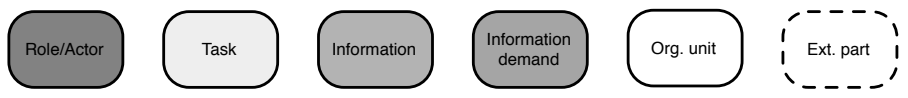

Figure 20. The initial version of a notation for modelling information demand contexts.

While there was a need for a construct allowing the different notational elements to be interrelated, no special consideration to the requirements on such relationships was given at this stage. Instead the elements were meant to be interrelated by means of simple associations denoted by a line.

\subsection{EMPIRICAL EVALUATION OF APPROACHES TO MODELLING OF ORGANISATIONAL ASPECTS OF INFORMATION DEMAND}

Once the, admittedly simple, initial draft of the framework and the method component was defined, focus was shifted on to how existing methods for enterprise modelling could be utilised in the process of information demand analysis. As enterprise models, throughout the research, have been considered to be both a source from which context-related information can be extracted, as well as a way to gain additional organisational understanding, the author needed to evaluate methods for producing such models in order to assess their suitability for the intended purpose. To do so, two empirical cases was defined together with industrial partners with the intention of solving real-life problems by means of utilising two different methods for enterprise modelling.

\subsubsection{Case A: Knowledge Sharing through an Intranet Portal}

One of the partners, SYSteam Management (today part of the Swedish-Norwegian consulting firm Evry), wished to establish an intranet portal that would support effective collaboration among its employees as well as capturing and sharing inhouse knowledge, best practices, and information concerning its core business management consulting. The main emphasis for such a portal should be on consolidating various existing information artefacts and their sources. Additional information about the case can be found in Lundqvist et al. (2008a).

\subsubsection{Actors Involved}

The case was performed with a somewhat smaller number of organisational representatives than what might typically be the case for such a project but this was due to the fact that the case was performed together with our main industrial partner and therefore was just as much about exchanging methodological experiences as it was about the actual results. The following roles attended the modelling seminars: 
- Three representatives from the organisation

- Head of department

○ The "problem owner"

$\circ$ An intended end-user

- Three representatives from the research group

- A modelling facilitator

- A method expert

- A supervisor

It is usually not a good idea to be as many modelling experts as there are informants during sessions as this might have an intimidating effect on the individuals supposed to provide the experts with information. However, in this particular case this was not considered a problem due to the informants' involvement in the project.

\subsubsection{Work Approach}

The test case was divided into three main phases - preparation, participative modelling seminars, and reporting.

The preparation phase consisted of analysis and discussion of the project background and the possible case scenario. After that, the method experts analysed the partners' objectives with respect to the project objectives and prepared a framework for interviewing the domain experts. The main purpose of the interviews was to gain sufficient background information about the situation at the organisation, based on which the method experts then prepared a plan for the modelling seminar. The interviews led to the conclusion that the main issues to be addressed at the modelling seminar were: what should be included in the portal, what should be its main functionality, and what are the expectations of its users. In summary, the modelling was to address the future state of the existing employee portal on a conceptual level, not focusing at all on the implementation.

Considering the overall objective of the research project detailed here and the nature and focus of the case (see Figure 21. ) it was considered to be a suitable case for evaluating methods for analysing traditional enterprise modelling aspects of organisations. As members in the research group had previously been involved in the development of the $E K D$-method, it was decided that this method should be used.

The modelling phase consisted of three participative modelling seminars that followed an initial structure (see Figure 21. ) focusing on relevant issues that were uncovered during the preparation phase. As detailed in the figure, these questions mainly focus on traditional enterprise aspects such as information, processes, roles, goals, and problems rather than information demand but as detailed in Chapter 3 . such aspects of an organisation are highly relevant also when analysing information demand. 
Goals:

Why do we need a portal?

How does the portal contribute to SYSteam's business plan and business strategy?

\section{Problems:}

What hinders the achievement of goals?
Processes and Roles:

How will we use the portal?

Who will use the portal?

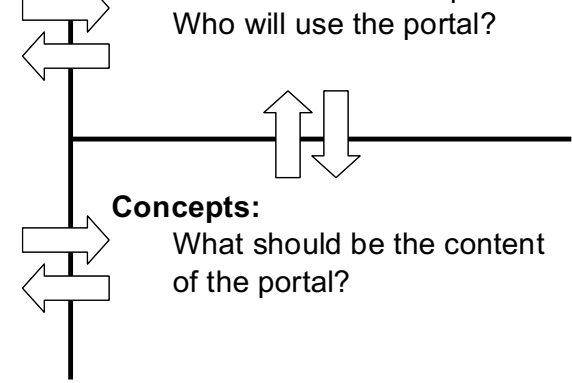

Figure 21. Overall structure of analysis.

\subsection{Modelling Seminar 1 - Modelling Business Goals and Concepts}

Modelling seminar 1. took place in the partner's head office. The main objective during this first seminar was to model goals, problems, and concepts in relation to the portal and consequently two models were created; a goal model and a concept model.

With respect to the objectives of the case the most relevant goals concerning the collaboration aspect of the portal was the following goal - collaborate with others within the enterprise - which requires, the ability to work in a distributed organisation (e.g. in different locations and in different companies/subsidiaries). At the time the case was performed, this was impeded by the fact that information was spread out throughout the company. To better support this it was concluded that a collaboration platform should be established, more specifically to:

- create better collaboration possibilities

- allow working from different locations

- support synchronous communication

- create an experience base to be used in new cases

- create a structured way of reusing experiences

- facilitate the ability to find information about earlier projects

- find products

- provide an easy way of finding templates

- allow reusing of work processes and practices

- be able to subscribe to areas in the portal according to personal preferences

- allow subscription to updates

- be able to manage various security levels 
Concerning the knowledge/information aspect of the portal, the model reflects the wish to improve the current situation of insufficiently structured information and the ambition to minimise unstructured distribution of documents, for instance, via email. Furthermore, there was an expressed need for being able to locate up-to-date information about customers and projects as well as customer development. At the same time, the portal should also contribute to quality improvements of deliverables, easier introduction of new employees, and minimising the organisational dependence on a particular employee.

The envisioned content of the portal was addressed in a concept model and the following key business concepts were identified:

- Customer information

- Project/assignment

- Business ratio

- Offer

- Information objects, which include:

○ Reports

○ Articles

- Externally located sources

○ Suggestions about books or courses

○ Notice board

○ Project documentation

- Training material

\subsection{Modelling Seminars 2 and 3 - Business Process Modelling}

Modelling seminar 2. also took place at the partner's office while modelling seminar 3. took place at Jönköping University. Modelling seminar 2. began with a walkthrough and refinement of the results of modelling seminar 1. After the walkthrough focus were switched to the objective of modelling seminar 2. - to model an example business process, which would show how different organisational actors use information objects at different stages of the process. The reasoning behind this was that this would further facilitate identification of possible portal content. This part of the seminar started with identifying a number of relevant processes that could be modelled for this purpose:

- Delivery process

- Sales process

- Customer development process

- Marketing process 
- Competence development process

- Business concept development process

- Management process

- Procurement process

In the end the choice fell on modelling the delivery process, which consisted of four main stages (sub-processes):

- Process 1: Planning of project/assignment

- Process 2: Carry out project/assignment

- Process 3: Delivery of project/assignment

- Process 4: Completion of project/assignments

Modelling seminar 2. focused on modelling processes 1 and 2 while modelling seminar 3. focused on modelling processes 3 and 4 and the overall refinement of the complete enterprise model.

The process model resulted in a number of sub-processes (or activities), roles that are involved in these activities, and information sets needed for performing efficient project planning. The information sets would consequently have to be represented in the portal in order to support efficient work and delivery of the project.

\subsubsection{Implications for the Continued Method Refinement}

The case did not only provide an example of the need to support people with knowledge and information at the right time and at the right place in relation to the performance of work tasks, it also constituted an opportunity to use a method for modelling and analysing organisational aspects of information demand. As the focus mainly was on evaluation of procedures and notation no real effort was put on elaborating the models themselves. They would therefore have to be substantially elaborated and refined in order to serve as a formal requirements specification for the development of the actual portal. However, since the main purpose of this case was to evaluate the $E K D$-approach in a real-life case of information demand analysis the case was considered both successful and useful as EKD turned out to be very suitable for modelling organisational aspects of information demand (see concepts 6.2.1. through 6.2.6. in Chapter 6.) as well as supporting the current version of the conceptual framework. Concerning analysis of information demand, it could also be concluded that already from only analysing the organisational aspects it was possible to make initial statements about information demand. As an example of this the model in Figure 22. (excerpt from a larger model produced during one of the seminars) illustrates that the role Project Manager needs to have access to information sets 1-16 to perform project planning (process 1.1). Furthermore, it was also confirmed that much of the philosophical perspective being the basis for the developed method is shared by EKD in terms of generating knowledge using participative approaches. The case clearly proved that this participative take on modelling works well for the intended purposes as the necessary organisational knowledge was generated to a satisfying degree with a 
relatively small amount of effort. Secondly, the conceptual foundation used in $E K D$ is in many aspects identical to the one used here. As shown in Figure 33. EKDs concepts and their interrelationships correspond well to the conceptual focus for modelling of enterprise aspects of information demand illustrated in Figure 12. While $E K D$ may be a method with a much broader scope than needed or intended here, it can, if the methodological focus is limited to what is listed in Section 6.2. be very well suited for incorporation into the method as a method component.

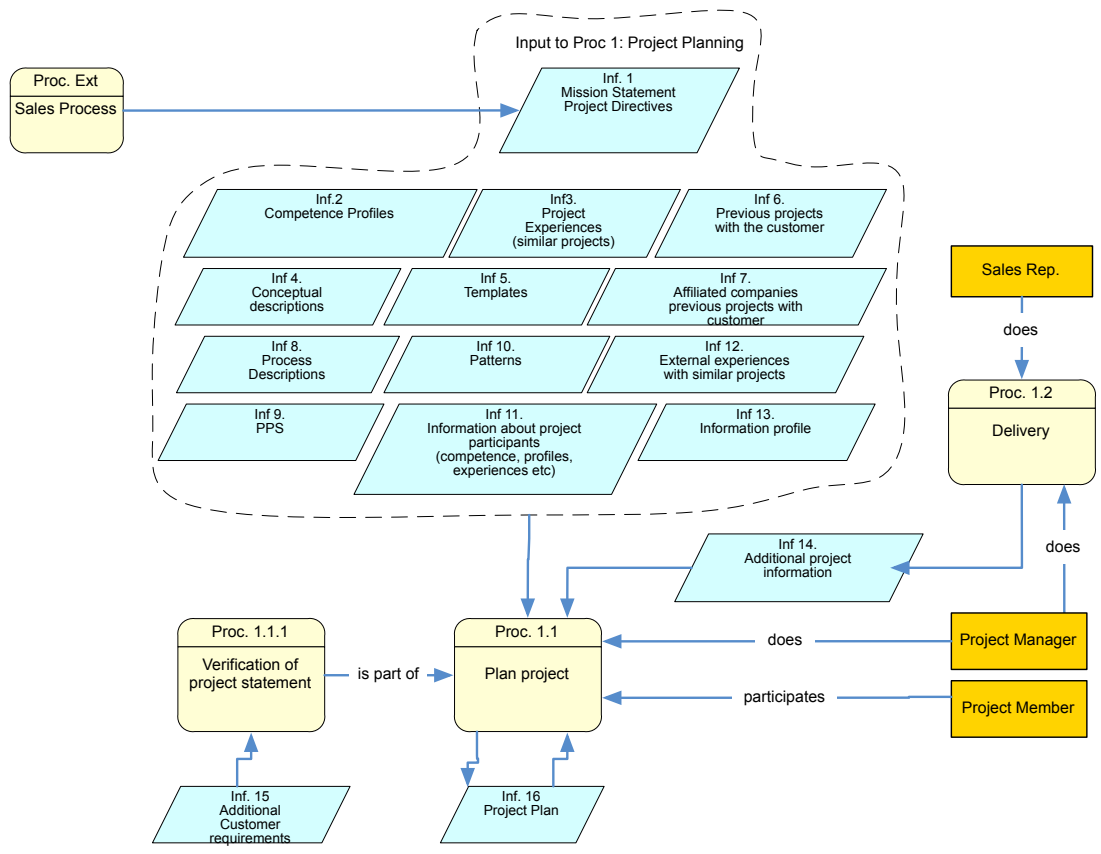

Figure 22. Excerpt from a larger process description.

\subsubsection{Case B: Improving Engineering Change Management Processes}

One of the industrial partners, Kongsberg Automotive $A B(K A)$, has during a period of a year been working on improving the internal processes for Engineering Change Management (ECM) under the project name C-process and has as a part of this, chosen to perform an inventory over the different activities performed as part of such processes, as well as the requirements this has on the underlying IT-infrastructure. To ensure the validity of this inventory an external asset was contracted in form of the Swedish research institute Swerea-IVF (IVF). IVF supplies the Swedish production industry with research- and consultancy services focusing on product-, process-, and production development.

From an information demand perspective the importance of utilising existing enterprise knowledge when analysing information demand is considered crucial and it was therefore decided that the author would participate in IVF's inventory in order to (1) observe and analyse alternative approaches to enterprise modelling and (2) add to the data collection by focusing on information demand related questions 
to in such a way ensure the applicability of the case results to the author's research as well as the InfoFlow project.

$E C M$ as a process is typically run in parallel with other production processes for development and introduction of new products and product improvement as a part of the internal quality assurance. In its existing form, it had been applied in a number of projects. IVF's main purpose was to describe the activities performed within two of these projects, as well as analyse certain performance metrics with respect to the formal description of ECM in order to suggest possible improvements. From a research perspective however, focus was more on the tasks performed in those projects and how those related to the flow of information within the organisation. More details concerning models, approaches, and results can be found in one of the InfoFlow-reports (Lundqvist 2008).

\subsubsection{Actors Involved}

Compared to the case described in Section 8.2.1., this one was substantially larger with respect to number of modelling sessions, scope, and involved actors:

- Four modelling experts, three from the research group and one from IVF of which the latter and the author performed all of the modelling.

- Three domain experts responsible for deciding on the relevant scope and arranging for meetings and sessions with relevant representatives from the various parts of the organisation involved in the processes to be modelled.

- 21 informants of which some was involved in both of the ECM-projects that was modelled. The informants were not only distributed over area of responsibility but also geographically in different cities and countries.

\subsubsection{Work Approach}

The investigation of practical experiences from the use of the new ECM-process comprised the following activities in the order of listing:

1. Identification of suitable $E C M$-projects

2. Initial planning of investigations and modelling seminars

3. Interviews of, and modelling with, informants

4. Walk-through modelling seminars

While the initial plan was to interview each of the informants individually before performing joint modelling seminar with all the informants, this turned out to be unpractical, partly due to the amount of informants but mostly because of time constraints. Instead, the informants were grouped together in accordance to their roles and activities in terms of sub-processes in the different projects and then subjected to a combined interview session and modelling seminar. The typical configuration of these sessions was two to three $K A$ informants, one or two representatives from InfoFlow, and one from IVF sitting down for about two to four hours discussing the activities performed with respect to time, responsibility, and information. The results from these sessions were documented during the sessions 
in models that incrementally grew to the final models (see Figure 23. and Figure 24. for excerpts from the models). To ensure the validity of the final models, two walkthrough seminars, one per project, were held, gathering as many of the informants from each project as possible. The modelling facilitators then explained the project activities in terms of the models thus allowing the informants to correct any mistakes or misunderstandings that might have resulted from gaps between groups of informants. This allowed for a holistic view on the complete ECM-process in each project rather than a series of loosely connected sub-processes, which might have been the case if these final seminars had not taken place.

\subsection{Gaiter Material Change Project}

The analysed material change project concerned itself with changes in the material used for shift gaiters in certain cars, due to changes in environmental requirements making the old material unavailable. The project was one of the first to implement changes according to the new ECM-process in the investigated organisation.

The project was analysed over a period of half a year in form of four different seminars in accordance to the description given above and resulted in a final model comprises roughly 60 activities divided over twelve sub-processes as well as a vast number of roles and information objects distributed over three different countries. Consequently, the model simply is too big to be included here its entirety but an excerpt is presented in Figure 23. as an illustration of concepts and notation.

\subsection{Sensor Arm Change Project}

The sensor arm change-project focused on redesigning a small movable plastic part in automatic gear shifters for some car models and was chosen as a part of the investigation due to the fact that it influences a number of different projects as well as blueprints within $K A$. The analysis of the project was performed over four months, much in the same way as the gaiter project but with partly different informants. The same notation and modelling procedures where used and thusly resulted in a model similar to the gaiter project's (see Figure 24. below). 

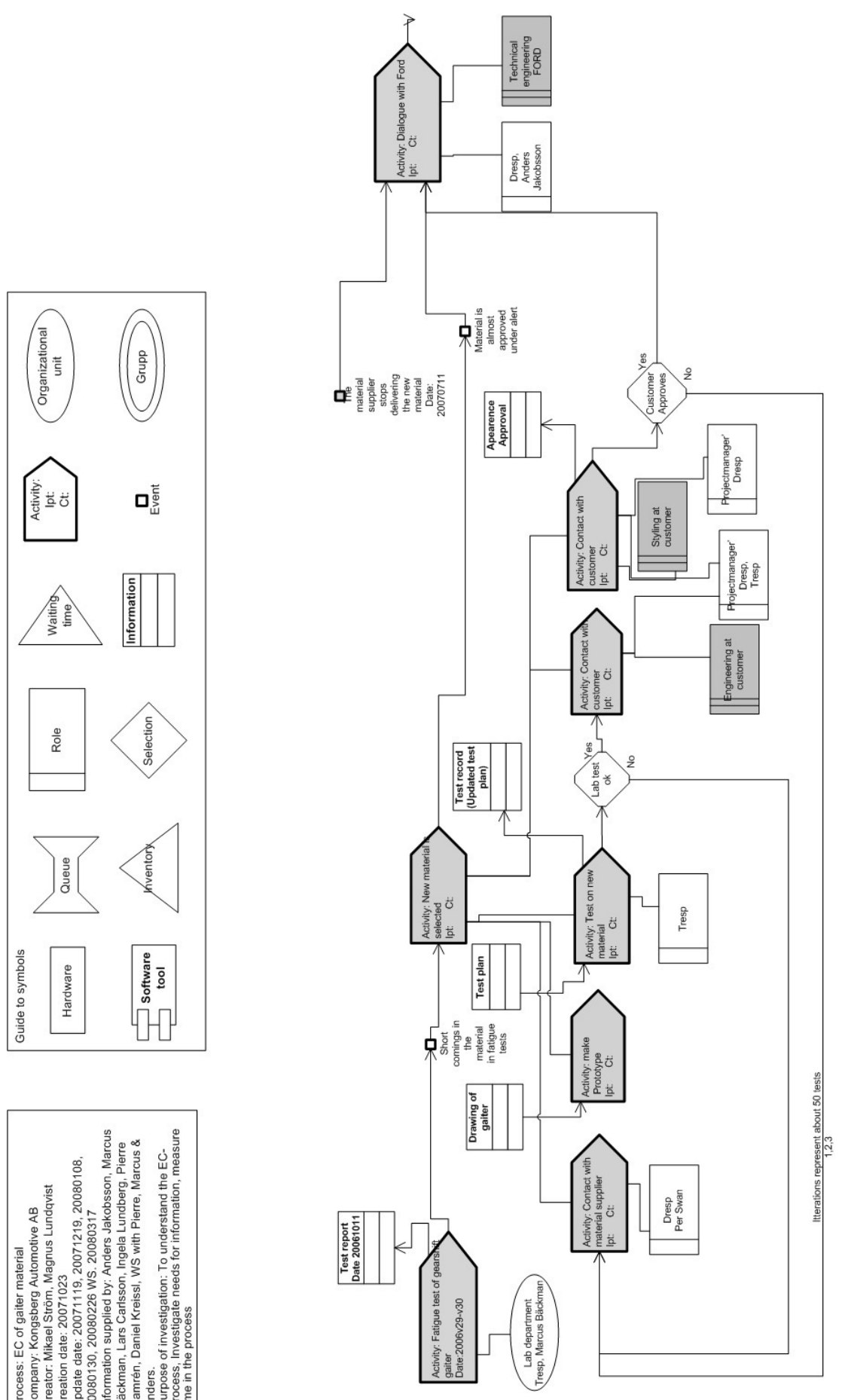

Figure 23. Excerpt from the gaiter material change process model. 

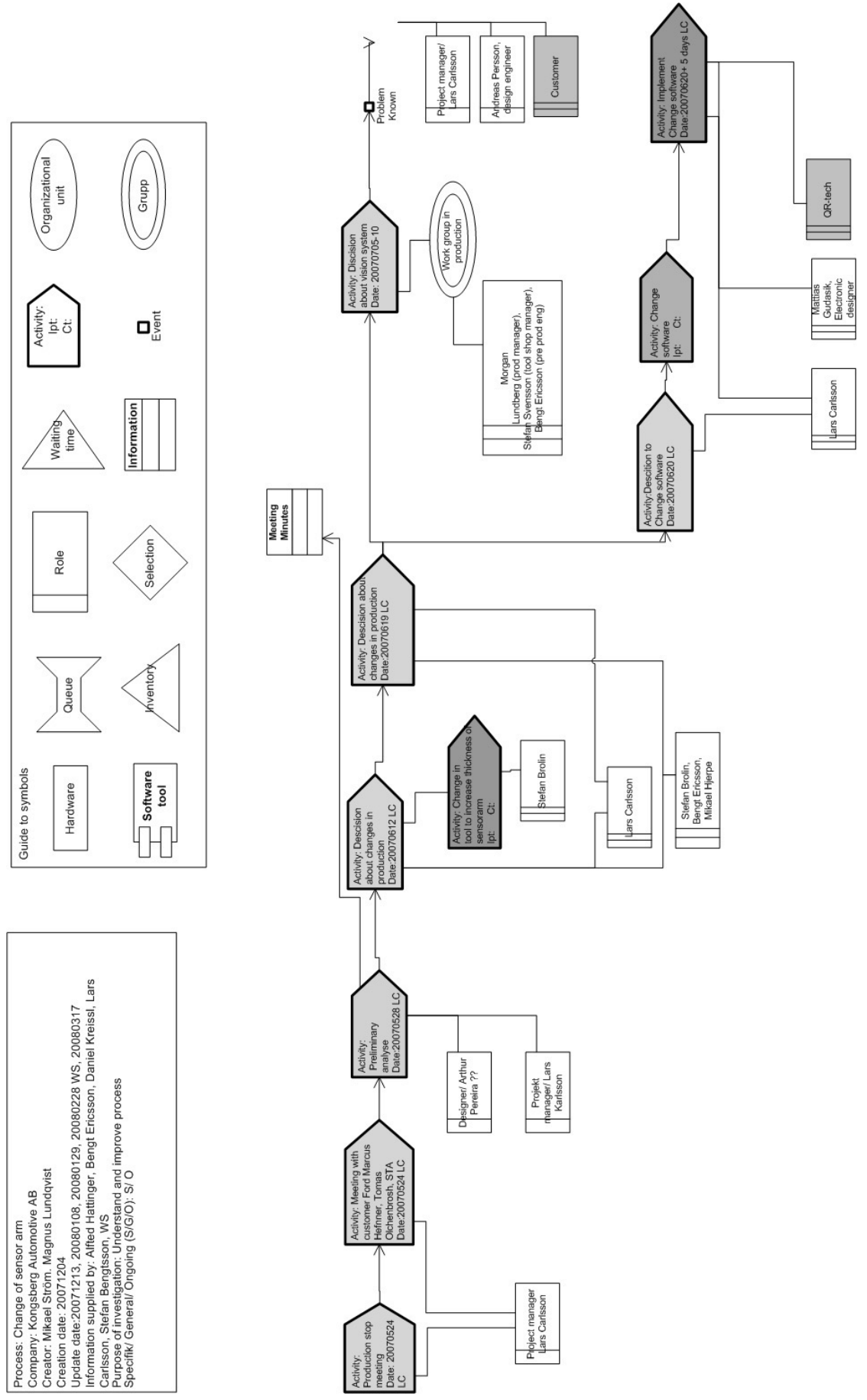

Figure 24. Excerpt from the sensor arm change project model. 


\subsubsection{Implications for Continued Method Refinement}

While the purpose of this case differed somewhat from the researchers' and the industrial partner's perspective, the investigation did, once the models were produced, split into two separate tracks, one focusing on the performance of the $E C M$-process, continued by $I V F$ and the other focusing on the resulting models and the information contained therein as the basis for information demand analysis. From a research perspective, the models produced had value since they not only identified and confirmed many of the concepts central to IDA (Role, Task, Resource etc.) but also instantiated these concepts in terms of documents, individuals, and actual resources. This has allowed for the material to be used during the development of the method to test a number of ideas, besides those concerning only the core concepts, examples of such ideas are the connection between areas of responsibility and tasks, individual aspects of $I D$ and its connection to social networks, competence, and resources. Furthermore, it was from this case the idea of viewing time and location as attributes to information demand, as illustrated in Figure 13. arose.

From a methodological perspective, not much effort went into analysing the actual procedures and notations used to model the processes. This was due to several reasons but mainly because the approach used by $I V F$ in the case did not contribute with anything not already covered by $E K D$, while at the same time being much less formalised, structured, and documented. 
This page is intentionally left blank. 


\section{METHOD VALIDATION}

In this chapter the draft version of the method, presented in the previous chapter, is discussed in the light of experiences from empirical validation efforts.

\subsection{CASE C: EVALUATION OF DRAFT OF METHOD COMPONENT FOR ID- CONTEXT MODELLING}

As both the conceptual refinement as well as the evaluation of various methods for modelling traditional enterprise aspects of information demand at this stage had progressed sufficiently, it was time to once again focus more on the core of the method. In order to identify the emerging methods strengths and weaknesses and procure the necessary experience for further development it was decided that the draft should be applied in a real-life situation together with one of the project partners, Proton Group. As the partner had experienced some problems relating to information flow with respect to sales and customer relations, this area was chosen as suitable for evaluation of the method draft. The case details and results are described in the InfoFlow-report Lundqvist \& Seigerroth (2008).

\subsubsection{Actors Involved}

- Three method experts from the research group and the main partner

- One modelling facilitator, the author

- One domain expert responsible for selecting relevant informants and arranging seminars, also acting as an informant.

- Three informants, each representing a different part in the value chain from sales to production planning. 


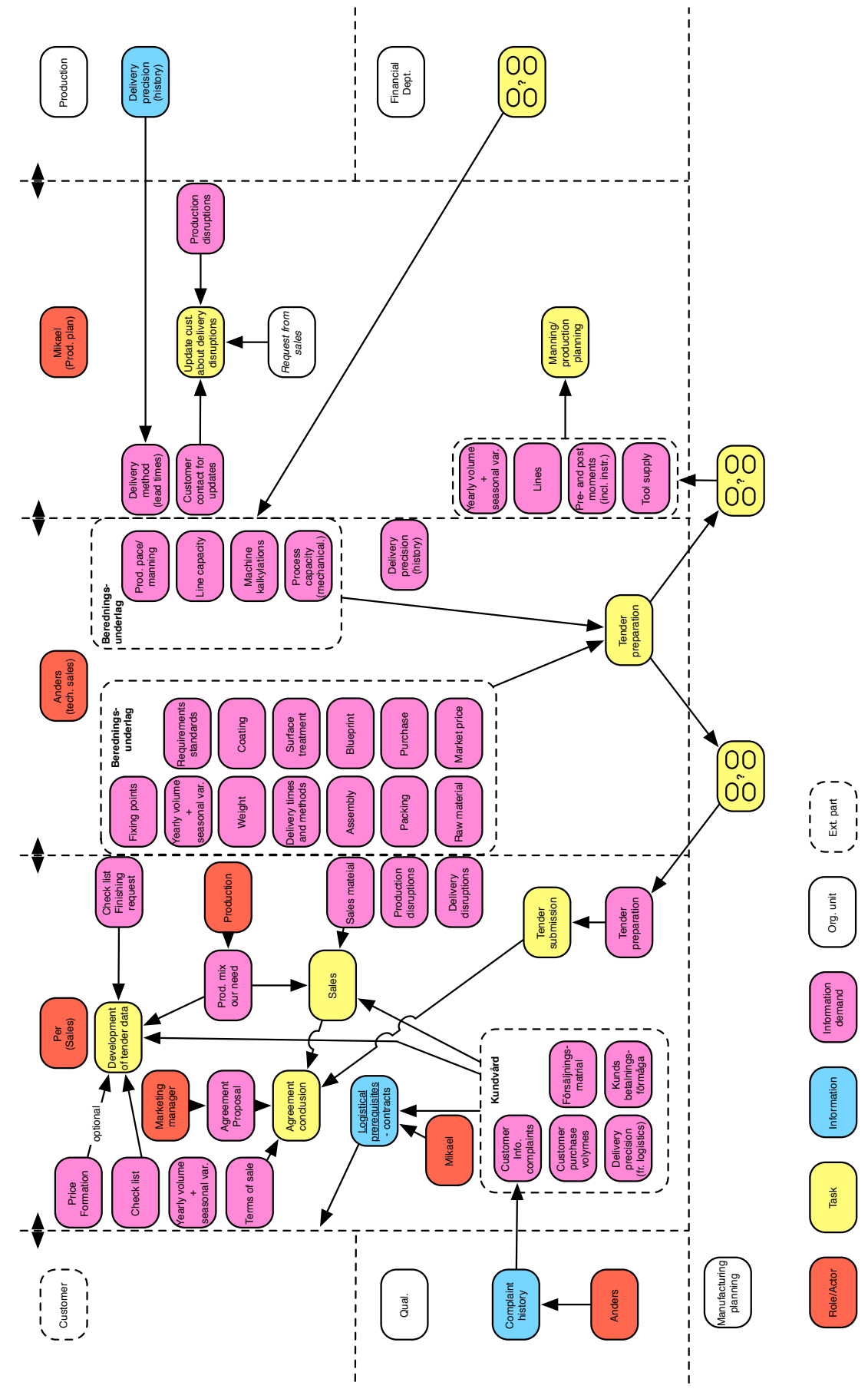

Figure 25. A draft model of an information demand context. 


\subsubsection{Work Approach}

The evaluation of the method draft was performed during one working day where the first half was spent on interviewing each of the informants individually to get a better understanding of their responsibilities, roles, and tasks as well as perceived problems with respect to information demand and flow. The second half of the day then focused on a joint modelling seminar. During the seminar the author got the opportunity to test the method draft with respect to notation, procedures as well as modelling facilitation with the clear focus of identifying information demand and -flow rather than processes or organisational structures. The notation used during this modelling seminar, as presented in the previous chapter, was rather simple and straight forward focusing only on the core concepts (see Section 6.1.) of information demand, i.e. information demand context-modelling. However, as will be explained and elaborated upon in Chapter 10. the idea behind this part of the method has always been to provide a fast and efficient way to establish a basic understanding of the information demand and the contexts in which they exist. The chosen approach, while obviously not without its shortcomings in this its first version, still proved quite well-suited for the task. Figure 25. above illustrates the resulting model from this session.

\subsubsection{Implications for Continued Method Refinement}

While this case might seem rather small and simple, it did allow for generation and validation of more method component-related knowledge and ideas than the previous cases. Not only did it provide the opportunity to try the emerging notation but it also allowed for the testing of work procedures as well as provided an initial validation of the conceptual framework. Based on the results from the case the method idea was refined leading to new design activities resulting in the current version of the notation presented in Chapter 10.Figure 32.

\subsection{CASE D: DEFINING INDUSTRIAL OBJECTIVES AND REQUIREMENTS}

Having performed a number of cases and thereby getting a better understanding of both methodological approaches as well as possible notations and procedures, some attention had to be given to the industrial needs and requirements for and on a method for modelling and analysis of information demand. Together with representatives from SYSteam Management, whom would be considered typical future users of the method, work on defining methodological needs, requirements, and objectives began. The main purpose behind doing so relates directly, not only to both the first and second research question presented in Chapter 1. but also to the relevance of the research presented here. The activities part of the elicitation process, lead to a number of objectives, needs, and requirements, detailed in depth in Lundqvist et al. (2008b). They are also listed here in a more condensed version.

\subsubsection{Method Objectives}

As a method defines prescriptions for action with the purpose of reaching certain goals, such goals obviously have to be defined. This is true both on a general framework-level as well as for individual components and parts thereof. While the main objective of any method for analysing information demand must be to capture all aspects of such demands, there are additional considerations just as important for the current scope of the project that also has to be captured by the method goals. 
With the expressed focus on SMEs and small-scale business contexts, an analysis method well adapted to the specific conditions applicable to such contexts is needed. Hence, in order to correctly and fully describe information demand the method needs to:

- Capture all relevant aspects of information demand contexts, i.e. answer questions such as:

- What are the responsibilities of different roles?

- What role performs what task within the organisation?

- Which (information) resources and what information are available when performing task?

- At what time and location do tasks have to be performed?

- From what location and at what time can resources be reached?

- Capture all relevant individual aspects of information demand and how they relate to specific information demand contexts, i.e. answer questions such as:

- Who are the individuals having roles within the organisation?

- What competence and goals do these individuals have?

- What expectation does the organisation have on such individuals and vice versa?

- What individual resources do such individuals utilise in their respective roles?

- What social networks do such individuals utilise when performing tasks and what information is exchanged within such social networks?

- Be flexible in terms of the amount of resources and effort required to perform an information demand analysis to better suit the conditions of SMEs, i.e. the method should be modular and scalable by design to allow for an incremental analysis of an organisation depending on the prerequisites valid for a specific organisation.

- As far as possible utilise existing externalised knowledge about the analysed enterprise for derivation of information demand context, i.e. making it possible to use existing process descriptions, organisational charts etc.

- The notation used for representing information demand (or aspects thereof) should if possible be machine understandable in order to better facilitate the use of information logistical solutions as an approach to improve information flow while at the same time be simple enough to be easily communicated between humans. 


\subsubsection{Method Requirements}

It was, together with the industrial partner, concluded that in order to reach the above listed objectives, any method for IDA developed had to adhere to several important requirements. Firstly, for the method developed to, in accordance to the expressed wish to focus on and work in small-scale business contexts, be as multifaceted as possible while at the same time require a minimum of resources and effort, it has to be adaptable to the conditions and prerequisites to the enterprise utilising it in real-life situations. To achieve this, it has to be modular in design and thus allowing the enterprise to choose the level of analysis depth and width required for any given situation. That is, it should, as stated in the objectives, be possible to perform the analysis stepwise in terms of which aspects of information demand that is analysed. This is referred to as the method supporting lightweight deployment. Therefore, the following requirement is defined:

\section{Requirement 1.}

To support both lightweight deployment and scalability the method should comprise a number of different analysis perspectives designed in such a way that any of the perspectives can be analysed and represented independently of the others in either a sequential or a parallel order. While additional perspectives might be added in the future, the two initial ones are:

- Context-based information demand analysis

- Individual-based information demand analysis

It should however be noted that the current approach, as described in Chapter 10., requires the context-based analysis to be done as the first step when analysing information demand. This is due to the results from the empirical investigation that showed that context is the most important part of information demand regarding the identification of such demands.

Moreover, to further decrease the effort of analysing information demand, the context-related part of the analysis should, as far as possible, utilise existing knowledge about the organisational structures, processes, and resources or any other concept within the analysed enterprise relevant for information demand analysis, leading to the following requirement:

\section{Requirement 2.}

The context derivation and definition should be possible to do partly based on any description of the enterprise that contains all the roles for which information demand should be identified, all tasks performed by those roles, and any resources necessary for performing such tasks. That is, any method, model, or description used for producing the necessary information should comprise:

- Roles and how they relate to;

- Tasks and;

- The information available for use when performing such tasks and; 
- Resources that the roles use to perform such tasks.

- Optionally, any specific time or location restraints put on either information or resources required for performing specific tasks as well as the tasks themselves, if such aspects are of interest in the specific case.

With InfoFlow's specific focus on SMEs and small-scale business contexts it is reasonable to assume that not every organisation that might have an interest in analysing information demand have existing knowledge about the organisation expressed or documented in such a manner that information demand contexts easily can be derived from it. Hence, an approach for capturing and communicating such knowledge has to be available. It is therefore concluded that:

\section{Requirement 3.}

Procedures for analysing and representing knowledge about an organisation relevant for deriving information demand contexts must be defined. Such procedures should capture:

- Organisational structures and roles within those structures as well as their relationships to;

- Processes and the tasks they are made up by

- Resources and information available to, and necessary for, the different roles when performing such tasks.

- Time and location-aspects of tasks if this are of interest in the specific case.

As well as:

\section{Requirement 4.}

Have a straightforward, simple, and clearly defined notation for describing the aspects listed in Requirement 3. in tools typically available to smaller organisations, i.e. Microsoft Visio, OmniGroup OmniGraffle, Sparx Systems Enterprise Architect etc. Furthermore, to support the objective of producing representations of information demand that is machine understandable such a notation should be based on formally described meta-model, either built in to the notation or tool itself or developed as a separate entity to be used when using the notation.

Since individual aspects of information demand are connected to an individual rather than an organisational role, the analysis of such aspects requires an understanding of the human being having a specific role rather than the organisation it works in. Because of this, the analysis of individual aspects has to be separated from the analysis of information demand contexts and therefore has a number of unique requirements, different from those relevant to context-based analysis. 


\section{Requirement 5.}

To analyse and define which individual aspects that might be considered relevant to a specific information demand context such an analysis has to identify:

- The relationship between individuals and roles, and thereby the context(s) the individual acts in.

- The relationship between individuals, their competence and personal goals, and how these aspects affects the information demand as it is defined by the information demand context of the role the individual has.

- The social networks relevant to a specific information demand context that the individual is a member of and the informal information flow with respect to tasks within that context, such networks may result in.

- The personal resources the analysed individual utilise when performing tasks within the information demand context(s) of its role.

Finally, some wishes regarding the method's properties to ensure its applicability were expressed by the industrial partner. These are:

- A method that is modifiable based on experiences from using it.

- A method that is adaptable based on situational prerequisites.

- A method that can be integrated with other methods already in use.

- A method that allows for reuse of existing methods and components.

- A method that is clearly defined, functional, and simple to understand and apply.

- A method that is applicable, i.e. has industrial relevance.

- A method that is communicable in the sense that its purpose, various parts, and results should be understandable by interested parties.

- A method that ensures the quality, correctness, and communicability of the models resulting from its use.

\subsubsection{Implications for Continued Method Refinement}

The definition of industrial objectives for, and requirements on, a method for the modelling and analysis of information demand has quite naturally had a large impact on the continued method development in the sense that it has guided the various generation efforts.

\subsection{CASE E: INDUSTRIAL VALIDATION OF THE METHOD}

Based on knowledge gained from the empirical cases presented in this and the previous chapter the author worked on elaborating and refining the method for information demand analysis. However, once the method framework, as well as the different components it specifies was starting to take form, there was a need for additional internal, empirical, and theoretical grounding to further support and 
strengthen the generation of the method. Consequently, an additional evaluation case of the method with respect to its applicability in real-life situations was defined. This case was however quite different in nature and format compared to the previous cases as it was performed by two bachelor students from Växjö University rather than by the author himself. The case also differs in the sense that the method was subjected to a completely different approach to evaluation than what had been used during the initial steps of the development, a framework named Normative Information Model-based System Analysis and Design (NIMSAD) (Jayaratna 1994). The reason behind choosing NIMSAD was mainly that it is a rather rigorously defined framework for method evaluation, which would simplify the task for the students. But also because its view on methods is quite similar to that of the author's; as a help to structure one's thinking and actions by prescribing a preferred sequence of steps to be taken. The framework suggests that methods are best evaluated by the asking of a number of questions concerning the approach, content, context, users and validation of the method. More details on NIMSAD can be found in the students' bachelor thesis (Nyberg \& Wass 2009) as the rest of this section focus more on the result of the evaluation.

Focus for this case was primarily the evaluation of how well the method complies with its requirements as well as its general applicability in an industrial context. For this purpose, a case scope was defined together with two manufacturing enterprises in the region, having a newly developed cooperation process in need of improvement with respect to information flow. The two bachelor students were given the task to evaluate the emerging method for analysing information demand by applying it on the process in question. As the scoping for the case was done by the enterprises themselves, the students did unfortunately not get a chance to evaluate the part of the method focusing on scoping (see Section 10.2.1.). They did however perform modelling and analysis of information demand contexts as well as represented the results in the EEML-notation. During and after performing the various activities defined by the method, as described in Chapter 10. they evaluated the method against the criteria listed in Table 4. below (Nyberg \& Wass 2009). The corresponding questions and their respective answers where then discussed with respects to the different aspects of the method and the results of its application.

Before getting in to the details of the evaluation efforts, it should however be noted that the method still was under development at the time of the evaluation. The results discussed here should therefore not be seen as a comment on the applicability, relevance, or rigor of method's final version but rather as the foundation for continued method refinement, it has been used as. It should also be clarified that the structure of the documentation of this case differs from the others due to the fact that it makes more sense to discuss implications for method development in relation to each criteria below, rather than in the end of the section as have been done with the previous cases. 
Table 4. The elements of the analysis and questions that it aims to answer (Nyberg \& Wass 2009).

\begin{tabular}{|c|c|}
\hline \multicolumn{2}{|c|}{ Elements } \\
\hline \multicolumn{2}{|c|}{ 1. Method Component } \\
\hline Defined steps & What can be said about the defined steps of the method? \\
\hline Concepts & What can be said about the concepts of the method? \\
\hline Guidance & What can be said about the notations of the method? \\
\hline \multicolumn{2}{|l|}{ 2. Method User } \\
\hline Role & Which roles and stakeholders are involved in the method? \\
\hline Knowledge and skills & $\begin{array}{l}\text { What knowledge sets and skills do the method users need in order to } \\
\text { accomplish tasks required by the method? }\end{array}$ \\
\hline \multicolumn{2}{|l|}{ 3. Method Context } \\
\hline Purpose and goals & What are the purpose and the specific goals of the method? \\
\hline Boundary settings & $\begin{array}{l}\text { How does the method help to understand the particular situation and } \\
\text { boundary setting? }\end{array}$ \\
\hline Method results & What are the results of the method? \\
\hline Outcome & Does the outcome of the method fulfil its purpose? \\
\hline \multicolumn{2}{|l|}{ 4. Method Validation } \\
\hline Well grounded & How well grounded is the method? \\
\hline Maturity & What can be said about the maturity of the method? \\
\hline General & How general is the method? \\
\hline \multicolumn{2}{|c|}{ 5. The Method Creator's Requirements } \\
\hline Requirements & How well does the method fulfil its requirements? \\
\hline \multicolumn{2}{|c|}{ 6. Wishes and Expectations of the Business Organisations } \\
\hline Way of thinking & Has the method affected the way of thinking? \\
\hline Holistic view & $\begin{array}{l}\text { What can be said about the problem owner's holistic view, after using } \\
\text { the method? }\end{array}$ \\
\hline Understanding & $\begin{array}{l}\text { What can be said about the problem owner's understanding for each } \\
\text { other, after using the method? }\end{array}$ \\
\hline
\end{tabular}

\subsubsection{Method Component}

It was concluded that the method has a clearly defined conceptual foundation helping the method user focusing on relevant parts of organisations thus directing the user in the search for information demand. It was however also experienced that the interrelationship between role, responsibility, and position was not that clear in relation to the case. It was furthermore stated that the method does not help the method user to understand any consequences following from ignoring some of the concepts in the conceptual framework.

As for the work steps defined in the method's framework, these were found to be insufficiently defined and that guidance for each step needed to be elaborated upon. The same was also concluded regarding the notations used for modelling information demand, which during the evaluation was perceived as unclear due to its strong focus on roles. Representation of information demand through the use of $E E M L$ was however conceived as a powerful, but time consuming, tool for focusing on the information demand of particular roles. 


\subsubsection{Implications for Continued Method Refinement}

A number of comments in the evaluation report regarding both modelling and representing information demand showed that the method's intentional focus on roles, rather than on processes, was not really understood by the students. Consequently, many of the comments relates to the recommendation of a more process-oriented method. This can most likely be explained by the case having a clear process-oriented scope and thus involved informants focusing mainly on processes. In such a situation, the method user needs to be able to understand, and argue for, the benefits of a role-centric approach.

Because of the comments regarding the conceptual relationship between role, responsibility, and position, this relationship has been clarified throughout the dissertation and in the method documentation.

\subsubsection{Method User}

The evaluation discusses two different types of method users, the main user, i.e. the person leading the process of modelling, analysing, and representing information demand, and the end-users, i.e. the participants having the information demand. The main conclusion was that none of the types of users get any support in terms of understanding different roles and responsibilities involved in using the method. It was also pointed out that using the method requires one to be experienced and knowledgeable in modelling and facilitation in order to successfully use it.

\subsubsection{Implications for Continued Method Refinement}

While the method since, and because of the evaluation indeed has been better described in terms of stakeholders and participants the very nature of participative modelling does to some extent requires skillsets and knowledge that cannot be built into the method. This is in some sense a weakness but also, as with most methods, a strength in that it does not limit the method user's freedom to act within its role. As an additional consequence, the method handbook was further developed to provide both method users and end-users with a better insight into the method and its application.

\subsubsection{Method Context}

The evaluation identifies the method as a way to improve information flow through the identification of gaps between information demand and access to information as well as representing such gaps so that they can be transformed into change requirements of technical or organisational character. It was however, felt that this purpose was not expressed clearly enough in the method itself and that it would benefit the method users if they more easily could decide on the suitability of the method for a specific purpose. Despite this, the method was perceived as providing the user with tools for everything from scoping to representation in a readable and communicable manner with the exception of the lack of a modelling formalism for expressing gaps in information identified during modelling seminars. 


\subsubsection{Implications for Continued Method Refinement}

A construct for expressing information gaps, denoting illustrating such information objects a role does not have access to despite of having a demand for it, has therefore been added to the notation for modelling information demand contexts (see Section 10.2.2.5.).

\subsubsection{Method Validation}

The extent to which the method is grounded was evaluated from three different perspectives; content, empirically and value-based (roughly translating to the internal, empirical and theoretical grounding discussed in Chapter 2.). The method was considered partly content-grounded as it rests on a conceptual foundation guiding the method user in terms of focus but as lacking procedural descriptions ensuring the fulfilment of goals. As the method have been generated through empirical cases together with industrial partners it was considered empirically grounded but it was also noted that additional grounding should be performed to further improve the quality and industrial applicability of the method. Furthermore, it was concluded that the method is value-grounded as it describes existing goals and expected outcomes while it at the same time was argued that some goals are not fulfilled due to shortcomings in the method and that the issue of value-based grounding therefore cannot be concluded completely.

\subsubsection{Implications for Continued Method Refinement}

Regarding the maturity of the method it is, not surprisingly, as the method was not completely developed at the time of evaluation, found rather immature. The generality of the method was however considered good due to the well-defined conceptual framework, which allows for the method to be applied in all types of organisations.

\subsubsection{Method Requirements}

Since the evaluation mainly focused on the component for modelling information demand context, it was not possible for the two students to discuss the method in terms of additional method components. The requirements regarding the method's flexibility and adaptability could therefore not be evaluated and any conclusions regarding requirement fulfilment had to be postponed.

\subsubsection{Implications for Continued Method Refinement}

As the method have been much more elaborated since this case was performed and such an evaluation now is possible, a discussion about the method in relation to industrial objectives and requirements can be found in Chapter 10.

\subsubsection{Wishes and Expectations of the Business Organisations}

The analysed organisations had wished that the method would help change their way of thinking regarding the analysed area, which they did not feel it did. They did however perceive the method as a good way to get a clear view of the situation in which it was applied. As the method does not really make any statements about organisational understanding beside those directly relating to information demand the method must be considered living up to it intensions in this respect. The enterprises involved in the case also expressed that they felt that the method resulted 
in a holistic view of the analysed scope, which provided them with an understanding for the complexity of information demand related problems. Furthermore, the act of modelling information demand facilitated a better, shared understanding of the scope. The participative nature of the modelling therefore resulted in the modelling activities being perceived as more useful than the actual representation of information demand in EEML.

\subsubsection{Implications for Continued Method Refinement}

As the comments above does not really state anything that can be directly related to the continued method development, not much in terms of implications can be concluded. There are however some comments that can be interpreted as confirmation of the emerging method's utility and applicability but any such discussion is best held to after the final version of the method has been presented in the next chapter. 


\section{REFINED METHOD HYPOTHESIS}

In the previous two chapters, various evaluation and validation activities have been described but not much of the emerging method for information demand analysis has been presented, besides the very simplistic, initial draft version. The rationale behind this intentional choice is that while the method development of course has been performed continuously in parallel with the evaluation and validation activities, it would not have contributed to the readability of this dissertation to show several different versions of the emerging method. Instead it is the author's hope that now, when the method finally is presented, it will, based on the theoretical, empirical, and conceptual foundation, be easier to understand why the method is designed and constructed in the manner that it is.

To further facilitate the communicability of the final version of the method in this text, its structure mirrors that of the notion of method used (introduced in Section 7.3). It first, in Chapter 10.1., describes the different method perspectives considered important during the development and use of the method. Once these are presented the method framework, with its structure reflecting the perspectives is presented in Chapter 10.2. The framework-description details the various activities with respect to sequence, goals, and results as well as the different method components in terms of notations and procedures, used to produce such results.

\subsection{METHODOLOGICAL PERSPECTIVES}

As discussed in Chapter 7., a method is a prescribed goal-oriented way to solve problems and perform actions in a problem-domain, guided by a predefined set of assumptions, values, and beliefs. While the domain in question to some extent already has been presented (Chapter 6.), additional discussion regarding both the domain and the underlying belief-system is warranted. Most of the methodological perspective is, for obvious reasons, based on the knowledge regarding information demand and -use, gained during the empirical work presented in Part 1. but the act of developing the actual method has also contributed to a better understanding of both industrial and theoretical needs and requirements. It is in this section therefore also relevant to discuss both the intended goals from an information demandperspective and the properties of the method from an industrial point-of-view. 


\subsubsection{Method Focus and Purpose}

In both Chapter 5. and 6. it is stated that understanding information demand is about understanding the information needed to perform work tasks and the roles that perform them. Consequently, the main goal of the method is to identify the relationship between work tasks, roles, and information, referred to as the information demand context, in order to improve the information flow with respect to such work tasks. Improving information flow here meaning, identifying change needs regarding organisation, resources, and information management, rather than actually performing such changes. Following from this statement is that any additional modelling of aspects of enterprises or individuals should only be performed as support for or refinement of already defined information demand contexts. While the method to some extent has to include parts that contribute to the understanding of such aspects as individual competence, processes, social networks etc., these components main purpose is to further improve the information demand contexts. That is to say, the method presented here is not, intended as a general method for enterprise modelling, as many such perfectly well suited methods already exist.

However, while the focus is on information demand contexts, there also is a need for connecting these contexts to the organisations they exist within, as well as to the individuals they involve. In Chapter 5. and 6. it is also claimed that various individual and organisational factors influence information demand contexts in different ways and that it therefore, depending on the situation, might be necessary to analyse such factors. Figure 17. (for convenience also repeated here as Figure 26. ) divides the relevant concepts into six different partitions in three layers. The intention behind this compartmentalisation is to reflect the prioritisation of the modelling activities as well as to allow for a component-based approach to the modelling. That is to say that each partition maps to one specific method component and that the method's framework defines a preferred order of analysis activities. The core of the method, information demand contexts, is found in the centre of the concept model (Figure 26. ), representing the starting point for information demand modelling. Once a sufficient understanding of the context is gained for a specific set of roles or tasks, modelling additional aspects can refine these contexts. Given the experiences from the empirical work presented in Chapter 8. and 9., the first step to refine such contexts usually is to connect them to various organisational aspects such as processes, employment positions, goals etc. Consequently, the middle layer in Figure 26. represents the conceptual focus for the first part of any additional modelling and analysis to be performed. If, once the information demand context and the organisational setting in which it exists is modelled, it is deemed necessary or relevant to focus on how information demand varies depending on time, location, or individual aspects such as goals, access to resources, competence, or social networks, such aspects can be modelled and analysed independently from each other. The outer layer of Figure 26. describes how these different aspects connect to each other and to the information demand context. 


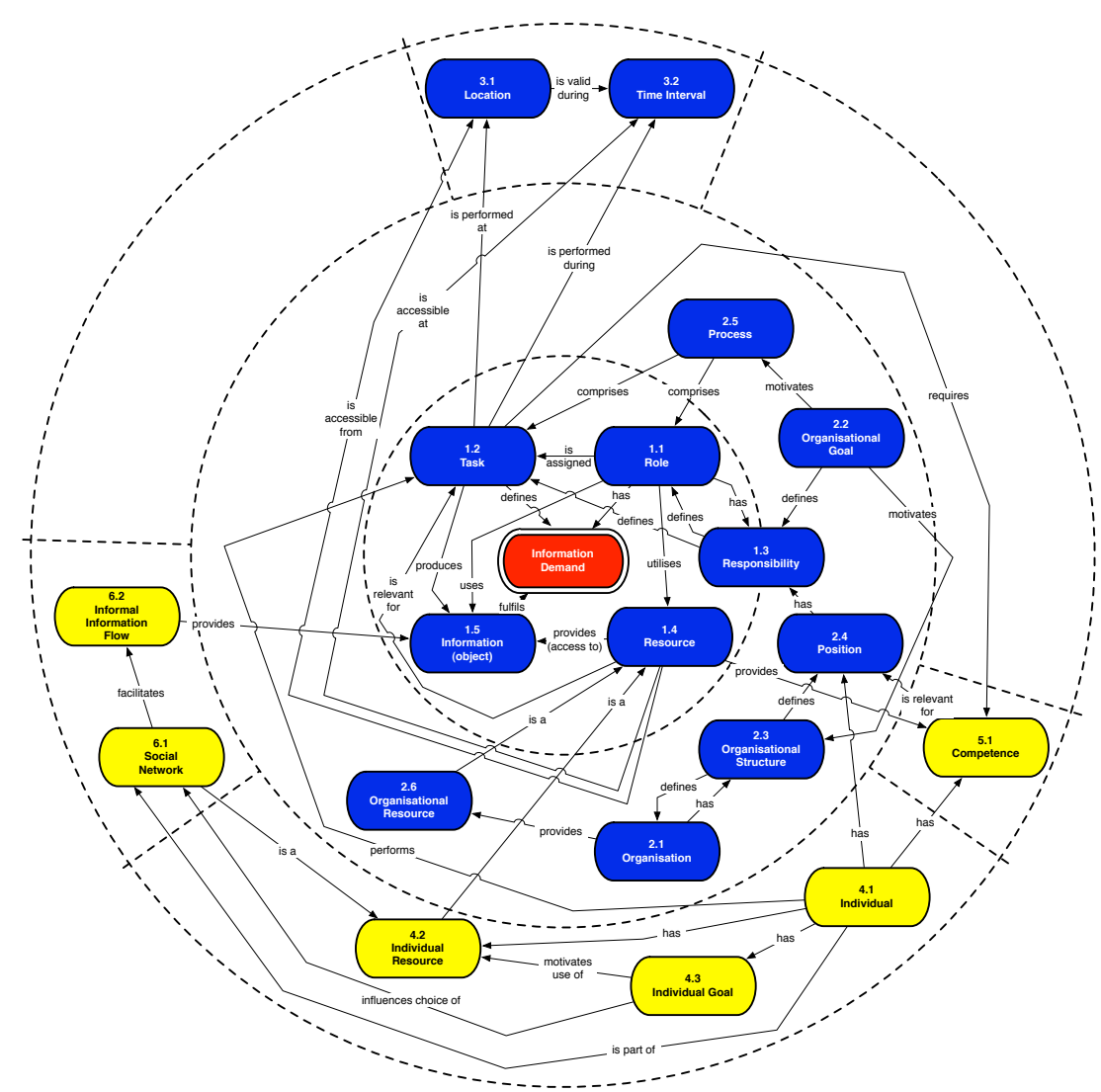

Figure 26. A complete conceptual framework for information demand.

This compartmentalised and layered but yet interconnected view on both the research area and the method is in alignment with the methodological requirements regarding a component-based, situational-adaptable method. Two different perspectives can be taken on this aspect of the method. Firstly, it is believed that this would improve the learnability, applicability, and adaptation of the method in real-life situations. Secondly, if one is interested in using the method for solving information flow-related problems, this property is essential for selecting the focus and depth of the information demand analysis, i.e. how and to what extent the information demand contexts should be elaborated once initially identified. The fact that concepts numbered from 3.1 to 6.2 in Figure 26. is located in the same layer is due to a wish to support this flexibility. Thusly, the method itself puts no requirements on what aspects to analyse nor the order of doing so, once the information demand contexts and their connection to organisational aspects are captured. This choice instead has to be based on the situation in which the method is applied.

\subsubsection{Mode of Working (Cooperation and Collection Principles)}

Generating a deeper knowledge about, and understanding for, the inner workings of an organisation with respect to information flow can of course be done in many different ways. While the study of various documents, information system, or actual 
work activities most certainly could derive certain aspects of information demand, focus in this case is more on participative approaches involving subjects from the analysed organisation (de Vreede 1996, Persson 2001). It has been shown during the empirical parts of this research that performing modelling in cooperation with the roles actually having information demands, is a particular good way to describe the actual reality within the organisations as well as ensuring correctness of the results (Stirna et al. 2007). This is a natural consequence of the informants' unique understanding of the organisation they act within and the problems they face when doing so. Relying solely on formal documents, a few key individuals, management representatives etc. might easily lead to an idealised or incomplete picture of the reality. Another, equally important aspect of modelling and analysing information demand is to generate a shared understanding for information flow-related problems and demands within the investigated organisation. This understanding is considered just as crucial to solving problems as the resulting models are by themselves. Furthermore, dealing with the organisational reality rather than with a formalised and structured view on an enterprise, it is considered equally important that the method captures both formal as well as informal aspects of information demand, the latter most definitely requiring involvement from individuals within the organisation. As working jointly in this manner provides all of these possibilities as well as provides the analysed organisations with an opportunity to reflect over the current situation with respect to internal goals, procedures, and intentions during the work with identifying information demand, the participative approach to working is considered a central part of the method. Almost all activities relating to data collection and information gathering are therefore performed in a participative manner. Examples of such activities are:

- Interviews with individuals acting in roles relevant to the modelling process.

- Modelling sessions with representatives from the part of the organisation to be modelled.

- Model walk-through sessions to verify and ensure the correctness of any models produced during previous parts of the modelling process.

Participative modelling-sessions are typically performed in groups of 3-8 participants at the time, facilitated by the method user. The reasoning behind the number of participants is that more than eight makes the session more complicated from facilitation point-of-view. The key to participative modelling is the activeness of the participants but in larger groups, group dynamics and social hierarchies often counteracts this. The models resulting from sessions with too many participants also easily get too complex in order to provide the intended overview of the scope. It is therefore generally considered better to perform several sessions with fewer participants and integrated the results during the analysis and evaluation activity. Because of these aspects, both the procedures and the notation used in this component are geared towards smaller working groups.

The procedural approach to participative modelling-seminars in general and information demand-modelling in particular is to get the participants themselves to identify the different tasks performed within the investigated scope as well as how this relates to information (needed and/or used) grouped by role. Typically, this is done by writing down different tasks and information objects on post-it notes and 
attaching them on a larger surface such as large paper or plastic sheets and then interconnecting them. The reasoning and motivation behind this low-tech approach is not only that it allows for easy restructuring and changes as the session progresses, it also has a number of psychological benefits. Firstly, as the participants themselves have an active part in constructing the models, it ensures that all participants get to express their view on the scope to be modelled. Secondly, it has during the test cases become clear that there is less psychological resistance in changing a rough, unfinished model by moving a piece of paper than there is in redrawing a computerised model that only can be changed by the individual at the computer. Other benefits of working in this participative manner are that it increases problem awareness, increase communicability, promotes consensus, and continuously anchors the result in the group. Figure 27 . below illustrates the working procedure during a seminar in one of the cases performed as a part of the InfoFlow-project.

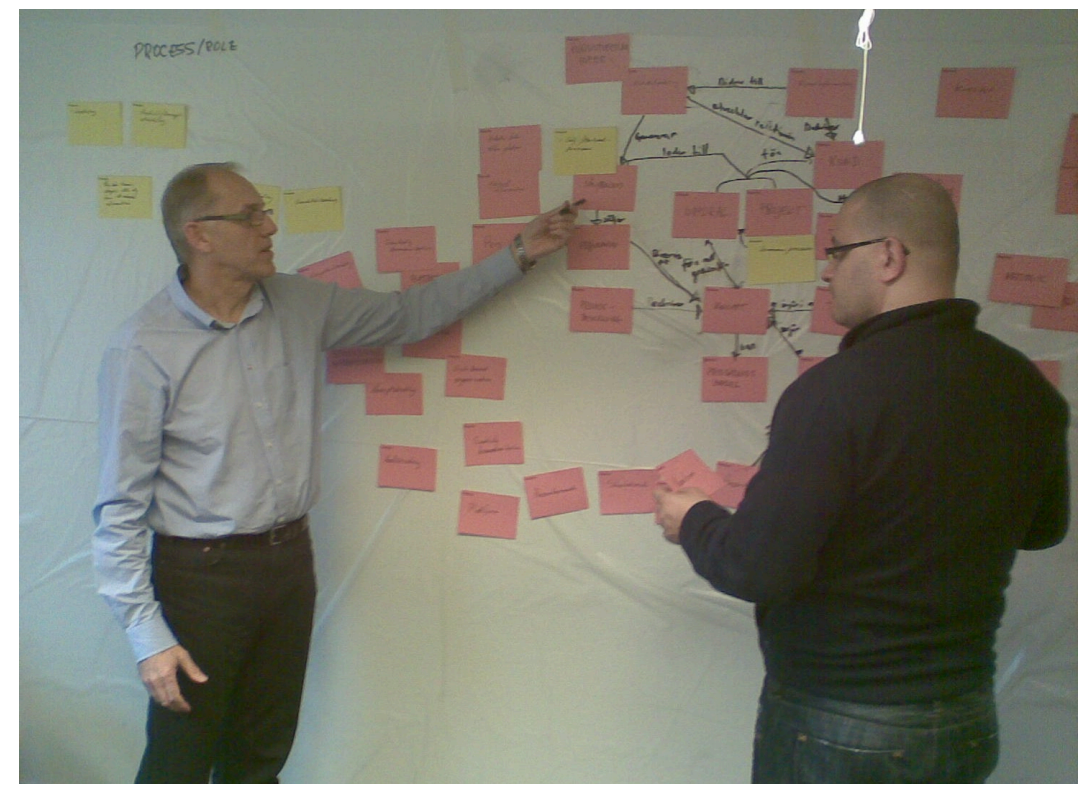

Figure 27. Illustration of a typical participative modelling seminar.

It should be noted that while the main purpose of such modelling seminars is to identify various aspects of information demand, the procedures for facilitating them cannot be too defined and rigid. A certain degree of flexibility is needed in terms of how the seminar is facilitated. If the participants get stuck on concepts, processes, and other aspects not directly related to the current scope, it might be necessary to deal with these issues by changing focus and direction of the seminar until the matter is resolved. Therefore, several models of different types might be produced during one seminar but the main purpose should nevertheless be to generate the knowledge necessary for reaching conclusions regarding the information demand. Obviously, the results produced during such sessions will depend not only on the skill and experience of the facilitator but also on the participants representing the investigated scope. It is crucial to the process that the scoping activities have identified the correct participants given the intended scope. The preferred way to 
ensure that the right individuals have been selected and to get a feeling for how each of the participants will act in the seminar, as well as what they will contribute, is to perform individual interview with each one of them. This part is not necessarily about gaining knowledge about information demand but rather about the individual having them. Relevant questions to ask during this part of the process may vary depending on the specific case but a number of general questions typically suitable in this situation are listed in Section 10.2.2.2. below.

Some general guidelines for successfully performing modelling seminars in a participative manner are (Stirna et al. 2007):

- Each modelling seminar should have a clear purpose.

- The notation used during modelling should be understood by all participants in order for them not having to spend time on understanding the notation instead of contributing with their knowledge.

- The participants should not be educated in method knowledge (possibly with exception of the basics of notation). It is the role of the modelling facilitator to provide method knowledge so that the participants can focus on the aspects being modelled.

- Keep all participants involved in the seminar and steer them away from discussions outside of the scope.

- Do not accept unknown participants not having the necessary background knowledge as they can impair the process and its results.

- Do not let the problem/domain owner dominate the seminar. All participants should have equal possibility to give their view on the problem/domain or else there would be no point in having them there.

- Allow for iterative development and refinement of the models. It might not be enough with one seminar to get a correct description of the scope being modelled.

\subsubsection{Method Applicability, Adaptability, Extendibility, and Learnability}

In Part 1. of this dissertation and during the InfoFlow-project, information demand was investigated mainly from what is referred to as small-scale business contexts, i.e. smaller organisations, or part thereof, with limited internal resources for, and knowledge about, identifying information demand. It was also apparent during the empirical parts of this research that the method needs to support cost- and time effective enterprise analysis from an information demand-perspective, as well as live up to the requirements defined in Section 9.2.2. Consequently, the method and its framework and components should be oriented towards small-scale application areas in such a way that it can be adapted to the prerequisites relevant for each situation it will be used in, in terms of extent, sequence, approach, and results while still be easy to understand and use with limited time and effort spent. Some of these requirements are already managed partly by the conceptual view on the problem domain as well as the method but others have to be considered during the design of the method framework. 
Having a method that by design allows for adapting to situational needs and requirements is of course beneficial from many points-of-views but not necessarily always enough. In some cases, changes that are more permanent might be preferable. In such cases, it is more a question of extendibility rather than adaptation. As neither the conceptual framework nor the method framework puts any restraints on extending the method, this is more a question of relating any new, modelled aspects to the existing ones. This can be done either by defining or reusing additional method components, interrelating its procedures, notations, and conceptual focus to the rest of the method, or by extending existing components to also include additional concepts. In relation to Figure 26. the difference between these approaches would be to either define a completely new layer, defining a new partition in an existing layer, or adding new concepts to an existing partition.

\subsubsection{Documentation and Communicability of Method Results}

As will be shown in the next section, each method component, in accordance to the notion of method presented in Chapter 7. introduces its own notation for documenting the results from its procedures. Such notations make it possible to communicate the various results from activities to individuals not present at the time of performance. However, to ensure the communicability of results in order to achieve the shared understanding of a problem, an incoherent set of models from various activities is not necessarily enough. Furthermore, communicability is not only about the results but also about properties of the method in itself. Hence, it is just as important for the method to be documented in such a way that both its users, and the organisations it will be used within, easily can understand it. As the idea behind the method is to identify and express change needs with respect to information flow-problems it is important to have an unambiguous way to represent the results from any combination of modelling activities in order for those results to be usable when implementing changes. It is of course also important that the results are produced and documented in a way that ensures quality and correctness. Consequently, a representation for documenting and communicating the method results has been developed and is presented in Chapter 10.2.5. To communicate knowledge about the method itself, a method handbook has been developed separately from this dissertation (Lundqvist et al. 2009).

\subsection{METHOD FRAMEWORK \& COMPONENTS}

If the methodological perspective defines the overall goals and preferred properties of the method, then the method framework is about how to fulfil these goals and properties. The framework defines the activities needed to ensure such fulfilment in terms of sequence and expected results as well as how the results from various activities can be incorporated into a coherent set of documentation. The activities themselves are further supported by a set of method components defined in Section 10.4. below.

The methodological perspective discussed in Section 10.1. is based on the theoretical and empirical background as well as the method requirements defined as a part of Case D. To ensure that the various activities involved in modelling, analysing, and representing information align with, and contribute to, these objectives and requirements in a manner that corresponds to the underlying assumptions and intentions, the framework has to define the relationship between 
these activities as well as the expected results. In Figure 28. below, an overview of both the relationship and the results between and from the activities are illustrated. The rationale behind the frameworks structure follows from the discussion regarding information demand covered in Chapter 5 , in which context is identified as the central aspect to be modelled before any other aspects are considered.

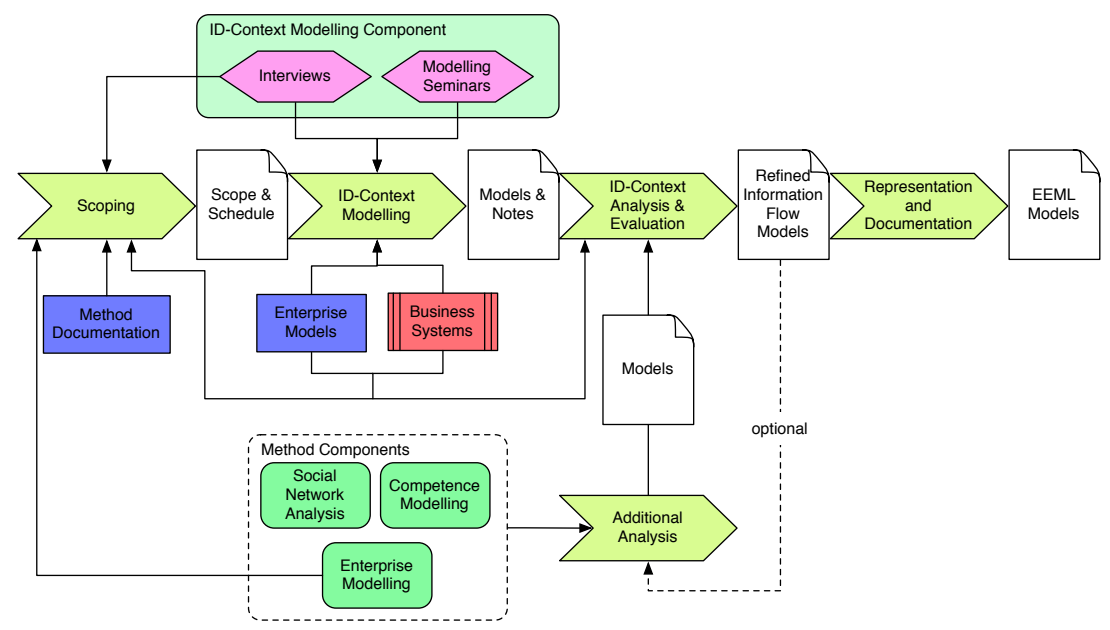

Figure 28. The process of information demand modelling, analysis, and representation.

\subsubsection{Scoping}

The starting-point of any information demand modelling and -analysis must be to decide on the scope of the investigation. Scoping is the process or activity of doing so and is done with the purpose of selecting the part of an organisation to analyse with respect to information demand as well as identifying the individuals that will be providing the necessary background information during the continued process of analysing. Scoping also serves the purpose of helping in the understanding and identification of perceived problems motivating information demand analysis, as well as identifying intentions, goals, and expectations with and on doing so.

Since scoping can be done in many different ways and settings, the method detailed here does not provide any method component defined specifically for supporting this part of the process in terms of procedures and tools. Instead, it provides general guidelines, some pointers on what to focus on, and a collection of tools in terms of procedures, notation, and concepts utilised in other method components that might support the method user in terms of performing this initial step. However, it should be noted that while there might be no real method support for performing this part of the analysis there is nevertheless a clear purpose of doing so and hence a number of activities that need to be performed and results to be produced with respect to several requirements and expected results as described below. Any additional work with analysing information demand should not be started until this initial phase has been performed and the expected results are achieved. 


\subsubsection{Activities}

Defining the activities to be performed in this phase of the analysis is not easily done due to the many possible situations in which scoping can be done but in a general sense the phase has its start in a perceived problem to which understanding information demand is a crucial part of the solution. Based on this problem the method user in cooperation with the party experiencing the problem has to define the problematic area and the actors within it. The typical way to achieve this is by interviewing key stakeholders within the customer's organisation such as process/product owners, department managers etc. but can also be done by more involved approaches such as observations, walkthroughs of existing models etc.

\subsubsection{Expected Results}

No matter the actual activities being performed during the scoping, the outcome should be the following:

- A well-defined and delimited focus area, understood and agreed upon by all involved parties in terms of expected results as well as time and resource requirements. This focus area might be a specific process (including the tasks performed as part of it and the roles performing them), a department, or a complete organisation. Key to this result is to identify the roles for which the information demand should be analysed.

- A list of individuals to be considered as informants during the continued activities, i.e. individuals having roles within the identified scope.

- A number of scheduled interview sessions and modelling seminars.

\subsubsection{Support and Tools}

In order to achieve the necessary shared understanding of the customer's needs, situation, and organisation, a number of supporting procedures and tools can be used when performing scoping activities. While a large part of the quality and correctness of the results from this phase is dependent on the experience and knowledge of the facilitator performing the scoping, the use of the following might facilitate the overall outcome:

- Concept graphs and definition - utilising concept modelling might facilitate a shared understanding of concepts central to the investigated organisation. Doing so ensures that all parties have the same understanding of the topics being discussed. A concept graph is simply a model, as the ones illustrated by Figure 17. that relates relevant concepts to each other and thereby defines the concepts. Support for producing such models is incorporated in most enterprise modelling-methods including the EKDmethod further detailed in Section 10.2.4.1.

- Enterprise modelling techniques - to support the various scoping activities traditional enterprise modelling-approaches can be used in order to define and understand processes and organisational structures. Such constructs are provided by EKD as a part of the enterprise modelling method component. 
- Method documentation - communicating the purpose of, as well as the procedures for, analysing information demand might facilitate the customer's understanding of the benefits of, and requirements for, continued activities. The method handbook (Lundqvist et al. 2009) is a typical example of such documentation.

- Domain knowledge and experience from previous projects - while the method user might have experiences from previously performed analysis sessions the customer's representatives have a unique understanding of the problems, structures, and processes relevant in the specific case. Utilising the human capital present during the scoping phase is therefore crucial.

\subsubsection{Information Demand Context Modelling}

Being the central aspect of information demand, ID-contexts, and the generation thereof, has to be well supported both from a procedural and a conceptual point-ofview. The conceptual focus for information demand contexts has already been both presented and discussed in Chapter 6. as well as illustrated in Figure 11. but the procedural and notational aspects still have to be elaborated upon.

The second phase focuses on identifying the basic information demands based on the information demand contexts, i.e. which role performs what tasks and what does this require in terms of resources and information. The purpose of doing so is to, in accordance with the methodological perspective, as quickly and with as little effort as possible, identify a foundation of basic information demand on which continued analysis work can be based. It is also important to note that this initial understanding, once again in accordance with the methodological perspective, should be based on roles rather than on processes. Consequently, traditional enterprise modelling-aspects such as processes, organisational goals etc. are not considered in this phase. The following is a detailed list of the purposes of performing such a context-modelling phase:

- Identify the tasks generating information demands

- Identify the roles performing tasks and the interrelationship between specific tasks and roles.

- Identify the information demand for specific tasks in terms of operative- and procedural information, i.e. information about the tasks themselves as well as information necessary in order to perform the tasks.

- Identify the information that fulfils the identified information demand.

- Identify the resources available and necessary in order to access information in accordance to the previous point.

- Identify the responsibilities of which roles are a part.

If considered relevant during the scoping and problem formulation additional concepts in terms of time- and location-aspects of information demand can be added in this phases. From a methodological point-of-view, these aspects are 
considered as attributes of a specific task and the information demand connected to it as illustrated in Figure 13.

At this stage of the analysis, no separation should be made between different individuals filling the same role as no individual aspects are yet considered. All individuals with the same organisational role are assumed to have the same information demand for a given task. While this in a deeper sense might be incorrect, this is done in order to quickly achieve initial best-effort results that can be refined, elaborated, and personalised later in the process if wanted or needed and hence is a concession to ensure adherence with the methodological perspective and requirements regarding ease and cost of use.

\subsubsection{Prerequisites}

In order to perform a modelling of the information demand contexts present within the analysed organisation a number of prerequisites must be fulfilled:

- A delimited and clearly defined focus area must have been identified as described in the section about scoping above.

- A number of individuals representing the different roles to be analysed as well as scheduled occasions for both interviews and seminars.

- Facilities necessary for performing interviews and modelling seminars (location, modelling material, equipment for note taking or recording etc.).

\subsubsection{Activities}

The context-modelling phase mainly involves two activities, modelling seminars and short individual semi-structured interviews with each of the selected individual. The interviews should be done in order to get a basic understanding of the individuals as well as their expectations, goals, problems and suitability as informants. Doing these interviews before any actual modelling facilitates the modelling seminars in the sense that the modelling facilitator then to some extent knows what to expect from different actors during the sessions. It also gives the informants the possibility to, in a relaxed situation, communicate their view on their situation with respect to information demands. The interviews of course have to be adapted for each situation depending on the unique settings in every project. However, some typical questions that could and should be asked are:

- Who are you, what position do you have and what are your responsibilities within the organisation and/or process?

- What roles do you have as a part of those responsibilities and what tasks are associated with those roles?

- What is the information demand associated with these tasks?

- What problems do you see regarding the information situation?

- What are your expectations on the activities performed as a part of the analysis and how do you think it will affect your future situation? 
- What, if anything, do you think should be covered during the continued activities?

The participative modelling sessions are where the actual information necessary for continued activities is collected and will be described in detail in Section 10.2.2.5.

\subsubsection{Expected Results}

The context-modelling should result in the following:

- Documented interviews (notes or recordings)

- A number of information demand context-models in the notation described below.

\subsubsection{Support and Tools}

To support the generation of the knowledge necessary for identifying information demand contexts in the next phase, a number of different tools and approaches can be utilised:

- Questionnaire for interviews as described above.

- Best-practices for participative modelling.

- The method component and its procedures and notation described below (or for a method user, the method handbook (Lundqvist 2009)).

- Modelling material conforming to the notation described below.

- Existing enterprise knowledge represented either as various models or as data in different business systems can, as illustrated in Figure 28. further support the information gathering as a complement to the modelling seminars.

\subsubsection{Method Component for Information Demand Context Modelling}

As the initial models are produced through participative modelling, focus is not mainly on producing clean and tidy models but rather on understanding. A certain degree of freedom therefore exists in the choice of notation to use during the sessions as having this freedom allows for the flexibility needed to solve any problems that might arise during the sessions. However, at some stage in the process the produced models usually have to be revised in order to improve readability and communicability and having a clearly defined notation facilitates this process. Whether or not to actually use this notation or some variation thereof already during the modelling sessions is in the end up to the method user.

The notation suggested here is based on the test cases and the notation draft presented in Figure 25. but is refined and extended to improve both the readability as well as the expressiveness of the produced models. The notation defines six objects illustrated in Figure 29. These entities correspond directly to the contextrelated concepts detailed in Figure 11. with the exception of the second and third that are abstractions of roles. These two entities are used in situations when the 
specific role in a different organisational unit or external organisation is unknown but still needs to be represented in the model.
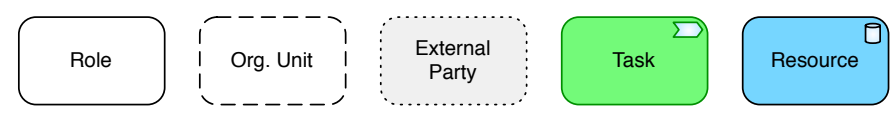

Information (object)

Figure 29. Information demand context entities.

The entities are connected to each other by seven different types of relationships illustrated in Figure 29. These relationships are used to connect the different entities in terms of information demand as illustrated in the example presented in Figure 32. below. It should be noted that while the notation has a relationship expressing sequence of tasks, emphasise should be put on information flow rather than on processes. Nevertheless, the relationship is included in the notation for the cases when it might be needed.

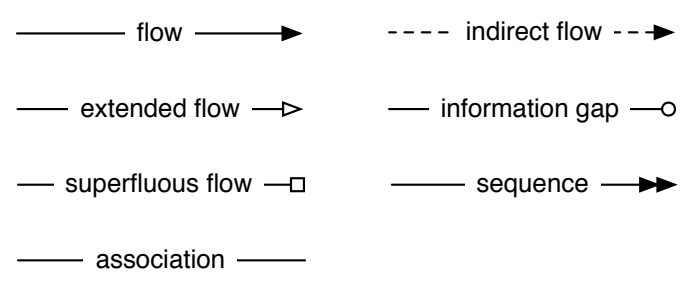

Figure 30. Information demand context relationships.

In addition to the presented constructs there are two additional ones providing the possibility to further clarify entities and relationships when needed.

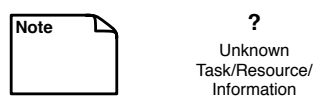

Figure 31. Constructs for extending meaning of entities and relationships.

As none of the empirical cases performed as part of this research produced models that expressed all possible aspects of information demand contexts and the models from the different cases could not be concatenated into a single coherent model, an illustrative example case was invented. This case was defined based on an academic scope with the sole purpose of illustrating the notation and is presented in Figure 32. below. 


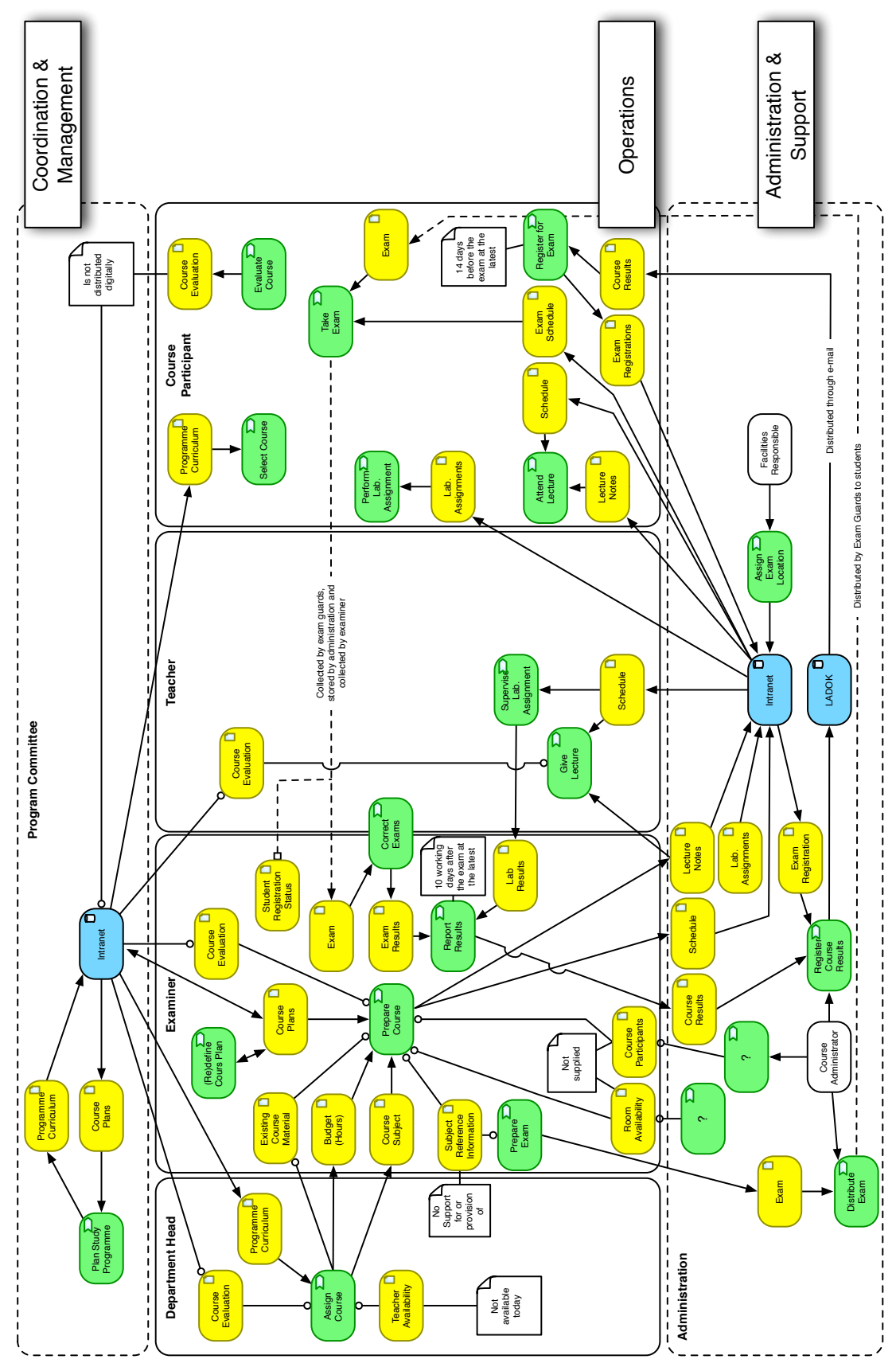

Figure 32. Example case illustration a notation for information demand context models. 
While all entities and relationships part of this notation might not be neither needed nor enough during the actual modelling sessions, the notation is suitable for expressing information demand contexts with respect to roles, tasks, information objects as well as the resources used to access information. The relationships furthermore allow for expressing the gap between any information available to a role when performing tasks and the information demand for doing so as well as any superfluous information a role might have to deal with in such situations. The notation also clearly partitions tasks, information, and resources according to the role or units they relate to. This property is in line with the focus information demand-modelling has on roles.

The notation described here is not fixed in terms of graphical elements, they are merely to be considered as examples, the emphasis is more on the properties, i.e. what shapes and colours one chose to use for modelling information demand contexts is secondary to the statements the models make about the relationships between the included concepts. Consequently, it is up to the method user to decide what is situationally most prudent both during the modelling seminars and for the analysis and evaluation, as long as the constructs used have the ability to express the conceptual underpinning. The same is true for the structure of the model as this is something that has to be based on the requirements and needs of the given modelling session. In the example, it was considered beneficial to structure roles according to organisational function (coordination \& management, operations, administration \& support) and as the notation itself puts no restraints on the structure, this can be done as see fit by the facilitator.

Finally, while it certainly would be possible to interconnect the tasks described in Figure 32. to in such a way also express processes or to structure and interrelate roles in organisational hierarchies, this has intentionally been avoided in the example. The motivation behind this choice is to keep the contextual focus. However, it is exactly for such situations where the need to capture more traditional enterprise aspects without losing the role-oriented view on information demand exists, the unified, EEML-based representation covered in Section 10.2.5. is intended.

\subsubsection{Information Demand Context Analysis and Evaluation}

Once the context-related information is gathered it has to be evaluated (and if necessary clarified and refined) and represented in a format useful for continued work. In addition to refining and digitalising the models, this phase also allows for comparing the resulting models to existing enterprise information if available. During this phase a choice has to be made whether or not the analysis should be continued and if so how in terms of what concepts to focus on and thereby also which additional method components to utilise. If the analysis at this stage is considered done with respect to its intended purposes, as defined during the scoping, the resulting models can be used as is or be represented in the Extended Enterprise Modelling Language as described in Section 10.2.5. depending on the intended use. In addition, during this phase, simple analysis of such things as existing information gaps (the difference between information demand and the information actually provided) or sets of superfluous information can be performed. 
It should however be noted that, as described in the framework (see Figure 28. above), this step has to be iterated over for every additional level of analysis that is added on top on the contextual one. This is required to ensure that any new information gained during such additional analysis activities keeps its connection to the information demand contexts identified during the initial steps of the process. In that sense any additional analysis is used to further refine the information demand identified during the context-modelling, i.e. if context-modelling identifies the general information demand for a specific role then these additional aspects can be used to further add to and/or reduce the information provided in relation to demands while still ensuring the role-perspective taken on information demand.

\subsubsection{Prerequisites}

Since the purpose of this phase is to refine and understand the results gained during the previous phase, the models resulting from that phase is needed. In order to compare and relate the gathered information to existing enterprise knowledge such knowledge has to be available in terms of process maps, organisation charts etc.

\subsubsection{Activities}

The first activity in this phase is to take the models produced during the modelling seminars in the previous phase and "transcribe" these into a well-defined notation with constructs for all concepts and relationships relevant for information demand contexts.

During these activities, the method user has a certain degree of freedom to restructure and change the results from the previous phase if deemed necessary. The reasons for doing so might be obvious mistakes and faults in the original models, additional knowledge gained by comparing the original models to existing documentation or by applying information demand-patterns to the current scope. However, not only should the motivation behind doing so be clear, any changes should also be communicated and explained to the customer at some point. This is preferably done by means of a model walkthrough with the relevant representatives from the customer.

\subsubsection{Expected Results}

The context-modelling should result in the following:

- Information demand context-models approved by the customer.

- Additional models such as enterprise models, competence models etc. also approved by the customer (if additional analysis steps have been performed).

\subsubsection{Support and Tools}

- Modelling software of choice with support for the notation to be used.

\subsubsection{Analysis of Additional and Optional Aspects of Information Demand}

The methodological perspective and its conceptual underpinning define the relevance of additional aspects of information demand besides the core concept of context. As the method is intended to be both extendible and adaptable, the 
framework has no requirements on the choice of methods, notations, and procedures besides what is defined in terms of purpose and intentions. The method components presented here should be viewed as suggestions on approaches to modelling and analysing the respective parts of information demand. If the method user so prefers, components from and/or parts of other methods can be used. Furthermore, all of the components presented in the rest of this section are well established and documented. The focus here is therefore more on describing the purpose of each component from an IDA-perspective rather than the procedures and notations used in each method. This information can be found in the respective method's documentation.

As a part of the overall framework the following activities are considered:

- Enterprise modelling as an approach to model traditional enterprise aspects such as business goals, organisational structures, processes, resources etc. While there are many different methods for enterprise modelling around, a method named Enterprise Knowledge Development (EKD) is considered suitable in this context and is therefore described more in detail in the next section (and also described and exemplified in Case A. in Chapter 8.).

- Social Network Analysis as an approach to understand social networks and informal information flow. For the purposes presented here, a method named $I$-Star $\left(I^{*}\right)$ has been considered and is presented in Section 10.2.4.2.

- Competence modelling as an approach to understand the consequences following from differences in competence between individuals having the same role. The Unified Enterprise Competence Modelling Language (UECML) is presented in Section 10.2.4.3. as a method component suitable for achieving this.

\subsubsection{Method Component for Modelling Enterprise Aspects}

In Chapter 6., common enterprise concepts as goals, resources, positions, and processes etc. are mentioned as relevant aspects of information demand in terms of how such concepts relates to the information demand context. It is also stated in the description of the method framework that such enterprise concepts might be both relevant and useful during the scoping part of the modelling and analysis process. Connecting the identified information demand contexts to the organisational setting in which they exist is indeed in many cases relevant but doing so requires a method component that is compatible with the view of such aspects taken in this method. While there exist many different methods for performing enterprise modelling, the methodological perspective taken here entails certain desirable properties that some existing methods simply do not live up to. The expressed intention to develop a method that is adaptable and extendable implies that the choice of procedures and notations for modelling enterprise aspects of information demand should not be forced upon the method user. As a result, only a suggestion on a suitable approach is given here. The method component, as it is described here, is considered particularly well-suited for the given task but might very well be replaced by others if that is considered beneficial in the given situation. Furthermore, the individual aspects of information demand depicted in Figure 14. can be identified and 
modelled in the same manner as organisational dittos, thus some of the approaches described here can also be used for that purpose.

The method component for enterprise modelling, presented here, is based on parts of the method Enterprise Knowledge Development used in the test case presented in Section 8.2.1. The reason behind this choice is that EKD not only provides all the necessary constructs for analysing all concepts relevant to information demand, it is also well aligned with the participative nature preferred here.

$E K D$ is a method that when developed, focused on generating knowledge about organisations in order to understand enterprise functioning, requirements and reasons for change. EKD is based on a set of description techniques for describing aspects of enterprises (notations), stakeholder participation (participative modelling), a set of guidelines for working (procedures) and a set of software tools with which the following can be produced:

- Goal Models - motivates why tasks are performed and why the organisation is structured in a specific manner. From an information demand perspective, these models can be used as a tool for understanding both organisational goals but also individual goals. Figure 33. is an example of such a goal model.

- Business Rules Models - can provide additional insight into temporal aspects of information demand in terms on the requirements it puts on the various tasks being part of the processes.

- Business Process Models - not only can such process models be used as a tool for modelling processes from an information demand-perspective but they can also be used for scoping purposes when selecting the parts of an organisation to analyse with respect to information demand.

- Actors and Resource Models - even though the context-modelling component is the main methodological approach to understanding the relationship between roles and resources, this part of EKD can be used to analyse and model the individual aspects of resources and connecting individuals to tasks and positions when performing the initial analysis of information demand.

- Concept Models - can be used as a tool during scoping and throughout the process as a tool for facilitating shared understanding of domain specific concepts. Figure 33. illustrates such a model resulting from one of the cases requiring an alignment between the informants and the facilitators understanding of concepts relevant to the case.

- Technical Component and Requirements Models - is intended for when $E K D$ is used to support the development of information system and thus has no relevance for modelling and analysing information demand. 


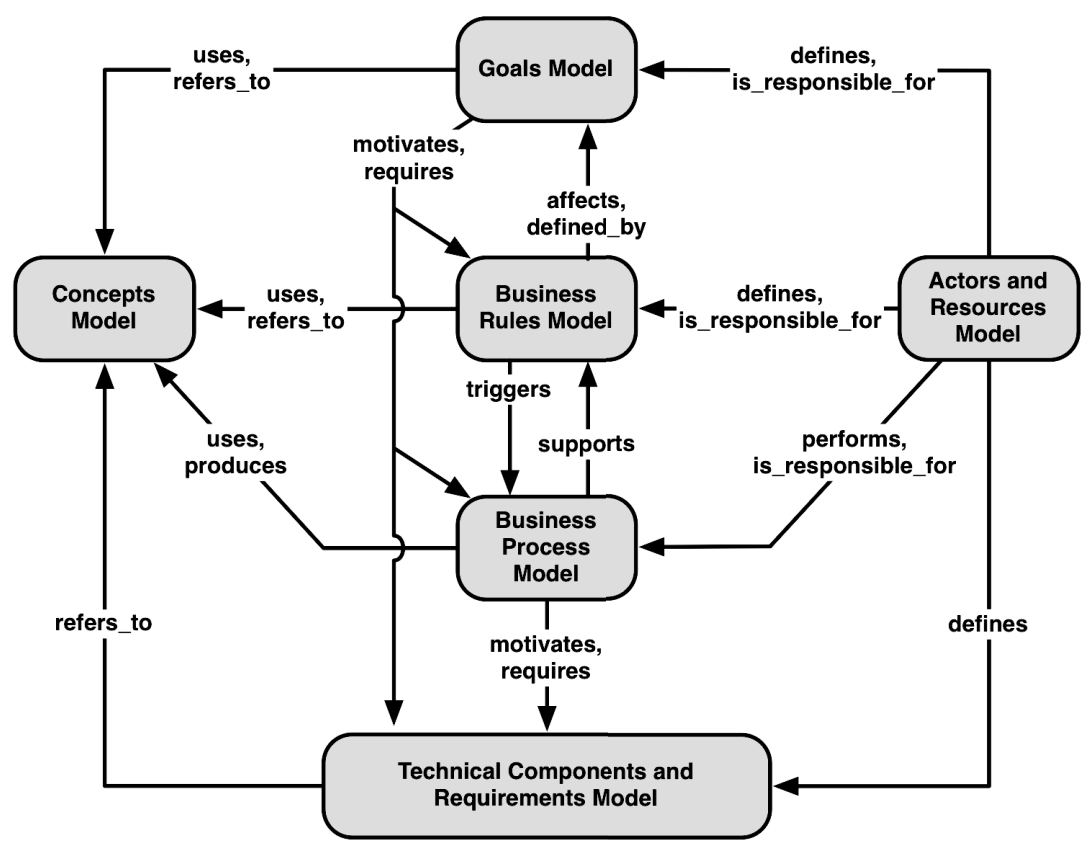

Figure 33. Enterprise Knowledge Development meta-model (Bubenko et al. 2001).

Figure 33. illustrates another concept model expressed in $E K D$, this one detailing the concepts and relationships in EKD itself. While such aspects as tasks, roles, and information objects are not part of the meta-model depicted, it is easy to see the similarities between the parts of this model and the enterprise concepts presented in Figure 12. The EKD-documentation (Bubenko et al. 2001) does in fact describe each component or model listed above in terms of included concepts and interrelationships, procedures, driving questions etc.

To ensure that the conceptual focus described in Figure 11. is properly considered when modelling and analysing enterprise aspects of information demand, the following should be the main orientation:

- How are tasks interrelated in terms of sequence and timing?

- What is the intended purpose with, and expected results from, tasks?

- Who has responsibility for a task (position not individual)?

- What is the organisational relationship between roles?

- Which individuals have which positions, responsibilities, and roles?

- How do the resources provided by the organisation and by individuals within the organisation facilitate the goal fulfilling properties of processes (and thereby tasks)? 
- How do individual's personal goals influence their achievements in their employment positions (and thereby responsibilities and roles) in relation to the organisational goals?

Once models that represent knowledge about an organisation that answers these questions have been produced, that knowledge can be related to existing contextmodels during an analysis activity. The result from this might be as simple as being able to express the sequence of tasks in accordance to some process but it might also result in more complex knowledge about how certain goals in the organisation require specific roles to get access to information not obvious based only on modelling tasks. EKD should in that sense be viewed as a general and useful tool for collecting and representing knowledge that can gain additional insight into information demand identified during the context-analysis.

\subsubsection{Method Component for Modelling of Competence}

The focus on role, repeatedly emphasised throughout this dissertation, allows for a straightforward view on information demand in relation to work tasks, taking a view on demand as an almost functional consequence of a number of well-defined factors. This is of course a quite simplified view on both information demand and the actual individuals having such demand. Even two individuals having the same role, performing the same tasks within the same organisation will have different information demand. This is not only due to different ambitions and goals for performing tasks but also because of differences in experiences and knowledge as well as different preferences regarding planning and execution of work tasks. Some of these individual variations in information demand in relation to roles and tasks can be dealt with by modelling and analysing competence. Competence here being defined as; a combination of tacit and explicit knowledge, behaviour and skill set that gives an individual the potential for effectively performing tasks (Draganidis \& Mentaz, 2006) within a domain or context at different levels of proficiency (Chivers \& Cheetam, 2005).

While competence most certainly can be modelled based on groups or organisation, the view taken here is that of individual competences as this is considered more relevant from the role-based perspective taken in the rest of the method. The conceptual relationship between information demand context and competence modelled in Figure 15. is not very elaborated in the sense that a very simplistic view is taken on competence as a concept. The reason behind this is two-fold; firstly, the meta-models and methods for modelling competence incorporates many of the concepts already defined in other places in this dissertation, secondly, the conceptual view taken is sufficient for formulating the following procedural focus:

- Which individual has what competence?

- How does this competence relate to different positions within the organisation (and thereby to responsibilities and roles)?

- What are the competence requirements for a specific task?

- Through which resources are relevant competence (or information necessary to generate competence) distributed? 
From this focus two methodological properties can be derived; any method used for analysing individual competence with respect to information demand must include constructs for modelling tasks, roles/positions/responsibility, and resources, and competence can only be modelled after the information demand contexts and enterprise aspects have been modelled and integrated.

As UECML is not a method in itself but rather a language and a notation for modelling competence, it does not provide any guidance or procedures for working with it. However, from an information demand-modelling point-of-view, the same participative approach to collecting information about competence as used when modelling contexts or enterprise aspects can be used. The knowledge gained during these activities can then be integrated with the information demand context by differentiating between the roles in terms of their demand based on differences in competence.

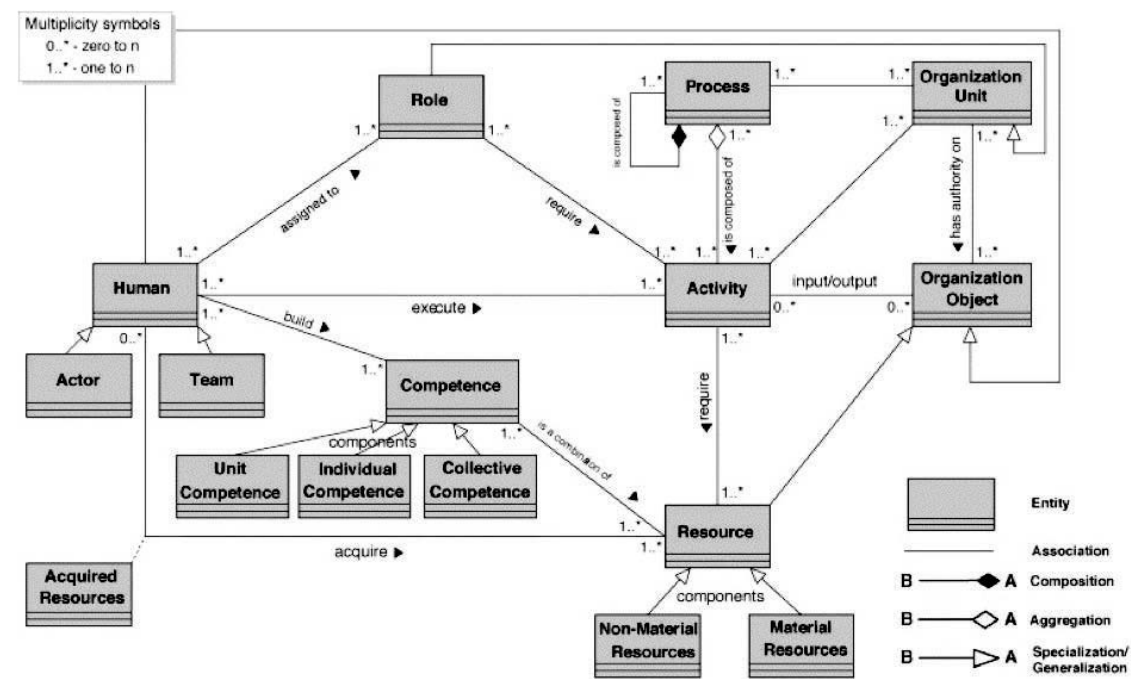

Figure 34. A meta-model for competence modelling in UECML.

\subsubsection{Method Component for Modelling of Social Networks}

The final additional aspect of information demand-modelling, detailed in Figure 16. is social networks and the informal information flow following from them. As such networks are considered a purely individual aspect, it is not directly connected to any one role but rather to the individual having a role. This also means that it is individuals that decide when, how, and to what extent such networks are utilised, depending on their individual goals and preferences. To relate social networks and informal information flow to the actual task to which information demand is related, networks are considered as individual resources and the information provided through them as information objects. Modelling these aspects of information demand thusly focuses on:

- Which individual is part of which social network?

- For what tasks is a specific social network utilised? 
- What individual goals influence the choice of a social network?

- What information does a social network provide?

- What information demands are fulfilled through social networks and how can such demands be met by and through official, organisational channels?

The last question above is not directly related to the modelling and analysis of social networks but from an organisational point-of-view it makes sense to ensure that information necessary to perform certain tasks is available independently of any one individual.

Not many formalised, structured, and conceptualised methods for modelling social networks, as defined here, exist but one of the few is $I$-star $\left(i^{*}\right)$. Strictly speaking $i^{*}$ is not mainly intended for modelling social networks but as it consists of two main modelling components (Yu, 1997) of which the Strategic Dependency model focuses on the dependencies between actors in relation to performing tasks and achieving goals (Dalrymple et al. 2009) it also works for that purpose. Similar to $E K D, i *$ introduce a number of constructs as well as procedures used to analyse and model social networks with respect to actors, goals, tasks and resources (Abdulahadi, 2007). $i^{*}$ also covers many additional aspects of dependencies between actors, agents, processes and software systems, not directly related to the purposes intended here but is nevertheless corresponding well to the social network aspects of information demand. Furthermore, the prescribed way of generating models in $i^{*}$ is by the use of participative methods, therefore aligning the approach with the current methodological perspective.

With respect to $I D A$, analysing social networks is from a practical point-of-view no different than modelling any other type of information source. The difference instead lies in the fact that social networks cannot be modelled role-based as they are connected to the individuals filling such roles, rather than the roles themselves.

\subsubsection{Representation and Documentation of Information Demand}

How to represent the results produced to ensure the communicability of such results is, as discussed in Section 10.2.4., an important aspect of the method presented and discussed here. While a number of different notations are used in the various components the method defines, these are viewed more as working tools used to gain and capture the initial knowledge necessary to understand the information demand. Once the different components are applied the results can, if beneficial or needed, be gathered, compiled, and represented in a unified way. For these purposes, a subset of the Extended Enterprise Modelling Language (EEML) (Krogstie 2003) has been adapted for use with IDA. EEML not only allows for all constructs of IDA to be represented but also provides a clearly defined meta-model as well as a textual representation fulfilling the method requirement concerning communicability. It furthermore provides an unambiguous and clear manner to document an ideal state with respect to information flow that can be used when developing technical solutions to information management. Since both information demand and the method presented here have a clear role-focus, so too will the resulting EEML models. EEML is divided into four different sub-languages well linked together: 
- Process modelling

- Data modelling

- Resource modelling

- Goal modelling

These four sub-languages in turn provide the necessary constructs to provide many of the aspects of information demand discussed here. However, it should be noted that the purpose of representing information demand in EEML-models is not to represent all the information gained during the different modelling efforts but rather to represent the knowledge about information demand gained during them. Consequently, not everything present in the different models and notations produced by applying the various method components might be present in the EEML-models. Furthermore, at this stage in the process it is no longer relevant to distinguish between information provided to the individual and information demands not fulfilled since the purpose of these models is to capture all information needed for a specific task, i.e. the ideal situation from an information perspective.

\subsubsection{EEML Object types}

EEML can be broken down into the various elements, and related to, concepts of $I D A$ as following (all definitions taken from Krogstie 2003):

\section{Task}

The task concept in EEML is used to represent a limited piece of work within a process and can therefore both be decomposed into smaller tasks and be a part of a larger task. This view on representing task works well with the view taken on tasks in IDA. Graphically, tasks are represented as in Figure 35. below. The notation also allows for the status of a task to be expressed by assigning the task a colour. However, as this aspect of tasks is not necessary for $I D A$, this has not been utilised thus far. Figure 35. does not only illustrates task-subtask structure but also the use of decision points (the circular objects on the left and right) which can be of the types; and, xor, and unspecified. EEML use this construct for expressing logical flow in relation to goals but with respect to $I D A$, this is instead used to express relationships between tasks.

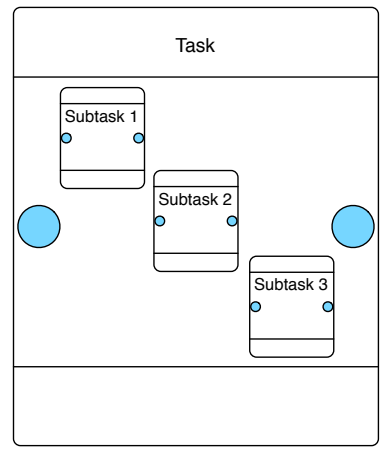

Figure 35. The concept of task expressed in EEML-notation. 


\section{Role}

In its process view EEML defines role as a part played by some resource in a given context, detailing different types of roles; person role, organisational unit role, tool role, and object role. This view on role differs somewhat from that within IDA where only persons and organisational roles are considered as proper roles. The difference in view stems mainly from EEML's more process-oriented view on modelling where for instance machinery can have a clear role in a process and information objects tend to be viewed as transformation objects. Consequently, only person role and organisational unit role are used as role concepts in IDA with the following definitions:

- A person role can only be filled by a person and can designate an active as well as a passive role, hence an object of this type does not necessarily represents an actor.

- An organisation unit role is typically used to express either a group of person roles or the fact that the actual role within an organisation (or unit thereof) is unknown.

In Figure 36. the graphical representation for both types of roles is illustrated. It should however be noted that, when expressing the results from IDA in EEML, the concept of roles as described here is only used when referring to other roles as information resources (as in social networks or as competence support). For dividing tasks over roles, the author has extended EEML with the textual construct of acting role as an attribute to task (exemplified in Figure 39. )

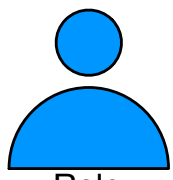

Role

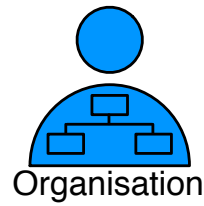

Figure 36. The concept of role expressed in EEML-notation.

\section{Tools and Objects}

The view IDA takes on roles above as well as on tools and objects are instead defined in EEML's resource view where it defines two different types of tools (Software Tool and Manual Tool) and two types of objects (Information Object and Material Object). Such tools and objects are considered to have specific roles during task execution either as enablers or as transformation objects. From an IDAperspective this view on tools and objects are well suited even though there are no real need for capturing Manual Tools and Material Objects. Focus is instead put on the two elements illustrated in Figure 37.

- Software Tool representing software or software-enabled hardware, such as browsers, smartphones etc., used to access information needed for performing tasks. 
- Information Object representing such information needed for performing tasks. Information objects can, when warranted, also be viewed as transformation objects, being the result of work tasks. This is usually the case when one role as a consequence of its work tasks produces information needed by another role later in a process.

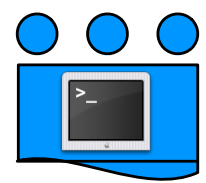

Software Tool

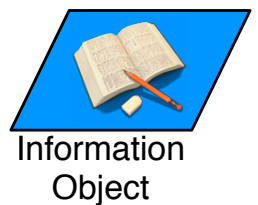

Figure 37. The concepts of tool and object expressed in EEML-notation.

\section{Flow}

Even though IDA does not concerns itself with process sequence to any greater extent there can, as many organisations tend to think in terms of processes, sometimes be cases when it is useful to be able to do so. The method component for context modelling does support expressing sequence between tasks whenever so is wanted or warranted. EEML includes the concept of flow expressing the same function. This is achieved by simply interconnecting tasks with arrows.

The EEML-concepts presented so far can be incorporated to complete models expressing the knowledge about $I D A$ gained during the various modelling activities, thus leading to structures as the one illustrated in Figure 38. The example illustrates not only a sequence of tasks but also how Person Role, Organisation Unit Role, Software Tool, and Information Object can be used as resources when performing tasks. The figure also illustrates an example of an Information Object being used as a transformation object moved between tasks.

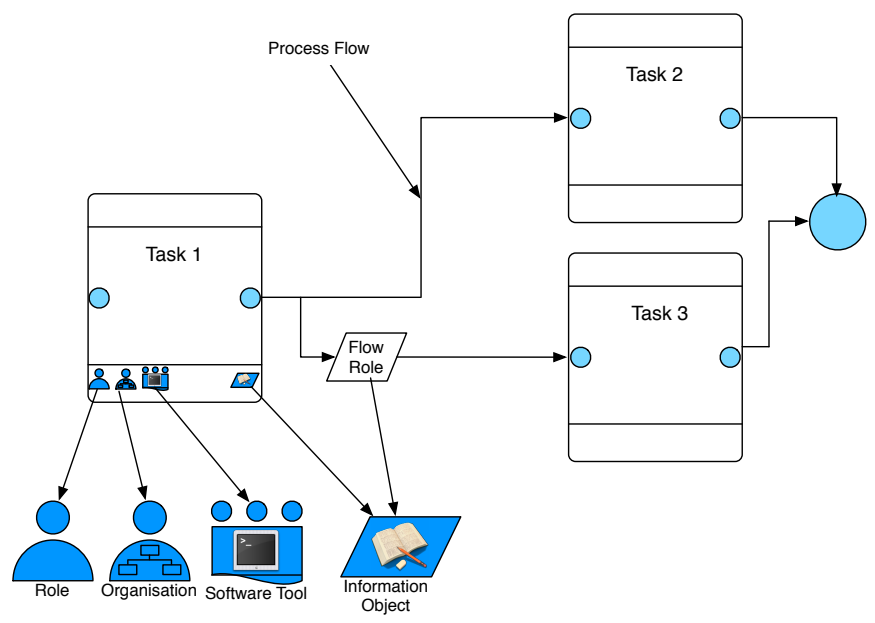

Figure 38. An illustration of a compounded EEML-model. 


\subsubsection{Expressing Results from IDA in EEML}

As the individual method components produces models and documents expressed in different notations the purpose of this phase is to collect and combine the results from any such components used, into a unified, coherent representation that can be used to communicate the information demand as well as utilise it in various activities aimed at improving information demand. This part of the process is a continuous, iterative one that can be done as soon as some part of an organisation has been modelled and analysed with respect to information demand contexts, in the end of several analysis steps or not at all depending on the purposes one have with performing modelling and analysis of information demand.

To exemplify the use of EEML for representing information demand such a model for the role examiner is presented in Figure 39. below. When compared with the information demand context-model described in Figure 32. all tasks as well as information objects can be identified as present with their respective interrelationships. Furthermore, the typical sequence of the different tasks has also been added, something that is not present in the context-model but rather is the consequence of additional process modelling. It also includes the connection between the analysed roles and other roles and organisational departments (independently of the degree of formality involved in this connection). This illustrates the incorporation of both traditional enterprise aspects and individual aspects such as social networks and individual resources in conjunction with information demand into EEML-models. However, as such aspects as time, location, goals, and competence is used more to define differences in demand for specific contexts, these are not represented in the models directly but rather in terms of the actual demand for information and corresponding information objects.

The model in Figure 39. represents all information demands role-based (in this case for the examiner role) for the current scope but can also be further broken down for each task. That is, the information objects detailed in the main task is for the complete context but only some of the objects might be relevant for the sub-task Report Results. Depending on the tool used for generating the models, each task can be represented either as sub-models or as separate models, each with its specific set of information demands and sub-tasks. EEML by itself sets no limits on the depth of representation, as this is something that has to be decided based on the needs and requirement for the specific scope.

\subsubsection{Prerequisites}

In order to collect and unify the results from previous phases any such results must be available and verified as correct with respect to the different stakeholders involved in the analysis, i.e. the models from previous phases and activities must be available.

\subsubsection{Activities}

This phase only contains a single but rather time consuming activity, that of transforming existing models into EEML-models unifying existing results from the preceding modelling and analysis activities. 


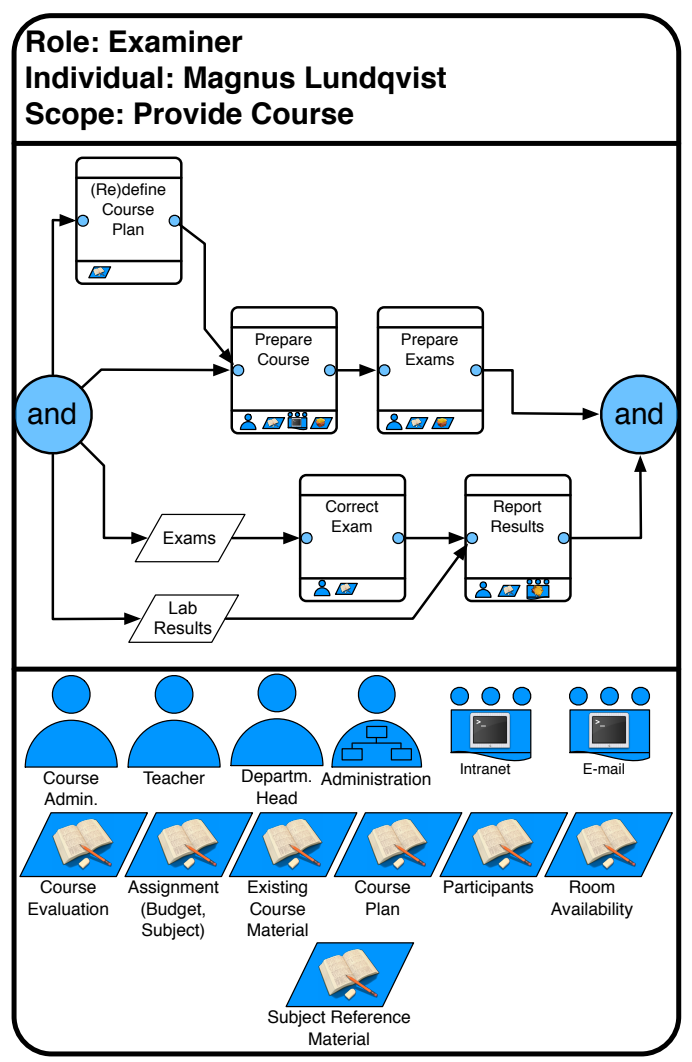

Figure 39. An example information demand context represented in EEML.

\subsubsection{Expected results}

A number of role-focused EEML-models expressing information demand.

\subsubsection{Support and tools}

While it is quite possible to produce EEML-models in any modelling tool, the process is greatly simplified by using a modelling tool that has support for the EEML meta-model and supports expandable views on model such as Troux Technologies Architect (previously named Computas Metis) or Sparx Systems Enterprise Architect. However, there exist simplified templates also for tools such as Microsoft Visio and OmniGroup OmniGraffle. 
This page is intentionally left blank. 


\section{REFLECTIONS ON METHOD DEVELOPMENT}

Before getting in to details on the validity of the method hypothesis presented in the previous chapter, a brief discussion concerning the development process itself is warranted. Generating a method according to the ideas presented in Chapter 2. greatly benefits from a development process that by design allows for the incorporation of revisions to the method, based on new knowledge and experience. As illustrated in Figure 40. the process has a loop over the activities method design, method application, and method validation (and to some extent also method ideals), relying on this approach has allowed for new ideas to be incorporated into the design either based on empirical experience, theoretical knowledge, or internal aspects with respect to cohesion, consistency, and purpose.

The notion of method used (presented in Chapter 7.) allows for existing theories and methods to be evaluated with respect to the emerging method by means of method evaluation, thus providing both empirical- and theoretical grounding. Working with existing methods also allowed for reflection over conceptual focus, procedures, and notations contributing to the methods internal structure thus leading to internal grounding. By applying the emerging method in various cases, both during the development process and after (as detailed below), additional empirical grounding has been gained. Generation and validation of the method has therefore been an incorporated part of the development process itself, just as intended and expressed in Chapter 2. The rest of this chapter discusses various aspects of the method and its development with respect to the Design Science-principles and what have been done in order to ensure their fulfilment. However, as it is the final version of the method hypothesis that has most relevance for what is presented in this dissertation, focus is put on the validation of that final version. It should also be noted that the chapter does not cover any discussion about how the developed method relates to the research questions and intended knowledge contributions presented in Chapter 1. as such a discussion can be found in the next chapter. 


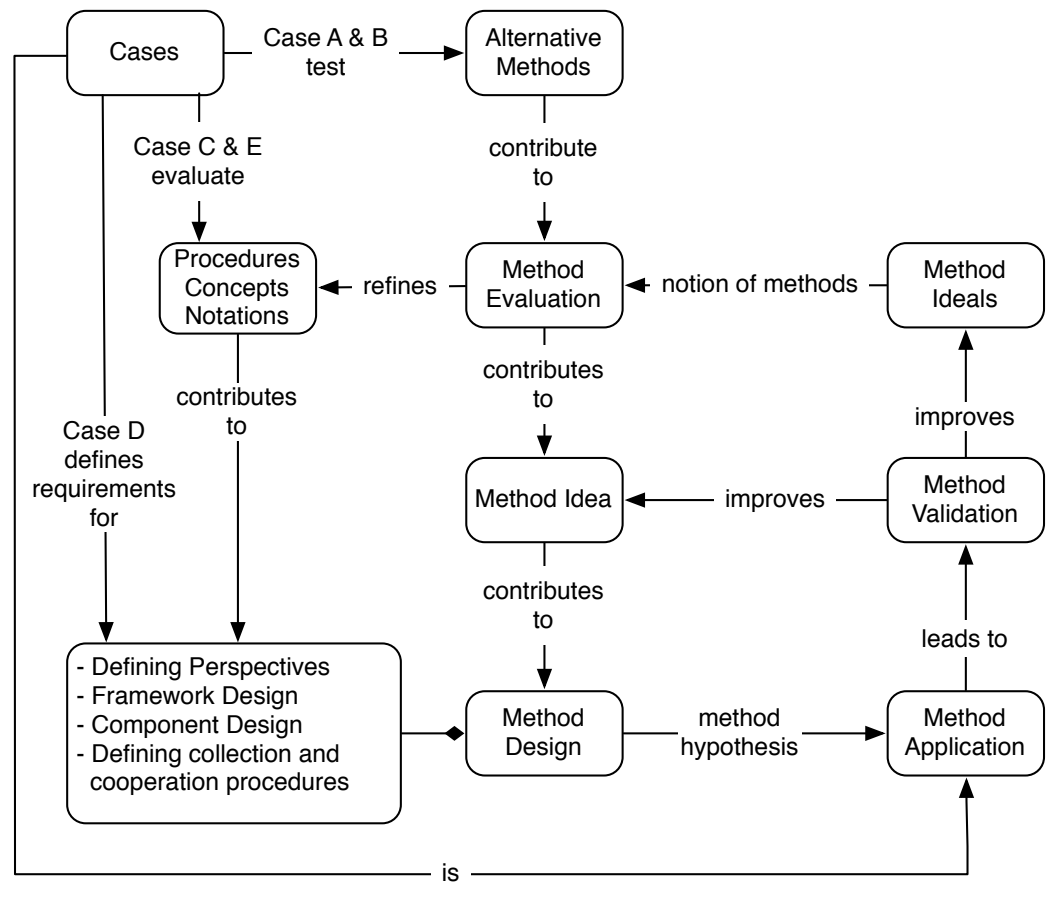

Figure 40. Research process for grounded generation and validation.

\subsection{RELEVANCE \& UTILITY FOR AN ORGANISATIONAL PROBLEM-DOMAIN}

According to the ideas behind the Design Science research methodology, a developed artefact has to be purposeful in the sense that it aims at changing an occurring, problematic phenomenon in an organisational problem-domain (Guideline 2) and it defines problematic as the difference between the current state and a goal state (Hevner et al. 2004). In the case of the artefacts for information demand analysis, this problem-domain is the lack of understanding of information demand in an enterprise context and the consequences following from that. The idea of relevance of the developed artefacts is therefore in large parts based on the assumptions that analysing and understanding information demand is a relevant undertaking in order to improve information flow or to develop demand-driven approaches to information management. One can of course always debate the validity of such a claim but as the empirical- and theoretical foundation presented in Part 2. details the efforts focused on ensuring such validity, it is here claimed that this in fact have been concluded. Any discussion regarding the relevance of the developed artefacts is therefore better focused on the artefacts themselves and whether or not they live up to their intentions. The empirical- and theoretical foundation is however still relevant as exactly that, a foundation to which the developed artefacts have to be related. The way this mainly has been dealt with during the development process is by means of the conceptual refinement presented in Chapter 6 (ART 1.). By, based on the experiences gained from the work on establishing the empirical- and theoretical perspective on information demand, defining the conceptual framework (see Figure 26. ), a connection between the 
organisational problem-domain and the purpose of the methodological framework (ART 2.) have been ensured. To further strengthen this connection that conceptual framework (ART 1.) has been subjected to both theoretical- and empirical grounding throughout the research. The theoretical grounding has been achieved mainly by constantly comparing the concept definitions to definitions used in other methods and fields, which in turn has furthered the development. Parts of that work have been documented in Chapter 6. (theoretical definitions) and in Chapter 9. where other methods, are related to the method hypothesis. From an empirical standpoint, the conceptual framework has been partly generated by the application of the emerging methodological framework (ART 2.) in Case $\mathbf{C}$ and $\mathbf{E}$, and by the use of other approaches to Enterprise Modelling (Case A and B) presented in Chapter 8 . but more importantly, validated through reflective discussions with both industrial and academic partners throughout the development process. It is therefore concluded that the method hypothesis presented here is relevant in the sense that it has a clear focus on a specific organisational problem-domain, i.e. adhering to guideline 2 of $D S$.

Establishing relevance of the method's purpose and focus is however only one part of what is necessary. The method also has to be relevant in its application, i.e. it has to actually do what it says it does and it has to do it in a way that provides utility for the intended users. As utility mainly regards applicability in an industrial context, which the author considers one of the most important aspects of the artefacts developed, this perspective on relevance is best dealt with from an empirical perspective. Consequently, almost all of the generation and validation activities have been performed in cooperation with industrial partners.

Section 9.2. lists a number of industrial objectives for, and requirements on, the developed methodological framework (ART 2.) that was formulated together with representatives from SYSteam Management AB (Evry), which would be considered typical intended method users. Grounding of ART 2. with respect to relevance have therefore mostly been a question of letting these objectives and requirements guide the generation of the artefact and then continuously validate the method hypothesis against them. Below is a list of the different industrial objectives and requirements mentioned in Section 9.2. together with a short discussion on their fulfilment.

\subsubsection{Information Demand Context Aspects}

The first objective defined for the method was that it should be able to capture all relevant aspects of information demand contexts, i.e. answer questions such as:

- What are the responsibilities of different roles?

- What role performs what task within the organisation?

- Which (information) resources and what information are available when performing task?

- At what time and location do tasks have to be performed?

- From what location and at what time can resources be reached? 
As been covered in Chapter 10. this is dealt with by a method component for $I D$ context modelling. Identifying which roles that perform what tasks using what resources and information is done during modelling seminars, optionally together with the time- and location aspects, and then documented with the suggested notation. While the connection between roles and responsibilities is not a part of what can be described by that notation, it can nevertheless be captured during the interviews performed before the seminars. Hence, the method hypothesis is valid with respect to this objective. The way the method component for ID-context modelling is designed also means that it follows the details of Requirement 2. listed in Section 9.2., while the fact that the context-related aspects are modelled separately from the individual-specific aspects means that Requirement 1. also is fulfilled. Furthermore, as the organisational aspects necessary for deriving the context-aspects of information demand is supported by the component for Enterprise Modelling, the same is said about Requirement 3.

\subsubsection{Individual Aspects of Information Demand}

The second objective states that the method should be able to capture all relevant individual aspects of information demand and how they relate to specific information demand contexts, i.e. answer questions such as:

- Who are the individuals having roles within the organisation?

- What competence and goals do these individuals have?

- What expectation does the organisation have on such individuals and vice versa?

- What individual resources do such individuals utilise in their respective roles?

- What social networks do such individuals utilise when performing tasks and what information is exchanged within such social networks?

As the method does provide method components for analysing and modelling these aspects, the objective is considered met on a general level. It should however be made clear that not much empirical testing has been performed yet with regards to such individual aspects. It is therefore highly relevant with continued elaboration and evaluation to ensure the quality of results generated by the application of said components before stating anything conclusive about the utility and relevance from an industrial perspective. However, the conceptual framework clearly states how the individual aspects of information demand should relate to both the information demand context and the organisational aspects, which means that Requirement 5. can be considered fulfilled.

\subsubsection{Method Modularity and Scalability}

To ensure that the developed method has utility for its intended user base within small-scale business contexts, an objective regarding the amount of resources and effort required to reach knowledge about information demand in an analysed organisation was defined. The design of the method framework and its componentbased view has been defined specifically to this end. By making the method 
modular and scalable, a method user can choose how far the analysis of information demand should be taken given the needs and prerequisites for any given situation. This is further supported by the fact that the method allows for other method components to be used instead of the ones provided for Social Network Analysis, Competence Modelling, and Enterprise Modelling as long as such components generates knowledge in accordance with the conceptual framework.

\subsubsection{Utilisation of Existing Knowledge}

In line with the idea of minimising resources and efforts needed to perform an information demand analysis, discussed in the previous section, it was considered as a method objective that the developed method as far as possible should utilise existing organisational knowledge. As the method framework is design to allow existing knowledge to be used during the ID-context Modelling as well as for allowing other method components than the ones defined here to be used when analysing additional aspects of information demand, it is claimed that this objective is fulfilled.

\subsubsection{Machine Understandable Representation}

Some of the industrial partners see knowledge about information demand as something that can be used in the development of IT-solutions for demand-driven information supply. In order for that to be possible, there is however, a need for the method to be able to represent such knowledge in a way that is machine-readable. The EEML-notation for representing information demand, presented in Section 10.2.5. defines exactly that as there is an underlying meta-model in EEML that allows for graphically represented models to be transformed into textual, parsable dittos. This does however require that a tool that supports such transformations to be used when producing the models but as long as so is done Requirement 5. will be met as well.

\subsection{RIGOR OF METHODOLOGICAL EFFORTS}

While the previous sections illustrated that the method indeed have utility for the specified problem-domain and thus, adheres to guideline 3 in $D S$, they do not discuss to what extent this has been rigorously demonstrated. Rigor in research generally, is about how research has been conducted and is therefore often dealt with, as in the case of Part 2. of this dissertation, by relying on the application of appropriate data collection and analysis techniques. From a Design Scienceperspective rigor is however more about relying on effective use of the knowledge base to evaluate the internal cohesion and consistency of the developed artefact. In a sense rigor of artefact development efforts also relates to relevance, as the resulting artefact's utility is a metric on how well it is constructed with its intended purpose in mind. This section will discuss what have been done in terms of validation and generation throughout the development process to ensure rigor of the two artefacts that together constitute a method for analysing information demand.

Rigor of the artefacts presented here have been ensured in a number of different ways with respect to both generation and validation. Firstly, and as discussed in the previous section, quite some effort has been concentrated on the theoretical- and empirical grounding of the conceptual framework (ART 1.) with respect to both the foundation presented in Part 2. and to other methods and theories. Secondly, and more significantly, the notion of method presented in Section 7.3 has been chosen 
specifically to facilitate the design of a internally consistent and coherent methodological framework (ART 2.) as well as the fulfilment of the industrial requirements and objectives. The latter by themselves an example of empirical grounding, performed specifically to ensure both relevance, utility, and rigor of the resulting artefact.

Table 5. Development efforts from a generation and validation perspective.

\begin{tabular}{|c|c|c|}
\hline & Generation & Validation \\
\hline Internally & $\begin{array}{l}\text { Reflective discussions with } \\
\text { academic and industrial partners } \\
\text { where the emerging internal } \\
\text { structure and content of IDA was } \\
\text { questioned with respect to } \\
\text { interrelationships, definitions, } \\
\text { purpose etc. }\end{array}$ & $\begin{array}{l}\text { Evaluation of method consistency in } \\
\text { terms of interrelationships of its } \\
\text { various parts, both by comparing it } \\
\text { to existing theory as well as } \\
\text { reflecting over results from } \\
\text { empirical cases. }\end{array}$ \\
\hline Theoretically & $\begin{array}{l}\text { Relating conceptual definitions to } \\
\text { existing methods and established } \\
\text { knowledge. } \\
\text { Use of a theoretically sound and } \\
\text { valid method notion to provide a } \\
\text { conceptual structure for IDA. } \\
\text { Relating method components to } \\
\text { existing methods. }\end{array}$ & $\begin{array}{l}\text { Analysis of validity in comparison to } \\
\text { existing method's practices. }\end{array}$ \\
\hline Empirically & $\begin{array}{l}\text { Interview-based investigation for } \\
\text { deriving method focus, conceptual } \\
\text { foundation, and requirements. } \\
\text { Practical application of the evolving } \\
\text { method together with industrial } \\
\text { partners. } \\
\text { Development of support } \\
\text { documentation together with } \\
\text { industrial partners (method } \\
\text { handbook). } \\
\text { Comparison of the emerging method } \\
\text { against defined requirements. }\end{array}$ & $\begin{array}{l}\text { Evaluating the usefulness and } \\
\text { applicability of the method in } \\
\text { several industrial cases. } \\
\text { Industrial method-use and - } \\
\text { evaluation by external parties by } \\
\text { means of a formal method } \\
\text { evaluation framework. } \\
\text { Industrial use and evaluation of } \\
\text { method handbook. (Not covered in } \\
\text { this dissertation). } \\
\text { Comparison of the method against } \\
\text { defined requirements. }\end{array}$ \\
\hline
\end{tabular}

The method's framework (ART 2.B.), in line with the prescriptive view on methods taken in Chapter 7., supports and reflects the method's perspectives (ART 2.A.). It also clearly specifies sequence and expected outcomes of the method's various components (ART 2.C.), which in turn can be directly related to specific parts of the conceptual framework (ART 1.) It also specifies how a unified way to represent information demand (ART 2.D.) should be used. As this view on methods made development of method components an issue of ensuring that they produce the results defined in the framework, it allowed for an incremental and iterative approach to method development where each component could be generated and validated on its own. The different cases, presented in Chapter 8 . and 9 respectively, are examples of how ideas for method components have been tested in an empirical setting and thereby generated knowledge to be used during the continued 
refinement of the components. The emerging method components were also constantly related and compared to statements made in the method framework, as well as to the conceptual framework to ensure that they indeed do produce the required results in the prescribed manner. On a procedural level, theoretical grounding has been ensured by, as far as possible relying, on existing and wellestablished methods and procedures, such as EKD, $i^{*}$, and UECML. Rather than inventing new method components, using parts or components from such existing methods have simplified as well as strengthen the validity of the developed method. Table 5. above summarise what has been done in terms of design evaluation as well as ensuring rigor of the two artefacts and thereby adhering to $D S$ guideline 3 and 5 .

\subsection{METHOD COMMUNICABILITY}

Design Science details requirements for the communicability of research results with respect to both technology and management-oriented audiences (Guideline 7). It does so with the argument that artefacts such as methods have to be understandable by both people focusing on development and people focusing on application and usage. Independently of $D S$, this is a highly relevant subject also for the method presented here. As already been touched upon in several parts of this dissertation, not the least of which in the industrial requirements in Section 9.2. and the validation of the method draft performed in Case E., utility of the method for modelling and analysing information demand, is highly dependent on the communicability of its various parts. At the same time this dissertation clearly is more oriented towards a scientific community interested in aspects of the development process, which makes it a less suitable medium for providing intended method users with the method knowledge needed. The way this has been dealt with throughout the research process is by creating a multitude of documentation geared towards different audiences.

The scientific aspects are mainly communicated through this dissertation but also through the peer-reviewed papers listed in Section 1.4., specifically the following:

- Lundqvist, M., Holmquist, E., Sandkuhl, K., Seigerroth, U., Strandesjö, J. (2009) Information Demand Context Modelling for Improved Information Flow: Experiences and Practices, in The Practice of Enterprise Modeling, Lecture Notes in Business Information Processing Book Series, ISSN 18651348. pp. 8-22

- Lundqvist, M., Sandkuhl, K. \& Seigerroth, U. (2011) Modelling Information Demand in an Enterprise Context: Method, Notation, and Lessons Learned, in Gustas, R. (Ed.) International Journal of Information System Modeling and Design, Vol. 2, Issue 3, July-September, 2011. ISSN 1947-8186.

- Lundqvist, M., Sandkuhl, K., Seigerroth, U. (2012) Enterprise Modelling in Distributed Teams-Lessons Learned from Information Demand Modelling. In: M. Kirikova, J. Stirna (Eds.): Proceedings of the CAiSE'12 Forum, Gdansk, Poland, June 28, 2012. CEUR Workshop Proceedings 855, pp. 139-146. 
- Lundqvist, M., Sandkuhl, K. \& Seigerroth, U. (2012) Transfer of Method Knowledge and Modelling in Distributed Teams - Lessons Learned, in N. Asseva, E. Babkin, \& O. Kozyrev, eds. Perspectives in Business Informatics Research. $11^{\text {th }}$ International Conference, BIR2012, Nizhny Novgorod, Russia. Proceedings LNBIP 128, pp. 26-40. Springer 2012, ISBN 978-3-64233280-7.

For the reader with a specific interest in the work presented here from a scientific point-of-view, those should, together with this dissertation, provide everything that is need regarding both information demand and the suggested method for modelling and analysing it. However, for those readers with an interest more focused on the organisational application and benefits of the method presented in this dissertation there are better alternatives. In order to support such readers two language versions (Swedish and English) of a method handbook (Lundqvist et al. 2009) have been written. This has been done in cooperation with representatives from one of the industrial partners, SYSteam Management AB (Evry), as they are considered typical intended method users. As a part of the development of the handbook the various versions have been reviewed by a number of management consultants from the perspective of intended method users with respect to readability, comprehension, and completeness, thus rectifying the comments regarding communicability that was made during the method evaluation in Case $\mathbf{E}$.

\subsection{SUMMARY OF METHODOLOGICAL EFFORTS WITH REGARDS TO DESIGN SCIENCE}

Given the work and the results presented so far in Part 3., it is relevant to relate the research process, in terms of artefact development, to the seven guidelines the Design Science research methodology stipulates.

Table 6. Development efforts in relation to Design Science guidelines.

\begin{tabular}{|c|c|}
\hline Guideline & Description \\
\hline 1: Design as an Artefact & $\begin{array}{l}\text { Design-science research must produce a viable artifact in the } \\
\text { form of a construct, a model, a method, or an instantiation. } \\
\text { The research presented in Part 3. of this dissertation has } \\
\text { focused on the development of two separate (but related) } \\
\text { artefacts; a conceptual framework (ART 1.) and a } \\
\text { methodological framework (ART 2.). }\end{array}$ \\
\hline 2: Problem Relevance & $\begin{array}{l}\text { The objective of design-science research is to develop } \\
\text { technology-based solutions to important and relevant business } \\
\text { problems. } \\
\text { A business problem has been identified through a theory } \\
\text { review and an empirical investigation. } \\
\text { A conceptual framework (ART 1.) has been designed with } \\
\text { respect to this business problem in terms of industrial } \\
\text { requirements, in adherence with the theoretical and empirical } \\
\text { foundation as well as evaluated through its ability to act as a } \\
\text { basis for a methodological framework. } \\
\text { A methodological framework (ART 2.) has been design with } \\
\text { respect to this business problem through the use of the }\end{array}$ \\
\hline
\end{tabular}




\begin{tabular}{|c|c|}
\hline & $\begin{array}{l}\text { conceptual framework. It has been both developed and } \\
\text { evaluated together with industrial partners in real-world cases. }\end{array}$ \\
\hline 3: Design Evaluation & $\begin{array}{l}\text { The utility, quality, and efficacy of a design artifact must be } \\
\text { rigorously demonstrated via well-executed evaluation } \\
\text { methods. } \\
\text { The methodological framework (ART 2.) has been } \\
\text { continuously evaluated with regards to utility, quality, and } \\
\text { efficacy in real-world cases through the use of a method for } \\
\text { well-grounded method development as well as by use of the } \\
\text { Normative Information Model-base System Analysis and } \\
\text { Design-approach (NIMSAD). } \\
\text { The conceptual framework (ART 1.) has been evaluated } \\
\text { mainly through its ability to act as a conceptual foundation for } \\
\text { ART 2. but also through reflective discussions with industrial } \\
\text { and academic partners as well as by being subjected to peer- } \\
\text { review. }\end{array}$ \\
\hline 4: Research Contribution & $\begin{array}{l}\text { Effective design-science research must provide clear and } \\
\text { verifiable contributions in the areas of the design artifact, } \\
\text { design foundations, and/or design methodologies. } \\
\text { The research process has besides the two artefacts themselves } \\
\text { also resulted in new definitions and increased understanding of } \\
\text { design foundations for a specific problem-domain, } \\
\text { documented in a transparent and detailed manner. }\end{array}$ \\
\hline 5: Research Rigor & $\begin{array}{l}\text { Design-science research relies upon the application of } \\
\text { rigorous methods in both the construction and evaluation of } \\
\text { the design artifact. } \\
\text { Research rigor regarding artefact development has been } \\
\text { ensured by internal, theoretical, and empirical grounding } \\
\text { according to a method for well-grounded method development } \\
\text { as well as through evaluation with the NIMSAD-approach. }\end{array}$ \\
\hline 6: Design as a Search Process & $\begin{array}{l}\text { The search for an effective artifact requires utilizing available } \\
\text { means to reach desired ends while satisfying laws in the } \\
\text { problem environment. } \\
\text { Artefact-development has been performed by, as far as } \\
\text { possible, utilising existing artefacts and in accordance to } \\
\text { theoretical and empirical knowledge regarding the business } \\
\text { problem. }\end{array}$ \\
\hline 7: Communication of Research & $\begin{array}{l}\text { Design-science research must be presented effectively both to } \\
\text { technology-oriented as well as management-oriented } \\
\text { audiences. } \\
\text { The research has been communicated in form of scientific } \\
\text { publications focusing on methodological aspects, as well as in } \\
\text { form of handbooks focusing on usage and application. }\end{array}$ \\
\hline
\end{tabular}


This page is intentionally left blank. 


\section{PART 4 - RESEARCH RESULTS}

This, the final part, concludes the research regarding information demand by discussing the results and consequences of what have been detailed in the previous parts of the dissertation. 
This page is intentionally left blank. 


\section{DISCUSSION \& CONCLUSIONS}

The main intent and focus of the research presented in this dissertation have been on the development of a method for modelling and analysis of information demand in an enterprise context. The ambition has been to do so based on empirically and theoretically grounded needs and requirements. The discussion covered in this chapter will focus on the research presented, in relation to the research questions defined in Chapter 1. and the implications this has for the intended knowledge contributions. It will also cover a reflection on the research itself.

\subsection{RESEARCH QUESTIONS}

In Chapter 1. two different research questions were presented:

RQ1. What is, and what defines, information demand from an enterprise perspective?

RQ2. How is a structured and industrially relevant approach to analysing and representing information demand supported?

As the research into these two questions now has reached its end, it is relevant to discuss if, and how, they have been answered. Based on the content of Part 2. of this dissertation it can here be concluded that information demand indeed has been defined and as this definition is sufficiently grounded both empirically and theoretically to be considered valid. It is therefore here claimed that RQ1. is answered.

Given the notion of methods used, and the method designed accordingly, it is the author's view that the research presented in this dissertation has resulted in two separate but related artefacts that together constitutes a method for analysing and representing information demand, which lives up to the intentions regarding results and practical contributions presented in Chapter 1.2. The developed method is, based on a conceptual framework, is utilising both existing and newly developed method components, held together by a coherent framework expressing how to sequence, and combine different method steps. It is furthermore claimed that this method and its foundation has been proven to work in accordance with both empirical and theoretical requirements, as well as having relevance and utility with respect to the indented purpose. It is therefore claimed that also RQ2. has been answered and that it has been answered in such a way that it adheres well with the seven guidelines of Design Science. 


\subsection{KNOWLEDGE CONTRIBUTIONS}

Just answering a number of research questions, even if done in a scientifically valid and sound way, does however not by itself ensure that such answers contributes to the general body of scientific knowledge. As inventing a method for analysing information demand would be pointless if such a method did not solve actual reallife problems and added to the general body of knowledge, the method and its parts will be discussed from the perspective of each intended contribution, as listed in Chapter 1.3.

\subsubsection{An Information Demand Perspective on Enterprise Analysis}

Even though it cannot be claimed that the perspective on information demand anduse presented here is completely unique and novel in all its parts, it is claimed that this work in fact is the most comprehensive piece available on the subject up to date. Regardless of the developed method itself, the preparatory work done on information demand and -use in Lundqvist (2007) in conjunction with the elaboration of the conceptual underpinning presented in Chapter 6. provide the foundation necessary for such a perspective on enterprise analysis. No matter if one is interested in actually analysing information demand or just being able to reason about it, this work should provide the necessary constructs for doing so. It is therefore also believed that this work indeed can be used as an approach to better understand organisations from an information demand perspective and thus support better alignment between business needs and technical solutions. The fact that many already well established concepts and constructs are incorporated into this work does not contradict this conclusion. The novelty in the approach and its inherent parts lies not in the parts themselves but rather in how they are combined for a specific purpose. This is from the author's standpoint an advantage of the work as this allows existing knowledge to be utilised in the generation of new ditto. From a research methodological point-of-view, this also integrates well into the ideas of Design Science in terms of utility and rigor. It is this new perspective on enterprise analysis that defines the basic requirements on the resulting method, as the conceptual underpinning of the area as such also define the methodological perspective and focus taken. By, on a conceptual level deciding that information demand contexts are at the core of information demand, one decides that so should be the case also on a methodological level. This is also exactly what has been done as the component for analysing information demand context has a central role in the framework as well as being the one component that is most elaborated upon.

A large part of contributing to an information demand-perspective on enterprise analysis, as described above, has been to refine the conceptual foundation on which such a perspective rests. The conceptual underpinning of information demand presented in Chapter 6 . is proven well suited as a basis for reasoning about information demand and as a foundation for developing a method that generates the knowledge necessary for doing so. When relating the method hypothesis presented in Chapter 10. to the conceptual refinement of information demand, one can observe a clear connection between the method's various parts and the concepts identified as important and central to information demand. As this conceptual refinement by now is empirically, theoretically, and internally grounded as well as evaluated in several real-life cases it is consequently claimed that this contribution 
is achieved and that the research question regarding the wanted properties and requirements on a method for information demand analysis is sufficiently answered.

\subsubsection{Evaluation and Use of Existing Methods from a Demand Perspective}

As detailed in Chapter 8., 9., and 10. respectively, several existing methods for analysing various aspects of enterprises have been studied, considered, and to some extent evaluated through application in empirical cases. As a method specifically adopted in accordance with this new perspective has already been presented, one may ask what the relevance of this evaluation is outside the scope of this research. The answer lies in the separation of conceptual and methodological perspective taken on knowledge contributions. While the author does present a methodological approach to analysing information he also believes that there is an inherent value in allowing for other methods being developed or used with the same purpose. That is, the purpose of analysing information demand is from the author's perspective more important than the choice of actual method used in order to do so. Adding to this, the clear intent that the developed method should be both flexible and adoptable, as well as based on existing knowledge and methods, and the value of this contribution should be considered clarified.

Given the initial research problem, the intention and wish to, as far as possible, utilise and/or adapt existing methods when analysing information demand, a survey of existing methods was needed. As also stated in Chapter 1., it was quite early on in the process realised that there was no existing method for analysing information demand. Consequently, focus was instead put on identifying exiting method that that are suitable for analysing and representing specific parts of information demand and as shown in Chapter 8 and 9. there definitely are such methods. The question therefore rather became one of integration more than that of utilisation or adaptation. Besides the conceptual framework already discussed, another contribution of this work is the methodological framework presented in Chapter 10., which is relevant as it is on a framework level this integration has to be dealt with. As the methodological framework is based on a combination of well-defined methodological theories as well as empirically grounded conceptual foundation it is claimed that the framework is well-suited as a tool for promoting an information demand-perspective on enterprise analysis in general and information demand in particular.

With that said, the framework can of course be both additionally evaluated and developed. As will be explained later in this chapter work with exactly this purpose has already been performed.

To some extent, the issue of generating new procedures and notations relates to that of developing a method framework. As explained in Chapter 7 and 10. the method framework ties the various method components together in terms of sequence and goal. It is consequently also a relationship between the intended knowledge contributions and the research question discussed in the previous sections. In the cases where existing method fragments have been chosen, such procedures and notation have been integrated into the method framework. In that sense most of the methodological work has been focused on the framework level rather than on component level. 
The work that after all has been done on procedures and notations has for obvious reasons been done on the areas where existing methods have not been able to provide the necessary constructs and approaches, mainly in the area of information demand contexts. The author claims that from a contribution perspective this also makes the most sense. With a framework allowing for the integration of existing method fragments where suitable, the effort is best spent on the parts that are novel and thus most in need of development.

\subsection{METHODOLOGICAL AND PRACTICAL REFLECTIONS}

Considering that the dissertation you just have read is the documentation of a research process spanning roughly ten years, there are some comments to be made concerning its coverage of said research process. Even though it in this dissertation might appear as the results generated have been the output of a cohesive and sequential process, quite the opposite is in fact true. As the author has spent the last five years working with enterprise modelling and -integration in an industrial setting, while at the same time continued publishing scientific articles $(15,16,17$ in the list presented in Chapter 1.), many new insights into the area of information demand have been gained. During those five years, the method detailed in this dissertation also has been applied in several industrial projects by the author, as well as by SYSteam management $A B$ (Evry) as a service offering to their customers. Additionally, other researchers have, as covered in the next section, during recent years published research that is both directly related to, and relevant for, the utility, relevance, and rigor of the developed method. It has therefore, to say the least, been quite a challenge to document a series of loosely related research- and industrial activities and relating them to a constantly evolving purpose in a way that is communicable. One of the hardest aspects of authoring a dissertation under such circumstances is to know when to stop, to decide on an appropriate level of generated knowledge, despite the fact that such knowledge is continuously generated also during the process of writing, especially so when the writing take such long time as it has in this case.

It is the author's belief that the dissertation, as it has been presented, provides a valid and sound scientific foundation for the area of information demand analysis but it should nevertheless be noted that it is not an entirely accurate representation of the current state of knowledge on the subject. That, which has been presented here is therefore in many aspects best considered as a method hypothesis rather than a finished method. Consequently, there are extensions and elaborations to the research presented here, which could be beneficial to the area. In some cases, as with additional empirical application and evaluation below, it mainly is a question of documenting and building on what have already been done but not included in the dissertation. In other cases, it involves defining completely new research efforts.

\subsection{FUTURE RESEARCH}

The core of the method for IDA, focusing on information demand context is by now considered conceptual and methodological defined and proven. Still, the component for analysing such contexts would benefit from additional industrial application, as this would further evaluate the various notations and procedures involved. Furthermore, doing so would also prove if and to what extent the method component is domain independent. At the time of this text being written, several 
instances of such additional empirical evaluation already have been, or are being, performed. Several of the partners involved in the InfoFlow-project are using the method in both an academic and an industrial setting. There have also been additional research activities performed, focusing on the theoretical and empirical elaboration of results presented here. Some examples of such additional work is:

- Sandkuhl, K. (2010) Validation and Use of Information Demand Patterns in Higher Education. BIS 2010 International Workshops, Berlin, Germany, May 3-5, 2010. LNBIP Volume 57, Springer, 2010.

- Sandkuhl, K. (2012) Improving Quote Preparation in Project Management with Information Demand Patterns. In: N. Aseeva, E. Babkin and O. Kozyrev (Eds.): Perspectives in Business Informatics Research - 11th International Conference, BIR 2012, Nizhny Novgorod, Russia, September 24-26, 2012. Proceedings. LNBIP 128, pp. 41-53. Springer 2012, ISBN 978-3-642-33280-7.

- Zeiner, V. (2013) Development and Validation of a Team Pattern using an Example from Project Management. Master Thesis. Rostock University, March 2013. (To be published as an article in beginning of 2016).

- Sandkuhl, K. (2013) Improving Engineering Change Management with Information Demand Patterns. In: Henk Jan Pels, Abdelaziz Bouras, Chris McMahon (Eds.) Product Lifecycle Management: Virtual Product Lifecycles for Green Products and Services. Proc. PLM11, Eindhoven, The Netherlands, pp. 47 - 58. Inderscience Enterprises Ltd. 2013. ISBN 97890 79182268 .

- Sandkuhl, K., Matulevičius, R., Kirikova, M. and Ahmed, N (2015) Integration of IT-Security Aspects into Information Demand Analysis and Patterns. Proceedings of Workshop and Doctoral Consortium at BIR 2015 Conference. CEUR Online Proceedings, August 2015, Tartu, Estonia.

\subsubsection{Notational Refinement}

The notation currently used for describing information demand contexts have evolved and changed several times during the research process and while it now is considered well suited for its purposes it could benefit from formal evaluation in terms of efficacy, communicability, and correctness as well as a more rigid underlying meta-model. Ideas for how this can and should be done, can either be based on investigating existing notations such as UML, EEML etc. or by relaying on evaluation principles as the ones presented in Moody (2009).

\subsubsection{Integration of Method Components}

In this dissertation, the focus has mainly been on defining the conceptual and methodological framework as well as the core method component for modelling of information demand context. The method would greatly benefit from elaboration on how to more closely integrate the method components for modelling competence, social networks, and enterprise aspects. 


\subsubsection{Method Extensions}

During the writing of this dissertation other research (see list above) have focused on identifying commonly occurring information demands in different situations and contexts. The aim of such research is to, by means of information demand modelling through the use of the method presented here, identify and describe commonly recurring information demands as information demand patterns. The purpose of such patterns is to facilitate the application of technological and organisational solutions to solve information demand related problems.

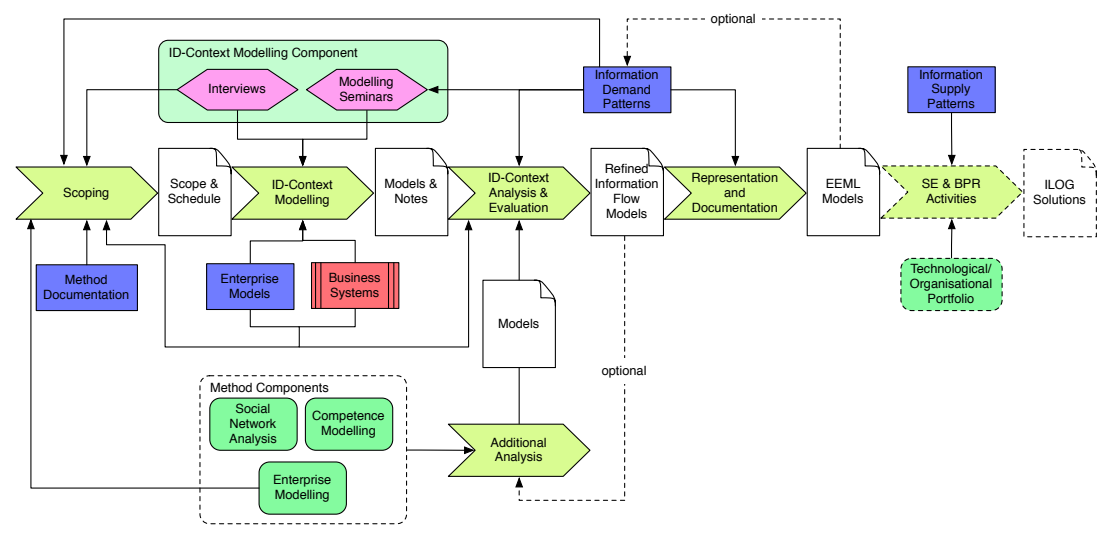

Figure 41. Extended process for information demand analysis.

The general idea is that by applying the method covered in this dissertation on many different types of cases in different domains, the knowledge necessary for generalising information demand contexts into patterns can be incorporated into the method framework described in Chapter 10. Figure 41. above illustrates how the existing framework would utilise such patterns throughout the process. It is believed that patterns of this type would not only shortens and simplify the analysis needed but also improve the possibilities to quickly and efficiently solve information demand-related problems.

\subsubsection{Information Demand Analysis and the Field of Enterprise Modelling}

As is to be expected quite a lot happens within a field during a period of 5-10 years and for a method to have lasting value in an industrial context, it too has to evolve in sync with what is happening in such a context. When it comes to the fields of enterprise analysis quite a lot has been happening only the last 3-5 years or so, that has relevance for what has been presented here. Most notably is the fact that enterprise modelling as an approach to analyse, document, understand, and change organisations really has taken off. What used to be something only some, usually larger, organisations relied on when this research process was initiated, is today something that is leveraged, at least in Sweden, on a regular basis. There are of course still large differences between organisations in terms of maturity and coverage with respect to usage but by and large enterprise modelling has proliferated. As a consequence of this more and more organisations have also started to think about such aspects of enterprise modelling as traceability, reuse, governance, project management etc. If the method developed and described here 
should have industrial utility also in the future, it has to change in relation to such trends. It needs to be possible to use the method in a larger enterprise landscape, together with other methods for, and approaches to, enterprise modelling. Results produced with the method have to be possible to relate to, and managed together with, other models. These are aspects of the method that have not been considered at all during the research presented here and is consequently an important topic for future research. 
This page is intentionally left blank. 


\section{REFERENCES}

Extended methodological framework for IDA., Department of Computer and Systems Sciences, Royal Institute of Technology, Stockholm, Sweden, $\mathrm{ftp}$ //ftp.dsv.su.se/users/js/ekd_user_guide_2001.pdf

Baeza-Yates, R. \& Ribeiro-Neto, B. (1999) Modern Information Retrieval. Harlow, UK: Addison-Wesley.

Bennett, Robert, Bratton, William \& Robson, Paul (2000). Business Advice: The Influence of Distance. Regional Studies, vol. 34, p. 813-28.

Bouwan, Harry \& van de Wijngaert, Lidwien (2002). Content and context: an exploration of the basic characteristics of information needs. New Media \& Society, vol. 4, p. 329-53.

Braverman, J (1984). Maximizing Profits in Small and Medium-Sized Businesses. New York, USA: Van Nostrand Reinhold Company.

Brinkkemper, S. (1995) Method engineering: engineering of information systems development methods and tools, in Information and Software Technology (37:11).

Burke, W. (1993) Organisational Development - A Process of Learning and Changing $2^{\text {nd }}$ ed., Addison-Wesley Publishing Company

Calof, J.L. (1994). The relationship between firm size and export behaviour revisited. Journal of International Business Studies, vol. 2, p. 367-87.

Checkland, P. (1981) Systems Thinking, Systems Practice. New York, NY, USA: John Wiley and Sons. ISBN 978-0471279112.

Cheetham, G. \& Chivers, G. (2005) Professions, Competence and Informal Learning. Cheltenham, UK: Edward Elgar Publishing Limited. ISBN 1-84376-4083.

Clarke, Thomas \& Rollo, Christine (2001) Corporate initiatives in knowledge management. Education + Training, vol. 43, p. 206-14.

Cole, C. (1998) Intelligent Information Retrieval: Diagnosing Information Need. Part 1. The Theoretical Framework for Developing an Intelligent IR Tool. Information Processing \& Management, vol. 34, p. 709-20.

Cole, K. \& Carter, S. (1996) The Optimization of Online Searches Through the Labelling of a Dynamic, Situation-Dependent Information Need: the Reference Interview and Online Searching for Undergraduates Doing a Social-Science Assignment. Information Processing \& Management, vol. 32, p. 709-17.

Cushway, B., Lodge, D. (1999) Organizational Behaviour and Design $2^{\text {nd }}$ Edition. London, UK: Biddles Ltd, Guildford and King's Lynn. ISBN 0-7494-2953-4. 
Dalrymple, P. W., Rogers, M., An, Y. (2009) Effect of Early Requirements Analysis and Participative Design on Staff in an Urban Health Clinic: Civic Engagement through Collaboration.

(http://idea.library.drexel.edu/handle/1860/3152)

Davenport, T.H. (1993) Process Innovation: Reengineering Work Through Information Technology. Boston, MA, USA: Harvard Business School Press.

Deiters, W., Löffeler, T, Pfenningschmidt, S. (2003) The Information Logistical Approach toward a User Demand-driven Information Supply, in Spinellis (ed.) Cross-Media Service Delivery. Boston, Mass. US/Dordrecht, Germany/London, UK: Kluwer Academic Publisher. p. 37-48.

Delphi Group (2002) Perspectives on Information Retrieval. Boston Mass. US: Delphi Group. (Report/Perspectives on Information Retrieval).

Deschoolmeester, Dirk, Braet, Olivier \& Lootens, Annick (2002). Internet-ability: the feasibility and ability of information technology adoption by SMEs, in Proceedings of the 32nd Entrepreneurship Innovation and Small Business Conference, Sophia Antiplois, September 2002; p. 181-92.

Dey, Anind \& Abowd, Gregory (1999). Towards a Better Understanding of Context and Context-Awareness. Atlanta, Georgia, USA: Graphics, Visualization and Usability Center and College of Computing, Georgia Institute of Technology, Atlanta, GA, USA. (GVU Technical Report GIT-GVU-99-22).

Dick, B. (2002) Grounded theory: a thumbnail sketch. [online] Available at http://www.scu.edu.au/schools/gcm/ar/arp/grounded.html. Accessed 2010-09-24.

Draganidis, F. \& Mentaz, G. (2006) Competency based management: a review of systems and approaches, in Information Management \& Computer Security, Vol. 14, No. 1, p. 51-64. Emerald Group Publishing Limited.

Edmunds, A. \& Morris, A. (2000) The problem of information overload in business organisations: a review of the literature, in International Journal of Information Management, Vol. 20, No. 4, p. 17-28. Elsevier Science Ltd.

Eppler, M. \& Mengis, J. (2004) The Concept of Information Overload: A Review of Literature from Organization Science, Accounting, Marketing, MIS, and Related Disciplines. The Information Society. Vol. 20. Issue. 5, p. 325-344. Taylor \& Francis Inc.

EU-Commission (2003). Commission Recommendation (2003/261/EC) of 6 May 2003 concerning the definition of micro, small and medium-sized enterprises, in European Communities Official Journal.

Feather, J. (1998). In The information society: A study of continuity and change. London, UK: Library Association. p. 11.

Fitzgerald, B. (1994) Systems development dilemma: whether to adopt formalised systems development methodologies or not? in Proceedings of the $2^{\text {nd }}$ European Conference on Information Systems, p. 691-706. Nijenrode: Nijenrode University Press. 
Fuellhart, Kurtis \& Glasmeier, Amy (2003). Acquisition, assessment and use of business information by small- and medium-sized businesses: a demand perspective. Entrepreneurship and Regional Development, vol. 15, p. 229-52.

Fuhr, Norbert. Information Retrieval - Introduction and Survey, in Course Notes on Information Retrieval (2004).

Gabriel, Y., Fineman, S., Sims, D. (2000) Organizing \& Organizations, $2^{\text {nd }}$ Edition. London, UK: SAGE Publications Ltd. ISBN 0-7619-6279-4.

Gartner, W., B., Bellamy, M., G. (2008) Enterprise. Mason, OH, USA: SouthWestern Cengage Learning. ISBN 978-0-324-78534-0.

Gibb, A \& Dyson, J (1984). Stimulating the Growth of Owner Managed Firms, in Lewis, Stansworth \& Gibb (ed.). Success and Failure in Small Business Aldershot: Gower Publishing Company. p. 249-58.

Glaser, G., B., Strauss, L., A. (1967) The discovery of grounded theory: Strategies of qualitative research. London, UK: Wiedenfeld and Nicholson. ISBN 978-0-20230260-7.

Glaser, G., B. (1992) Basics of grounded theory analysis: emergence vs. forcing. Mill Valley, Ca. US: Sociology Press.

Goldkuhl, G. (1999) The Grounding of Usable Knowledge: An Inquiry in the Epistemology of Action Knowledge, CMTO Research Papers No. 1999:03, Linköping University.

Goldkuhl, G., Lind, M. \& Seigerroth, U. (1998) Method integration: the need for a learning perspective, in IEEE proceedings - Software, Special issue on Information Systems Methodologies, Vol. 145 No. 4, August, p. 113-118.

Grover, V., Kettinger, W., J. (1995) Business Process Change: Reengineering Concepts, Methods and Technologies. Hershey, PA, USA: Idea Group Publishing. ISBN 1-878289-29-2.

Hardy, C., J., Thompson, J., B. \& Edwards, H., M. (1995) The use, limitations and customisation of structured systems development methods in United Kingdom, in Information and Software Technology (37:9), p. 467-477.

Harmon, P. (2010) The Scope and Evolution of Business Process Management, in Brocke, J. \& Rosemann, M. (eds.) Handbook on Business Process Management vol 1. Heidelberg/Berlin, Germany: Springer Verlag, p. 37-81.

Harmsen, F., Brinkkemper, S. \& Oci, H. (1994) Situational Method Engineering for Information System Project Approaches, in Verrijn-Stuart, A., A. \& Olle, T., W. (eds), Methods and Associated Tools for the Information System Life Cycle, p. 169194. Holland: Elsevier Science B.V.

Henderson-Sellers, B., Ralyté, J., Ågerfalk, P., J. \& Rossi, M. (2014) Situational Method Engineering. Berlin: Springer Verlag, p. 310. ISBN 978-3-642-41467-1 
Hevner, A., March, S., Park, J., and Ram, S. (2004) Design Science in Information Systems Research, MIS Quarterly (28:1) 2004, p. 75-105.

Hidding, G. (1996) Method engineering; experiences in practice, in Brinkkemper, S., Lyytinen, K. \& Welke, R., J. (eds), Method Engineering: Principles of Method Construction and Tool Support. London, UK: Chapman \& Hall.

Iivari, J., Hirschheim, R., Heinz, K., K. (2001) A Dynamic Framework for Classifying Information Systems Development Methodologies and Approaches in Journal of Management Information Systems (17:3) 2001, pp 179-218.

Introna, L., D., Whitley, E., A. (1997) Against method-ism - Exploring the limits of method in Information Technology \& People (10:1) 1997, p. 31-45.

Jaksch, Stefan, Pfenningschmidt, Stefan, Sandkuhl, Kurt \& Thiel, Christoph (2003). Information Logistic Applications for Information-on-Demand Scenarios: Concepts and Experiences from WIND project, in Proceedings of the 29th Euromicro Conference (EUROMICRO'03); September 1-6, 2003; Belek-Antalya, Turkey. p. 141-7.

Jayrantna, N. (1994) Understanding and Evaluating Methodologies: NIMSAD - A Systematic Framework. The McGraw-Hill Information Systems, Management and Strategy Series. Maidenhead, UK: McGraw-Hill Book Company. ISBN 0-07707882-9.

Klintberg, T. (2008) The Overflowing Brain: Information Overload and the Limits of Working Memory. USA: Oxford University Press. ISBN: 9780195372885.

Krogstie, J. (2003) Project UEML - Deliverable 3.1 - Requirements analysis: initial core and architecture, Annex 2.1. Torino, Italy: University of Torino. IST-200134229 .

Lee, S. A. (1999) Rigor and Relevance in MIS Research: Beyond the Approach of Positivism Alone, MIS Quarterly (23:1), March, 1999, p. 29-33.

Lewis, D. M. (1996) Dying for Information? Reuters Business Information. London, UK. p. 2.

Lin, Rey-Long \& Lin, Wan-Jung (2003). Mining for interactive identification of users' information needs. Information Systems, vol. 28, p. 815-33.

Lind, M. \& Seigerroth, U. (1997) Integrating Change Methods - framework and experiences from integrating two methods for change work, presented at $20^{\text {th }}$ Information Systems Research Seminar (IRIS 20), 9-12 August 1997, Hanko, Norway.

Lundqvist, M. \& Sandkuhl, K. (2004) Modelling Information Demand for Collaborative Engineering in Proceedings of $2^{\text {nd }}$ Intl. Workshop on Challenges in Collaborative Engineering (CCE'04), Stara Lesna, Slovakia. p. 111-120. 
Lundqvist, M. (2005) Context as a Key Concept in Information Demand Analysis in Proceedings of the Doctoral Consortium associated with the $5^{\text {th }}$ Intl. and Interdisciplinary Conference on Modelling and Using Context (Context-05), Paris, France. p. 63-73.

Lundqvist, M. (2007) Information Demand and Use: Improving Information Flow within Small-scale Business Contexts. Licentiate thesis, Linköping studies in science and technology, ISSN 0280-7971; 1323, Department for Computer and Information Science, Linköping University.

Lundqvist, M. (2008) InfoFlow Deliverable D2.1. Application Case KA Experiences from Modelling Activities.

Lundqvist, M., Holmquist, E., Sandkuhl, K., Seigerroth, U., Strandesjö, J. (2009) Information Demand Context Modelling for Improved Information Flow:

Experiences and Practices, in The Practice of Enterprise Modeling, Lecture Notes in Business Information Processing Book Series, ISSN 1865-1348. pp. 8-22.

Lundqvist, M., Sandkuhl, K. \& Seigerroth, U. (2009) InfoFlow Deliverable D4 Method Handbook for Information Demand Analysis.

Lundqvist, M., Sandkuhl, K. \& Seigerroth, U. (2011) Modelling Information Demand in an Enterprise Context: Method, Notation, and Lessons Learned, in Gustas, R. (Ed.) International Journal of Information System Modeling and Design, Vol. 2, Issue 3, July-September, 2011. ISSN 1947-8186.

Lundqvist, M., Sandkuhl, K., Seigerroth, U. (2012) Enterprise Modelling in Distributed Teams-Lessons Learned from Information Demand Modelling. In: M. Kirikova, J. Stirna (Eds.): Proceedings of the CAiSE'12 Forum, Gdansk, Poland, June 28, 2012. CEUR Workshop Proceedings 855, pp. 139-146.

Lundqvist, M., Sandkuhl, K. \& Seigerroth, U. (2012) Transfer of Method Knowledge and Modelling in Distributed Teams - Lessons Learned, in N. Asseva, E. Babkin, \& O. Kozyrev, eds. Perspectives in Business Informatics Research. $11^{\text {th }}$ International Conference, BIR2012, Nizhny Novgorod, Russia. Proceedings LNBIP 128, pp. 26-40. Springer 2012, ISBN: 978-3-642-33280-7.

Lundqvist, M. \& Seigerroth, U. (2008) InfoFlow Deliverable D2.2 Application Case Proton Finishing - Experiences from Modelling Activities.

Lundqvist, M., Seigerroth, U. \& Stirna, J. (2008a) InfoFlow Deliverable D2.3 Application Case SYSteam Management - Experiences from Modelling Activities.

Lundqvist, M., Seigerroth, U., Stirna, J. \& Sandkuhl, K. (2008b) InfoFlow Deliverable D1. Information Demand Analysis Methodology - Initial objectives, requirements, and prerequisites.

Lybaert, Nadine (1998). The Information Use in a SME: Its Importance and Some Elements of Influence. Small Business Economics, vol. 10, p. 171-91. 
Mackenzie, O. \& Wiercx, A. (1995). Information for SMEs: strategic issues and information brokerage, in Policy Issues in Creating the European Information Society; July 6, 1995; Luxembourg.

Maier, Ronald (2002). State-of-Practice of Knowledge Management Systems. Results of an Empirical Study. UPGRADE: the European Journal for the Informatics Professional, vol. 3, p. 15-23.

Markus, M. L., Majchrzak, A., and Gasser, L. (2002) Design Theory for Systems that Support Emergent Knowledge Processes in MIS Quarterly (26:3), September, 2002, p. 179-212.

Maslow, A., H. (1943) A Theory of Human Motivation. In Psychological Review, Vol. 50, No. 4. p. 370-396.

Meissen, U., Pfennigschmidt, S., Voisard, A., Wahnfried, T. (2004) Context- and Situation-Awareness in Information Logistics, in Proceedings of Workshops of the International Conference on Extending Database Technology (EDBT 2004); March 14-18, 2004; Heraklion, Crete, Greece. p. 335-44.

Melinat, P., Kreuzkam, T. \& Stamer, D., 2014. Information Overload: a Systematic Literature Review. In B. Johansson, B. Andersson, \& N. Holmberg, eds.

Perspectives in Business Informatics Research - 13th International Conference, BIR 2014, Lund, Sweden, September 22-24, 2014. Proceedings. Lecture Notes in Business Information Processing. Springer International Publishing, pp. 72-86.

Meyer, D. (2011) Nutzungspotenziale von Semantischen Technologien in Kleinund Mittelständischen Unternehmen. Matrikel-Nr.: 5204183, B.Sc.

Wirtschaftsinformatik.

Mirabel, I. \& Ralyté, J. (2006) Situational method engineering: combining assembly-based and roadmap-driven approaches, in Requirements Engineering 2006:11, p. 58-78. London, UK: Springer Verlag London Limited.

Moody, L., D. (2009) The "Physics" of Notation: Towards a Scientific Basis for Constructing Visual Notations in Software Engineering, in IEEE Transactions of Software Engineering, Vol. 35, No. 6, November/December 2009, p. 756-779.

Moore, Nick (2000). The Information Needs of Visually Impaired People: a Review of Research for the RNIB. Royal National Institute for the Blind (RNIB), UK.

Moore, Nick (2002). A Model of Social Information Need. Journal of Information Science, vol. 28, p. 297-303.

Moorman, C, Zaltman, G \& Deshpandé, R (1992). Relationships between providers and users of market research: the dynamics of trust within and between organisations. Journal of Marketing Research, vol. 26, p. 314-28.

Nonaka, Ikujiro (1991). The Knowledge-Creating Company. Harvard Business Review, vol. 69, p. 96-104. 
Nonaka, Ikujiro \& Takeuchi, Hirotaka (1995). The Knowledge-Creating Company: How Japanese Companies Create the Dynamics of Innovation. New York, NY, USA: Oxford University Press. p. 298.

Nyberg, C., Wass, S. (2009) Does IDA meet the requirements - Evaluating the method Information Demand Analysis. Bachelor thesis, Reports from MSI, ISSN 1650-2647; 09006, School of Mathematics and System Engineering, Växjö University.

O'Reilly, C.A. (1980). Individuals and information overload in organizations: is more necessarily better? Academy of Management Journal, vol. 23, p. 684-96.

Oettinger, Anthony \& Read, William (1999). Introduction, in Compaine, M. (ed.). The Information Resources Policy Handbook Boston, MA, USA: MIT Press. p. 656.

Palinski, Agnes, Wallen, Fabian, Andersson-Stråberg, Alexandra, Ericson, Peter, Fall, Johan, Frycklund, Jonas, Fölster, Stefan \& Juth, Per (2004). Ett Sverige för alla - Om människors möjlighet att känna sig delaktiga i Sveriges utveckling. Stockholm, Sweden: Confederation Swedish Enterprises, Stockholm, Sweden. (Confederation of Swedish Enterprises).

Persson, A. (2001) Enterprise Modelling in Practice: Situational Factors and their Influence on Adopting a Participative Approach. PhD dissertation, Stockholm University.

Persson, A. \& Stirna, J. (2002). An explorative study into the influence of business goals on the practical use of Enterprise Modelling methods and tools. In $G$.

Harindranath et al., eds. New Perspectives on Information Systems Development: Theory, Methods and Practice. New York, NY, USA: Kluwer Academic/Plenum Publisher.

Pépiot, G., Cheikhrouhou, N., Furbringer, J. \& Glardon, R. (2007) UECML: Unified Enterprise Competence Modelling Language, in Computers in Industry, Vol. 58, No. 2., p. 130-142.

Polanyi, Michael (1967). The Tacit Dimension. London, UK: Routledge \& Kegan Paul. p. 108.

Ralyté, J. \& Rolland, C. (2001) An approach for method reengineering, in Proceedings of $20^{\text {th }}$ International Conference on Conceptual Modeling (ER2001). LNCS 2224, Springer. p. 471-484.

Rodgers, Paul \& Clarkson, John (1998). Knowledge usage in new product development (NPD), in Proceedings of International Conference on Design and Technology Educational Research and Curriculum Development (IDATER 98); August 24-26, 1998; Loughborough University, UK. p. 252-8.

Russo, N., L. \& Stolterman, E. (2000) Exploring the assumptions underlying information systems methodologies - Their impact on past, present and future ISM research in Information Technology \& People (13:4), 2000, p. 313-327. 
Sandkuhl, K. et al., 2014. Enterprise Modeling: Tackling Business Challenges with the 4EM Method, Berlin/Heidelberg, Germany: Springer Verlag. ISBN 978-3-66243724-7.

Saracevic, Tefko (1996). Relevance reconsidered, in Information science: Integration in perspectives. Proceedings of the Second Conference on Conceptions of Library and Information Science (CoLIS 2), 14-17 Oct, 1996, Copenhagen, Denmark; p. 201-18.

Saracevic, Tefko (1975). RELEVANCE: A Review of and a Framework for the Thinking on the Notation in Information Science. Journal of American Society for Information Sciences, p. 321-43.

Schuster, S., 2005. Working Document WD.A1.1.2 - Second Version of State of the Art in Enterprise Modelling Techniques and Technologies to Support Enterprise Interoperability,

Sommerville, Ian (2001). Software Engineering 6th ed. Harlow, UK: Pearson Education Ltd.

Stirna, J., Persson, A. \& Sandkuhl, K. (2007) Participative Enterprise Modeling: Experiences and Recommendations, in Krogstie, J, Opdahl, A., L. \& Sindre, G. (eds.) CAISE 2007 and WES 2007. Springer Lecture Notes on Computer Science, vol. 4495, p. 546-560. Heidelberg, Germany: Springer Verlag.

Stojanovic, Nenad (2005). On the Role of a User's Knowledge Gap in an Information Retrieval Process. in Proceedings of the 3rd International Conference on Knowledge Capture 2005, Banff, Alberta, Canada; p. 83-90.

Stolterman, E. (1992) How system designers think about design and methods: some reflections based on an interview study in Scandinavian Journal of Information Systems, (4:1), 1992, p. 137-150.

Stolterman, E., \& Russo, N., L. (1997) The paradox of information systems methods: public and private rationale in Proceedings of the $5^{\text {th }}$ British Computer Society's Annual Conference on Information System Methodologies.

Strauss, A. \& Corbin, J. (1990) Basics of qualitative research: Grounded theory procedures and techniques. Newbury Park, CA, US: Sage Publications, Inc.

Sundgren, Bo (2005). What is a Public Information System? International Journal of Public Information Systems (IJPIS), vol. 2005, p. 81-99.

Toffler, A. (1965) The future as a way of life. Horizon Magazine, Vol. 7, No. 3, p. $108-116$

Vernadat, F. (1996). Enterprise Modelling and Integration: Principles and Applications. London, UK: Kluwer Academic Publishers.

Vernadat, F. (2002). Enterprise modeling and integration (EMI): current status and research perspectives, in Annual Reviews in Control, Vol. 26, No. 1, p. 15-25. 
Voerman, Liane, Wedel, Michael \& Zwarts, Peter (1998). Export Market Information Behaviour of SMEs: The Influence of Firm Characteristics, in Proceedings of the 43rd International Council of Small Business World Conference, Singapore;

de Vreede, G-J. (1996) Participative Modelling for Understanding: Facilitating Organizational Change with GSS, in Proceedings of the $29^{\text {th }}$ Hawaii International Conference on System Sciences, vol. 3: Collaboration Systems and Technology, p. 398. Washington, DC, USA: IEEE Computer Society.

Wallis, J. G., Widmeyer, G. R. \& El Sawy, O. A. (1992) Building an Information System Design Theory for Vigilant EIS, Information Systems Research (3:1), March, 1992, p. 36-59.

Webster, J. \& Watson, R.T., 2002. Analyzing the Past to Prepare for the Future: Writing a Literature Review. MIS Quarterly, 26(2), pp.xiii-xxiii. Available at: http://dl.acm.org/citation.cfm?id=2017160.2017162.

Whitman, L. \& Huff, B. L. (1997). A living enterprise model, in Proceedings of the $6^{\text {th }}$ Industrial Engineering Research Conference, Miami Beach, FL, USA: CiteSeer

Williams, Jasmine (2003). Export information use in small and medium-sized industrial companies: An application of Diamantopoulos' and Souchon's Scale. International Marketing Review, vol. 20, p. 44-66.

Yu, E. (1997) Towards Modelling and Reasoning Support for Early-Phase Requirements Engineering in Proceedings of the $3^{\text {rd }}$ IEEE int. Symp. On Requirements Engineering (RE'97) Jan. 6-8, 1997, Washington D.C., USA. Pp 226-235.

Öhgren, A. (2009) Towards an Ontology Development Methodology for Small and Medium-sized Enterprises. Licentiate thesis, Linköping studies in science and technology, ISSN 0280-7971; 1401, Department for Computer and Information Science, Linköping University. 
This page is intentionally left blank. 


\section{APPENDIX}

1. Swedish investigation plan and interview questions

2. Selected statements in Swedish 
This page is intentionally left blank. 


\section{PLANNERAD UNDERSÖKNING RÖRANDE INFORMATIONS- ANVÄNDNING I SMEs}

\section{Bakgrund}

Informationsteknikgruppen på Ingenjörshögskolan i Jönköping har som en av två forskningsinriktningar framtagandet av metoder, verktyg och tekniker för Informationslogistik och underlättandet av införandet av dylika lösningar. Informationslogistik kan kort beskrivas som tillhandahållandet och förmedlandet av rätt information, till rätt person vid rätt tid och till rätt plats. Som ett led i forskningen kring detta bedrivs ett doktorandprojekt med målet att ta fram en metod för informationsbehovsanalys vars syfte är att avgöra vad rätt information, person, tid och plats innebär. Under förarbetet inför utvecklandet av denna metod har ett antal antaganden formulerats:

1. Informationsbehov är situationsberoende så till vida att behoven existerar utifrån den roll och de arbetsuppgifter en entitet har i en organisation. Ändras rollen och/eller uppgifterna kommer också behoven att förändras.

2. Informationsbehov är temporalt beroende. Ett specifikt behov av information är relevant vid en speciell tidpunkt alternativt under en period och behoven ändras över tid.

3. Informationsbehov är spatialt beroende. Behov förändras beroende på var en entitet befinner sig och påverkas till viss del i form av förflyttning.

4. Informationsbehov tillfredställs idag i någon utsträckning genom informella informationsutbyteskanaler, det vill säga sådana kanaler som inte finns representerade i organisatoriska strukturer, processbeskrivningar eller andra verksamhetsmodeller.

5. Idag tillgängliga informationssystem tar inte tillräcklig hänsyn till ovan angivna aspekter.

6. Det finns ett behov för informationssystem som tar en sådan hänsyn.

Dessa antaganden utgör grunden och motiveringen för det forskningsprojekt, undersökningen berörd i denna plan är en del av. För att få en uppfattning om huruvida dessa antaganden har någon faktisk relevans kommer en empirisk undersökning beträffande informationsanvändningen i små- och medelstora företag (s.k. SME) att utföras i form av semistrukturerade intervjuer.

\section{Omfattning}

I undersökningen ingår följande företag:

- KA

- Proton Group

- SBA 


\section{Upplägg}

För att säkerställa att undersökningen resulterar i relevanta svar kommer densamma att ha en kvalitativ ansats med fokus på djup snarare än omfång. Genom att ta avstamp på ledningsnivå i de deltagande företagen och sedan jobba neråt $\mathrm{i}$ den organisatoriska strukturen ges en möjlighet att inte bara identifiera de övergripande målen, strategierna, planerna och rutinerna hos respektive företag utan också i vilken utsträckning dessa faktiskt är förankrade och efterlevs i organisationen. Vi antar att det är i det eventuella glapp som kan finnas däremellan som de informella informationsutbyteskanalerna uppstår. Avsikten är att på varje företag intervjua representanter för följande, eller i den grad det är möjligt närliggande, nivåer:

- $\quad$ Ledning - roller med övergripande ansvar för företagets mål och strategier samt implementation av dessa. T ex. VD, marknadschefer etc.

- Mellanchefer - ansvariga för att realisera ledningens mål genom införandet av rutiner, stödsystem och bestämmelser. T ex. kvalitetschef, produktchef, IT-chef etc.

- Arbetsledning - roller ansvariga för det löpande arbetet och implementerandet av ovan angivna punkter. $\mathrm{T}$ ex. förmän, linjeledare, projektledare, systemansvariga etc.

- Verkställande - De som enligt ovan angivna anvisningar utför produktionen. $\mathrm{T}$ ex. programmerare, administratörer, tekniker, konstruktörer etc.

Detta innebär också att frågeställningarna till viss del måste anpassas beroende på vilken organisatorisk nivå intervjupersonen hör hemma. Som en grundmall kommer dock följande att användas:

\section{Allmänna frågeställningar inriktade på enskilda roller}

1. Vem är du och vad är din roll inom företaget?

2. Vilka uppgifter är förknippade med den rollen?

a. Skulle du beskriva din roll inom företaget som rådgivande eller producerande?

3. Vad behöver du för information för att fullgöra dina uppgifter?

a. Vilken typ är den av (kunskap, anvisningar, mätsiffror etc.)?

b. Var får du den ifrån (Internet/Kunder/Konkurrenter/Internt/Akademin)?

c. Är den tillräcklig med avseende på:

i. Tillförlitlighet

ii. Relevans

iii. Tillgänglighet

d. Vilken form har den (välstrukturerad/taktil)? 
4. Var är det tänkt att du ska få information ifrån (om annat än 3b)?

5. I vilken utsträckning förlitar du dig på kollegor för information

a. Vad är valet av kollega baserat på?

6. Hur hanterar du den information du făr med avseende på:
a. Lagring
b. Vidareförmedling
c. Återsökning

7. Finns det några svårigheter som du ser det med informationshanteringen?

8. Har du tillgång till någon form av stöd i den hanteringen och i så fall vad?

9. Får du mer information än vad du faktiskt behöver och vad har det i så fall för effekter?

a. Blir det svårare att hitta "din" information?

b. Får det dig att undvika några specifika källor?

10. Ser du några samband mellan vilken information du behöver eller i vilken form du behöver den och specifika tidpunkter och platser?

11. Har du någon vision av hur informationshanteringen borde se ut om du fick bestämma fritt?

\section{Övergripande frågor om företaget och verksamhetsstyrning}

1. Vilken information skulle du beskriva som viktigast för företaget?

a. Var kommer den informationen ifrån (internt/externt)?

2. Hur hanterar organisationen den idag med avseende på

a. Lagring

b. Förmedling inom organisationen

3. Vilka är svårigheterna kopplad till en sådan hantering?

4. Vad finns det för system för informationshanteringen?

5. Finns det någon koppling mellan informationshanteringen och:

a. Organisationens struktur

b. Arbetsprocesser

c. Om så:

i. Hur förändras hanteringen när organisationen eller arbetssätten ändras?

ii. Följs den kopplingen i den dagliga verksamheten eller söker de anställda information på andra ställen 
This page is intentionally left blank. 
Statement 1 .

“Jag handlägger ärenden beträffande fukt och grönsaker...bereder och bevakar regelverket kring tobak, frukt och grönt... producerar material som ligger till grund för jordbruksdepartementets [och därmed också Sveriges] ständpunkt $i$ EU...behöver kunskap om hur man skriver rapporter...kännedom om myndigheten och landets mål och [politiska] inriktning dessutom behövs produktion och konsumtionsstatistik"

Handläggare, SBA

Statement 2.

"Informationen som behövs för det kommer från underställda [förmän] och via E-post...kunskap om rollen och uppgifter fäs genom kurser och genom att besöka tillverkare, mässor, företagsnätverk [konkurrenter] och akademin...ja men det kräver att information fran flera olika källor aggregeras..."

Produktionsteknisk chef, KA

Statement 3.

“...behöver hålla reda på trender för att kunna skapa [kund] behov [efter nya funktioner], vi försöker få sådan information från marknadsavdelningen.

Ibland träffar jag också kunder direkt...ett bredare nätverk används också för informationens skull...högskolor, branschinstitut, mässor. Informationen från säljarna kommer huvudsakligen som E-post och resten är muntligt som broschyrer...kundkontakt.

Produktutvecklingschef, KA

Statement 4.

“...informationen är extremt ostrukturerad och taktil...det är upp till mig att skaffa den..."

Produktutvecklingschef, KA

Statement 5.

“...behöver översiktsplanering av underhåll, underhållsspecar...laddar ner arbetsinstruktioner från intranätet och fär felrapporter från arbetsledarna eller produktionen..."

Arbetsledare, Service och underhåll, KA

Statement 6.

"Sysprod [affärssystemet] lämnar produktionsuppgifter för två veckor framöver [körplan]"

Driftsledare, PE

Statement 7.

“...orderinformationen som behövs för produktionsplaneringen tas ur SAP"

Material Controller, KA

Statement 8.

"både mätetal [produktionsstatistik] och rutiner tas från SAP medan information om problem [i produktionen] fås som mötesprotokoll från dagliga möten som halls med produktionen ... tar information frän tänkta källor"

Gruppledare, Produktionsteknik, KA 


\section{Statement 9.}

"För den dagliga verksamheten behövs kännedom om förekommande problem och information om utrustning...för projekten behövs produktionskalkyler och àtgärdspunkter... informationen kommer från personliga kontakter internt och från maskin- och utrustningstillverkare. I projekten kommer informationen främst frän projektledare och projektberedare...oftast i pappersform ...ätgärdspunkterna laddas ner från projektkatalogerna på de nätverksutdelningar man använder."

\section{Produktionstekniker, KA}

Statement 10.

"bidragsansökningar direkt från källan, förordningar från EU och protokoll från handläggarnas möten i Bryssel...sådant som ska publiceras på nätet kommer frän medarbetarna...

$$
\text { Assistent/Administratör, SBA }
$$

\section{Statement 11 .}

“...information från handläggarna [muntlig och som statistik]

...tillförlitligheten på information som kommer från handläggarna kan vara lite så där, man måste ofta dubbelkolla med flera olika handläggare..."

Handläggare, SBA

\section{Statement 12.}

"Tillgängligheten är beroende på att man vet vem man ska vända sig till ...ganska mycket irrelevant information från leverantörer"

$$
\text { Material Controller, KA }
$$

Statement 13 .

“...informationen från tillverkarna är ofta 'friserad' för att framstå som bättre...”

$$
\text { Produktionsteknisk chef, KA }
$$

Statement 14.

“...EU-lagstiftning och föreskrifter finns på Internet. Protokoll från EU-möten kommer också via elektroniska källor...man försöker använda officiella källor $i$ så hög grad som möjligt...

Enhetschef, SBA

\section{Statement 15 .}

“...vi har ju insett att alla tjänar på att vi delar både information och teknik med varandra än vad vi gör om vi håller den för oss själva."

$$
\text { IT-chef, KA }
$$

Statement 16.

“...dynamiskt flöde av information kommer genom generaldirektören [från t ex regering och departement]...andra källor [för information] är verksledningsmöten med generaldirektören, Anna Olsson [informationschefen], chefsekonomerna osv... övergripande information $i$ lantbrukspress..." 
Statement 17.

"viss kommunikation är ju inbegripit i arbetet, informellt så söker man hjälp om sådant som redan har gjorts i form av verksamhetsutveckling

[huvuduppgiften för hennes enhet] snarare än att använda den ursprungliga

källan. Samma sak gäller för sökningar i datalagret...sen finns det ju

handläggare som inte använder systemet för att de inte är nöjda med det, istället pratar de med varandra..."

Handläggare, SBA

Statement 18.

“...inte alla dokument finns $i$ systemen, vissa finns inte ens digitalt så man måste prata med andra"

Enhetschef, SBA

Statement 19.

“...därför att det är viktigt att se människorna bakom datorn ..."

Produktionschef, KA

Statement 20.

"Det [skaffar information från kollegor] gör jag definitivt för det är hopplöst att försöka hitta något på intranätet eller på nätverksutdelningarna...det baseras på kunskap och personliga kontakter"

Material Controller, KA

Statement 21.

“[pratar med kollegor] ofta för systemen är så komplexa och innehålla så mycket information... man "vet" med vem man ska prata..."

Produktionsteknisk chef, KA

Statement 22.

“...sammanfaller kunskapsområdena med hur vi sitter placerade rent fysiskt vilket gör att rumsgrannarna används mycket”

Handläggare, SBA

\section{Statement 23.}

“...upplever svårigheter med hanteringen för det är för mycket information. Det gäller dock inte EU-informationen för den är sä uppstyrd men den egeninsamlade är svårare... man förlitar sig så mycket på kronologisk ordning vilket ställer till problem om man vill söka på produktnamn...ätersökning sker i de strukturer man har definierat [standard filsystemsökningar eller browsing]. Ateranvändning av material sker inte $i$ så stor utsträckning eftersom man inte riktigt har koll på vad andra avdelningar och personer gör eller har gjort...överflöd av information är ett problem överlag. E-post är också ett problem...vissa mail kastas bort utan att ens ha lästs"

Handläggare, SBA 
Statement 24.

"Atersökning av projekterfarenheter fungerar dåligt, man har ingen àterkoppling mellan projekt utan man måste fräga andra som 'var med'. Viss personlig återsökning sker baserat på minne men det finns inget stödsystem... versionshantering baseras helt på filstrukturer"

$$
\text { Handläggare, SBA }
$$

Statement 25.

“...att man saknar projektgemensamma filstrukturer gör att det är svårt med återsökning...För att kunna dra nytta av tidigare projekterfarenheter måste man dels veta att ett projekt man skulle kunna ha nytta av har utförts och dels måste man veta vem det var som ansvarade för det."

\title{
Produktutvecklingschef, KA
}

Statement 26.

"har definitivt problem med för mycket information...svårare att hitta den informationen som är relevant, "sin" information...Detta gäller främst E-post...Det är väldigt stressande att informationen kommer från så många källor...ibland undviker jag vissa källor"

$$
\text { Material Controller, KA }
$$

Statement 27.

“Ja, på grund av att det saknas projektgemensamma filstrukturer så skickas mycket onödiga mail med redundant information... man fär mer än vad man behöver ha"

$$
\text { Produktutvecklingschef, KA }
$$

Statement 28.

"kopplingen mellan processer och tekniskt stöd är för svag"

$$
\text { IT-chef, KA }
$$

Statement 29.

"...att man kan styra vilken information man vill och inte vill ha"

Produktionsledare, PE

Statement 30 .

“...mer struktur och bättre flöde...förr eller senare en nödvändighet för såväl ekonomi som medarbetarnas hälsa..."

Informationschef, SBA

Statement 31 .

“...flödet i huvudprocessen är mappat till beskrivningar och dokument uppdelat på ansvarsområden men detta gäller bara styrande dokument...”

\section{Kvalitetsansvarig, KA}

Statement 32.

“...det händer att jag sätter mig in i underlaget när det gäller utredande uppgifter men det är mest för att jag är ny $i$ omrädet och vill ha en överblick"

\author{
Avdelningschef, SBA
}




\section{Dissertations}

\section{Linköping Studies in Science and Technology \\ Linköping Studies in Arts and Science \\ Linköping Studies in Statistics \\ Linköping Studies in Information Science}

Linköping Studies in Science and Technology

No 14 Anders Haraldsson: A Program Manipulation System Based on Partial Evaluation, 1977, ISBN 917372-144-1.

No 17 Bengt Magnhagen: Probability Based Verification of Time Margins in Digital Designs, 1977, ISBN 91-7372157-3.

No 18 Mats Cedwall: Semantisk analys av processbeskrivningar i naturligt språk, 1977, ISBN 91- 7372168-9.

No 22 Jaak Urmi: A Machine Independent LISP Compiler and its Implications for Ideal Hardware, 1978, ISBN 91-7372-188-3.

No 33 Tore Risch: Compilation of Multiple File Queries in a Meta-Database System 1978, ISBN 91- 7372-232-4.

No 51 Erland Jungert: Synthesizing Database Structures from a User Oriented Data Model, 1980, ISBN 917372-387-8.

No 54 Sture Hägglund: Contributions to the Development of Methods and Tools for Interactive Design of Applications Software, 1980, ISBN 91-7372-404-1.

No 55 Pär Emanuelson: Performance Enhancement in a Well-Structured Pattern Matcher through Partial Evaluation, 1980, ISBN 91-7372-403-3.

No 58 Bengt Johnsson, Bertil Andersson: The HumanComputer Interface in Commercial Systems, 1981, ISBN 91-7372-414-9.

No 69 H. Jan Komorowski: A Specification of an Abstract Prolog Machine and its Application to Partial Evaluation, 1981, ISBN 91-7372-479-3.

No 71 René Reboh: Knowledge Engineering Techniques and Tools for Expert Systems, 1981, ISBN 91-7372489-0.

No 77 Östen Oskarsson: Mechanisms of Modifiability in large Software Systems, 1982, ISBN 91- 7372-527-7.

No 94 Hans Lunell: Code Generator Writing Systems, 1983, ISBN 91-7372-652-4.

No 97 Andrzej Lingas: Advances in Minimum Weight Triangulation, 1983, ISBN 91-7372-660-5.

No 109 Peter Fritzson: Towards a Distributed Programming Environment based on Incremental Compilation, 1984, ISBN 91-7372-801-2.

No 111 Erik Tengvald: The Design of Expert Planning Systems. An Experimental Operations Planning System for Turning, 1984, ISBN 91-7372- 805-5.

No 155 Christos Levcopoulos: Heuristics for Minimum Decompositions of Polygons, 1987, ISBN 91-7870133-3.

No 165 James W. Goodwin: A Theory and System for NonMonotonic Reasoning, 1987, ISBN 91-7870-183-X.

No 170 Zebo Peng: A Formal Methodology for Automated Synthesis of VLSI Systems, 1987, ISBN 91-7870-225-9.

No 174 Johan Fagerström: A Paradigm and System for Design of Distributed Systems, 1988, ISBN 91-7870301-8.

No 192 Dimiter Driankov: Towards a Many Valued Logic of Quantified Belief, 1988, ISBN 91-7870-374-3.

No 213 Lin Padgham: Non-Monotonic Inheritance for an Object Oriented Knowledge Base, 1989, ISBN 917870-485-5.

No 214 Tony Larsson: A Formal Hardware Description and Verification Method, 1989, ISBN 91-7870-517-7.
No 221 Michael Reinfrank: Fundamentals and Logical Foundations of Truth Maintenance, 1989, ISBN 917870-546-0.

No 239 Jonas Löwgren: Knowledge-Based Design Support and Discourse Management in User Interface Management Systems, 1991, ISBN 91-7870-720-X.

No 244 Henrik Eriksson: Meta-Tool Support for Knowledge Acquisition, 1991, ISBN 91-7870-746-3.

No 252 Peter Eklund: An Epistemic Approach to Interactive Design in Multiple Inheritance Hierarchies, 1991, ISBN 91-7870-784-6.

No 258 Patrick Doherty: NML3 - A Non-Monotonic Formalism with Explicit Defaults, 1991, ISBN 917870-816-8.

No 260 Nahid Shahmehri: Generalized Algorithmic Debugging, 1991, ISBN 91-7870-828-1.

No 264 Nils Dahlbäck: Representation of DiscourseCognitive and Computational Aspects, 1992, ISBN 91-7870-850-8.

No 265 Ulf Nilsson: Abstract Interpretations and Abstract Machines: Contributions to a Methodology for the Implementation of Logic Programs, 1992, ISBN 917870-858-3.

No 270 Ralph Rönnquist: Theory and Practice of Tensebound Object References, 1992, ISBN 91-7870-873-7.

No 273 Björn Fjellborg: Pipeline Extraction for VLSI Data Path Synthesis, 1992, ISBN 91-7870-880-X.

No 276 Staffan Bonnier: A Formal Basis for Horn Clause Logic with External Polymorphic Functions, 1992, ISBN 91-7870-896-6.

No 277 Kristian Sandahl: Developing Knowledge Management Systems with an Active Expert Methodology, 1992, ISBN 91-7870-897-4.

No 281 Christer Bäckström: Computational Complexity of Reasoning about Plans, 1992, ISBN 91-7870-979-2.

No 292 Mats Wirén: Studies in Incremental Natural Language Analysis, 1992, ISBN 91-7871-027-8.

No 297 Mariam Kamkar: Interprocedural Dynamic Slicing with Applications to Debugging and Testing, 1993, ISBN 91-7871-065-0.

No 302 Tingting Zhang: A Study in Diagnosis Using Classification and Defaults, 1993, ISBN 91-7871-078-2

No 312 Arne Jönsson: Dialogue Management for Natural Language Interfaces - An Empirical Approach, 1993, ISBN 91-7871-110-X.

No 338 Simin Nadjm-Tehrani: Reactive Systems in Physical Environments: Compositional Modelling and Framework for Verification, 1994, ISBN 91-7871-237-8.

No 371 Bengt Savén: Business Models for Decision Support and Learning. A Study of Discrete-Event Manufacturing Simulation at Asea/ABB 1968-1993, 1995, ISBN 91-7871-494-X.

No 375 Ulf Söderman: Conceptual Modelling of Mode Switching Physical Systems, 1995, ISBN 91-7871-5164.

No 383 Andreas Kågedal: Exploiting Groundness in Logic Programs, 1995, ISBN 91-7871-538-5.

No 396 George Fodor: Ontological Control, Description, Identification and Recovery from Problematic Control Situations, 1995, ISBN 91-7871-603-9.

No 413 Mikael Pettersson: Compiling Natural Semantics, 1995, ISBN 91-7871-641-1. 
No 414 Xinli Gu: RT Level Testability Improvement by Testability Analysis and Transformations, 1996, ISBN 91-7871-654-3.

No 416 Hua Shu: Distributed Default Reasoning, 1996, ISBN 91-7871-665-9.

No 429 Jaime Villegas: Simulation Supported Industrial Training from an Organisational Learning Perspective - Development and Evaluation of the SSIT Method, 1996, ISBN 91-7871-700-0.

No 431 Peter Jonsson: Studies in Action Planning: Algorithms and Complexity, 1996, ISBN 91-7871-7043.

No 437 Johan Boye: Directional Types in Logic Programming, 1996, ISBN 91-7871-725-6.

No 439 Cecilia Sjöberg: Activities, Voices and Arenas: Participatory Design in Practice, 1996, ISBN 91-7871728-0.

No 448 Patrick Lambrix: Part-Whole Reasoning in Description Logics, 1996, ISBN 91-7871-820-1.

No 452 Kjell Orsborn: On Extensible and Object-Relational Database Technology for Finite Element Analysis Applications, 1996, ISBN 91-7871-827-9.

No 459 Olof Johansson: Development Environments for Complex Product Models, 1996, ISBN 91-7871-855-4.

No 461 Lena Strömbäck: User-Defined Constructions in Unification-Based Formalisms, 1997, ISBN 91-7871857-0.

No 462 Lars Degerstedt: Tabulation-based Logic Programming: A Multi-Level View of Query Answering, 1996, ISBN 91-7871-858-9.

No 475 Fredrik Nilsson: Strategi och ekonomisk styrning En studie av hur ekonomiska styrsystem utformas och används efter företagsförvärv, 1997, ISBN 917871-914-3.

No 480 Mikael Lindvall: An Empirical Study of Requirements-Driven Impact Analysis in Object-Oriented Software Evolution, 1997, ISBN 91-7871-927-5.

No 485 Göran Forslund: Opinion-Based Systems: The Cooperative Perspective on Knowledge-Based Decision Support, 1997, ISBN 91-7871-938-0.

No 494 Martin Sköld: Active Database Management Systems for Monitoring and Control, 1997, ISBN 91-7219-002-7.

No 495 Hans Olsén: Automatic Verification of Petri Nets in a CLP framework, 1997, ISBN 91-7219-011-6.

No 498 Thomas Drakengren: Algorithms and Complexity for Temporal and Spatial Formalisms, 1997, ISBN 91-7219019-1.

No 502 Jakob Axelsson: Analysis and Synthesis of Heterogeneous Real-Time Systems, 1997, ISBN 91-7219-035-3.

No 503 Johan Ringström: Compiler Generation for DataParallel Programming Languages from Two-Level Semantics Specifications, 1997, ISBN 91-7219-045-0.

No 512 Anna Moberg: Närhet och distans - Studier av kommunikationsmönster i satellitkontor och flexibla kontor, 1997, ISBN 91-7219-119-8.

No 520 Mikael Ronström: Design and Modelling of a Parallel Data Server for Telecom Applications, 1998, ISBN 917219-169-4.

No 522 Niclas Ohlsson: Towards Effective Fault Prevention An Empirical Study in Software Engineering, 1998, ISBN 91-7219-176-7.

No 526 Joachim Karlsson: A Systematic Approach for Prioritizing Software Requirements, 1998, ISBN 917219-184-8.

No 530 Henrik Nilsson: Declarative Debugging for Lazy Functional Languages, 1998, ISBN 91-7219-197-x.

No 555 Jonas Hallberg: Timing Issues in High-Level Synthesis, 1998, ISBN 91-7219-369-7.

No 561 Ling Lin: Management of 1-D Sequence Data - From Discrete to Continuous, 1999, ISBN 91-7219-402-2.

No 563 Eva L Ragnemalm: Student Modelling based on Collaborative Dialogue with a Learning Companion, 1999, ISBN 91-7219-412-X.
No 567

Jörgen Lindström: Does Distance matter? On geographical dispersion in organisations, 1999, ISBN 917219-439-1.

No 582 Vanja Josifovski: Design, Implementation and Evaluation of a Distributed Mediator System for Data Integration, 1999, ISBN 91-7219-482-0.

No 589 Rita Kovordányi: Modeling and Simulating Inhibitory Mechanisms in Mental Image Reinterpretation Towards Cooperative Human-Computer Creativity, 1999, ISBN 91-7219-506-1.

No 592 Mikael Ericsson: Supporting the Use of Design Knowledge - An Assessment of Commenting Agents, 1999, ISBN 91-7219-532-0.

No 593 Lars Karlsson: Actions, Interactions and Narratives, 1999, ISBN 91-7219-534-7.

No 594 C. G. Mikael Johansson: Social and Organizational Aspects of Requirements Engineering Methods - A practice-oriented approach, 1999, ISBN 91-7219-541-X.

No 595 Jörgen Hansson: Value-Driven Multi-Class Overload Management in Real-Time Database Systems, 1999, ISBN 91-7219-542-8.

No 596 Niklas Hallberg: Incorporating User Values in the Design of Information Systems and Services in the Public Sector: A Methods Approach, 1999, ISBN 917219-543-6.

No 597 Vivian Vimarlund: An Economic Perspective on the Analysis of Impacts of Information Technology: From Case Studies in Health-Care towards General Models and Theories, 1999, ISBN 91-7219-544-4.

No 598 Johan Jenvald: Methods and Tools in ComputerSupported Taskforce Training, 1999, ISBN 91-7219547-9.

No 607 Magnus Merkel: Understanding and enhancing translation by parallel text processing, 1999, ISBN 917219-614-9.

No 611 Silvia Coradeschi: Anchoring symbols to sensory data, 1999, ISBN 91-7219-623-8.

No 613 Man Lin: Analysis and Synthesis of Reactive Systems: A Generic Layered Architecture Perspective, 1999, ISBN 91-7219-630-0.

No 618 Jimmy Tjäder: Systemimplementering i praktiken En studie av logiker i fyra projekt, 1999, ISBN 91-7219657-2.

No 627 Vadim Engelson: Tools for Design, Interactive Simulation, and Visualization of Object-Oriented Models in Scientific Computing, 2000, ISBN 91-7219709-9.

No 637 Esa Falkenroth: Database Technology for Control and Simulation, 2000, ISBN 91-7219-766-8.

No 639 Per-Arne Persson: Bringing Power and Knowledge Together: Information Systems Design for Autonomy and Control in Command Work, 2000, ISBN 91-7219796-X.

No 660 Erik Larsson: An Integrated System-Level Design for Testability Methodology, 2000, ISBN 91-7219-890-7.

No 688 Marcus Bjäreland: Model-based Execution Monitoring, 2001, ISBN 91-7373-016-5.

No 689 Joakim Gustafsson: Extending Temporal Action Logic, 2001, ISBN 91-7373-017-3.

No 720 Carl-Johan Petri: Organizational Information Provision - Managing Mandatory and Discretionary Use of Information Technology, 2001, ISBN-91-7373-1269.

No 724 Paul Scerri: Designing Agents for Systems with Adjustable Autonomy, 2001, ISBN 9173732079.

No 725 Tim Heyer: Semantic Inspection of Software Artifacts: From Theory to Practice, 2001, ISBN 91 73732087

No 726 Pär Carlshamre: A Usability Perspective on Requirements Engineering - From Methodology to Product Development, 2001, ISBN 9173732125. 
No 745 Johan Åberg: Live Help Systems: An Approach to Intelligent Help for Web Information Systems, 2002, ISBN 91-7373-311-3.

No 746 Rego Granlund: Monitoring Distributed Teamwork Training, 2002, ISBN 91-7373-312-1.

No 757 Henrik André-Jönsson: Indexing Strategies for Time Series Data, 2002, ISBN 917373-346-6.

No 747 Anneli Hagdahl: Development of IT-supported Interorganisational Collaboration - A Case Study in the Swedish Public Sector, 2002, ISBN 91-7373-314-8.

No 749 Sofie Pilemalm: Information Technology for NonProfit Organisations - Extended Participatory Design of an Information System for Trade Union Shop Stewards, 2002, ISBN 91-7373-318-0.

No 765 Stefan Holmlid: Adapting users: Towards a theory of use quality, 2002, ISBN 91-7373-397-0.

No 771 Magnus Morin: Multimedia Representations of Distributed Tactical Operations, 2002, ISBN 91-7373-4217.

No 772 Pawel Pietrzak: A Type-Based Framework for Locating Errors in Constraint Logic Programs, 2002, ISBN 91-7373-422-5.

No 758 Erik Berglund: Library Communication Among Programmers Worldwide, 2002, ISBN 91-7373-349-0.

No 774 Choong-ho Yi: Modelling Object-Oriented Dynamic Systems Using a Logic-Based Framework, 2002, ISBN 91-7373-424-1.

No 779 Mathias Broxvall: A Study in the Computational Complexity of Temporal Reasoning, 2002, ISBN 917373-440-3.

No 793 Asmus Pandikow: A Generic Principle for Enabling Interoperability of Structured and Object-Oriented Analysis and Design Tools, 2002, ISBN 91-7373-479-9.

No 785 Lars Hult: Publika Informationstjänster. En studie av den Internetbaserade encyklopedins bruksegenskaper, 2003, ISBN 91-7373-461-6.

No 800 Lars Taxén: A Framework for the Coordination of Complex Systems' Development, 2003, ISBN 917373-604-X

No 808 Klas Gäre: Tre perspektiv på förväntningar och förändringar i samband med införande av informationssystem, 2003, ISBN 91-7373-618-X.

No 821 Mikael Kindborg: Concurrent Comics programming of social agents by children, 2003, ISBN 91-7373-651-1.

No 823 Christina Ölvingson: On Development of Information Systems with GIS Functionality in Public Health Informatics: A Requirements Engineering Approach, 2003, ISBN 91-7373-656-2.

No 828 Tobias Ritzau: Memory Efficient Hard Real-Time Garbage Collection, 2003, ISBN 91-7373-666-X.

No 833 Paul Pop: Analysis and Synthesis of Communication-Intensive Heterogeneous Real-Time Systems, 2003, ISBN 91-7373-683-X.

No 852 Johan Moe: Observing the Dynamic Behaviour of Large Distributed Systems to Improve Development and Testing - An Empirical Study in Software Engineering, 2003, ISBN 91-7373-779-8.

No 867 Erik Herzog: An Approach to Systems Engineering Tool Data Representation and Exchange, 2004, ISBN 91-7373-929-4.

No 872 Aseel Berglund: Augmenting the Remote Control: Studies in Complex Information Navigation for Digital TV, 2004, ISBN 91-7373-940-5.

No 869 Jo Skåmedal: Telecommuting's Implications on Travel and Travel Patterns, 2004, ISBN 91-7373-935-9.

No 870 Linda Askenäs: The Roles of IT - Studies of Organising when Implementing and Using Enterprise Systems, 2004, ISBN 91-7373-936-7. gies in Information-Providing Dialogue Systems, 2004, ISBN 91-7373-947-2.

No 873 Peter Bunus: Debugging Techniques for EquationBased Languages, 2004, ISBN 91-7373-941-3.

No 876 Jonas Mellin: Resource-Predictable and Efficient Monitoring of Events, 2004, ISBN 91-7373-956-1.

No 883 Magnus Bång: Computing at the Speed of Paper: Ubiquitous Computing Environments for Healthcare Professionals, 2004, ISBN 91-7373-971-5

No 882 Robert Eklund: Disfluency in Swedish humanhuman and human-machine travel booking dialogues, 2004, ISBN 91-7373-966-9.

No 887 Anders Lindström: English and other Foreign Linguistic Elements in Spoken Swedish. Studies of Productive Processes and their Modelling using Finite-State Tools, 2004, ISBN 91-7373-981-2.

No 889 Zhiping Wang: Capacity-Constrained Production-inventory systems - Modelling and Analysis in both a traditional and an e-business context, 2004, ISBN 9185295-08-6.

No 893 Pernilla Qvarfordt: Eyes on Multimodal Interaction, 2004, ISBN 91-85295-30-2.

No 910 Magnus Kald: In the Borderland between Strategy and Management Control - Theoretical Framework and Empirical Evidence, 2004, ISBN 91-85295-82-5.

No 918 Jonas Lundberg: Shaping Electronic News: Genre Perspectives on Interaction Design, 2004, ISBN 9185297-14-3.

No 900 Mattias Arvola: Shades of use: The dynamics of interaction design for sociable use, 2004, ISBN 9185295-42-6.

No 920 Luis Alejandro Cortés: Verification and Scheduling Techniques for Real-Time Embedded Systems, 2004, ISBN 91-85297-21-6.

No 929 Diana Szentivanyi: Performance Studies of FaultTolerant Middleware, 2005, ISBN 91-85297-58-5.

No 933 Mikael Cäker: Management Accounting as Constructing and Opposing Customer Focus: Three Case Studies on Management Accounting and Customer Relations, 2005, ISBN 91-85297-64-X.

No 937 Jonas Kvarnström: TALplanner and Other Extensions to Temporal Action Logic, 2005, ISBN 9185297-75-5.

No 938 Bourhane Kadmiry: Fuzzy Gain-Scheduled Visual Servoing for Unmanned Helicopter, 2005, ISBN 9185297-76-3.

No 945 Gert Jervan: Hybrid Built-In Self-Test and Test Generation Techniques for Digital Systems, 2005, ISBN: 91-85297-97-6.

No 946 Anders Arpteg: Intelligent Semi-Structured Information Extraction, 2005, ISBN 91-85297-98-4.

No 947 Ola Angelsmark: Constructing Algorithms for Constraint Satisfaction and Related Problems - Methods and Applications, 2005, ISBN 91-85297-99-2.

No 963 Calin Curescu: Utility-based Optimisation of Resource Allocation for Wireless Networks, 2005, ISBN 91-85457-07-8.

No 972 Björn Johansson: Joint Control in Dynamic Situations, 2005, ISBN 91-85457-31-0.

No 974 Dan Lawesson: An Approach to Diagnosability Analysis for Interacting Finite State Systems, 2005, ISBN 91-85457-39-6.

No 979 Claudiu Duma: Security and Trust Mechanisms for Groups in Distributed Services, 2005, ISBN 91-8545754-X.

No 983 Sorin Manolache: Analysis and Optimisation of Real-Time Systems with Stochastic Behaviour, 2005, ISBN 91-85457-60-4.

No 986 Yuxiao Zhao: Standards-Based Application Integration for Business-to-Business Communications, 2005, ISBN 91-85457-66-3. 
No 1004 Patrik Haslum: Admissible Heuristics for Automated Planning, 2006, ISBN 91-85497-28-2.

No 1005 Aleksandra Tešanovic: Developing Reusable and Reconfigurable Real-Time Software using Aspects and Components, 2006, ISBN 91-85497-29-0.

No 1008 David Dinka: Role, Identity and Work: Extending the design and development agenda, 2006, ISBN 9185497-42-8

No 1009 Iakov Nakhimovski: Contributions to the Modeling and Simulation of Mechanical Systems with Detailed Contact Analysis, 2006, ISBN 91-85497-43-X.

No 1013 Wilhelm Dahllöf: Exact Algorithms for Exact Satisfiability Problems, 2006, ISBN 91-85523-97-6.

No 1016 Levon Saldamli: PDEModelica - A High-Level Language for Modeling with Partial Differential Equations, 2006, ISBN 91-85523-84-4.

No 1017 Daniel Karlsson: Verification of Component-based Embedded System Designs, 2006, ISBN 91-85523-79-8

No 1018 Ioan Chisalita: Communication and Networking Techniques for Traffic Safety Systems, 2006, ISBN 9185523-77-1.

No 1019 Tarja Susi: The Puzzle of Social Activity - The Significance of Tools in Cognition and Cooperation, 2006, ISBN 91-85523-71-2

No 1021 Andrzej Bednarski: Integrated Optimal Code Generation for Digital Signal Processors, 2006, ISBN 9185523-69-0.

No 1022 Peter Aronsson: Automatic Parallelization of Equation-Based Simulation Programs, 2006, ISBN 9185523-68-2.

No 1030 Robert Nilsson: A Mutation-based Framework for Automated Testing of Timeliness, 2006, ISBN 9185523-35-6.

No 1034 Jon Edvardsson: Techniques for Automatic Generation of Tests from Programs and Specifications, 2006, ISBN 91-85523-31-3.

No 1035 Vaida Jakoniene: Integration of Biological Data, 2006, ISBN 91-85523-28-3.

No 1045 Genevieve Gorrell: Generalized Hebbian Algorithms for Dimensionality Reduction in Natural Language Processing, 2006, ISBN 91-85643-88-2.

No 1051 Yu-Hsing Huang: Having a New Pair of Glasses Applying Systemic Accident Models on Road Safety, 2006, ISBN 91-85643-64-5.

No 1054 Åsa Hedenskog: Perceive those things which cannot be seen - A Cognitive Systems Engineering perspective on requirements management, 2006, ISBN 91-85643-57-2.

No 1061 Cécile Åberg: An Evaluation Platform for Semantic Web Technology, 2007, ISBN 91-85643-31-9.

No 1073 Mats Grindal: Handling Combinatorial Explosion in Software Testing, 2007, ISBN 978-91-85715-74-9.

No 1075 Almut Herzog: Usable Security Policies for Runtime Environments, 2007, ISBN 978-91-85715-65-7.

No 1079 Magnus Wahlström: Algorithms, measures, and upper bounds for Satisfiability and related problems, 2007, ISBN 978-91-85715-55-8.

No 1083 Jesper Andersson: Dynamic Software Architectures, 2007, ISBN 978-91-85715-46-6.

No 1086 Ulf Johansson: Obtaining Accurate and Comprehensible Data Mining Models - An Evolutionary Approach, 2007, ISBN 978-91-85715-34-3.

No 1089 Traian Pop: Analysis and Optimisation of Distributed Embedded Systems with Heterogeneous Scheduling Policies, 2007, ISBN 978-91-85715-27-5.

No 1091 Gustav Nordh: Complexity Dichotomies for CSPrelated Problems, 2007, ISBN 978-91-85715-20-6.

No 1106 Per Ola Kristensson: Discrete and Continuous Shape Writing for Text Entry and Control, 2007, ISBN 97891-85831-77-7.

No 1110 He Tan: Aligning Biomedical Ontologies, 2007, ISBN 978-91-85831-56-2.
No 1112 Jessica Lindblom: Minding the body - Interacting socially through embodied action, 2007, ISBN 978-9185831-48-7.

No 1113 Pontus Wärnestål: Dialogue Behavior Management in Conversational Recommender Systems, 2007, ISBN 978-91-85831-47-0.

No 1120 Thomas Gustafsson: Management of Real-Time Data Consistency and Transient Overloads in Embedded Systems, 2007, ISBN 978-91-85831-33-3.

No 1127 Alexandru Andrei: Energy Efficient and Predictable Design of Real-time Embedded Systems, 2007, ISBN 978-91-85831-06-7.

No 1139 Per Wikberg: Eliciting Knowledge from Experts in Modeling of Complex Systems: Managing Variation and Interactions, 2007, ISBN 978-91-85895-66-3.

No 1143 Mehdi Amirijoo: QoS Control of Real-Time Data Services under Uncertain Workload, 2007, ISBN 97891-85895-49-6.

No 1150 Sanny Syberfeldt: Optimistic Replication with Forward Conflict Resolution in Distributed Real-Time Databases, 2007, ISBN 978-91-85895-27-4.

No 1155 Beatrice Alenljung: Envisioning a Future Decision Support System for Requirements Engineering - A Holistic and Human-centred Perspective, 2008, ISBN 978-91-85895-11-3.

No 1156 Artur Wilk: Types for XML with Application to Xcerpt, 2008, ISBN 978-91-85895-08-3.

No 1183 Adrian Pop: Integrated Model-Driven Development Environments for Equation-Based Object-Oriented Languages, 2008, ISBN 978-91-7393-895-2.

No 1185 Jörgen Skågeby: Gifting Technologies Ethnographic Studies of End-users and Social Media Sharing, 2008, ISBN 978-91-7393-892-1.

No 1187 Imad-Eldin Ali Abugessaisa: Analytical tools and information-sharing methods supporting road safety organizations, 2008, ISBN 978-91-7393-887-7.

No 1204 H. Joe Steinhauer: A Representation Scheme for Description and Reconstruction of Object Configurations Based on Qualitative Relations, 2008, ISBN 978-91-7393-823-5.

No 1222 Anders Larsson: Test Optimization for Core-based System-on-Chip, 2008, ISBN 978-91-7393-768-9.

No 1238 Andreas Borg: Processes and Models for Capacity Requirements in Telecommunication Systems, 2009, ISBN 978-91-7393-700-9.

No 1240 Fredrik Heintz: DyKnow: A Stream-Based Knowledge Processing Middleware Framework, 2009, ISBN 978-91-7393-696-5.

No 1241 Birgitta Lindström: Testability of Dynamic RealTime Systems, 2009, ISBN 978-91-7393-695-8.

No 1244 Eva Blomqvist: Semi-automatic Ontology Construction based on Patterns, 2009, ISBN 978-91-7393-683-5.

No 1249 Rogier Woltjer: Functional Modeling of Constrain Management in Aviation Safety and Command and Control, 2009, ISBN 978-91-7393-659-0.

No 1260 Gianpaolo Conte: Vision-Based Localization and Guidance for Unmanned Aerial Vehicles, 2009, ISBN 978-91-7393-603-3.

No 1262 AnnMarie Ericsson: Enabling Tool Support for Formal Analysis of ECA Rules, 2009, ISBN 978-91-7393598-2.

No 1266 Jiri Trnka: Exploring Tactical Command and Control: A Role-Playing Simulation Approach, 2009, ISBN 978-91-7393-571-5.

No 1268 Bahlol Rahimi: Supporting Collaborative Work through ICT - How End-users Think of and Adopt Integrated Health Information Systems, 2009, ISBN 978-91-7393-550-0.

No 1274 Fredrik Kuivinen: Algorithms and Hardness Results for Some Valued CSPs, 2009, ISBN 978-91-7393-525-8.

No 1281 Gunnar Mathiason: Virtual Full Replication for Scalable Distributed Real-Time Databases, 2009, ISBN 978-91-7393-503-6. 
No 1290 Viacheslav Izosimov: Scheduling and Optimization of Fault-Tolerant Distributed Embedded Systems, 2009, ISBN 978-91-7393-482-4.

No 1294 Johan Thapper: Aspects of a Constraint Optimisation Problem, 2010, ISBN 978-91-7393-464-0.

No 1306 Susanna Nilsson: Augmentation in the Wild: User Centered Development and Evaluation of Augmented Reality Applications, 2010, ISBN 978-917393-416-9.

No 1313 Christer Thörn: On the Quality of Feature Models, 2010, ISBN 978-91-7393-394-0.

No 1321 Zhiyuan He: Temperature Aware and DefectProbability Driven Test Scheduling for System-onChip, 2010, ISBN 978-91-7393-378-0.

No 1333 David Broman: Meta-Languages and Semantics for Equation-Based Modeling and Simulation, 2010, ISBN 978-91-7393-335-3.

No 1337 Alexander Siemers: Contributions to Modelling and Visualisation of Multibody Systems Simulations with Detailed Contact Analysis, 2010, ISBN 978-91-7393317-9.

No 1354 Mikael Asplund: Disconnected Discoveries: Availability Studies in Partitioned Networks, 2010, ISBN 978-91-7393-278-3.

No 1359 Jana Rambusch: Mind Games Extended: Understanding Gameplay as Situated Activity, 2010, ISBN 978-91-7393-252-3.

No 1373 Sonia Sangari: Head Movement Correlates to Focus Assignment in Swedish,2011,ISBN 978-91-7393-154-0.

No 1374 Jan-Erik Källhammer: Using False Alarms when Developing Automotive Active Safety Systems, 2011, ISBN 978-91-7393-153-3.

No 1375 Mattias Eriksson: Integrated Code Generation, 2011, ISBN 978-91-7393-147-2.

No 1381 Ola Leifler: Affordances and Constraints of Intelligent Decision Support for Military Command and Control - Three Case Studies of Support Systems, 2011, ISBN 978-91-7393-133-5.

No 1386 Soheil Samii: Quality-Driven Synthesis and Optimization of Embedded Control Systems, 2011, ISBN 978-91-7393-102-1.

No 1419 Erik Kuiper: Geographic Routing in Intermittentlyconnected Mobile Ad Hoc Networks: Algorithms and Performance Models, 2012, ISBN 978-91-7519981-8.

No 1451 Sara Stymne: Text Harmonization Strategies for Phrase-Based Statistical Machine Translation, 2012, ISBN 978-91-7519-887-3.

No 1455 Alberto Montebelli: Modeling the Role of Energy Management in Embodied Cognition, 2012, ISBN 978-91-7519-882-8.

No 1465 Mohammad Saifullah: Biologically-Based Interactive Neural Network Models for Visual Attention and Object Recognition, 2012, ISBN 978-91-7519-838-5.

No 1490 Tomas Bengtsson: Testing and Logic Optimization Techniques for Systems on Chip, 2012, ISBN 978-917519-742-5.

No 1481 David Byers: Improving Software Security by Preventing Known Vulnerabilities, 2012, ISBN 97891-7519-784-5.

No 1496 Tommy Färnqvist: Exploiting Structure in CSPrelated Problems, 2013, ISBN 978-91-7519-711-1.

No 1503 John Wilander: Contributions to Specification, Implementation, and Execution of Secure Software, 2013, ISBN 978-91-7519-681-7.

No 1506 Magnus Ingmarsson: Creating and Enabling the Useful Service Discovery Experience, 2013, ISBN 97891-7519-662-6.

No 1547 Wladimir Schamai: Model-Based Verification of Dynamic System Behavior against Requirements: Method, Language, and Tool, 2013, ISBN 978-917519-505-6.
No 1551 Henrik Svensson: Simulations, 2013, ISBN 978-917519-491-2.

No 1559 Sergiu Rafiliu: Stability of Adaptive Distributed Real-Time Systems with Dynamic Resource Management, 2013, ISBN 978-91-7519-471-4.

No 1581 Usman Dastgeer: Performance-aware Component Composition for GPU-based Systems, 2014, ISBN 978-91-7519-383-0.

No 1602 Cai Li: Reinforcement Learning of Locomotion based on Central Pattern Generators, 2014, ISBN 978-917519-313-7.

No 1652 Roland Samlaus: An Integrated Development Environment with Enhanced Domain-Specific Interactive Model Validation, 2015, ISBN 978-917519-090-7.

No 1663 Hannes Uppman: On Some Combinatorial Optimization Problems: Algorithms and Complexity, 2015, ISBN 978-91-7519-072-3.

No 1664 Martin Sjölund: Tools and Methods for Analysis, Debugging, and Performance Improvement of Equation-Based Models, 2015, ISBN 978-91-7519-071-6.

No 1666 Kristian Stavåker: Contributions to Simulation of Modelica Models on Data-Parallel Multi-Core Architectures, 2015, ISBN 978-91-7519-068-6.

No 1680 Adrian Lifa: Hardware/Software Codesign of Embedded Systems with Reconfigurable and Heterogeneous Platforms, 2015, ISBN 978-91-7519-0402.

No 1685 Bogdan Tanasa: Timing Analysis of Distributed Embedded Systems with Stochastic Workload and Reliability Constraints, 2015, ISBN 978-91-7519-022-8.

No 1691 Håkan Warnquist: Troubleshooting Trucks Automated Planning and Diagnosis, 2015, ISBN 97891-7685-993-3.

No 1702 Nima Aghaee: Thermal Issues in Testing of Advanced Systems on Chip, 2015, ISBN 978-91-7685949-0.

No 1715 Maria Vasilevskaya: Security in Embedded Systems: A Model-Based Approach with Risk Metrics, 2015, ISBN 978-91-7685-917-9.

No 1729 Ke Jiang: Security-Driven Design of Real-Time Embedded System, 2016, ISBN 978-91-7685-884-4.

No 1733 Victor Lagerkvist: Strong Partial Clones and the Complexity of Constraint Satisfaction Problems: Limitations and Applications, 2016, ISBN 978-91-7685856-1.

No 1734 Chandan Roy: An Informed System Development Approach to Tropical Cyclone Track and Intensity Forecasting, 2016, ISBN 978-91-7685-854-7.

No 1746 Amir Aminifar: Analysis, Design, and Optimization of Embedded Control Systems, 2016, ISBN 978-917685-826-4.

No 1747 Ekhiotz Vergara: Energy Modelling and Fairness for Efficient Mobile Communication, 2016, ISBN 978-91-7685-822-6.

No 1748 Dag Sonntag: Chain Graphs - Interpretations, Expressiveness and Learning Algorithms, 2016, ISBN 978-91-7685-818-9.

No 1768 Anna Vapen: Web Authentication using ThirdParties in Untrusted Environments, 2016, ISBN 978-91-7685-753-3.

No 1778 Magnus Jandinger: On a Need to Know Basis: A Conceptual and Methodological Framework for Modelling and Analysis of Information Demand in an Enterprise Context, 2016, ISBN 978-91-7685-713-7.

Linköping Studies in Arts and Science

No 504 Ing-Marie Jonsson: Social and Emotional Characteristics of Speech-based In-Vehicle Information Systems: Impact on Attitude and Driving Behaviour, 2009, ISBN 978-91-7393-478-7. 
No 586 Fabian Segelström: Stakeholder Engagement for Service Design: How service designers identify and communicate insights, 2013, ISBN 978-91-7519-554-4.

No 618 Johan Blomkvist: Representing Future Situations of Service: Prototyping in Service Design, 2014, ISBN 978-91-7519-343-4.

No 620 Marcus Mast: Human-Robot Interaction for SemiAutonomous Assistive Robots, 2014, ISBN 978-917519-319-9.

No677 Peter Berggren: Assessing Shared Strategic Understanding, 2016, ISBN 978-91-7685-786-1.

\section{Linköping Studies in Statistics}

No 9 Davood Shahsavani: Computer Experiments Designed to Explore and Approximate Complex Deterministic Models, 2008, ISBN 978-91-7393-976-8.

No 10 Karl Wahlin: Roadmap for Trend Detection and Assessment of Data Quality, 2008, ISBN 978-91-7393$792-4$.

No 11 Oleg Sysoev: Monotonic regression for large multivariate datasets, 2010, ISBN 978-91-7393-412-1.

No 13 Agné Burauskaite-Harju: Characterizing Temporal Change and Inter-Site Correlations in Daily and Subdaily Precipitation Extremes, 2011, ISBN 978-91-7393110-6.

\section{Linköping Studies in Information Science}

No 1 Karin Axelsson: Metodisk systemstrukturering- att skapa samstämmighet mellan informationssystemarkitektur och verksamhet, 1998. ISBN-9172-19-296-8.

No 2 Stefan Cronholm: Metodverktyg och användbarhet en studie av datorstödd metodbaserad systemutveckling, 1998, ISBN-9172-19-299-2.

No 3 Anders Avdic: Användare och utvecklare - om anveckling med kalkylprogram, 1999. ISBN-91-7219606-8.

No 4 Owen Eriksson: Kommunikationskvalitet hos informationssystem och affärsprocesser, 2000, ISBN 917219-811-7.

No 5 Mikael Lind: Från system till process - kriterier för processbestämning vid verksamhetsanalys, 2001, ISBN 91-7373-067-X.

No 6 Ulf Melin: Koordination och informationssystem i företag och nätverk, 2002, ISBN 91-7373-278-8.

No 7 Pär J. Ågerfalk: Information Systems Actability - Understanding Information Technology as a Tool for Business Action and Communication, 2003, ISBN 917373-628-7.

No 8 Ulf Seigerroth: Att förstå och förändra systemutvecklingsverksamheter - en taxonomi för metautveckling, 2003, ISBN91-7373-736-4.

No 9 Karin Hedström: Spår av datoriseringens värden Effekter av IT i äldreomsorg, 2004, ISBN 91-7373-9634.

No 10 Ewa Braf: Knowledge Demanded for Action Studies on Knowledge Mediation in Organisations, 2004, ISBN 91-85295-47-7.

No 11 Fredrik Karlsson: Method Configuration method and computerized tool support, 2005, ISBN 91-8529748-8.

No 12 Malin Nordström: Styrbar systemförvaltning - Att organisera systemförvaltningsverksamhet med hjälp av effektiva förvaltningsobjekt, 2005, ISBN 91-8529760-7.

No 13 Stefan Holgersson: Yrke: POLIS - Yrkeskunskap, motivation, IT-system och andra förutsättningar för polisarbete, 2005, ISBN 91-85299-43-X.

No 14 Benneth Christiansson, Marie-Therese Christiansson: Mötet mellan process och komponent - mot ett ramverk för en verksamhetsnära kravspecifikation vid anskaffning av komponent- baserade informationssystem, 2006, ISBN 91-8564322-X. 
